\title{
WATER EXTRACTION FROM COAL-FIRED POWER PLANT FLUE GAS
}

\author{
Final Report
}

(For the period September 26, 2003, through June 30, 2006)

Prepared for:

AAD Document Control

U.S. Department of Energy

National Energy Technology Laboratory

PO Box 10940, MS 921-107

Pittsburgh, PA 15236-0940

Cooperative Agreement No.: DE-FC26-03NT41907

Prepared by:

Bruce C. Folkedahl Greg F. Weber Michael E. Collings

Energy \& Environmental Research Center University of North Dakota 15 North 23rd Street, Stop 9018

Grand Forks, ND 58202-9018

John Copen

Terry Sullivan

Phil Deen

Siemens Power Generation, Inc. 4400 Alafaya Trail, MC Q2-286

Orlando, FL 32826-2399 


\title{
WATER EXTRACTION FROM COAL-FIRED POWER PLANT FLUE GAS
}

\author{
Final Report
}

(For the period September 26, 2003, through June 30, 2006)

Prepared for:

AAD Document Control

U.S. Department of Energy

National Energy Technology Laboratory

PO Box 10940, MS 921-107

Pittsburgh, PA 15236-0940

Cooperative Agreement No.: DE-FC26-03NT41907

Prepared by:

Bruce C. Folkedahl

Greg F. Weber Michael E. Collings

Energy \& Environmental Research Center

University of North Dakota 15 North 23rd Street, Stop 9018

Grand Forks, ND 58202-9018

John Copen Terry Sullivan

Phil Deen

Siemens Power Generation, Inc. 4400 Alafaya Trail, MC Q2-286

Orlando, FL 32826-2399 


\section{DISCLAIMER}

This report was prepared as an account of work sponsored by an agency of the United States Government. Neither the United States Government, nor any agency thereof, nor any of their employees makes any warranty, express or implied, or assumes any legal liability or responsibility for the accuracy, completeness, or usefulness of any information, apparatus, product, or process disclosed or represents that its use would not infringe privately owned rights. Reference herein to any specific commercial product, process, or service by trade name, trademark, manufacturer, or otherwise does not necessarily constitute or imply its endorsement, recommendation, or favoring by the United States Government or any agency thereof. The views and opinions of authors expressed herein do not necessarily state or reflect those of the United States Government or any agency thereof.

This technical report was prepared with the support of the U.S. Department of Energy, under Award No. DE-FC26-03NT41907. However, any opinions, findings, conclusions, or recommendations expressed herein are those of the author(s) and do not necessarily reflect the views of the DOE.

\section{EERC DISCLAIMER}

LEGAL NOTICE. This research report was prepared by the Energy \& Environmental Research Center (EERC), an agency of the University of North Dakota, as an account of work sponsored by U.S. Department of Energy and Siemens Power Generation, Inc. Because of the research nature of the work performed, neither the EERC nor any of its employees makes any warranty, express or implied, or assumes any legal liability or responsibility for the accuracy, completeness, or usefulness of any information, apparatus, product, or process disclosed, or represents that its use would not infringe privately owned rights. Reference herein to any specific commercial product, process, or service by trade name, trademark, manufacturer, or otherwise does not necessarily constitute or imply its endorsement or recommendation by the EERC. 


\title{
WATER EXTRACTION FROM COAL-FIRED POWER PLANT FLUE GAS
}

\begin{abstract}
The overall objective of this program was to develop a liquid desiccant-based flue gas dehydration process technology to reduce water consumption in coal-fired power plants. The specific objective of the program was to generate sufficient subscale test data and conceptual commercial power plant evaluations to assess process feasibility and merits for commercialization. Currently, coal-fired power plants require access to water sources outside the power plant for several aspects of their operation in addition to steam cycle condensation and process cooling needs. At the present time, there is no practiced method of extracting the usually abundant water found in the power plant stack gas. This project demonstrated the feasibility and merits of a liquid desiccant-based process that can efficiently and economically remove water vapor from the flue gas of fossil fuel-fired power plants to be recycled for in-plant use or exported for clean water conservation. After an extensive literature review, a survey of the available physical and chemical property information on desiccants in conjunction with a weighting scheme developed for this application, three desiccants were selected and tested in a bench-scale system at the Energy \& Environmental Research Center (EERC). System performance at the bench scale aided in determining which desiccant was best suited for further evaluation. The results of the bench-scale tests along with further review of the available property data for each of the desiccants resulted in the selection of calcium chloride as the desiccant for testing at the pilot-scale level. Two weeks of testing utilizing natural gas in Test Series I and coal in Test Series II for production of flue gas was conducted with the liquid desiccant dehumidification system (LDDS) designed and built for this study. In general, it was found the LDDS operated well and could be placed in an automode in which the process would operate with no operator intervention or adjustment.
\end{abstract}

Water produced from this process should require little processing for use, depending on the end application. Test Series II water quality was not as good as that obtained in Test Series I; however, this was believed to be due to a system upset that contaminated the product water system during Test Series II. The amount of water that can be recovered from flue gas with the LDDS is a function of several variables, including desiccant temperature, $\mathrm{L} / \mathrm{G}$ in the absorber, flash drum pressure, liquid-gas contact method, and desiccant concentration. Corrosion will be an issue with the use of calcium chloride as expected but can be largely mitigated through proper material selection. Integration of the LDDS with either low-grade waste heat and or ground-source heating and cooling can affect the parasitic power draw the LDDS will have on a power plant. Depending on the amount of water to be removed from the flue gas, the system can be designed with no parasitic power draw on the power plant other than pumping loads. This can be accomplished in one scenario by taking advantage of the heat of absorption and the heat of vaporization to provide the necessary temperature changes in the desiccant between the absorber and the regeneration tank. Questions remain as to the long-term interaction of the desiccant with the flue gas and precipitates that may form and how to handle them. These questions must be addressed in subsequent testing before scale-up of the process can be confidently completed. 


\section{TABLE OF CONTENTS}

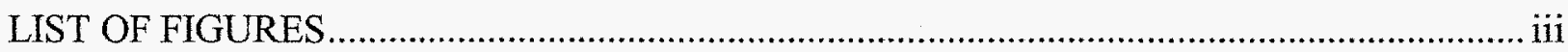

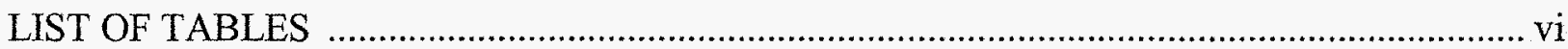

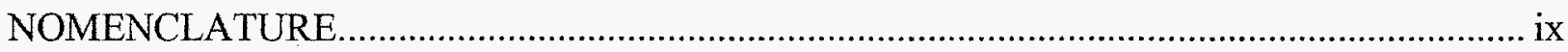

EXECUTIVE SUMMARY ................................................................................................

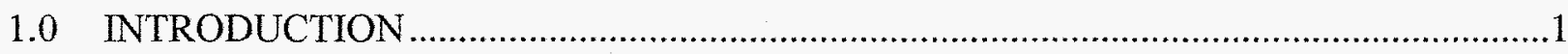

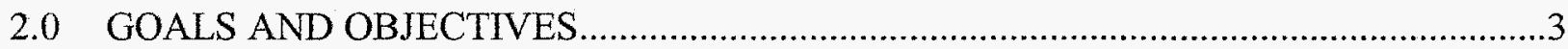

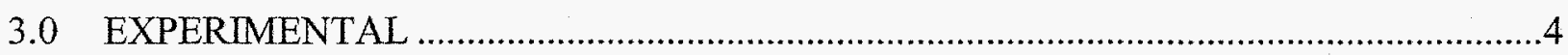

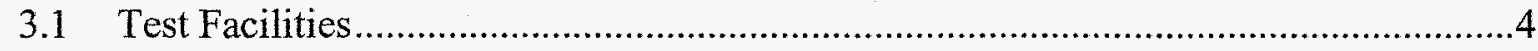

3.1.1 CEPS Description and Modification............................................................

3.1.2 Pilot-Scale Slagging Furnace System ……………………………………....

3.1.3 Description of the Liquid Desiccant-Based Dehumidification System ............17

3.2 Measurement and Sampling Procedures..............................................................30

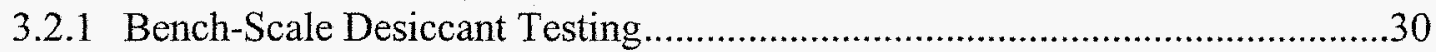

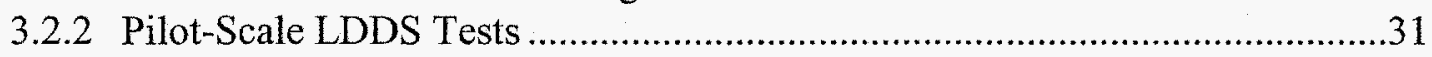

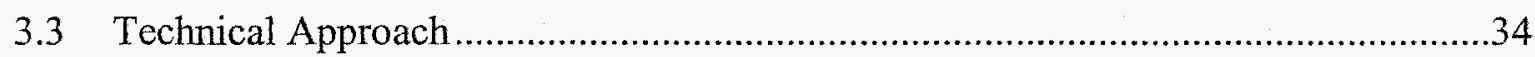

3.3.1 Task 1 - Desiccant Selection ………..........................................................35

3.3.2 Task 2 - Bench-Scale Testing......................................................................39

3.3.3 Task 7 - Pilot-Scale Testing ..........................................................................39

3.3.4 Evaluation of LDDS Performance for a Gas Turbine System -

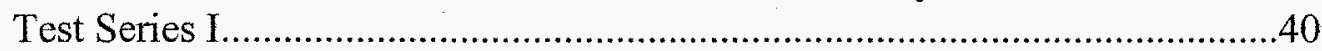

3.3.5 Evaluation of LDDS Performance for a Coal-Fired Boiler/FGD

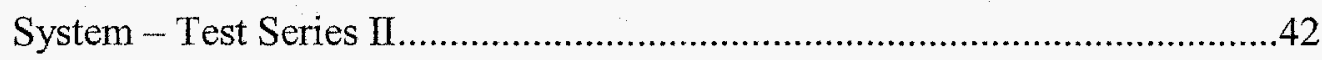

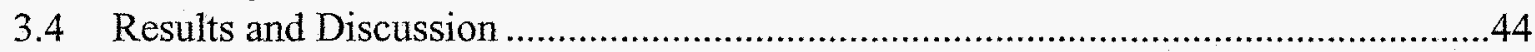

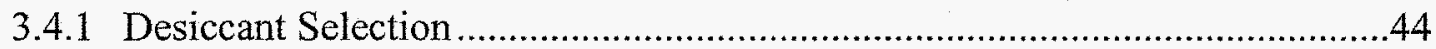

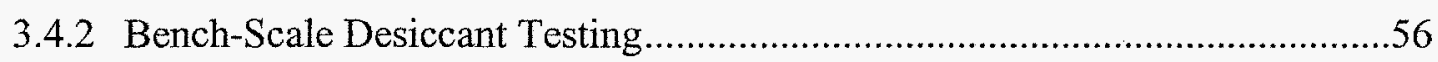

3.4.3 Pilot-Scale Desiccant Testing ........................................................................66

3.4.4 Commercial Power Plant Evaluation ............................................................118

3.4.5 Space Availability ................................................................................... 121

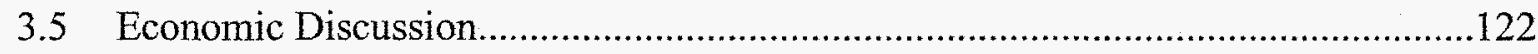

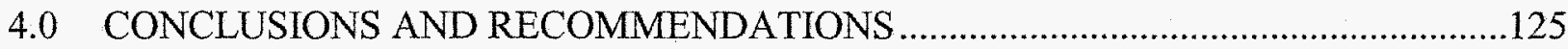

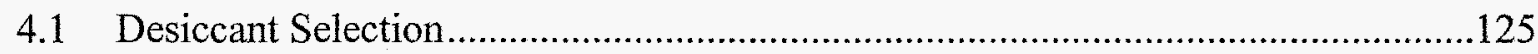

4.2 Desiccant Bench-Scale Testing.............................................................................126

4.3 Desiccant Pilot-Scale Testing .............................................................................127

Continued... 


\section{TABLE OF CONTENTS (CONTINUED)}

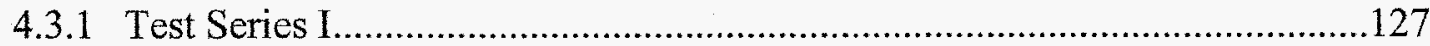

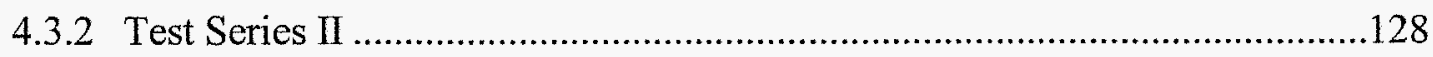

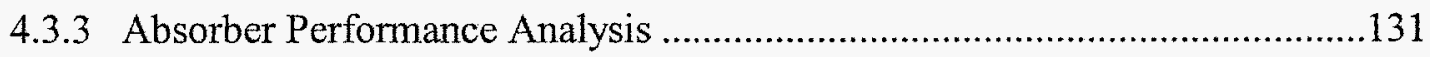

4.3.4 Commercial Power Plant Evaluation ......................................................133

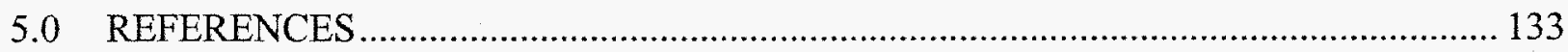




\section{LIST OF FIGURES}

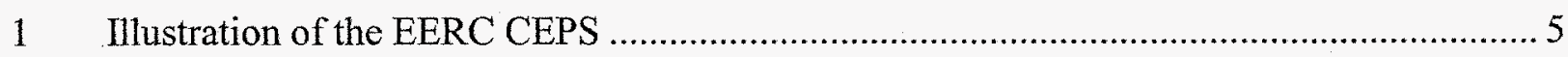

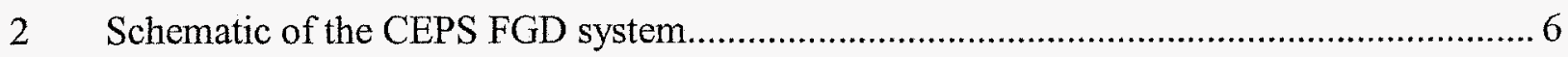

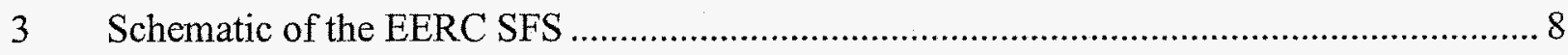

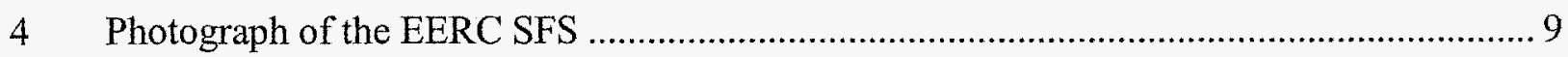

5 Schematic of the SFS basic burner design, an IFRF-type adjustable secondary

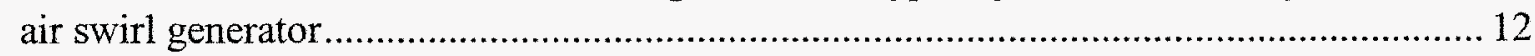

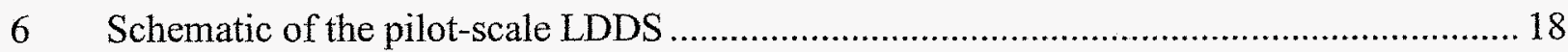

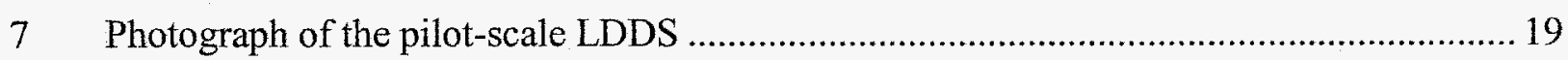

$8 \quad$ Photograph of the flash drum vessel and inlet piping ..................................................... 23

9 Photograph of the flash drum top, vapor discharge to product water condenser ................2. 24

10 Photograph of the electronic platform scale and product water recovery drums ................29

11 Schematic of the EPA Method 5 sample train used at the inlet and outlet of the absorber column .......................................................................................................... 33

12 Number of of publications and U.S. patents related to liquid desiccant systems.................35

13 References on desiccant cooling and dehumidification ...................................................36

14 Vapor pressure of liquid desiccants as a function of temperature for

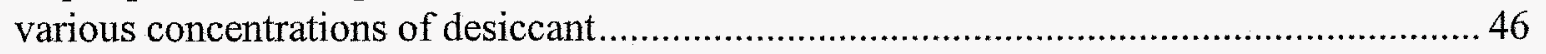

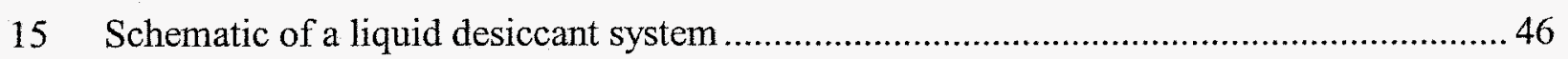

16 Percent moisture reduction using the CEPS absorber desiccant system

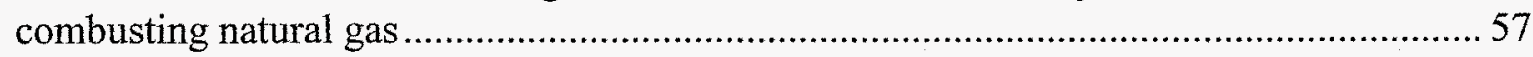

17 Percent moisture reduction using the CEPS absorber desiccant system

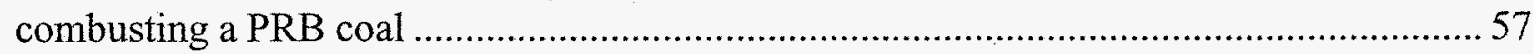

$18 \mathrm{CO}_{2}$ percent in the flue gas after the CEPS absorber when natural gas is combusted .........58

Continued... 


\section{LIST OF FIGURES (Continued)}

$19 \mathrm{CO}_{2}$ percent in the flue gas after the CEPS absorber when a PRB coal is combusted........59

$20 \mathrm{CO}_{2}$ percent in the flue gas with no absorber when a PRB coal is combusted ....................59

$21 \mathrm{SO}_{2}$ in the flue gas before and after the absorber with $\mathrm{CaCl}_{2} \ldots \ldots \ldots \ldots \ldots \ldots \ldots \ldots \ldots \ldots \ldots \ldots \ldots \ldots \ldots . . .60$

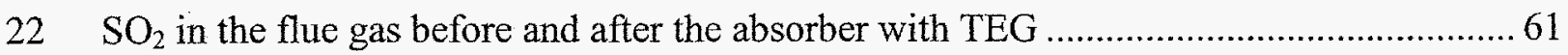

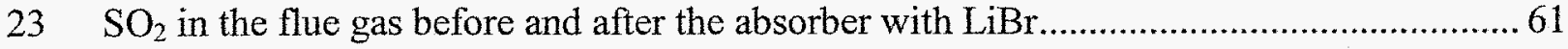

$24 \mathrm{SO}_{2}$ levels in the flue gas prior to the absorber when natural gas is fired ........................... 62

25 Low-magnification image showing strontium chloride crystals .....................................6 63

$26 \mathrm{pH}$ of desiccant samples taken during the natural gas combustion tests .............................64

$27 \mathrm{pH}$ of desiccant samples taken during the Antelope coal combustion tests ........................6 65

28 Average absorber water recovery rate versus absorber desiccant circulation rate and absorber configuration, Test Series I ....................................................................... 78

29 Water quality from the LDDS compared to RO-treated water ........................................... 79

30 Produced water quality from Test Series I compared to ROO water ….............................8. 82

31 Average absorber water recovery rate versus absorber desiccant circulation rate and absorber configuration, Test Series II...................................................................... 101

32 Average product water recovery rate varying desiccant temperature and $\mathrm{L} / \mathrm{G}$,

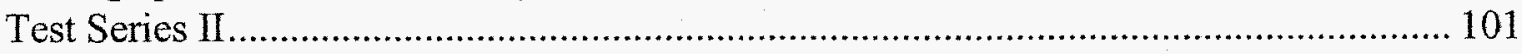

33 Operating and equilibrium lines for the flue gas $\mathrm{CaCl}_{2}$ desiccant system....................... 104

34 The bulk moisture concentration versus the numerical integration factors:

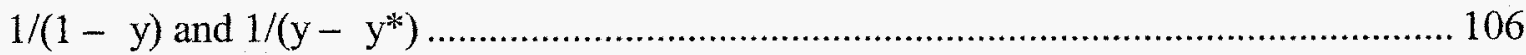

35 NTU as a function of desiccant mass flow rate ……..................................................... 107

36 Height of transfer unit as a function of desiccant mass flow rate...................................... 109

Continued... 


\section{LIST OF FIGURES (Continued)}

37 HTU data recalculated for a constant absorber height of 10 feet

38 Desiccant equilibrium moisture as a function of desiccant temperature and $\mathrm{CaCl}_{2}$ concentration

39 Flue gas water removal by the absorber as a function of desiccant mass flow rate

40. Approach to desiccant equilibrium moisture as a function of desiccant mass flow rate... 113

41 Approach to desiccant equilibrium moisture as a function of NTUs .......................... 114

42 Energy required to regenerate desiccant as a function of design parameters .................. 115

43 Desiccant regeneration energy requirements as a function of temperature and weight fraction of total stream treated

44 The effect of absorber exit flue gas moisture on desiccant regeneration energy requirements

45 Conceptual diagram of a full-flow LDDS

46 Conceptual diagram of a slipstream LDDS

47 Layout of essential components of an LDDS

48 Typical flue gas water content

49. Dry-cooled power plant orders vs. time 125 


\section{LIST OF TABLES}

1 LDDS Nominal System Design Conditions 2

2 Characteristics of Desiccant and Condensation Options for Flue Gas Water Recovery ....... 3

3 Theoretical Flow and Heat-Transfer Data for the Slagging Furnace and Refractory Ducts..... 11

4 Pressure, Temperature, and Flow Specifications for SFS Blowers. 15

6 LDDS Pressure Measurement Locations 28

7 Measurement Methods for Continuously Measured Flue Gas Constituents in CEPS .........30

8 Sampling and Analytical Methods Used for the Test Program ........................................... 31

9 Measurement Methods for Continuously Measured Flue Gas Constituents ........................ 32

10 Selected Power Plant Designs with Available Water in the Flue Gas ................................. 34

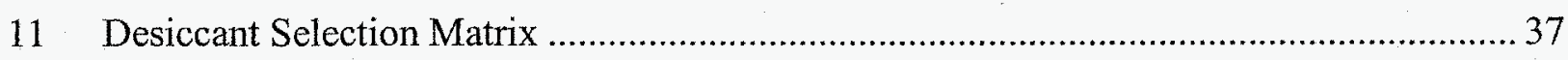

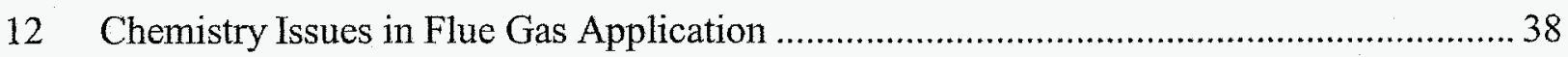

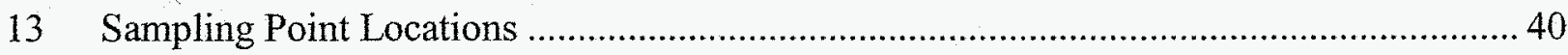

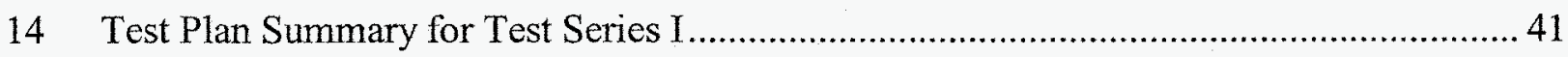

15 Planned SFS Test Parameters for Test Series I ............................................................ 42

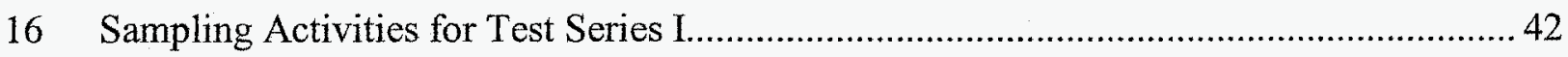

17 Test Plan Summary for Test Series II......................................................................... 43

18 Planned SFS Test Parameters for Test Series II .............................................................. 45

19 Sampling Activities for Test Series II ……………...................................................... 45

20 Activity of Water in Solution with Inorganic Desiccants.................................................... 49

Continued... 


\section{LIST OF TABLES (Continued)}

21 Activity of Water in Solution with Organic Desiccants ............................................. 50

22 Estimate of Glycol Loss in Flue Gas .................................................................... 52

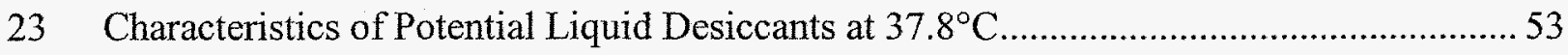

24 Desiccant Selection Factors and Weighing Scenarios............................................ 54

25 Level of Sulfates in Solution for Combustion Tests ............................................ 62

26 Level of Mercury in Solution for Combustion Tests......................................... 64

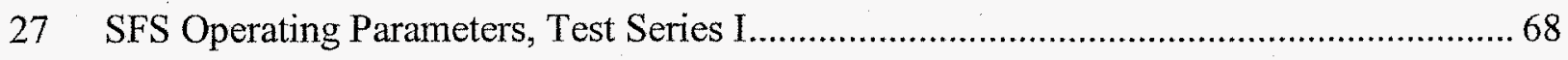

28 LDDS Absorber Operating Parameters, Test Series I .......................................... 70

29 LDDS Flash Drum Operating Parameters, Test Series I ........................................ 71

30 LDDS Product Water Condenser Operating Parameters, Test Series I........................... 73

31 Main Flue Gas Constituent Concentration Data, Test Series I...................................... 75

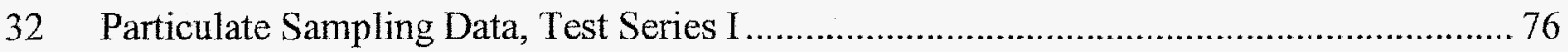

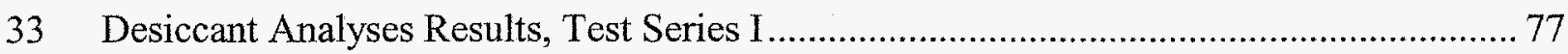

34 Product Water Analyses Results, Test Series I ...................................................... 80

35 Nalco Analytical Resources Product Water Analyses Results, Test Series I.................. 81

36 Results of Coal and Coal Ash Analyses for Test Series II ....................................... 83

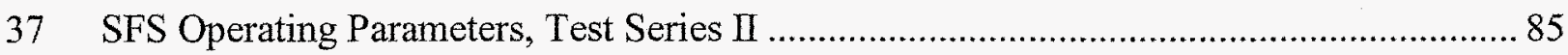

38 LDDS Absorber Operating Parameters, Test Series II ............................................. 87

39 LDDS Flash Drum Operating Parameters, Test Series II......................................... 89

40 LDDS Product Water Condenser Operating Parameters, Test Series II......................... 90

Continued... 


\section{LIST OF TABLES (Continued)}

41 Main Flue Gas Constituent Concentration Data, Test Series II .................................... 92

$42 \mathrm{SO}_{2}$ Removal Efficiency Across the Absorber, Test Series II.................................. 93

$43 \mathrm{NO}_{\mathrm{x}}$ Removal Efficiency Across the Absorber, Test Series II .................................. 94

44 Particulate Sampling Data, Test Series II............................................................... 96

45 Absorber Inlet EPA Method 5 Sample Filter Analyses Results, Test Series II............... 97

46 Absorber Outlet EPA Method 5 Sample Filter Analyses Results, Test Series II.............. 97

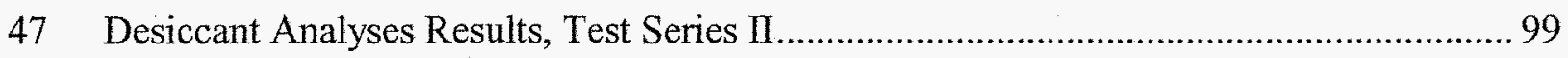

48 Product Water Analyses Results, Test Series II ............................................... 102

49 Nalco Analytical Resources Product Water Analyses Results, Test Series II................ 103

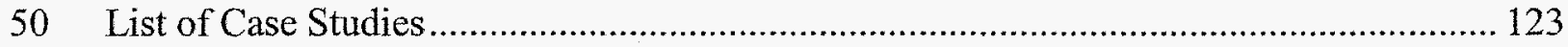

51 YUMA Reference Plant WETEX Process Revised Performance ............................... 124

52 Actual and Predicted Outlet Flue Gas Moisture Levels .......................................... 127 


\section{NOMENCLATURE}

$\begin{array}{ll}\text { abs } & \text { absolute } \\ \mathrm{ABS} & \text { desiccant absorber } \\ \mathrm{ACC} & \text { air-cooled condenser } \\ \text { acfm } & \text { actual cubic feet per minute } \\ \mathrm{APH} & \text { air preheater } \\ { }^{\circ} \mathrm{C} & \text { degrees Celsius } \\ \mathrm{CaCl}_{2} & \text { calcium chloride } \\ \mathrm{CaSO}_{4} & \text { calcium sulfate } \\ \mathrm{CAH} & \text { convective air heater } \\ \mathrm{CELD} & \text { cost-effective liquid desiccant } \\ \mathrm{CEM} & \text { continuous emission monitor } \\ \mathrm{CEPS} & \text { conversion and environmental process simulator } \\ \mathrm{cm} & \text { centimeter } \\ \mathrm{CO} & \text { carbon monoxide } \\ \mathrm{CO} & \text { carbon dioxide } \\ \mathrm{CPVC} & \text { chlorinated polyvinyl chloride } \\ \mathrm{CVAA} & \text { cold-vapor atomic adsorption } \\ \mathrm{DI} & \text { deionized } \\ \mathrm{DOE} & \text { U.S. Department of Energy } \\ \mathrm{EERC} & \text { Energy \& Environmental Research Center } \\ \mathrm{EI} & \text { Engineering Index } \\ \mathrm{EPA} & \text { U.S. Environmental Protection Agency } \\ \mathrm{EVAP} & \text { heat recovery heat exchanger } \\ { }^{\circ} \mathrm{F} & \text { degrees Fahrenheit } \\ \text { FD } & \text { forced draft } \\ \mathrm{FF} & \text { full flow } \\ \mathrm{FGD} & \text { flue gas desulfurization } \\ \text { FGR } & \text { flue gas recirculation } \\ \mathrm{ft} & \text { foot } \\ \text { gph } & \text { gallon per hour } \\ \text { gpm } & \text { gallon per minute } \\ \mathrm{H}_{2} \mathrm{SO}{ }_{4} & \text { sulfuric acid } \\ \text { hr } & \text { hour } \\ \mathrm{HRSG} & \text { heat recovery steam generator } \\ \mathrm{HTHX} & \text { high-temperature heat exchanger } \\ \mathrm{HTU} & \text { height of transfer unit } \\ \mathrm{HVAC} & \text { heating, ventilating, and air-conditioning } \\ \mathrm{HX} & \text { heat exchanger } \\ \mathrm{IC} & \text { ion chromatography } \\ \mathrm{i} . \mathrm{d} . & \text { inner diameter } \\ \mathrm{ID} & \text { induced draft } \\ \mathrm{IFRF} & \text { international flame research foundation } \\ & \end{array}$




\begin{tabular}{|c|c|}
\hline $\mathrm{IGCC}$ & integrated gasification combined cycle \\
\hline in. & inch \\
\hline IR & infrared \\
\hline IRZ & internal recirculation zone \\
\hline kBtu & thousand British thermal unit \\
\hline $\mathrm{kJ}$ & kilojoule \\
\hline LDDS & liquid desiccant-based dehumidification system \\
\hline L & liters \\
\hline $\mathrm{L} / \mathrm{G}$ & liquid to gas \\
\hline Lpm & liters per minute \\
\hline $\mathrm{m}$ & meter \\
\hline M5 & EPA Method 5 \\
\hline $\min$ & minute \\
\hline MMBtu & million British thermal units \\
\hline $\mathrm{NO}_{\mathrm{x}}$ & nitric oxide and nitrogen dioxide \\
\hline NREL & National Renewable Energy Laboratory \\
\hline NTU & number of transfer units \\
\hline $\mathrm{O}_{2}$ & oxygen \\
\hline $\begin{array}{l}\text { OSHA } \\
\mathrm{pc}\end{array}$ & $\begin{array}{l}\text { Occupational Safety and Health Association } \\
\text { pulverized coal }\end{array}$ \\
\hline $\mathrm{PCA}$ & primary combustion air \\
\hline ppm & parts per million \\
\hline PRB & Powder River Basin \\
\hline PSD & particle-size distribution \\
\hline psia & pounds per square inch absolute \\
\hline psig & pounds per square inch gauge \\
\hline PTFE & polytetrafluoroethylene \\
\hline PVC & polyvinyl chloride \\
\hline RAH & radiative air heater \\
\hline $\mathrm{RO}$ & reverse osmosis \\
\hline $\mathrm{ROO}$ & reverse osmosis system output \\
\hline s & second \\
\hline SAR & regenerator \\
\hline SCA & secondary combustion air \\
\hline $\begin{array}{l}\text { SCEM } \\
\text { scfm }\end{array}$ & $\begin{array}{l}\text { semicontinuous emission monitor } \\
\text { standard cubic feet per minute }\end{array}$ \\
\hline SEM & scanning electron microscopy \\
\hline SFS & slagging furnace system \\
\hline $\mathrm{SO}_{2}$ & sulfur dioxide \\
\hline $\mathrm{SO}_{3}$ & sulfur trioxide \\
\hline SPG & Siemens Power Generation \\
\hline SS & slipstream \\
\hline $\mathrm{T} \& \mathrm{~S}$ & tube and shell \\
\hline TBD & to be determined \\
\hline TDS & total dissolved solids \\
\hline
\end{tabular}




$\begin{array}{ll}\text { TEFC } & \text { totally enclosed fan-cooled } \\ \text { TEG } & \text { triethylene glycol } \\ \text { TSS } & \text { total suspended solids } \\ \mu \mathrm{m} & \text { micrometer } \\ \text { UV } & \text { ultraviolet } \\ \text { XRD } & \text { x-ray diffraction } \\ \text { XRF } & \text { x-ray fluorescence }\end{array}$




\section{WATER EXTRACTION FROM COAL-FIRED POWER PLANT FLUE GAS}

\section{EXECUTIVE SUMMARY}

\section{Introduction}

Power plants burning fossil fuels have, in the past, been designed to generate electricity at least cost under circumstances of abundant coal and natural gas resources and adequate supplies of water for plant cooling. Future plants will increasingly need to be designed and operated to conserve both fuel and water. Water is becoming scarce and expensive in many parts of the United States, including California, where there is atready a strong economic incentive to reduce the net cooling water requirements of power plant subsystems cooling steam turbine condensers and scrubbing stack gases. Access to sufficient water supplies for future power generation facilities will affect the siting of the plant and the combustion and postcombustion technologies chosen and will certainly affect the overall cost of the electricity generated (Couch, 2006).

Currently, coal-fired power plants require access to water sources outside the power plant for several aspects of their operation in addition to steam cycle condensation and process cooling needs. In integrated gasification combined-cycle (IGCC) systems, significant water is used in the coal gasification process and for syngas saturation, which is lost through the power plant stack. In pulverized coal ( $\mathrm{pc}$ ) power plants, water inherent in the coal as well as water associated with flue gas scrubbing is lost through the stack. At the present time, there is no practiced method of extracting the usually abundant water found in the power plant stack gas. There are two basic options for water removal from power plant flue gas: condensation and desiccant dehumidification. Desiccant technology employs chemical agents (i.e., desiccants) which possess a strong physicochemical affinity for water to extract water vapor. By absorbing the water vapor into a desiccant instead of cooling the gas to a temperature below its dew point, desiccant technology has several important advantages over condensation options. Typically, condensed water from coal combustion flue gas will also have other phases in the water such as condensed acid gases which are present in the flue gas. Condensation processes also need energy input to provide the cooling surface on which to cool the flue gas. The advantage of using a desiccant is to facilitate the recovery of useful amounts of water at flue gas temperatures that can be reasonably achieved during power plant operation. The desiccant approach can be operated with no additional heating or cooling to produce water by taking advantage of the heat of absorption and the heat of vaporization, providing a performance advantage. Direct contact cooling with a desiccant solution can be engineered to minimize pressure drop, and any water evaporating into the flue gas from an upstream scrubber would be recovered for reuse. The alternative of indirect cooling in an air/flue gas-condensing heat exchanger without a desiccant, which would be limited to applications involving low ambient temperatures, raises significant engineering and economic problems involved with the size and cost of the heat exchanger, pressure drop, corrosion, and fouling.

This project demonstrated the feasibility and merits of a liquid desiccant-based dehumidification system (LDDS) that can efficiently and economically remove water vapor from the 
flue gas of fossil fuel-fired power plants to be recycled for in-plant use or exported for clean water conservation. Reduction of water consumption by power plants is quickly becoming a significant issue when plants attempt to obtain permits and when they are required to meet new, more restrictive water consumption allowances currently being considered by the U.S. Environmental Protection Agency (EPA) under proposed Rule 316b.

\section{Technical Approach}

The overall objective of this program was to develop a liquid desiccant-based flue gas dehydration process technology to reduce water consumption in coal-fired power plants. The specific objective of the program was to generate sufficient subscale test data and conceptual commercial power plant evaluations to assess the process feasibility and merits for commercialization. Through the dehumidification process, water in the flue gas can be recovered for use elsewhere in the power plant. The nominal power output and mass flow rate of water available in the flue gas of three selected power plant designs is shown in Table ES-1.

For these three designs, the available water flow rate ranges from 2.4 to $6.0 \times 10^{5} \mathrm{lb} / \mathrm{hr}(1.1$ to $2.7 \mathrm{~kg} / \mathrm{hr}$ ). This is a substantial water resource that is particularly attractive in regions where fresh water is in short supply or where government regulations limit the use of available water. Of the two options available for water removal from flue gas, it was determined that commercial condensation systems already exist for flue gas moisture removal and that the quality of the water produced by condensation requires expensive cleanup operations to be able to use the condensed water in most situations. Additionally, such systems would require massive and expensive heat rejection equipment, would be severely limited by high ambient temperatures, and would result in decreased gas turbine performance as a result of higher back pressure due to closed heat exchangers in the flow path. For these reasons, the LDDS was the technology pursued under this project. The LDDS-based recovery scheme described here is a promising method of recovering a portion of this otherwise wasted resource.

\section{Test Facilities}

Bench-scale testing of potential desiccants was performed in the Energy \& Environmental Research Center's (EERC's) conversion and environmental process simulator (CEPS). A specific objective of this testing was to evaluate the interaction of the candidate desiccant solutions with actual combustion gas from both coal and natural gas combustion. The CEPS is designed to nominally top-fire $4.4 \mathrm{lb} / \mathrm{hr}(2 \mathrm{~kg} / \mathrm{hr})$ of pulverized coal, with a heat input of $40,000 \mathrm{Btu} / \mathrm{hr}$ $(42,202 \mathrm{~kJ} / \mathrm{hr})$. Other solid or liquid fuels can be utilized with slight system modifications. In

Table ES-1. Selected Power Plant Designs with Available Water in the Flue Gas

\begin{tabular}{lccc}
\hline Plant Type & $\begin{array}{c}\text { Natural Gas-Fired } \\
\text { Combined Cycle }\end{array}$ & $\begin{array}{c}\text { Pulverized Coal-Fired } \\
\text { Conventional Cycle }\end{array}$ & $\begin{array}{c}\text { Integrated Gasification } \\
\text { Combined Cycle }\end{array}$ \\
\hline $\begin{array}{l}\text { Nominal Output, MW } \\
\text { Mass Flow Rate } \mathrm{H}_{2} \mathrm{O},\end{array}$ & 500 & 600 & 300 \\
lb/hr & 233,409 & 595,534 & 241,095 \\
\hline
\end{tabular}


juxtaposition to the CEPS, there is a small-scale tank and spray tower used to simulate sulfurreduction scrubber systems in coal-fired power plants that can either be isolated from the CEPS when not in use or be a portion of the flue gas path for the combustion gases from the CEPS. This apparatus was used to simulate an absorber spray tower system to evaluate the candidate desiccants.

Pilot-scale tests using an LDDS were conducted by firing natural gas (Test Series I and II) and subbituminous coal (Test Series II) in the EERC's $\sim 2.5-\mathrm{MMBtu} / \mathrm{hr}\left(2.6 \times 10^{6} \mathrm{~kJ} / \mathrm{hr}\right)$ pilot-scale combustor referred to as the slagging furnace system (SFS). The pilot-scale LDDS was designed, fabricated, installed, and operated by EERC personnel with technical support from Siemens Power Generation (SPG).

The EERC pilot-scale SFS was completed in 1997 and was designed to operate at very high temperatures $\left(2700^{\circ}-2900^{\circ} \mathrm{F}\left[1482^{\circ}-1593^{\circ} \mathrm{C}\right]\right)$ at the furnace exit. In the high-temperature mode, a substantial portion of the ash generated is removed from the system as slag. In support of the LDDS, the furnace was operated firing natural gas or pc at whatever furnace exit temperature necessary to achieve desired LDDS inlet flue gas flow rate and temperature.

Key SFS components pertinent to operation of the pilot-scale LDDS include the fuel feed system and burners, the slagging furnace, heat exchangers for flue gas temperature control, system fans, baghouse (to remove fly ash from the flue gas upstream of the LDDS), and a process control and data acquisition system.

A schematic of the pilot-scale LDDS installed at the EERC is shown in Figure ES-1.

\section{Results}

\section{Desiccant Selection}

An extensive literature review and a survey of the available physical and chemical property information on desiccants in conjunction with a weighting scheme developed for this application led to the selection of three desiccants to be tested in the EERC CEPS. The desiccants selected were lithium bromide, calcium chloride, and triethylene glycol. The three desiccants had a good mix of qualities for the bench-scale testing. All three desiccants chosen had unique beneficial qualities as well as challenges to overcome.

\section{Bench-Scale Tests}

System performance at the bench scale was used to aid in determining which desiccant was best suited for further evaluation. The tests were performed in a small-scale spray tower designed to simulate a wet flue gas desulfurization (FGD) system by recirculating a spray of liquid desiccant in a flue gas stream generated in the CEPS. The desiccant was assayed by $\mathrm{pH}$, specific gravity, and visual examination. The desiccant materials all performed as expected with respect to the amount of moisture removed from the flue gas stream of both the natural gas and coal combustion tests. The lower the vapor pressure of the desiccant was, the more moisture it removed from the flue gas 


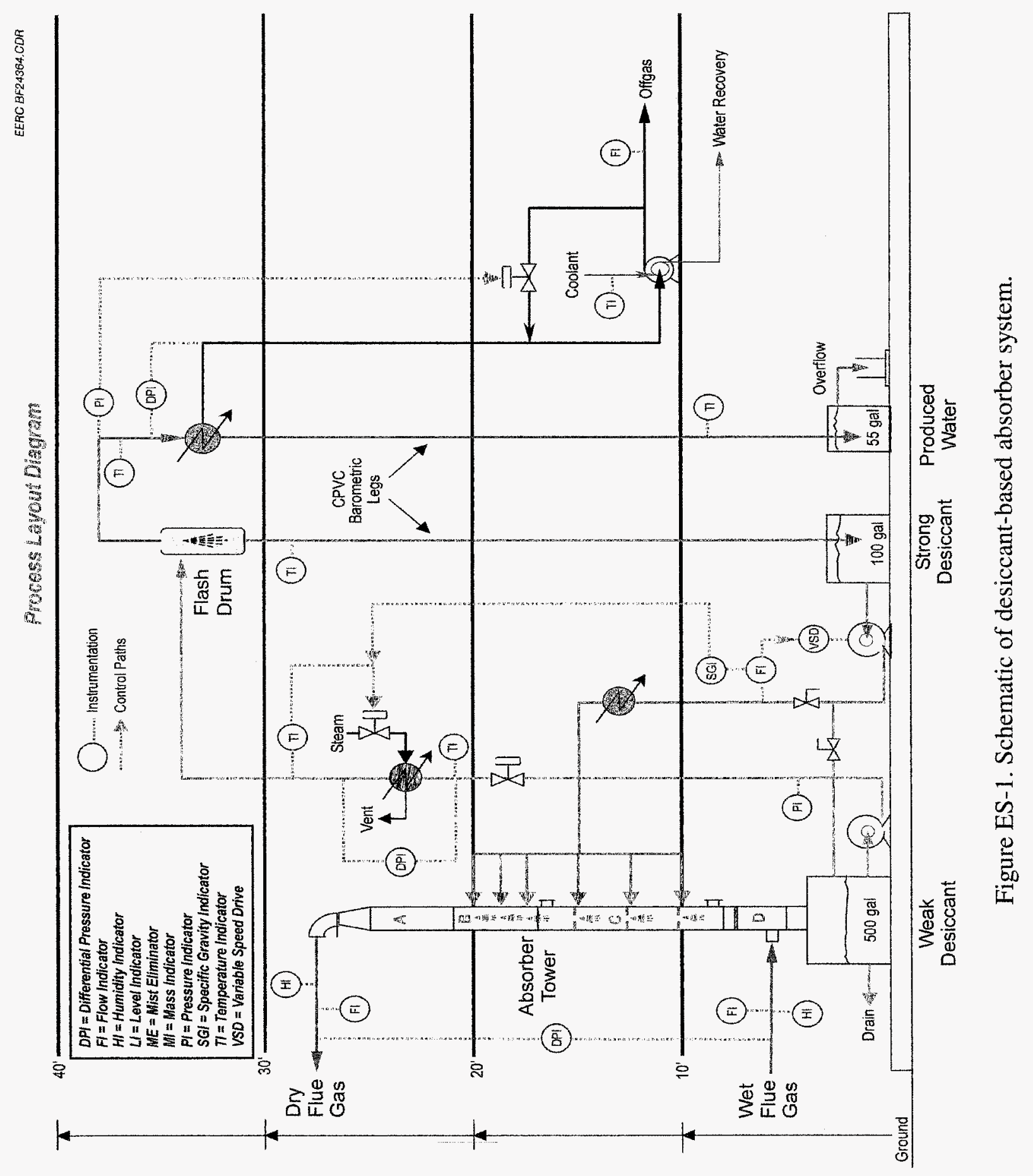


stream. The flow behavior of all of the desiccants was as expected for the duration of the tests. The results of the bench-scale tests, along with further review of the available property data for each of the desiccants, resulted in the selection of calcium chloride as the desiccant for testing at the pilotscale level. Desiccant cost and the relatively environmentally benign nature of the desiccant were dominant factors in the selection.

\section{Test Series I}

Test Series I was a weeklong test utilizing the EERC SFS pilot-scale combustion system for flue gas production. The SFS was operated in such a way as to simulate flue gas conditions in a gasfired turbine with a heat recovery steam generation (HRSG) system. A spray tower absorber designed for this project was employed for gas liquid contact in both a spray tower and a packed-bed configuration. Control of the system proved to be straightforward, and the system was able to operate in automated mode with little or no operator interaction for extended periods of time. Water production was a function of several variables including desiccant temperature, desiccant concentration, flow rates, desiccant-gas contact method, and flash drum pressure. Figure ES-2 illustrates desiccant flow rate and water recovery during this test series. Figure ES-3 is a comparison of the water quality produced in the LDDS during this test series and that of reverse osmosis (RO)treated water. This produced water would require little or no treatment prior to use in many plant applications.

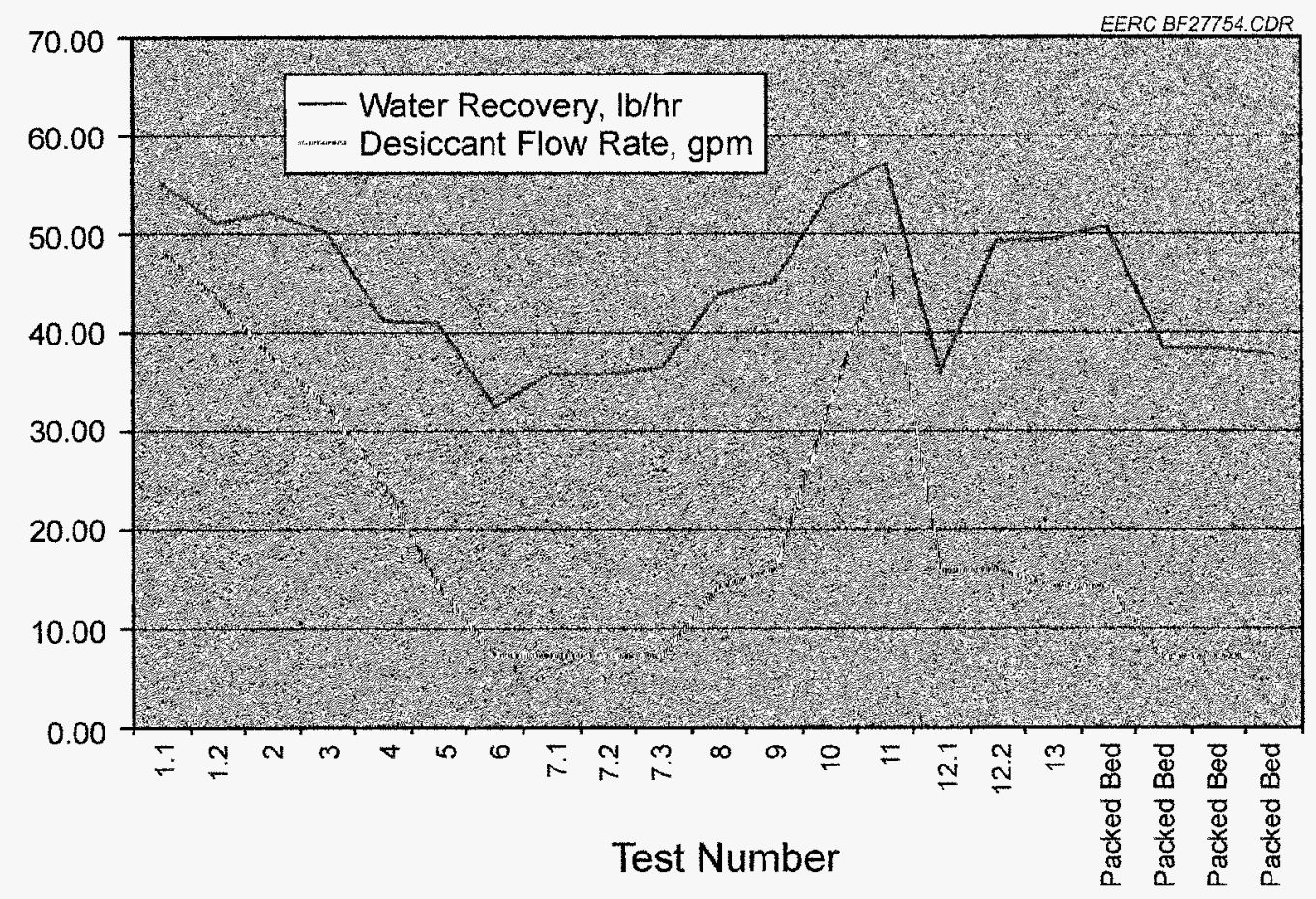

Figure ES-2. Average absorber water recovery rate versus absorber desiccant circulation rate and absorber configuration, Test Series I. 


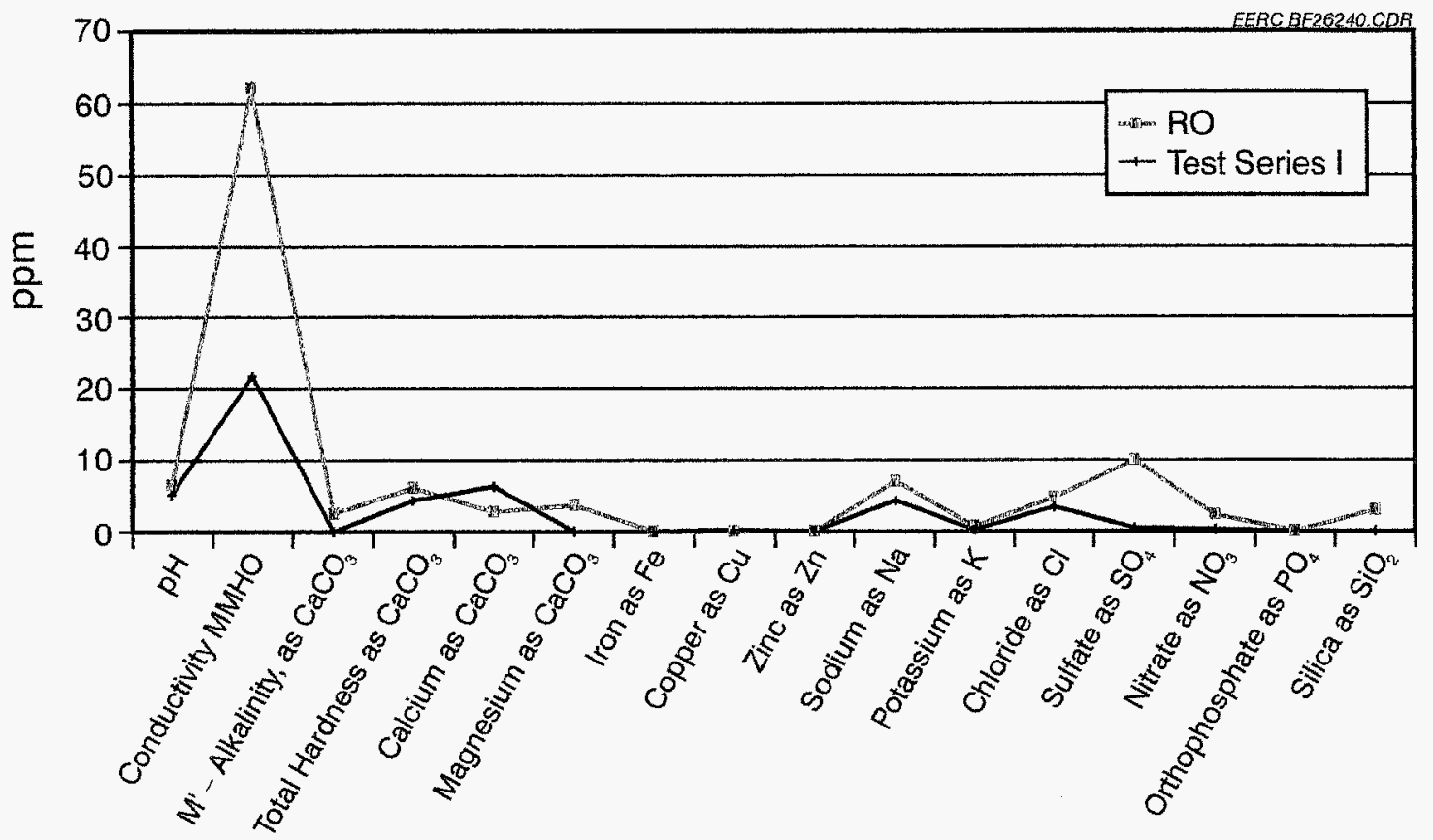

Figure ES-3. Water quality from the LDDS compared to RO-treated water.

\section{Test Series II}

Test Series II consisted of a weeklong effort firing coal in the EERC SFS. Natural gas was fired in support of select test periods for the Test Series II. The SFS was operated in such a way as to simulate flue gas conditions downstream of a particulate control device and wet FGD system. As in Test Series I, a spray tower absorber designed for this project was employed for gas-liquid contact in both a spray tower and a packed-bed configuration. Figure ES-4 shows the water recovery rate as a function of desiccant circulation rate through the absorber tower and absorber configuration. The large difference in water recovery between Test 3-2 and Test 6 illustrates the ability of the system to be tailored for different levels of water recovery. The drop in water recovery is due to an increase in desiccant temperature entering the absorber from $144^{\circ}$ to $152^{\circ} \mathrm{F}\left(62^{\circ}\right.$ to $\left.67^{\circ} \mathrm{C}\right)$ and a decrease in desiccant concentration from 46.4 to $42.8 \mathrm{wt} \%$, respectively. Figure ES-5 illustrates the effect of a change in desiccant temperature and a slight increase in desiccant flow rate through the absorber. Water recovery increases significantly with a $10^{\circ} \mathrm{F}\left(6^{\circ} \mathrm{C}\right)$ decrease in temperature of the desiccant to the absorber from $140^{\circ}$ to $130^{\circ} \mathrm{F}\left(60^{\circ}\right.$ to $\left.54^{\circ} \mathrm{C}\right)$ with an additional slight increase in liquid-to-gas ratio (L/G).

\section{Conclusions and Recommendations}

Two weeks of testing utilizing natural gas in Test Series I and coal in Test Series II for production of flue gas were conducted with the LDDS. In general, it was found the LDDS operated well and could be placed in an auto mode in which the process would operate with no operator intervention or adjustment. Water produced from this process should require little processing for use 


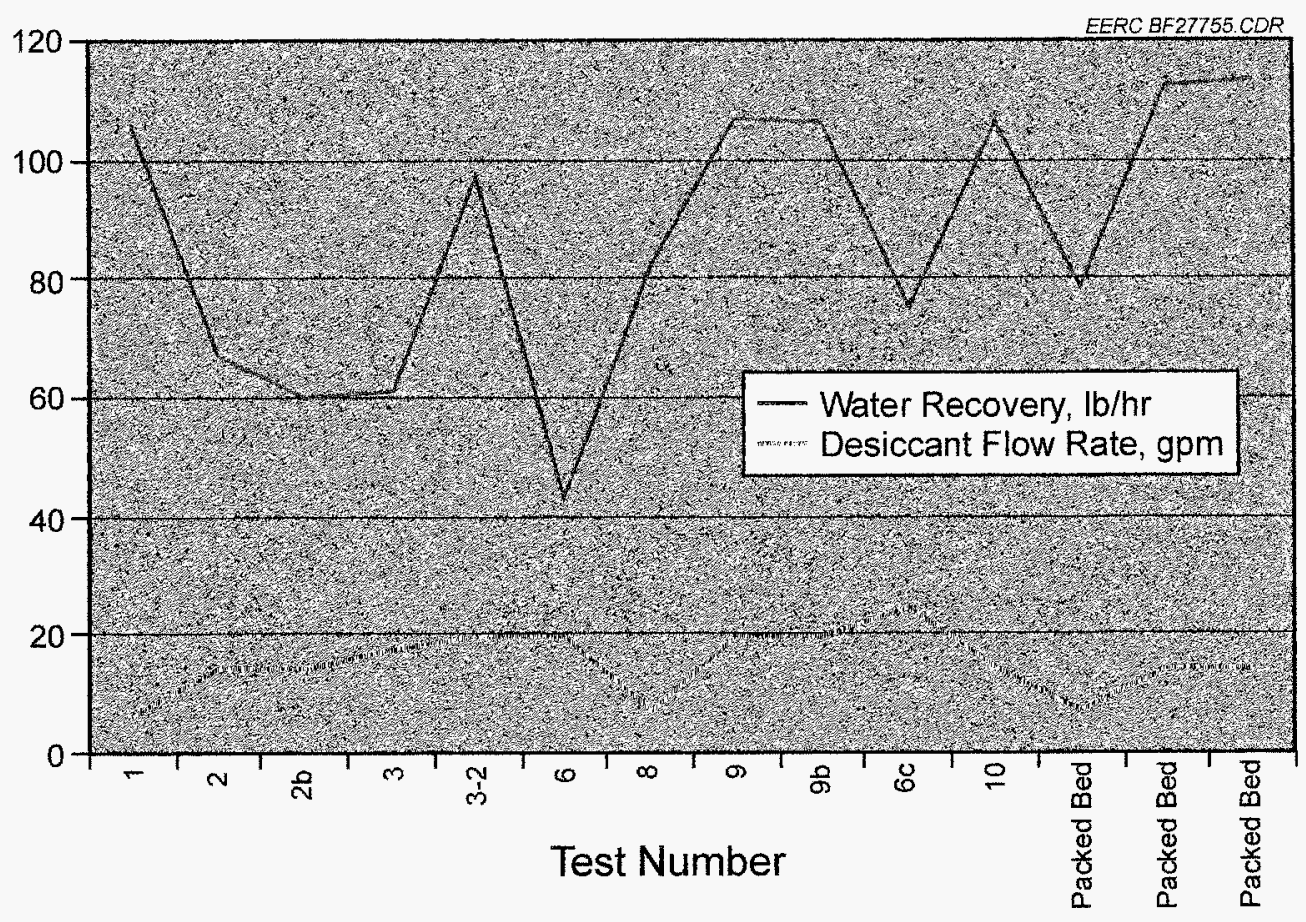

Figure ES-4. Average absorber water recovery rate versus absorber desiccant circulation rate and absorber configuration, Test Series II.

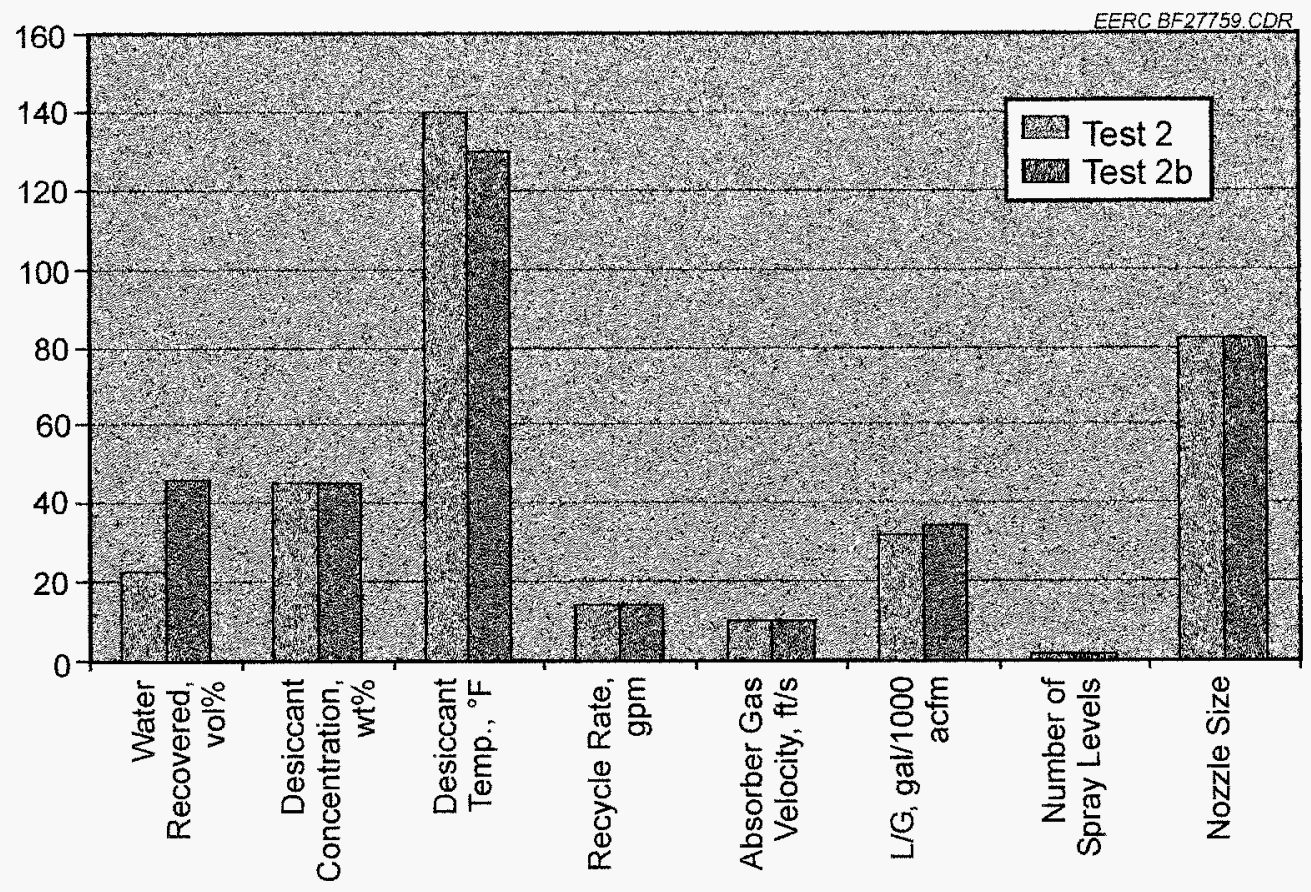

Figure ES-5. Average product water recovery rate varying desiccant temperature and L/G, Test Series II. 
depending on the end application. Test Series II water quality was not as good as that obtained in Test Series I; however, this was believed to be because of a system upset that contaminated the product water system during Test Series II.

The amount of water that can be recovered from flue gas with the LDDS is a function of several variables, including desiccant temperature, $L / G$ in the absorber, flash drum pressure, liquidgas contact method, and desiccant concentration. Corrosion will be an issue with the use of calcium chloride, as expected, but can be largely mitigated through proper material selection. Integration of the LDDS with either low-grade waste heat and or ground-source heating and cooling can affect the parasitic power draw the LDDS will have on a power plant. Depending on the amount of water to be removed from the flue gas, the system can be designed with no parasitic power draw on the power plant other than pumping loads.

This can be accomplished in one scenario by taking advantage of the heat of absorption and the heat of vaporization to provide the necessary temperature changes in the desiccant between the absorber and the regeneration tank. If this is coupled with utilization of waste heat from the plant and ground-source cooling, the process can be tailored for different applications. Interaction of the flue gas and the desiccant caused the $\mathrm{pH}$ to drop to low levels in Test Series II when coal was fired. This was primarily due to sulfur in the flue gas combining with the desiccant. This $\mathrm{pH}$ depression occurred at the end of Test Series II and was effectively controlled through the introduction of calcium hydroxide to the desiccant to raise the $\mathrm{pH}$. Questions remain as to the long-term interaction of the desiccant with the flue gas and precipitates that may form and how to handle them. These issues will need to be addressed in subsequent testing before scale-up of the process can be confidently completed. 


\section{WATER EXTRACTION FROM COAL-FIRED POWER PLANT FLUE GAS}

\subsection{INTRODUCTION}

Power plants burning fossil fuels have, in the past, been designed to generate electricity at least cost under circumstances of abundant coal and natural gas resources and adequate supplies of water for plant cooling. Future plants will increasingly need to be designed and operated to conserve both fuel and water. Water is becoming scarce and expensive in many parts of the United States, including California, where there is already a strong economic incentive to reduce the net cooling water requirements of power plant subsystems cooling steam turbine condensers and scrubbing stack gases. Access to sufficient water supplies for future power generation facilities will affect the siting of the plant and the combustion and postcombustion technologies chosen and will certainly affect the overall cost of the electricity generated (Couch, 2006).

Currently, coal-fired power plants require access to water sources outside the power plant for several aspects of their operation in addition to steam cycle condensation and process cooling needs. In integrated gasification combined-cycle (IGCC) systems, significant water is used in the coal gasification process and for syngas saturation, which is lost through the power plant stack. In pulverized coal (pc) power plants, water inherent in the coal as well as water associated with flue gas scrubbing is lost through the stack. Currently, the strategy used to reduce water consumption in areas where water restrictions are stringent is to employ an air-cooled condenser (ACC) as opposed to once-through cooling or a cooling tower. However, even plants with an ACC to minimize water consumption require a significant amount of water in several cases in order to allow for required steam drum blowdown, power augmentation systems, and gas turbine inlet evaporative cooling or fogging systems. At the present time, there is no practiced method of extracting the usually abundant water found in the power plant stack gas. There are two basic options for water removal from power plant flue gas: condensation and desiccant dehumidification. Desiccant technology employs chemical agents (i.e., desiccants), which possess a strong physicochemical affinity for water to extract water vapor. By absorbing the water vapor into a desiccant instead of cooling the gas to a temperature below its dew point, desiccant technology has several important advantages over condensation options. For the flue gas application, ambient cooling represents an interesting base design option against which to compare the desiccant option. For one of the liquid desiccant-based dehumidification system (LDDS) design conditions (natural gas column in Table 1), the partial pressure of water in the flue gas is $1.45 \mathrm{psi}(10 \mathrm{kPa})$ which corresponds to a condensing temperature of $114^{\circ} \mathrm{F}\left(46^{\circ} \mathrm{C}\right)$. This implies that ambient-cooled condensation is a borderline option that will produce water recovery only at low ambient temperature conditions.

Another condensing alternative is to provide lower condensing temperatures using active refrigeration as is used in air-conditioning applications (Pesaran et al., 1992; Lowenstein, 1993; Lowenstein et al., 1998). A gas stream can be dried to very low humidity levels by using low condensing temperatures. However, refrigeration designs involve a thermodynamic machine with

inherent Carnot losses. One can conceive a waste heat-fired refrigeration system, but the performance of such a system in the LDDS application is very poor because of the 
Table 1. LDDS Nominal System Design Conditions

\begin{tabular}{|c|c|c|c|}
\hline Plant Type & $\begin{array}{c}\text { Natural Gas- } \\
\text { Fired Combined } \\
\text { Cycle }\end{array}$ & $\begin{array}{c}\text { Pulverized Coal- } \\
\text { Fired Conventional } \\
\text { Cycle }\end{array}$ & $\begin{array}{c}\text { Integrated } \\
\text { Gasification } \\
\text { Combined Cycle }\end{array}$ \\
\hline Nominal Output, MW & 500 & 600 & 300 \\
\hline Flue Gas Flow, lb/hr & $3,695,000$ & $6,560,000$ & $3,260,000$ \\
\hline $\begin{array}{l}\text { Flue Gas Temperature at Inlet to } \\
\text { Absorber, }{ }^{\circ} \mathrm{F}\end{array}$ & 114 & 128 & 121 \\
\hline Flue Gas $\mathrm{CO}_{2}$ Volume Fraction & 0.035 & 0.120 & 0.082 \\
\hline Flue Gas $\mathrm{N}_{2}$ Volume Fraction & 0.732 & 0.683 & 0.669 \\
\hline Flue $\mathrm{Gas} \mathrm{H}_{2} \mathrm{O}$ Volume Fraction & 0.099 & 0.145 & 0.118 \\
\hline Flue Gas $\mathrm{O}_{2}$ Volume Fraction & 0.126 & 0.043 & 0.123 \\
\hline Flue Gas Ar Volume Fraction & 0.009 & 0.009 & 0.008 \\
\hline Flue Gas $\mathrm{NO}_{\mathrm{x}}$ Concentration, ppmv & 5 & 127 & 15 \\
\hline Flue Gas $\mathrm{SO}_{\mathrm{x}}$ Concentration, ppmv & 0.2 & 246 & 15 \\
\hline Flue Gas HCl Concentration, ppmv & 0 & 3 & 1 \\
\hline Flue Gas Particulate, ppmw & 0 & 4 & 0.1 \\
\hline Effective Molecular Weight, g/mol & 28.21 & 28.75 & 28.72 \\
\hline Mass Fraction $\mathrm{H}_{2} \mathrm{O}$ & 0.0632 & 0.0908 & 0.0740 \\
\hline Mass Flow Rate $\mathrm{H}_{2} \mathrm{O}, \mathrm{lb} / \mathrm{hr}$ & 233,409 & 595,534 & 241,095 \\
\hline
\end{tabular}

thermodynamic losses. A simple analysis predicts that the desiccant system will produce four times as much water as an absorption refrigeration system operating from the same waste heat source (Herald, 2006). The performance benefit of the desiccant system stems from the fact that desiccant designs involve simple heating which avoids several sources of losses inherent in a heat-driven refrigeration system. The desiccant application is an excellent match to the available waste heat.

In addition to the performance advantage over condensing technologies, desiccant technology has the potential to provide several other advantages, including lower pressure drop and simpler heat exchanger geometry. However, some design challenges are associated with desiccant water recovery from flue gas. In particular, corrosion of the stack structure and contamination of the desiccant by flue gas constituents may require significant design attention. The major characteristics of the desiccant option are listed along with the characteristics of the condensing option in Table 2.

This project demonstrated the feasibility and merits of a liquid desiccant-based process that can efficiently and economically remove water vapor from the flue gas of fossil fuel-fired power plants to be recycled for in-plant use or exported for clean water conservation. Reduction of water consumption by power plants is quickly becoming a significant issue when power plants attempt to obtain permits and when they are required to meet new, more restrictive water consumption allowances currently being considered by the U.S. Environmental Protection Agency (EPA) under proposed Rule $316 b$. 
Table 2. Characteristics of Desiccant and Condensation Options for Flue Gas Water Recovery

\begin{tabular}{|c|c|}
\hline & Key Characteristics \\
\hline Desiccant & $\begin{array}{l}\text { - More water recovery than condensation option. } \\
\text { - } \text { to drive regeneration - good match with available } \\
\text { low-temperature waste heat in flue gas. } \\
\text { - Requires heat rejection to ambient. } \\
\text { - Liquid desiccant provides flexible design options. } \\
\text { Absorber and regenerator can be installed at different } \\
\text { locations; liquid can be transported directly to the } \\
\text { source of regeneration heat. } \\
\text { - Desiccant may absorb contaminants from the gas. } \\
\text { - May be able to combine with } \mathrm{SO}_{2} \text { control for low- } \\
\text { sulfur fuels. } \\
\text { Significant corrosion issues may exist downstream of } \\
\text { the desiccant absorber. May require costly flue } \\
\text { modifications. }\end{array}$ \\
\hline Condensation & $\begin{array}{l}\text { Requires heat rejection to ambient or refrigeration } \\
\text { system. } \\
\text { - Separation of working fluid from flue gas. Avoids } \\
\text { contamination issues. } \\
\text { - Less water recovery than desiccant option. } \\
\text { - Significant corrosion issues exist because of acidic } \\
\text { condensate. } \\
\text { Requires flue gas reheating to avoid condensing } \\
\text { conditions in the flue downstream of the condenser } \\
\text { section. }\end{array}$ \\
\hline
\end{tabular}

\subsection{GOALS AND OBJECTIVES}

The goals of this project were to develop technology for recovering water from combustion flue gases to reduce the net water requirements of power plants burning fossil fuels and to perform an engineering evaluation to determine how such technology can be integrated into various powergenerating systems, including steam turbine and combined-cycle plants. More specifically, the objectives of the project were as follows:

- Desiccant selection

- Desiccant laboratory test evaluation

- Test plan development

- Test facility and equipment design

- Equipment and materials procurement

- Test equipment installation

- Testing

- Test data evaluation 
- Commercial power plant evaluation

The project goals were facilitated through the execution of the project objectives.

\subsection{EXPERIMENTAL}

\subsection{Test Facilities}

Bench-scale LDDS tests were conducted in the Energy \& Environmental Research Center's (EERC's) conversion and environmental process simulator (CEPS). The CEPS is designed to fire pulverized coal. However other solid or liquid fuels can be utilized with slight system modifications. One of the emission control devices connected to the CEPS is a wet flue gas desulfurization (FGD) system that was used in this work to simulate a spray tower absorber for gas-liquid desiccant contact.

Pilot-scale tests using an LDDS were conducted by firing natural gas (Test Series I and $\mathrm{I}$ ) and subbituminous coal (Test Series II) in the EERC's $\sim 2.5$-MMBtu $/ \mathrm{hr}\left(2.6 \times 10^{6} \mathrm{~kJ} / \mathrm{hr}\right)$ pilot-scale combustor referred to as the slagging furnace system (SFS). The pilot-scale LDDS was designed, fabricated, installed, and operated by EERC personnel with technical support from Siemens Power Generation (SPG). The balance of this section will briefly describe the CEPS bench-scale system (3.1) and the two primary pilot-scale systems configured to support this project: the SFS (Section 3.2) and the LDDS (Section 3.3).

\subsubsection{CEPS Description and Modification}

The CEPS is illustrated in Figure 1. The CEPS is designed to nominally top-fire $4.4 \mathrm{lb} / \mathrm{hr}$ ( $2 \mathrm{~kg} / \mathrm{hr}$ ) of pulverized coal, with a heat input of $40,000 \mathrm{Btu} / \mathrm{hr}(42,202 \mathrm{~kJ} / \mathrm{hr}$ ). It is designed to maintain the flue gas (approximately $8 \mathrm{scfm}\left[0.2 \mathrm{~m}^{3} / \mathrm{min}\right]$ ) generated by the combustion of the fuel at a maximum of $1500^{\circ} \mathrm{C}\left(2732^{\circ} \mathrm{F}\right)$ for the first $4 \mathrm{~m}(12 \mathrm{ft})$ of the system, which is referred to as the radiant zone. The first $3 \mathrm{~m}(9 \mathrm{ft})$ of the heated radiant zone has an inside diameter (i.d.) of $15.2 \mathrm{~cm}(6$ in.), with the last heated zone reducing down to $7.62 \mathrm{~cm}(3 \mathrm{in}$.). The radiant zone exit is through a horizontal, $3.8-\mathrm{cm}(1.5$-in.)-i.d. ceramic tube. A portion of the particulate is removed before the convective pass section of the CEPS. After the convective section, flue gas flows through an optional ash-fouling test section, a baghouse for final removal of particulate, and optionally through a wet FGD, an air eductor, and up to a stack through the roof. The entire system is lined with either ceramic or refractory material, eliminating the possibility of reaction with and contamination of metal surfaces. There is ample access for sampling, observation, and optical diagnostics through access ports located throughout the CEPS. A personal computer displays and records temperatures, gas flows, feed rates, and flue gas compositions. Flue gas $\left(\mathrm{O}_{2}, \mathrm{CO}_{2}, \mathrm{CO}, \mathrm{SO}_{2}\right.$, and $\left.\mathrm{NO}_{\mathrm{x}}\right)$ compositions are sampled from ports in the radiant section and after the collection device. Acute control of gas temperatures and composition throughout the CEPS furnace is possible independent of the heat capacity of the fuel because of the external heating capacity of the CEPS. Heating elements line the main furnace, convective pass section, and baghouse chambers. 


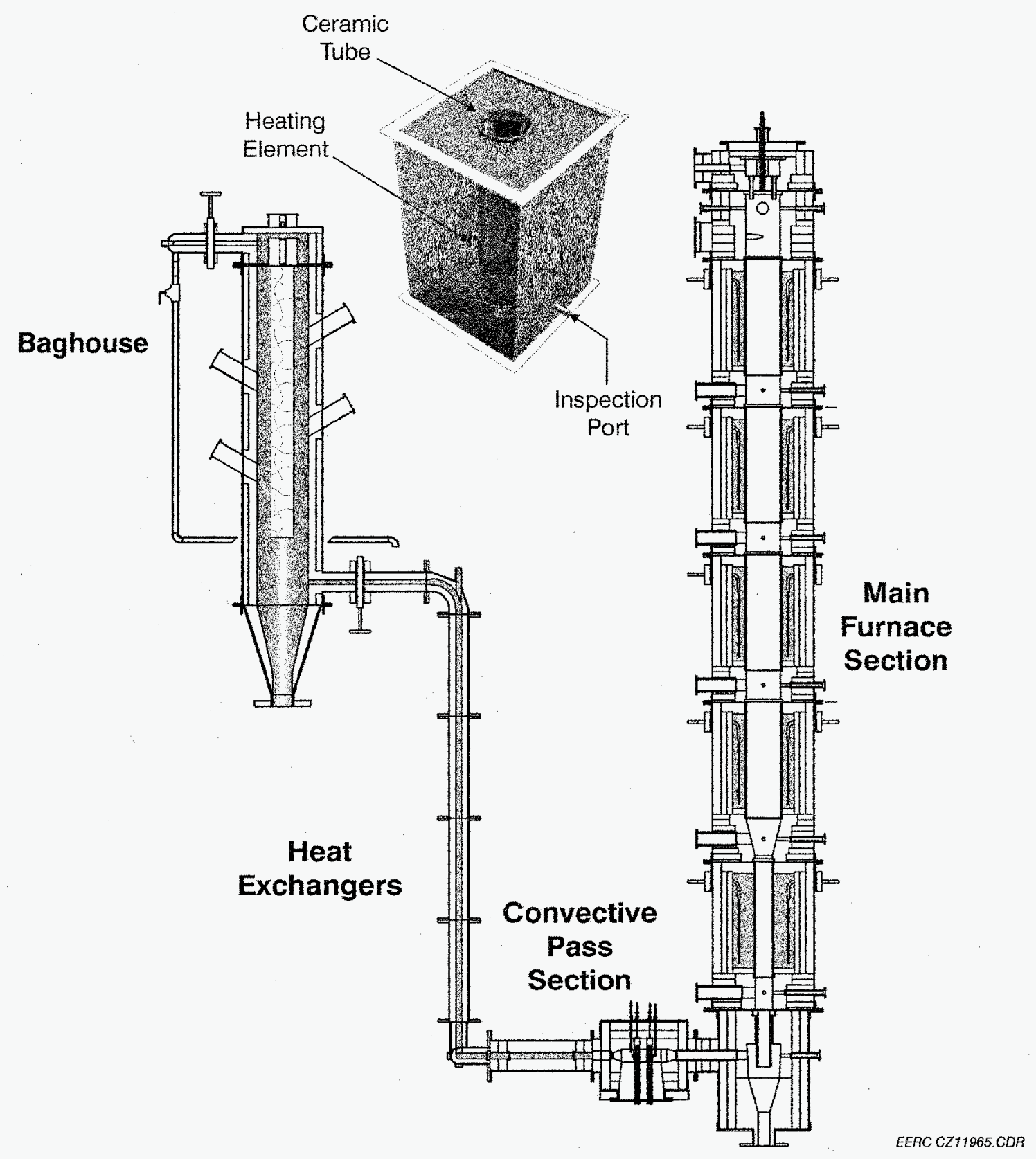

Figure 1. Illustration of the EERC CEPS.

The overall CEPS system is housed inside a series of rectangular stainless steel sections bolted together. In juxtaposition to the CEPS, there is a small-scale tank and spray tower which is illustrated in Figure 2. This system is used to simulate sulfur-reduction wet FGD scrubber systems in coal-fired power plants. The FGD can either be isolated from the CEPS when not in use or be a portion of the flue gas path for the combustion gases from the CEPS. This apparatus was used to simulate an absorber spray tower system to provide a preliminary evaluation of the desiccants selected in Task 1 . The combustion gases were directed into the spray tower where it was contacted by the desiccant stream in a countercurrent flow. 


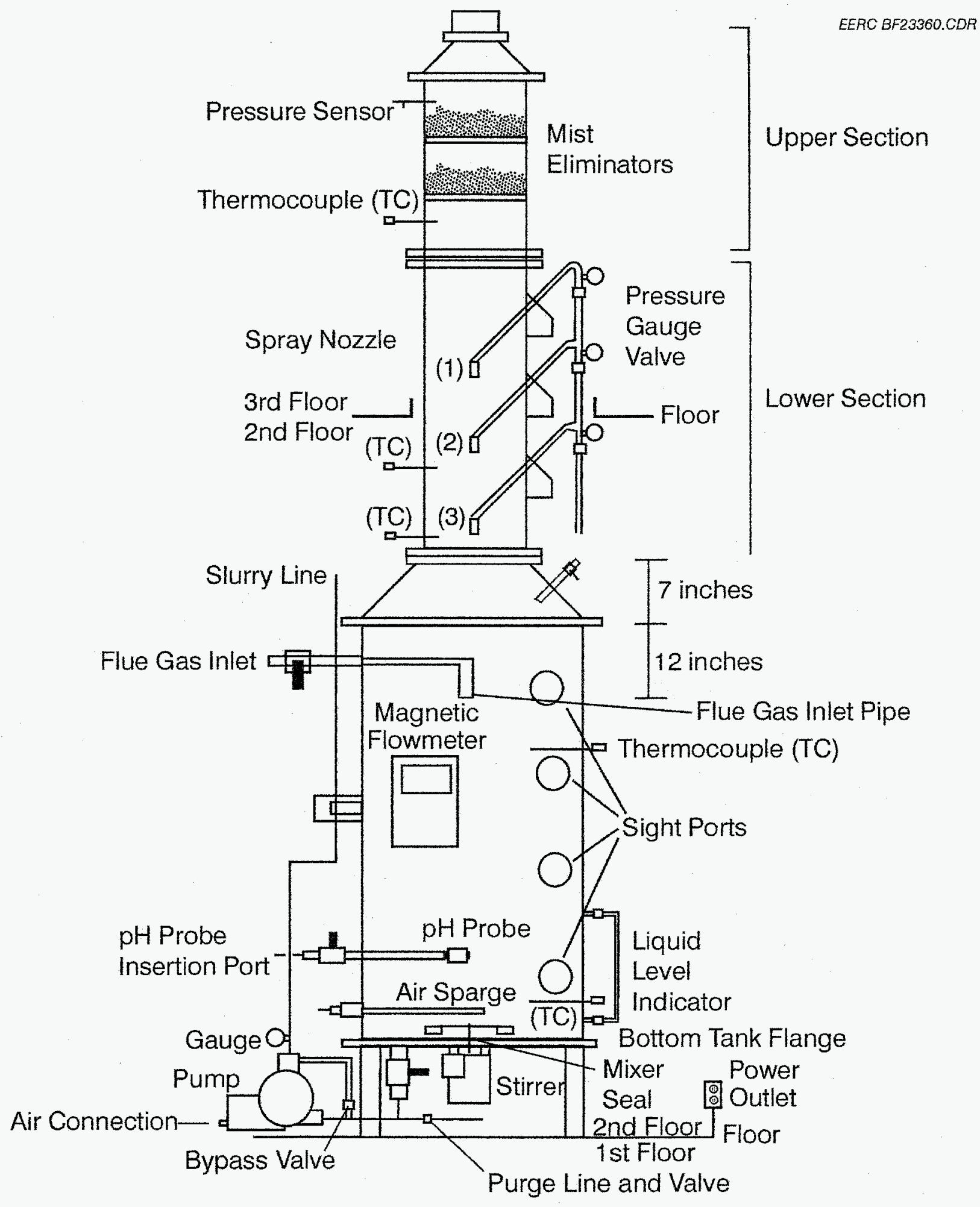

Figure 2. Schematic of the CEPS FGD system. 
A gas burner was constructed for this series of tests on the EERC CEPS to evaluate the effect of flue gas from the combustion of natural gas on the desiccants. The burner was initially test-fired horizontally outside of the furnace to ensure proper functioning of the burner and attached safety equipment such as the flame sensor and the gas flow shutoff valves. After successful completion of this test, the burner was installed in the CEPS. The gas burner was operated at nominal flow rates of $2 \mathrm{~m}^{3} / \mathrm{hr}(70 \mathrm{scfh})$ primary air and $0.7 \mathrm{~m}^{3} / \mathrm{hr}(24 \mathrm{scfh})$ natural gas to give approximately $33,760 \mathrm{~kJ} / \mathrm{hr}$ $(32,000 \mathrm{Btu} / \mathrm{hr})$.

Modifications to the FGD system included the installation of a heat exchanger for maintaining the temperature of the desiccant solution. This was connected to a controller with a thermocouple reading the temperature of the heat exchanger. A valve was installed on the line from the absorber spray pump to the flowmeter. The line continues from the flowmeter to the spray nozzles. The heat exchanger was connected to this valve for inlet fluid, and the outlet was connected to a fitting on the absorber tank to put the heated fluid back into the solution tank. Whenever the pump for the absorber was on, the fluid was passing through this heat exchanger. The valve on the pump line allowed the flowmeter and spray nozzles to be isolated from the pump while the desiccant solution was heating. This reduced the time required to heat the solution at the beginning of tests and allowed for trimming of the temperature during the tests.

\subsubsection{Pilot-Scale Slagging Furnace System}

The EERC pilot-scale SFS that supported operation of the pilot-scale LDDS began operating in 1997. The unit was originally designed to operate at very high temperatures $\left(2700^{\circ}-2900^{\circ} \mathrm{F}\left[1482^{\circ}-\right.\right.$ $\left.1593^{\circ} \mathrm{C}\right]$ ) at the furnace exit, providing higher thermal conversion efficiencies than conventional pcfired boilers. In the high-temperature mode, a substantial portion of the ash generated is removed from the system as slag. For more than 6 years, the SFS was operated in support of advanced power system projects while firing bituminous and subbituminous coals and lignite. In support of the LDDS, the furnace was operated firing natural gas or $\mathrm{pc}$ at whatever furnace exit temperature was necessary to achieve the desired LDDS inlet flue gas flow rate and temperature. A diagram and a photograph of the SFS are shown in Figures 3 and 4, respectively. A description of the various parts of the system is presented below.

\subsubsection{Fuel Feed System}

The coal feeder for the SFS was manufactured by K-Tron. Coal feed system components include two intermediate coal hoppers with pneumatically actuated valves to minimize the possibility of coal feed interruptions caused by plugging, bridging, or valve failure in a single intermediate hopper Each intermediate hopper has a level indicator, hopper vent, and dust collector. The programmable controller for the coal feeder is integrated with the data acquisition system.

Desired feed rate ranges can be achieved by proper screw selection as well as changing the coal feeder gear ratio (permitting a fivefold increase or decrease in feed rate capacity). Well-controlled feed rates as low as $60 \mathrm{lb} / \mathrm{hr}(27 \mathrm{~kg} / \mathrm{hr})$ and as high as $400 \mathrm{lb} / \mathrm{hr}(182 \mathrm{~kg} / \mathrm{hr})$ have been demonstrated. The maximum potential coal feed rate is believed to be about $1500 \mathrm{lb} / \mathrm{hr}(681 \mathrm{~kg} / \mathrm{hr})$, well beyond the firing rate capacity of the SFS. 


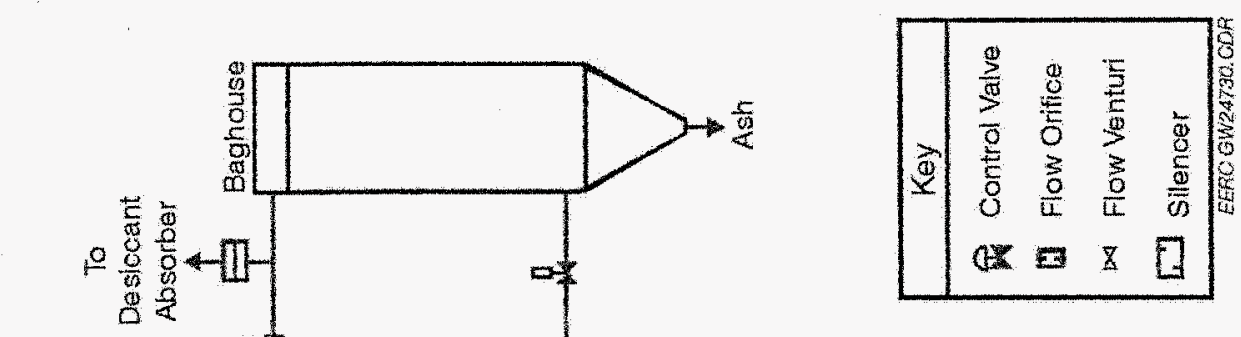

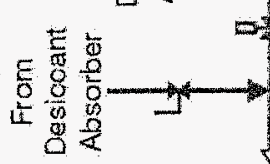
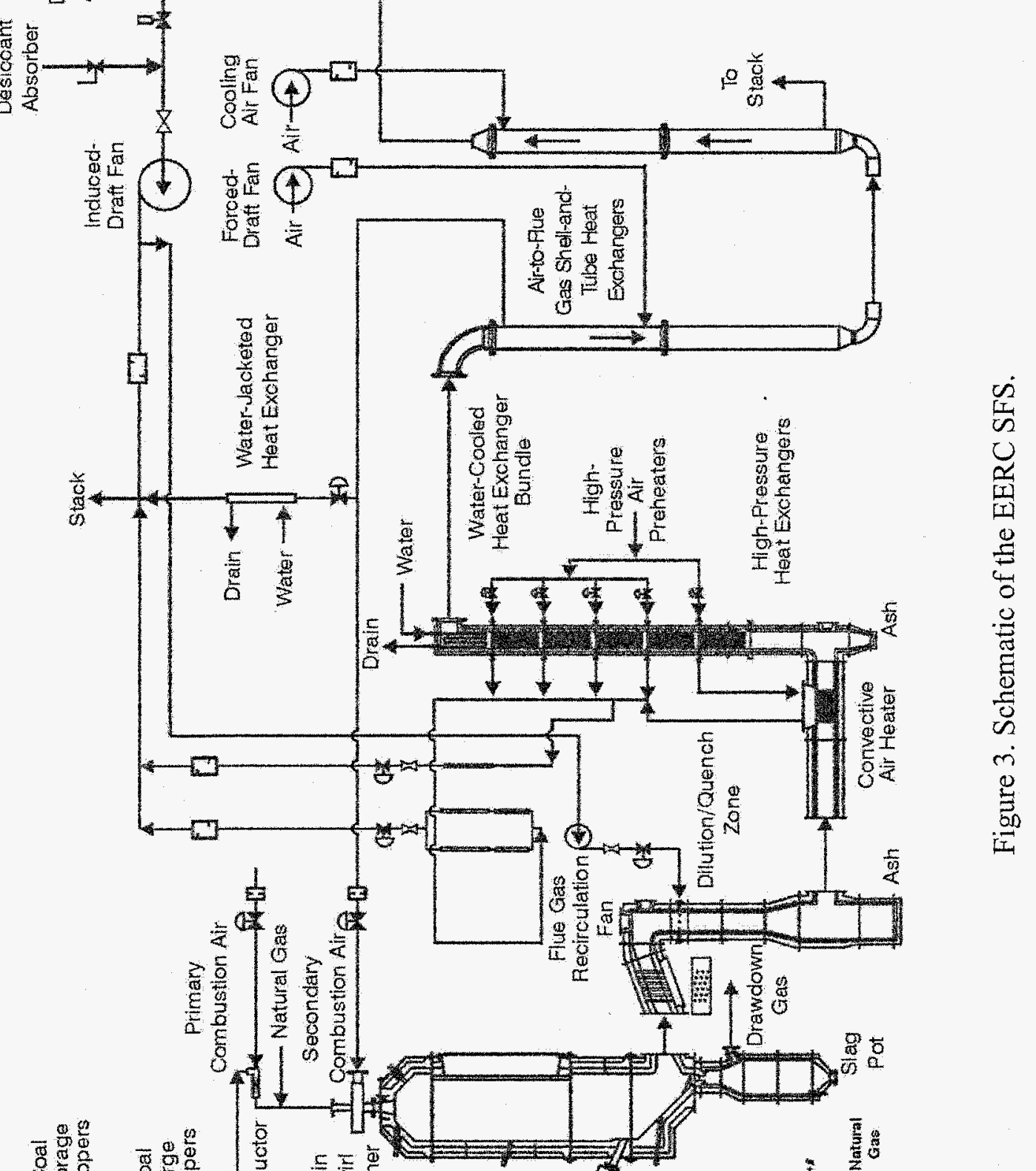


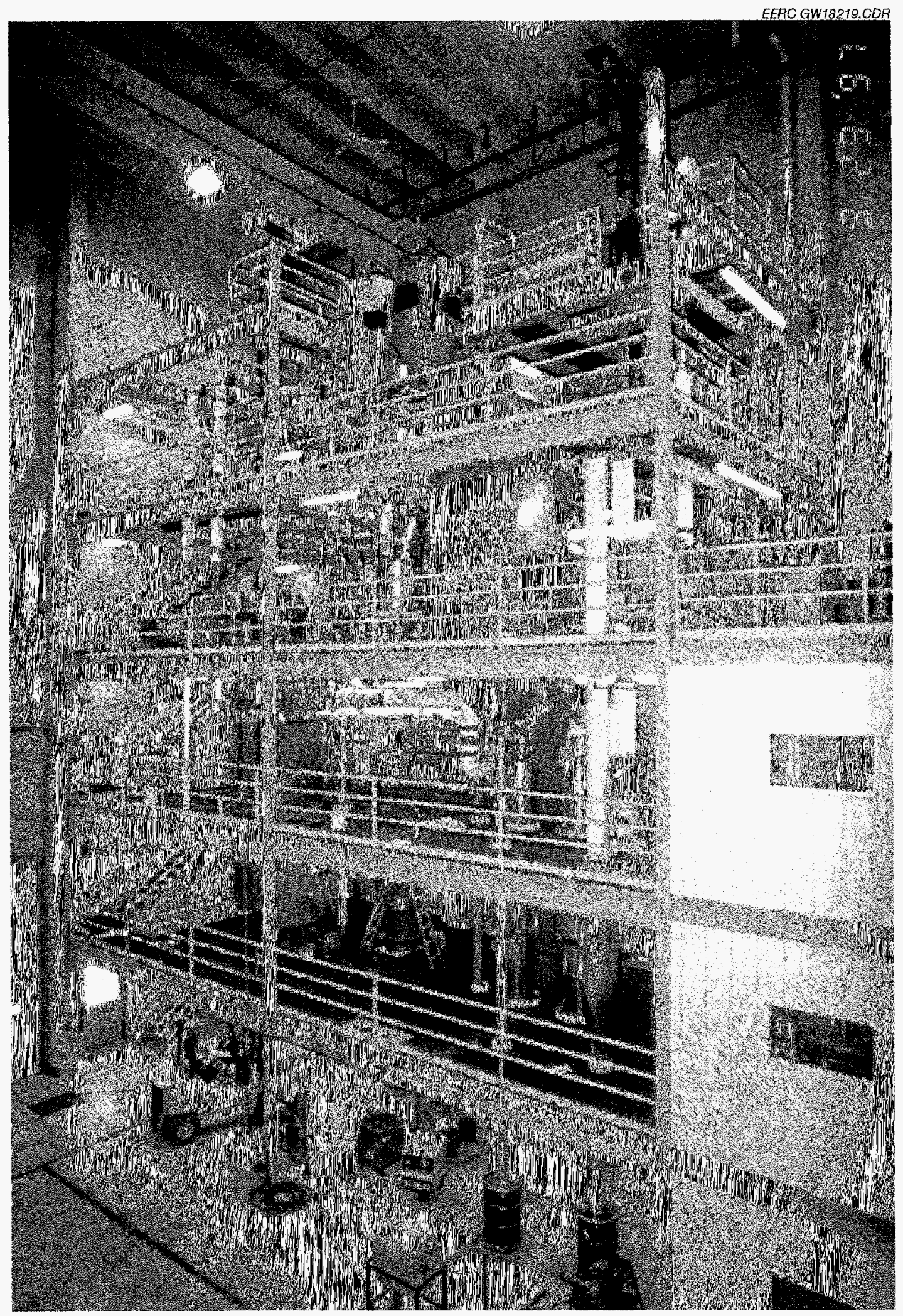

Figure 4. Photograph of the EERC SFS. 
Natural gas can also be fired in the SFS. Natural gas is delivered to the SFS at about 8 psig $(0.6 \mathrm{bar})$. The natural gas system includes piping, valve/control systems, and flame safety systems for the main and auxiliary burners as well as the slag tap burners. Although natural gas can be utilized as the primary fuel, generally the purpose of the natural gas system is to support main burner operation during heatup and cooldown. Auxiliary burner firing is used, as necessary, to control furnace exit and slag screen temperatures. However, the EERC did not use the auxiliary or slag tap burners in support of pilot-scale LDDS operation.

\subsubsection{Pilot-Scale Slagging Furnace}

The pilot-scale slagging furnace design is intended to be as fuel-flexible as possible, with maximum furnace exit temperatures of $2700^{\circ}$ to $2900^{\circ} \mathrm{F}\left(1482^{\circ}\right.$ to $\left.1593^{\circ} \mathrm{C}\right)$ in order to achieve desired furnace conditions to support high-temperature heat exchanger (HTHX) development projects and operate the combustor in a slagging mode. It has a nominal firing rate of $2.5 \mathrm{MMBtu} / \mathrm{hr}$ $(2.6 \times 106 \mathrm{~kJ} / \mathrm{hr})$ and a range of 2.0 to $3.0 \mathrm{MMBtu} / \mathrm{hr}(2.1$ to $3.2 \times 106 \mathrm{~kJ} / \mathrm{hr})$ using a single burner. The design is based on firing a bituminous coal (Illinois No. $6-11,100 \mathrm{Btu} / \mathrm{lb}[25,800 \mathrm{~kJ} / \mathrm{kg}]$ ) and a nominal furnace residence time of $3.2 \mathrm{~s}$. Resulting flue gas flow rates range from 425 to $645 \mathrm{scfm}$ (12.0 to $18.6 \mathrm{~m}^{3} / \mathrm{min}$ ), with a nominal value of $530 \mathrm{scfm}\left(15 \mathrm{~m}^{3} / \mathrm{min}\right)$ based on $20 \%$ excess air. Firing a subbituminous coal or lignite increases the flue gas volume, thereby decreasing residence time to about $2.6 \mathrm{~s}$. However, the high furnace temperature and volatility of the low-rank fuels result in high combustion efficiency ( $>99 \%$ ). The SFS furnace is oriented vertically (downfired) with a burner design based on that of a secondary air swirl generator. Slagging furnace dimensions are 47-in. (119-cm) inside diameter (i.d.) by $16 \mathrm{ft}(4.9 \mathrm{~m})$ in length. Table 3 summarizes the volumetric flow rate and temperature data upon which the furnace design was based.

The vertically oriented furnace shell was designed to include four distinct furnace sections, illustrated in Figure 3. The top section of the furnace supports the main burner connection. The upper-middle furnace section provides a location for installation of one or two HTHXs in the furnace wall. The lower-middle furnace section supports the auxiliary gas burner; the bottom section of the furnace includes the furnace exit to the slag screen as well as the slag tap opening. For the natural gas- and pc-fired LDDS tests discussed in this report, the slag screen was replaced with a refractorylined section of open duct. Construction materials for the furnace shell are mostly carbon steel. The only exceptions are the flanged pipe connections for the main and auxiliary burners and the sight ports; since their refractory protection is limited, they were fabricated using stainless steel.

Temperature measurement in the furnace is accomplished using Type $\mathrm{S}$ thermocouples and optical pyrometers. The optical pyrometers are mounted in relatively permanent locations to measure furnace flame temperature and flue gas temperature near the surface of the furnace wall and at the furnace exit. Operating experience has shown optical pyrometer performance to be acceptable when compared with Type $S$ thermocouples while natural gas and pc are fired. Verification of optical pyrometer performance is accomplished during each SFS operating period using Type S thermocouple data. For the purpose of the tests discussed in this report, the Type $S$ thermocouples were used along with two optical pyrometers. 


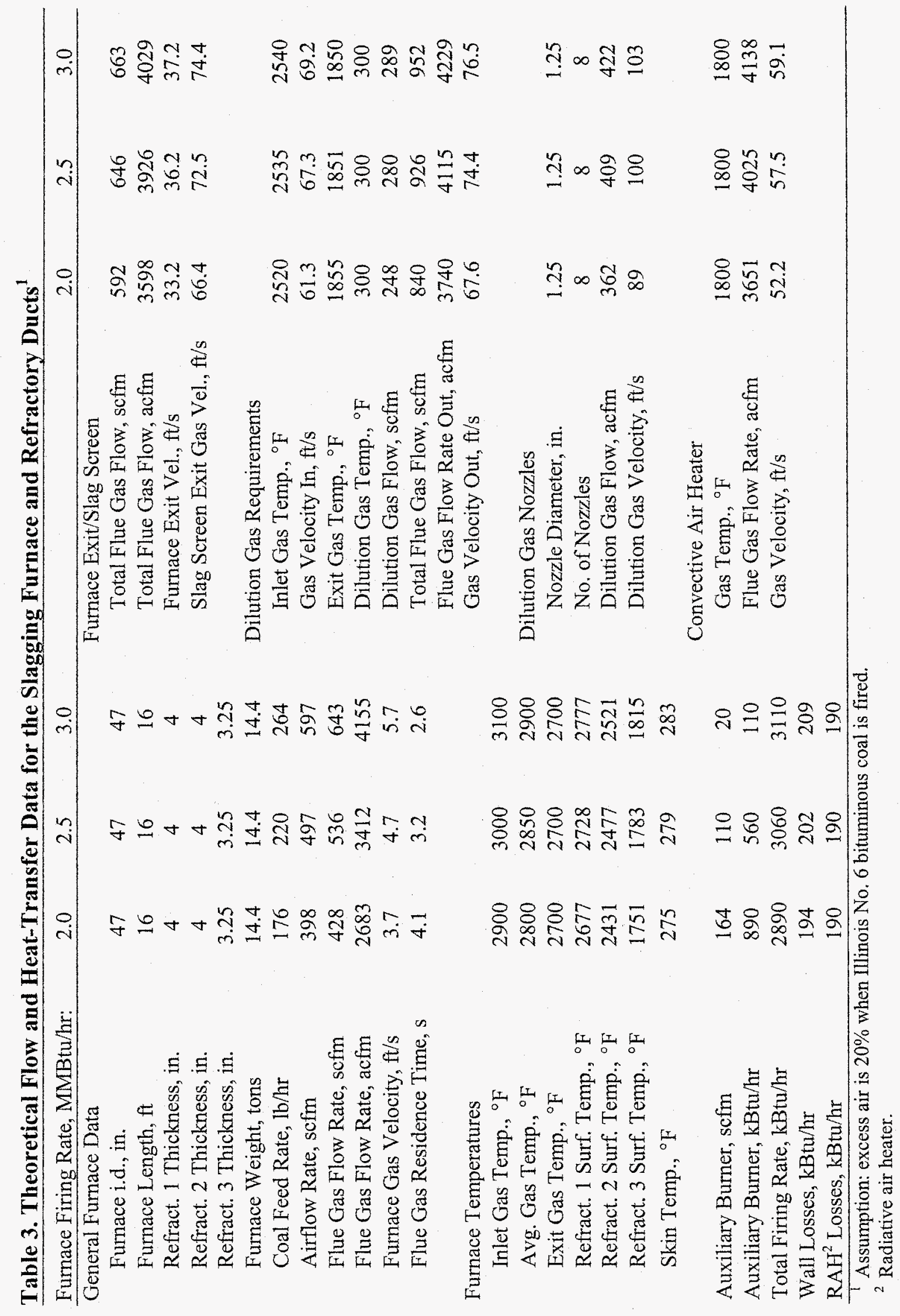


Secondary combustion air preheat control capabilities for the main burner are limited to a control range of $600^{\circ}$ to $800^{\circ} \mathrm{F}\left(316^{\circ}\right.$ to $\left.427^{\circ} \mathrm{C}\right)$, depending on ambient air temperatures and forceddraft (FD) fan capacity. Typically, two tube-and-shell heat exchangers are operated in series to recover heat from the flue gas to preheat secondary combustion air for the main burner. Primary combustion air for the main burner is not heated.

Observation ports are located in the furnace to permit visual observation of the main burner flame, slag screen, and slag tap. The refractory walls in the slagging furnace consist of three castable refractory layers: a high-density slag-resistant material, an intermediate refractory, and a low-density insulating refractory. Three refractory layers were selected as a cost-effective approach to keep the overall size and weight of the system to a minimum while slag corrosion and heat loss are reduced.

\subsubsection{Main and Auxiliary Burners}

The main burner is natural gas- and pc-capable, $70 \%-200$ mesh $(70 \%-75 \mu \mathrm{m})$, with some burner turndown factored into the design. Flame stability is assessed by observing the flame and its relation to the burner quarl as a function of secondary air swirl and operating conditions at full load and under turndown conditions. The basic burner design, an International Flame Research Foundation (IFRF)-type adjustable secondary air swirl generator, is illustrated in Figure 5. An IFRFtype adjustable secondary air swirl generator uses primary and secondary air at approximately $15 \%$ and $85 \%$ of the total air, respectively, to adjust swirl between 0 and a maximum of 1.9 . Swirl is defined as the ratio of the radial (tangential) momentum to axial momentum imparted to the secondary air by movable blocks internal to the burner and is used to set up an internal recirculation zone (IRZ) within the flame that allows greater mixing of combustion air and fuel.

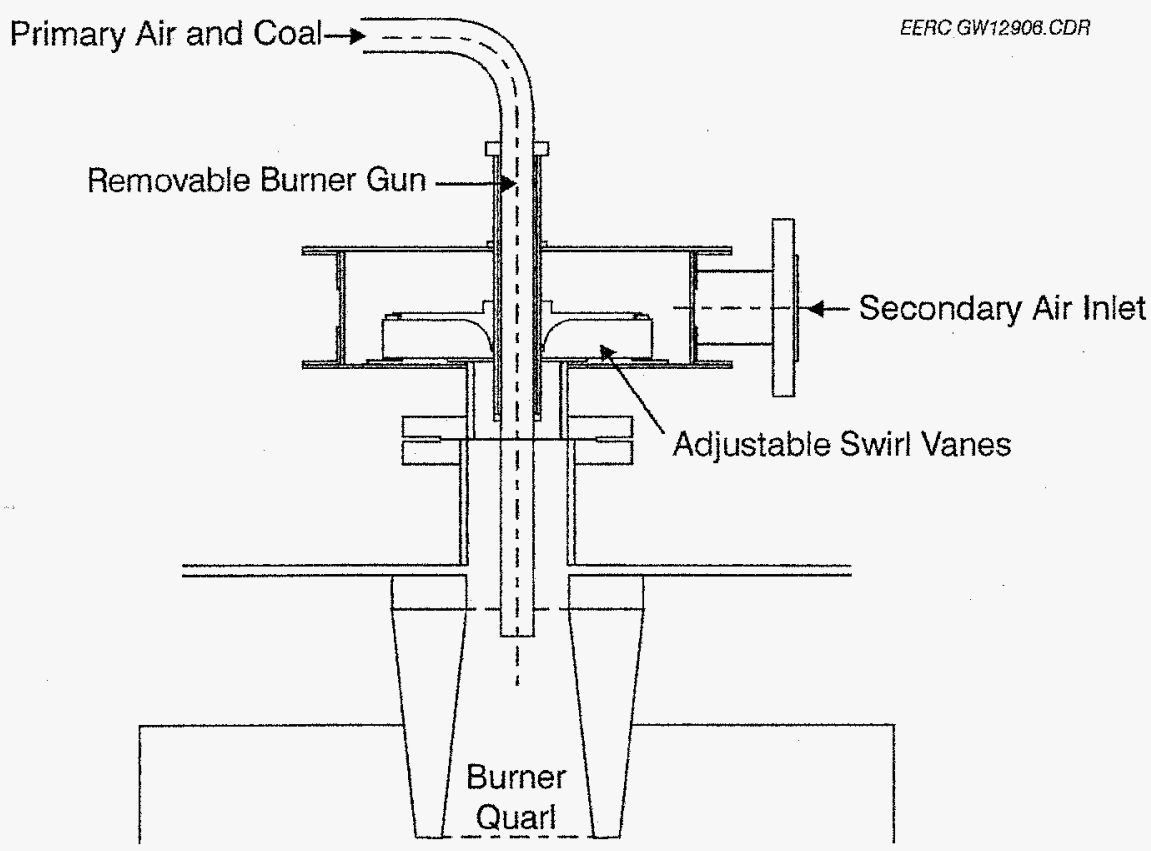

Figure 5. Schematic of the SFS basic burner design, an IFRF-type adjustable secondary air swirl generator. 
Secondary air swirl is used to stabilize the flame. In the absence of swirl, loss of flame may result, increasing the risk of a dust explosion. As swirl is applied to the combustion air, coal particles are entrained in the IRZ, increasing the heating rate of the particles, leading to increased release of volatiles and char combustion. The flame becomes more compact and intense as swirl is increased to an optimum level, which is characterized in EERC pilot-scale test facilities as the point at which the flame makes contact with the burner quarl. Increasing swirl beyond this level can pull the flame into the burner region, unnecessarily exposing metal burner components to the intense heat of the flame and possible combustion in the fuel delivery pipe.

Increasing swirl to provide flame stability and increased carbon conversion can also affect the formation of $\mathrm{NO}_{\mathrm{x}}$. The high flame temperatures and increased coal-air mixing associated with increased swirl create an ideal situation under which $\mathrm{NO}_{\mathrm{x}}$ may form. In full-scale burners with adjustable vanes, swirl is often increased to reach the optimum condition and then decreased slightly to reduce the production of $\mathrm{NO}_{\mathrm{x}}$. Although $\mathrm{NO}_{\mathrm{x}}$ emissions are of interest, their control was not an objective for these SFS pilot-scale tests. Therefore, burner operational settings were based on achieving a relatively uniform furnace temperature and limit slag conditions in the furnace. Flame stability under turndown conditions is characterized by firing the primary burner at reduced load (typically $66 \%$ to $85 \%$ of the full load rate), maintaining the same primary airflow, and adjusting the secondary airflow to meet excess air requirements.

Materials of construction for the main burner are entirely stainless steel because of the combustion air (up to $800^{\circ} \mathrm{F}\left[427^{\circ} \mathrm{C}\right]$ ) temperature range to which it is exposed. Combustion airflow rates through the main burner range from about 400 to $600 \mathrm{scfm}$ (11 to $17 \mathrm{~m}^{3} / \mathrm{min}$ ), depending on furnace firing rate and fuel type fired (natural gas, bituminous/subbituminous coal, or lignite).

As stated earlier, thermocouples are installed to measure inlet combustion air temperatures. Thermocouple data are automatically logged into the data acquisition system. Pressure transmitters and gauges are used to monitor static and differential pressures in order to monitor burner performance and measure combustion air flow rate. These data are also automatically logged into the data acquisition system, and flow control valves are used to adjust and maintain desired combustion air flow rates. As a backup, burner data are recorded manually on data sheets on a periodic basis.

\subsubsection{Furnace HTHX, Slag Screen, Dilution/Quench Zone, Convective Air Heater, and Process Air Heaters}

The furnace HTHX, slag screen, dilution/quench zone, convective air heater (CAH), and process air heaters are all part of the high-temperature, advanced combustion design of the SFS. For this project, the furnace HTHX and slag screen were not installed. The flue gas recirculation system of the dilution/quench zone was shut off to maintain proper flue gas flow rates to the LDDS. Although the CAH and process air heaters were used to support flue gas temperature control, the purpose of the project was not to evaluate these components. Therefore, no detailed description or discussion of any of these components is presented in this report. However, the location of these components is shown in Figures 3 and 4, and a detailed description of each subsystem was presented in final project reports to the U.S. Department of Energy (DOE) (Hurley et al., 2001; Collings et al., $1999 \mathrm{a}, \mathrm{b})$. 


\subsubsection{Slagging Furnace System Heat Exchangers}

The pilot-scale SFS includes four tube-and-shell heat exchangers for heat recovery and flue gas temperature control and two water-cooled heat exchangers to reduce the heat load on system fans. Their location in the overall process layout is illustrated in Figure 3. The first two tube-and-shell heat exchangers reduce flue gas temperature and preheat the secondary air for the main burner. For the purpose of this project, the first two tube-and-shell heat exchangers were the first stage of heat recovery used to achieve the desired flue gas temperature at the inlet of the pilot-scale LDDS absorber. Therefore, the LDDS absorber flue gas inlet temperature dictated the secondary combustion air temperature. The third and fourth tube-and-shell heat exchangers were used to control flue gas temperature at the inlet of the baghouse and function as the second stage of heat recovery used to achieve the desired flue gas temperature at the inlet of the pilot-scale LDDS absorber. Construction materials for the tube-and-shell heat exchangers are a combination of 304 stainless and carbon steels.

Two water-cooled heat exchangers are used to reduce the load on three SFS fans and ambient temperature on the upper levels of the SFS support structure. One water-cooled heat exchange tube bundle is installed in the flue gas stream between the five process air heater tube bundles and the first tube-and-shell heat exchanger. This water-cooled tube bundle reduces the cooling load on the fans supporting the tube-and-shell heat exchangers. The second water-jacketed heat exchanger is installed on the secondary air bypass line to the stack and is designed to reduce the air volume entering the stack and the amount of heat being emitted to the immediate area. However, for this project, the water source for this heat exchanger was diverted to support operation of the LDDS.

\subsubsection{System Fans}

The pilot-scale SFS has five fans: a combustion air FD fan, two cooling-air FD fans, an induced-draft (ID) fan, and a flue gas recirculation (FGR) fan. Table 4 summarizes the fan specifications. In support of the pilot-scale LDDS, only three of the fans were used. The smaller of the two cooling-air FD fans is used in support of the HTHX that was removed for this project, and the FGR blower, which supports the dilution/quench zone, was not used.

All four large fans are centrifugal-type fans, with variable-speed drives (speed controllers). The smaller cooling air fan is a regenerative blower. The combustion air FD blower supplies ambient air to tube-and-shell heat exchanger Nos. 1 and 2, plus combustion air to the auxiliary burner. A portion of the heated air exiting the heat exchangers is used as secondary combustion air to the main burner, with the rest exiting the system through the stack. Valves, orifice plates, and venturis are used to control and measure the air and flue gas flow in the SFS.

Final cooling of the flue gas before it enters the baghouse is provided by Cooling-Air Blower A, the larger of the two cooling-air blowers. This fan supplies ambient air to tube-and-shell heat exchanger Nos. 3 and 4. The heated air leaving the heat exchangers exits the system through the stack. An electronic speed controller on the fan is used to adjust the airflow from 0 to $1200 \mathrm{scfm}$ ( 0 to $34 \mathrm{~m}^{3} / \mathrm{min}$ ) to maintain a desired flue gas temperature entering the baghouse. This approach permits particulate control device operation at either cold-side $\left(350^{\circ} \mathrm{F}\left[177^{\circ} \mathrm{C}\right]\right)$ or hot-side $\left(650^{\circ} \mathrm{F}\right.$ 
Table 4. Pressure, Temperature, and Flow Specifications for SFS Blowers

\begin{tabular}{lccccc}
\hline & FD Blower & $\begin{array}{c}\text { Cooling-Air } \\
\text { Blower A }\end{array}$ & ID Blower & FGR Blower & $\begin{array}{c}\text { Cooling-Air } \\
\text { Blower B }\end{array}$ \\
\hline Inlet Pressure, psig & 0 & 0 & -1 & 0 & 0 \\
Exit Pressure, psig & 3 & 1.5 & 0.5 & 1.5 & 2 \\
Avg. Inlet Temp., ${ }^{\circ} \mathrm{F}$ & 60 & 60 & 350 & 350 & 80 \\
Min. Inlet Temp., ${ }^{\circ} \mathrm{F}$ & 20 & 20 & 250 & 250 & 60 \\
Max. Inlet Temp., ${ }^{\circ} \mathrm{F}$ & 100 & 100 & 450 & 450 & 100 \\
Max. Inlet Flow, scfm & 1200 & 1200 & 1200 & 450 & 200 \\
Max. Inlet Flow, acfm & 1292 & 1292 & 2255 & 788 & 200 \\
Avg. Inlet Flow, acfm & 1200 & 1200 & 1755 & 701 & 200 \\
Motor Horsepower & 40 & 20 & 25 & 10 & 5 \\
\hline
\end{tabular}

$\left.\left[344^{\circ} \mathrm{C}\right]\right)$ conditions. In support of this project, the cooling-air blower was operated to control flue gas temperature at the baghouse inlet at nominally $203^{\circ} \mathrm{F}\left(95^{\circ} \mathrm{C}\right)$ during Test Series I (SFS-WE1$0104)$ and in the range of $220^{\circ}$ to $230^{\circ} \mathrm{F}\left(105^{\circ}\right.$ to $\left.110^{\circ} \mathrm{C}\right)$ during Test Series II (SFS-WE2-0204).

Flue gas exiting the pilot-scale LDDS absorber was drawn through the ID blower and discharged through the stack. The blower speed is regulated with an electronic speed controller to maintain a zero-pressure balance point in the slagging furnace. Normally, a portion of the hot flue gas (nominally $350^{\circ} \mathrm{F}\left[177^{\circ} \mathrm{C}\right]$ ) from the $\mathrm{ID}$ fan exit is drawn through the FGR blower for use as dilution gas in the dilution/quench zone. However, as previously stated, FGR was not used while the SFS was operated in support of this project.

\subsubsection{Emission Control}

A pulse-jet baghouse is generally used for particulate control in the pilot-scale SFS. That was the case in support of this project in order to minimize the fly ash loading in the flue gas at the inlet of the LDDS absorber. The baghouse design permits operation at both cold-side $\left(250^{\circ}\right.$ to $400^{\circ} \mathrm{F}$ $\left[121^{\circ}\right.$ to $\left.\left.205^{\circ} \mathrm{C}\right]\right)$ and hot-side $\left(600^{\circ}\right.$ to $700^{\circ} \mathrm{F}\left[316^{\circ}\right.$ to $\left.\left.371^{\circ} \mathrm{C}\right]\right)$ temperatures. The primary baghouse chamber and ash hopper walls are electrically heated and insulated to provide adequate temperature control to minimize heat loss and avoid condensation problems on start-up and shutdown. Operation at low flue gas flow rates $\left(<400 \mathrm{scfm}\left[<11.3 \mathrm{~m}^{3} / \mathrm{min}\right]\right.$ ) and temperatures (as low as $203^{\circ} \mathrm{F}\left[95^{\circ} \mathrm{C}\right]$ ) were easily accomplished in support of this project, and moisture condensation problems were avoided, because of the electrically heated surfaces. The main baghouse chamber was designed with internal angle iron supports to handle a negative static pressure of 20 in. W.C. ( $37 \mathrm{~mm} \mathrm{Hg}$ ).

The original design basis assumed flue gas flow rates to the baghouse would range from a low of $630 \mathrm{scfm}\left(17.8 \mathrm{~m}^{3} / \mathrm{min}\right)$ at $350^{\circ} \mathrm{F}\left(177^{\circ} \mathrm{C}\right)$, to a maximum of $1063 \mathrm{scfm}\left(30.1 \mathrm{~m}^{3} / \mathrm{min}\right)$ at $700^{\circ} \mathrm{F}$ $\left(371^{\circ} \mathrm{C}\right)$. Therefore, the baghouse design was based on an average flue gas flow rate of $850 \mathrm{scfm}$ $\left(24.1 \mathrm{~m}^{3} / \mathrm{min}\right)$ at $350^{\circ} \mathrm{F}\left(177^{\circ} \mathrm{C}\right)$ or $1900 \mathrm{acfm}\left(53.8 \mathrm{~m}^{3} / \mathrm{min}\right)$ at $700^{\circ} \mathrm{F}\left(371^{\circ} \mathrm{C}\right)$, based on a nominal 
furnace firing rate of $2.5 \mathrm{MMBtu} / \mathrm{hr}\left(2.6 \times 10^{6} \mathrm{~kJ} / \mathrm{hr}\right)$. The baghouse is sized to accommodate a maximum of 36 bags mounted on wire cages with 2 -in. $(5-\mathrm{cm})$ bag spacing. Bag dimensions are nominally $6 \mathrm{in} .(15.2 \mathrm{~cm})$ in diameter by $10 \mathrm{ft}(3.0 \mathrm{~m})$ in length, providing a total filtration area of $565 \mathrm{ft}^{2}\left(52.5 \mathrm{~m}^{2}\right)$.

Each filter bag is secured to the tube sheet using a snap band sewn into the top cuff. Stainless steel (304 SS) wire cages with 20 vertical wires and 6-in. $(15-\mathrm{cm})$ ring spacing provide bag support. The pulse-jet baghouse is a single compartment capable of either on- or off-line cleaning. Pulse-jet cleaning can be triggered as a function of baghouse differential pressure or as a function of time. High-pressure/low-volume and low-pressure/high-volume cleaning options were included in the design of the pulse-air system. During heatup and off-line cleaning, the original design allowed for bypassing the baghouse by diverting flue gas flow through a cyclone. In support of this project, the baghouse was always online, allowing for the LDDS to be bypassed during heatup, cooldown, and whenever necessary to address operational problems or make system changes. The fabric type used during this project was a $22-\mathrm{oz} / \mathrm{yd}^{2}\left(744-\mathrm{g} / \mathrm{m}^{2}\right)$ woven glass bag with a polytetrafluoroethylene (PTFE) membrane.

For the purpose of this project, an $\mathrm{FGD}$ or $\mathrm{SO}_{2}$ control system was not employed as part of the pilot-scale system. Use of an FGD system was not appropriate during natural gas-fired tests and use of a low-sulfur fuel made it unnecessary during the coal-fired tests, offering an opportunity to observe potential $\mathrm{SO}_{2}$ impacts on the performance of the LDDS. Dispersion modeling data developed by the North Dakota Department of Health allow a permitted $\mathrm{SO}_{2}$ emission rate limit of $20.8-\mathrm{lb} / \mathrm{hr}(9.4-\mathrm{kg} / \mathrm{hr})$ for the SFS. Based on operating experience with bituminous, subbituminous, and lignite fuels, the EERC's SFS has never exceeded an $\mathrm{SO}_{2}$ emission rate of $17 \mathrm{lb} / \mathrm{hr}(7.7 \mathrm{~kg} / \mathrm{hr})$.

Originally, filters and heat trace lines were installed to support three SFS flue gas sample locations. The first location was at the exit of the slag screen; the second was upstream of the baghouse; and the third was downstream of the baghouse. As was the case with this project, these sample lines can be relocated, or additional sample ports can be added to the SFS. For this project, flue gas sample ports were installed in the inlet and outlet piping of the pilot-scale LDDS absorber to permit simultaneous flue gas sampling for gaseous/vapor-phase constituents as well as particulate mass loading and particle-size distribution (PSD). Using online instruments, specific routine flue gas measurements are made for carbon monoxide $(\mathrm{CO})$, carbon dioxide $\left(\mathrm{CO}_{2}\right)$, oxygen $\left(\mathrm{O}_{2}\right), \mathrm{SO}_{2}$, and nitric oxide and nitrogen dioxide $\left(\mathrm{NO}_{\mathrm{x}}\right)$ concentrations. Fly ash PSD and mass loading and the concentrations of other flue gas constituents of interest are determined periodically using standard sampling techniques that are described in Section 4.0 of this report.

\subsubsection{Instrumentation and Data Acquisition}

The instrumentation and data acquisition components for the pilot-scale SFS measure and record combustion air, flue gas, process air, cooling water, temperatures, static and differential pressures, and flow rates. Flue gas is simultaneously monitored at two locations for $\mathrm{O}_{2}, \mathrm{SO}_{2}, \mathrm{CO}$, $\mathrm{CO}_{2}$, and $\mathrm{NO}_{\mathrm{x}}$ on a continuous basis using two sets of online analyzers. For this project, these two

sets of flue gas analyzers were used to monitor the inlet and outlet of the LDDS absorber and occasionally check the vapor stream exiting the LDDS product water condenser. Numerous 
temperature measurements were made throughout the SFS to document flue gas, heat exchanger, and refractory conditions in the system. Orifice plates and venturis (monitored with pressure transducers and gauges on the main control panel) are used to measure combustion air flow rate, flue gas flow rate, and process air flow rates. For this project, annubars (monitored with pressure transmitters tied into the SFS data acquisition system) were installed to measure flue gas flow rate at the inlet and outlet of the LDDS absorber.

The data acquisition system uses three personal computers with battery backup power supplies and is based on a Genesis software package. All process data points are logged on the data acquisition system and stored. Integrated process control has been implemented extensively throughout the SFS, although all system processes can also be controlled manually. The integrated process control includes the 1) fuel feed system, 2) furnace static pressure, 3) drawdown gas flow control, 4) combustion air flow control, 5) cooling-air flow control to the tube-and-shell heat exchangers, 6) process air flow rate and temperature control to the CAH tube bank, 7) process air flow rate and temperature control to the HTHX, 8) FGR rate to the dilution/quench zone, and 9) baghouse cleaning and temperature control. In addition to the data acquisition system, process data are recorded manually on data sheets on an established time schedule for backup purposes. Process control related to the LDDS was generally a manual operation, except for desiccant temperature and flow rate to the LDDS absorber and desiccant regenerator, as these components were integrated into the SFS's computerized process control functions.

\subsubsection{Description of the Liquid Desiccant-Based Dehumidification System}

Prior to initiating any pilot-scale experimental work, the EERC developed a design basis in partnership with SPG for the pilot-scale LDDS. Key factors included selection of a flue gas flow rate to match the operating range of the EERC's SFS and, where possible, making use of components from an existing scrubber system. Once the basic design was agreed upon, EERC personnel completed detailed design, procurement, and installation activities. A schematic and photograph of the pilot-scale LDDS installed at the EERC are included as Figures 6 and 7, respectively. The illustration in Figure 6 represents the pilot-scale LDDS including both the absorber system where water is removed from the flue gas by the desiccant and the desiccant regeneration system where product water is recovered and the desiccant regenerated for circulation back to the absorber. Flue gas entering the LDDS absorber is generated in the SFS combustor. If coal or another solid fuel is fired, the flue gas passes through a baghouse to remove $>99.9 \%$ of the particulate prior to entering the LDDS absorber. If the combustor is natural gas-fired, as was the case for part of this project, the baghouse would not be necessary. However, to simplify the flue gas piping configuration, the baghouse was included in the flue gas path for all test periods. A description of the various parts of the LDDS is presented below.

\subsubsection{LDDS Absorber Tower}

As depicted in Figure 6, the flue gas entering the LDDS absorber tower can be contacted with as many as six spray levels of desiccant solution. Individual nozzles can be interchanged at each spray level to achieve a range of desiccant flow rates, nominally 5-16 gpm $(19-60 \mathrm{~L} / \mathrm{min})$, at each

spray level. Total desiccant circulation rate through the absorber is limited to $<50 \mathrm{gpm}(<189 \mathrm{~L} / \mathrm{min})$ 


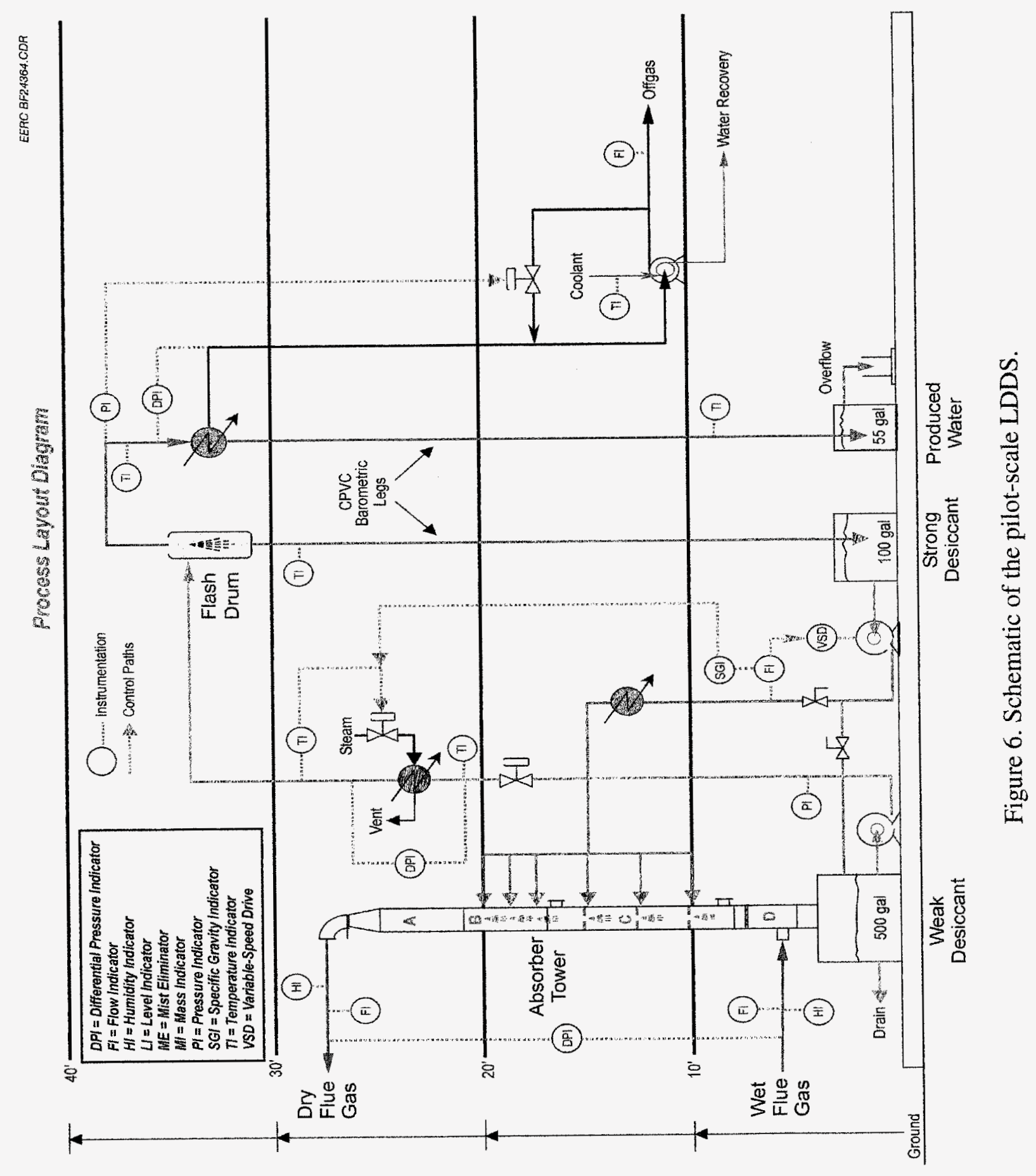




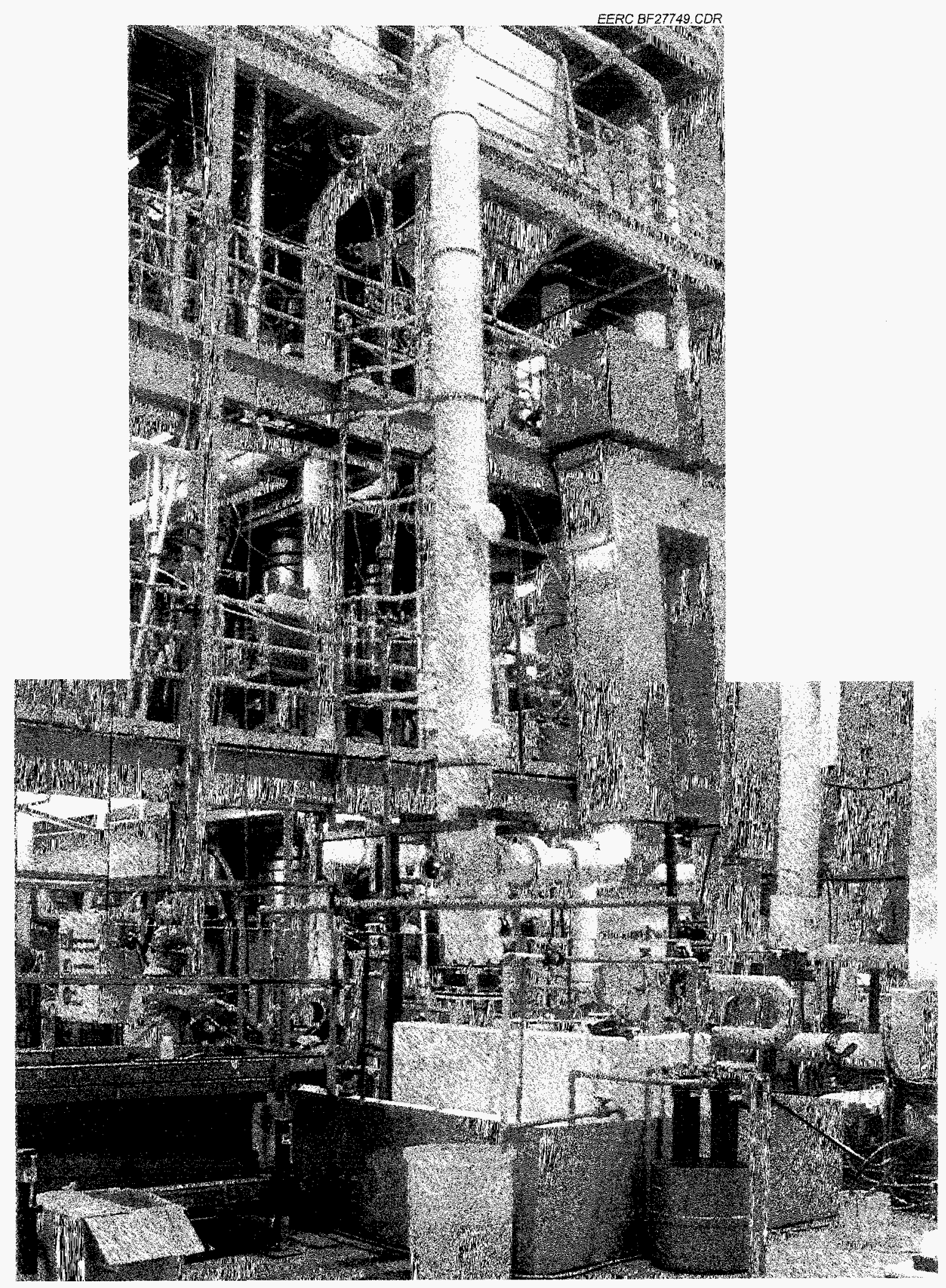

Figure 7. Photograph of the pilot-scale LDDS. 
based on pump capacity and desiccant specific gravity. An alternate configuration employed a single spray level (second from the bottom) and $3 \mathrm{ft}(0.9 \mathrm{~m})$ of commercial packing installed in a random manner. The packing used for the project was a polypropylene saddle packing measuring nominally 3 by 6 in. $(7.6$ by $15.2 \mathrm{~cm}$ ) supported by a screen with nominal 2 -in. $(5-\mathrm{cm})$ grid openings. Packing material was inserted and removed from the absorber column, once desiccant circulation was stopped and flue gas flow was bypassed, through $6-\mathrm{in} .(15.2-\mathrm{cm})$ access ports installed in the wall of the absorber column.

Materials of construction for the absorber column are 316 SS. Absorber tower dimensions are nominally $11.75 \mathrm{in} .(29.84 \mathrm{~cm})$ i.d. by $23 \mathrm{ft}(7 \mathrm{~m})$ in length. The absorber column was insulated using 1 -in. $(2.54-\mathrm{cm})$ fiberglass pipe insulation to minimize heat losses. Flue gas flow rate at the inlet of the absorber has been nominally $450 \mathrm{acfm}\left(12.7 \mathrm{~m}^{3} / \mathrm{min}\right)$ at $130^{\circ}$ to $205^{\circ} \mathrm{F}\left(55^{\circ}\right.$ to $\left.96^{\circ} \mathrm{C}\right)$ in order to limit the flue gas velocity through the absorber column to $10 \mathrm{ft} / \mathrm{s}(3 \mathrm{~m} / \mathrm{s})$. Once the flue gas exits the vicinity of the six spray levels, it passes through a high-efficiency mist eliminator to remove any entrained desiccant droplets before it is discharged through the stack. Water wash nozzles are located above and below the mist eliminator to permit periodic online cleaning when necessary to avoid plugging and/or differential pressure control problems. Piping, fittings, and isolation valves through which the desiccant solution is delivered to the absorber are chlorinated polyvinyl chloride (CPVC) plastic to effectively handle the chemical properties of the desiccant solution and the anticipated range of desiccant solution temperatures. Piping size is primarily 2 -in. $(5.1-\mathrm{cm})$ Schedule 80 with some 1-in. $(2.5-\mathrm{cm})$ and $0.5-$ in. $(1.3-\mathrm{cm})$ Schedule 80 material also employed. Flexible hose connections were employed between the riser and spray nozzle assemblies using braided-reinforced polyurethane tubing. CPVC piping and fittings supporting the absorber column were not insulated because of the poor heat-transfer properties of CPVC and the relatively low temperature differential between the desiccant solution and ambient.

Nozzles used in the absorber column varied in size and number depending on the desired desiccant flow rate. The nozzles were standard commercial small capacity, full cone, spiral jet spray nozzles constructed from $316 \mathrm{SS}$ with a 60 degree spray angle. Nozzle size designations include 053 , 082 , and 164 referring to nominal capacities of $5.3,8.2$, and $16.4 \mathrm{gpm}(20.1,31.0$, and $62.1 \mathrm{Lpm})$, respectively, at a pressure of $10 \mathrm{psig}(0.7 \mathrm{bar})$.

\subsubsection{LDDS Desiccant Tanks}

Two tanks support operation of the LDDS: one recovering desiccant solution from the flash drum and one recovering desiccant solution at the base of the absorber column. Both tanks were fabricated using a copolymer polypropylene, selected to effectively handle the chemical properties of the desiccant solution and the anticipated range of desiccant solution temperatures, $\angle 180^{\circ} \mathrm{F}\left(<83^{\circ} \mathrm{C}\right)$. Both tanks are located in a carbon steel containment area to control minor as well as potential catastrophic leaks. Each tank is anchored on one end to prevent movement yet allow for thermal expansion. The smaller of the two tanks, nominally 100 gal $(378 \mathrm{~L})$, was fabricated using 0.5 -in. $(1.3-\mathrm{cm})$ material, with a single internal baffle for wall support, and is located at ground level roughly $30 \mathrm{ft}(9 \mathrm{~m})$ below the flash drum. In addition to receiving regenerated desiccant solution from the flash drum, this tank supplies desiccant solution to the absorber pump which delivers

desiccant solution to the spray nozzles in the absorber column. Plumbing connections to this tank 
include four 2 -in. $(5.1-\mathrm{cm}), 150-\mathrm{lb}(68-\mathrm{kg})$ bolted flanges. The piping configuration supporting this tank permits desiccant solution circulation through the absorber pump and back to the tank as well as direct recovery of desiccant solution from the regeneration pump, bypassing the flash drum. Tank level is measured using a differential pressure transmitter and used as a set point to control absorber pump speed and achieve a desired desiccant solution circulation rate through the absorber column. An overflow discharge line is located near the top of the tank to prevent tank pressurization in the event of an upset condition with the excess desiccant solution diverted to a 55-gal (208-L) drum.

The larger of the two tanks, nominally 500 gal $(1893 \mathrm{~L})$ and shown in Figure 7, was fabricated using 0.75 -in. (1.9-cm) material, with two internal baffles for wall support, and is located at ground level directly below the absorber column. Separate structural supports handle the weight of the absorber column; therefore, the connection between the absorber column and the tank is a 12-in. $(30.5-\mathrm{cm})$ flanged neoprene expansion joint. In addition to collecting humidified desiccant solution from the absorber column, this tank supplies desiccant solution to the regeneration pump which delivers desiccant solution to the flash drum. Plumbing connections to this tank include one 12-in. $(30.5-\mathrm{cm})$, one 6 -in. (15.2-cm), three 4-in. $(10.2-\mathrm{cm})$, and one 2-in. $(5.1-\mathrm{cm}) 150-\mathrm{lb}(68-\mathrm{kg})$ bolted flanges. The piping configuration supporting this tank permits desiccant solution circulation through the regeneration pump and back to the tank as well as direct recovery of desiccant solution from the absorber pump, bypassing the absorber column. Tank level is measured using a differential pressure transmitter. However, desiccant solution level in this tank is not used as a set point. Regenerator pump speed is used to achieve a desired desiccant solution circulation rate through the flash drum. Because of the larger size of this tank, it is capable of handling the entire volume of desiccant solution in the LDDS. In addition, the tank is open to the flue gas path. Therefore, there is no overflow discharge line on this tank to prevent desiccant solution overflow or tank pressurization in the event of an upset condition.

\subsubsection{Desiccant Solution Filtration System}

A desiccant solution filtration system was set up to support operation of the LDDS. The filtration system is visible in the lower right portion of the photograph in Figure 7. Specifically, the filtration system is used to filter out insoluble contaminants when the 500-gal (1893 L) tank is loaded with fresh or used desiccant solution, filter out insoluble contaminants accumulated in the desiccant solution when the LDDS is operated, and filter out insoluble contaminants when used desiccant solution is unloaded from the 500-gal (1893-L) tank. The filtration system consists of a pneumatic diaphragm pump, two parallel filters, and CPVC pipe, fittings, and valves to control direction of desiccant solution flow. Depending on the position of multiple ball valves, desiccant solution can be pumped from a mix barrel through the filters into the 500-gal (1893-L) tank, the 500-gal (1893-L) tank through the filters into barrels for storage, or circulated from the 500-gal (1893-L) tank through the filters and back into the 500-gal (1893-L) tank. Solids collected in the filters are recovered by disassembling the individual filter holders. Changes in line pressure at the inlet to each filter are used to determine when an individual filter requires changing. The filter housings are a glass-reinforced nylon construction with a polypropylene basket for filter bag support. Individual filter capacity is 45

gpm $(170 \mathrm{~L} / \mathrm{min})$. Maximum temperature and pressure ratings for the housings are $200^{\circ} \mathrm{F}\left(94^{\circ} \mathrm{C}\right)$ and $200 \mathrm{psig}$ (13.8 bar), respectively. The individual filter bags are a polyester felt rated at $200^{\circ} \mathrm{F}\left(94^{\circ} \mathrm{C}\right)$. Multiple filter bags were used with particle filtration size ratings of 5,10 , and $25 \mu \mathrm{m}$. 


\subsubsection{LDDS Flash Drum}

The flash drum is a key component of the LDDS. Specifically, water that was removed from the flue gas stream by the desiccant solution in the absorber column is separated from the desiccant solution in the flash drum as a result of differential pressure. This is accomplished by spraying the water-laden desiccant solution into the flash drum volume, allowing the water to separate as a vapor and exit the top of the flash drum through a Teflon mist eliminator. The product water is then recovered in a downstream condenser. Key operating parameters for the flash drum are desiccant solution inlet temperature and flash drum vacuum pressure. Desiccant solution temperatures at the flash drum inlet have ranged from $140^{\circ}$ to $170^{\circ} \mathrm{F}\left(60^{\circ}\right.$ to $\left.77^{\circ} \mathrm{C}\right)$. Flash drum operating pressure was nominally 1 psia $(52 \mathrm{~mm} \mathrm{Hg}$ ). Desiccant solution flow rate to the flash drum has ranged from 6 to $45 \mathrm{gpm}$ (23 to $170 \mathrm{~L} / \mathrm{min})$ through a single spray nozzle. Spray nozzle size is changed depending on the flow rate. The nozzles used in the flash drum were standard commercial small and medium capacity, full cone, spiral jet spray nozzles fabricated from $316 \mathrm{SS}$, with a 60 degree spray angle. Nozzle size designations include $082,164,340$, and 470 referring to nominal capacities of $8.2,16.4$, 34.0 , and $47.0 \mathrm{gpm}(31.0,62.1,128.7$, and $177.9 \mathrm{Lpm})$, respectively, at a pressure of $10 \mathrm{psig}$ (0.7 bar).

Fabrication materials for the flash drum were limited to $316 \mathrm{SS}$, selected as a cost-effective option to handle the chemical properties of the desiccant solution, anticipated range of desiccant solution temperatures, $\angle 180^{\circ} \mathrm{F}\left(<83^{\circ} \mathrm{C}\right)$, and operating vacuum pressure. Flash drum dimensions are nominally 16 in. $(40.6 \mathrm{~cm})$ OD by $9 \mathrm{ft}(2.7 \mathrm{~m})$ in length. The flash drum is electrically heated and insulated using fiberglass mat and $1.5-\mathrm{in} .(3.8-\mathrm{cm})$ pipe insulation to eliminate heat losses. Flash drum location is at an elevation of nominally $30 \mathrm{ft}(9 \mathrm{~m})$ to permit the 2 -in. $(5-\mathrm{cm})$ Schedule 80 CPVC desiccant solution discharge line, to the 100-gal $(378 \mathrm{~L})$ tank, to function as a barometric leg providing a liquid vacuum pressure seal. Vertical orientation of the flash drum allows the vessel to be hung from the top flange allowing it to thermally expand downward. Water wash nozzles were not installed in the flash drum to clean the mist eliminator and, under normal operating conditions, were not necessary. However, mist eliminator wash water nozzles may be beneficial for washing away desiccant solution that may contact the mist eliminator or crystals that form during upset conditions. Piping, fittings, and isolation valves through which the desiccant solution is delivered to the flash drum are 2 -in. $(5.1-\mathrm{cm})$ Schedule 80 CPVC plastic to effectively handle the chemical properties of the desiccant solution and the anticipated range of desiccant solution temperatures. Between the flash drum and product water condenser, piping size is 3 -in. $(2.5-\mathrm{cm})$ Schedule 80 material. CPVC piping and fittings delivering the desiccant solution to, and removing product water vapor from, the flash drum are insulated to minimize heat losses. However, the CPVC piping and fittings transferring desiccant solution from the flash drum to the 100-gal (378-L) tank are not insulated.

The flash drum was fabricated using 16-in. (40.6-cm) Schedule 10 pipe and 16-in. (40.6-cm) $150-\mathrm{lb}(68-\mathrm{kg})$ raised face bolted flanges. Two of these flanges were slip-on, and two were blindflanges. Plumbing connections to the flash drum include one 4-in. $(10.2-\mathrm{cm})$, one 6-in. (15.2-cm), and one 3 -in. (7.6-cm) $150-\mathrm{lb}(68-\mathrm{kg})$ bolted flanges. The piping configuration supporting the flash drum permits desiccant solution circulation to be bypassed so that the desiccant solution spray nozzle 
in the flash drum can be changed or other maintenance can be completed without shutting down the entire LDDS. Photographs of the flash drum are included as Figures 8 (main vessel) and 9 (top and exit to product water condenser).

\subsubsection{LDDS Heat Exchangers}

Three heat exchangers support the operation of the LDDS: a desiccant solution cooler, a desiccant solution heater, and a product water condenser. The desiccant solution cooler is located between the desiccant solution absorber pump and the desiccant solution spray nozzles in the absorber column. The purpose of the desiccant cooler is to cool the desiccant solution to a desired temperature before it is sprayed into the absorber column. The cooling media in this case is water. This heat exchanger is a two pass shell-and-tube design with $59 \mathrm{ft}^{2}\left(5.5 \mathrm{~m}^{2}\right)$ of tube surface area. The

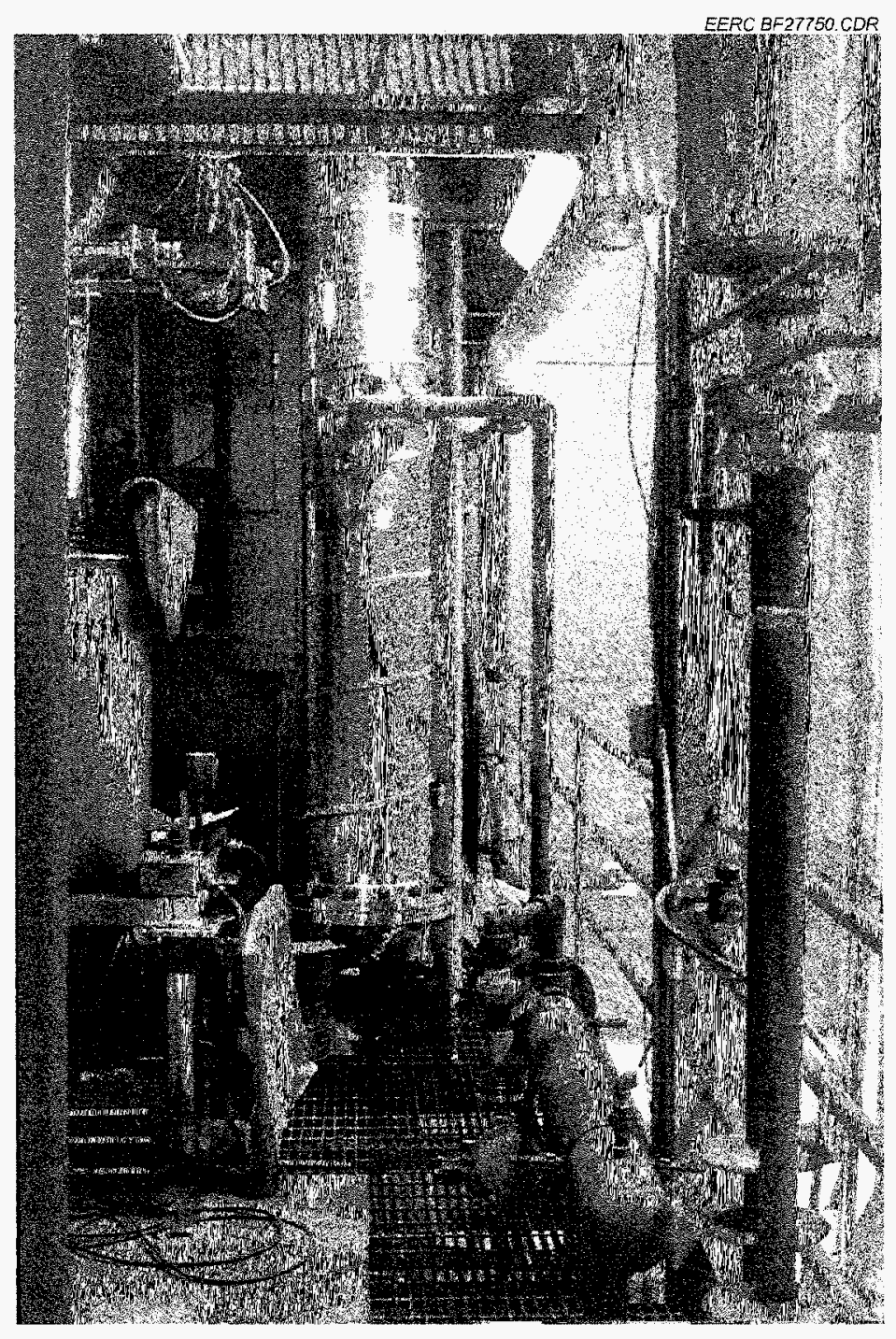

Figure 8. Photograph of the flash drum vessel and inlet piping. 


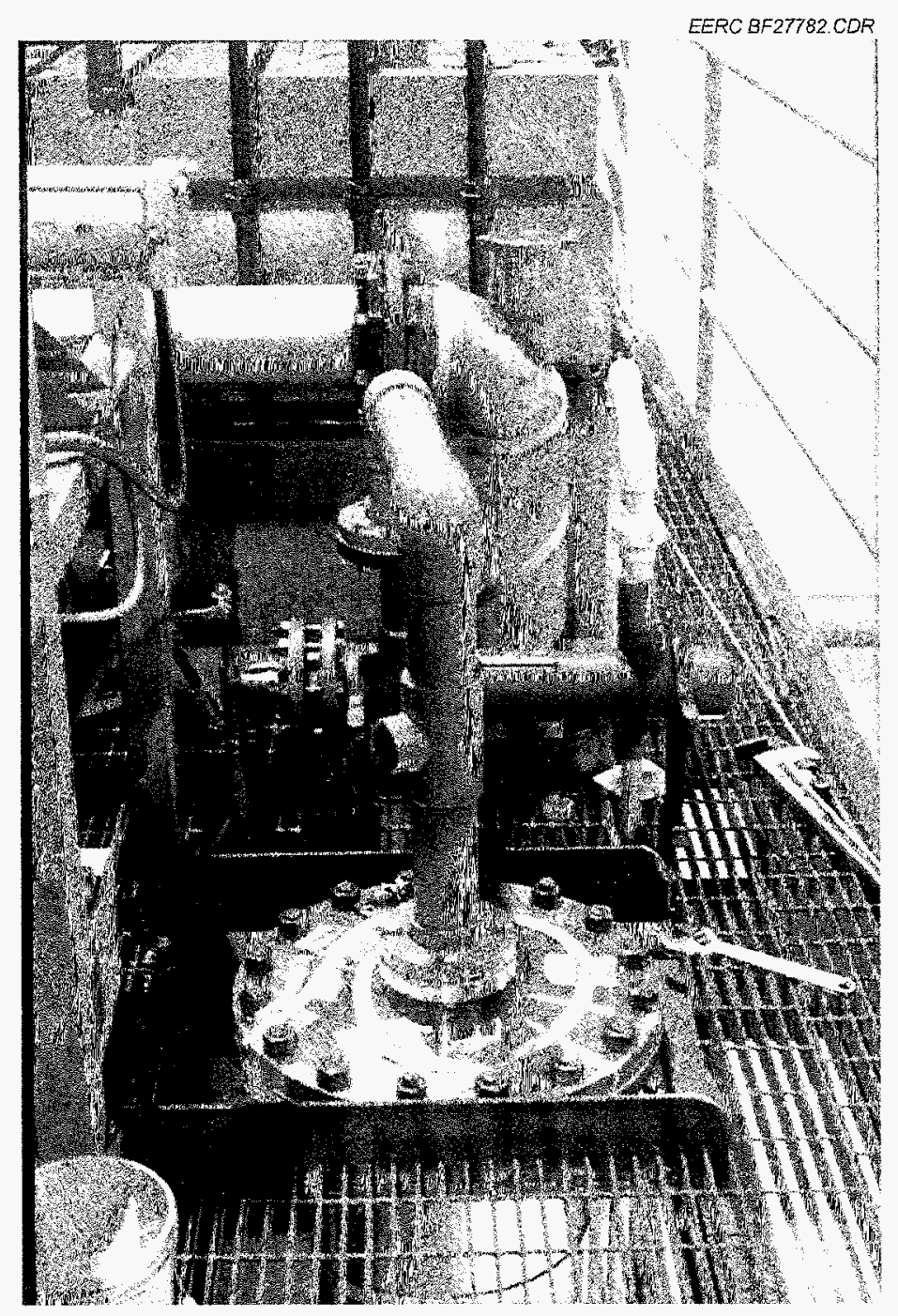

Figure 9. Photograph of the flash drum top, vapor discharge to product water condenser.

design assumes a desiccant solution flow rate of $45 \mathrm{gpm}(170 \mathrm{~L} / \mathrm{min})$ with inlet and outlet temperatures of $148^{\circ}$ and $120^{\circ} \mathrm{F}\left(65^{\circ}\right.$ and $\left.49^{\circ} \mathrm{C}\right)$, respectively. The maximum cooling water flow rate is assumed to be $45 \mathrm{gpm}(170 \mathrm{~L} / \mathrm{min})$ at $50^{\circ} \mathrm{F}\left(10^{\circ} \mathrm{C}\right)$. Materials of construction include 20 gauge 0.75-in. (1.9-cm) OD copper tubing, a brass tube sheet, a bronze head, and a shell fabricated from 8 -in. $(20.3-\mathrm{cm})$ carbon steel pipe. Design working pressure and maximum temperature for both the tube and shell sides of the heat exchanger are $150 \mathrm{psig}(10 \mathrm{bar})$ and $375^{\circ} \mathrm{F}\left(191^{\circ} \mathrm{C}\right)$, respectively. This heat exchanger was designed and constructed in accordance with ASME Section VIII, Division I codes. The desiccant cooler was insulated using $1-\mathrm{in} .(2.54-\mathrm{cm})$ fiberglass pipe insulation to minimize heat losses.

The desiccant solution heater is located between the desiccant solution regeneration pump and the flash drum. The purpose of the desiccant heater is to heat the desiccant solution to a desired temperature before it is sprayed into the flash drum. The heating media in this case is steam. This 
heat exchanger is a two pass shell-and-tube design with $27 \mathrm{ft}^{2}\left(2.5 \mathrm{~m}^{2}\right)$ of tube surface area. The design assumes a desiccant solution flow rate of $45 \mathrm{gpm}(170 \mathrm{~L} / \mathrm{min})$ with inlet and outlet temperatures of $133^{\circ}$ and $163^{\circ} \mathrm{F}\left(56^{\circ}\right.$ and $\left.73^{\circ} \mathrm{C}\right)$, respectively. The design assumes a steam pressure of 10 psig ( 0.7 bar). Materials of construction include 18 gauge $0.75-\mathrm{in}$. (1.9-cm) OD copper tubing, a brass tube sheet, a bronze head, and a shell fabricated from $6-$ in. $(15.2-\mathrm{cm})$ carbon steel pipe. Design working pressure and maximum temperature for both the tube and shell sides of the heat exchanger are $150 \mathrm{psig}(10 \mathrm{bar})$ and $375^{\circ} \mathrm{F}\left(191^{\circ} \mathrm{C}\right)$, respectively. This heat exchanger was designed and constructed in accordance with ASME Section VIII, Division I codes. The desiccant heater was insulated using 1-in. $(2.54-\mathrm{cm})$ fiberglass pipe insulation to minimize heat losses. The photograph in Figure 8 shows the heat exchanger used for desiccant heating.

The product water condenser is located between the flash drum and ring pump used to maintain a vacuum in the flash drum. The purpose of the condenser is to condense water vapor exiting the top of the flash drum for recovery as product water. Water is the cooling media in this case. This heat exchanger is a four-pass shell-and-tube design with $3.2 \mathrm{ft}^{2}\left(0.3 \mathrm{~m}^{2}\right)$ of tube surface area. The design assumes a cooling water flow rate of $2.8 \mathrm{gpm}(10.6 \mathrm{~L} / \mathrm{min})$ with inlet and outlet temperatures of $50^{\circ}$ and $100^{\circ} \mathrm{F}\left(10^{\circ}\right.$ and $\left.38^{\circ} \mathrm{C}\right)$, respectively. Materials of construction include 18 gauge 0.75-in. (1.9-cm) OD copper tubing, a carbon steel tube sheet, a carbon steel head, and a shell fabricated from 4-in. $(10.2-\mathrm{cm})$ carbon steel pipe. Design working pressure and maximum temperature for both the tube and shell sides of the heat exchanger are $150 \mathrm{psig}(10 \mathrm{bar})$ and $375^{\circ} \mathrm{F}$ $\left(191^{\circ} \mathrm{C}\right)$, respectively. This heat exchanger was designed and constructed in accordance with ASME Section VIII, Division I codes. The product water condenser was insulated using 1 -in. $(2.54-\mathrm{cm})$ fiberglass pipe insulation to minimize heat losses. The photograph in Figure 9 shows the heat exchanger used to condense product water.

Condenser location is at an elevation of nominally $30 \mathrm{ft}(9 \mathrm{~m})$ to permit the product water discharge line, to a 55-gal (208-L) drum, to function as a barometric leg providing a liquid vacuum pressure seal. Piping, fittings, and isolation valves through which the product water is recovered from the condenser are $1-\mathrm{in} .(2.5-\mathrm{cm})$ Schedule 40 PVC plastic to effectively handle the chemical properties of the product water and the anticipated range of product water temperatures. The PVC piping and fittings transferring product water from the condenser to the 55-gal (208-L) drum are not insulated.

\subsubsection{LDDS Pumps}

Four pumps support the operation of the LDDS: an absorber pump, a regenerator pump, a liquid ring pump, and a diaphragm pump. The absorber pump, purchased for this project, is located between the 100-gal (378-L) tank and the desiccant cooler heat exchanger. The purpose of the absorber pump is to control the delivery of desiccant solution to the spray nozzles in the absorber column. This centrifugal pump has mechanical silicon carbide seals with a viton o-ring. The impellor and housing are $316 \mathrm{SS}$, selected as a cost-effective option to handle the chemical properties of the desiccant solution and anticipated range of desiccant solution temperatures, $<180^{\circ} \mathrm{F}\left(<83^{\circ} \mathrm{C}\right)$. A direct-drive 3-Hp totally enclosed fan cooled (TEFC) electric motor, with an electronic speed controller, drives the pump. Desiccant solution circulation rate through this pump is limited to 
45-50 gpm (170-189 L/min) based on pump capacity, the specific gravity of the desiccant solution, and the elevation of the absorber nozzles.

The regenerator pump, an existing pump made available to support this project, is located between the 500-gal (1892-L) tank and the desiccant heater heat exchanger. The purpose of the regenerator pump is to control the delivery of desiccant solution to the spray nozzle in the flash drum. This centrifugal pump has mechanical silicon carbide seals. The impellor and housing are elastomer-lined cast iron. A 5-hp TEFC electric motor, with an electronic speed controller, drives the pump via a belt and sheave arrangement. Desiccant solution circulation rate through this pump is limited to $<60 \mathrm{gpm}(<227 \mathrm{~L} / \mathrm{min})$ based on pump capacity, the specific gravity of the desiccant solution, and the elevation of the flash drum.

The liquid ring pump, purchased for this project, is located downstream of the product water condenser. The purpose of the liquid ring pump is to assist with vacuum pressure control in the flash drum and remove noncondensable gas components from the flash drum and product water condenser. This centrifugal pump employs water as a liquid ring seal in a cast iron housing with a cast iron impellor. The cast iron impellor and housing were selected as a cost-effective option to handle the compressible and noncompressible gases and vapors exiting the product water condenser. A direct-drive 5-Hp TEFC electric motor drives the pump.

Noncondensable gases recovered with the product water vapor from the flash drum exit the condenser to the liquid ring pump. From the liquid ring pump, the noncondensable gases are discharged to the SFS flue gas piping through the ID fan and, finally, the stack. The process water providing the loop seal in the liquid ring pump is discharged to the sanitary sewer system in accordance with the EERC's discharge permit. Piping, fittings, and isolation valves through which the noncondensable gases and process water are discharged are 1.5- and 1-in. (3.8- and 2.5-cm) Schedule 40 PVC plastic to effectively handle the properties of the noncondensable gases and process water and their anticipated temperature ranges. The PVC piping and fittings transferring noncondensable gases and process water from the liquid ring pump are not insulated.

The diaphragm pump, an existing pump made available to support this project, is connected to the 500-gal (1892-L) tank. The purpose of the diaphragm pump is to load desiccant solution into and remove desiccant solution from the 500-gal (1892-L) tank and circulate desiccant solution through a filtration system when the pilot-scale LDDS is operating. This pump has Teflon seals and surfaces. Compressed air pressure and volumetric flow rate control pump speed. Desiccant solution circulation rate through this pump is limited to $<20 \mathrm{gpm}(<76 \mathrm{~L} / \mathrm{min})$ based on pump capacity and the specific gravity of the desiccant solution.

\subsubsection{LDDS Instrumentation and Data Acquisition}

Table 5 summarizes temperature measurements made in support of LDDS operation. Flue gas temperatures are measured at the inlet and outlet of the absorber column and a combination of flue gas/desiccant solution temperature are measured at four elevations in the absorber column. Desiccant solution temperatures were also measured at the inlet to the absorber pump, inlet and outlet of the desiccant cooler and heater, and flash drum discharge to the 100-gal (378-L) tank. Other temperature 
Table 5. LDDS Temperature Measurement Locations

\begin{tabular}{ll}
\hline Thermocouple Location & Temperature Measurement \\
\hline Absorber Inlet & Flue gas \\
Absorber Outlet & Flue gas \\
Absorber Inlet Annubar & Flue gas \\
Absorber Outlet Annubar & Flue gas \\
Absorber Column 1-4 & Flue gas/desiccant solution \\
Absorber Pump Inlet & Desiccant solution \\
Desiccant Cooler Inlet & Desiccant solution \\
Desiccant Cooler Outlet & Desiccant solution \\
Desiccant Cooler Inlet & Process cooling water \\
Desiccant Cooler Outlet & Process cooling water \\
Desiccant Heater Inlet & Desiccant solution \\
Desiccant Heater Outlet & Desiccant solution \\
Desiccant Heater & Process steam inlet \\
Desiccant Heater & Process steam outlet \\
Flash Drum Liquid Discharge & Desiccant solution \\
Flash Drum Vapor Discharge & Product water vapor/gases \\
Condenser Exit & Product water \\
Liquid Ring Pump & Inlet process water \\
Liquid Ring Pump & Outlet process water \\
\hline
\end{tabular}

measurements included the gas/vapor stream exiting the flash drum, the product water temperature exiting the condenser, inlet and outlet process water temperatures supporting the desiccant cooler and ring pump, and inlet and outlet steam temperatures supporting the desiccant heater. Temperature measurements were made using Type $\mathrm{K}$ thermocouples. Thermocouples exposed to desiccant solution were acquired with Hastelloy $\mathrm{C}$ sheaths. LDDS thermocouple data are automatically logged into the data acquisition system and periodically recorded on data sheets as a backup.

Table 6 summarizes pressure measurements made in support of LDDS operation using pressure transmitters. Specific applications include the measurement of differential and static pressures to determine flue gas flow rate at the inlet and outlet of the absorber column, differential pressure measurements across the absorber column, desiccant cooler, desiccant heater, and product water condenser, static pressure at the outlet of the desiccant cooler and heater, and vacuum pressure at the outlet of the flash drum. Differential pressure measurements are also used to monitor and control desiccant solution levels in the 100- and 500-gal (378- and 1892-L) tanks. LDDS pressure transmitter data are automatically logged into the data acquisition system and periodically recorded on data sheets as a backup.

Flue gas flow rate at the inlet and outlet of the absorber column was calculated and recorded nearly continuously using differential and static pressure data from annubars and pressure transmitters, thermocouple flue gas temperature measurements, and the data acquisition system. A difference in these flue gas measurements was one of the methods used to determine the amount of water recovered from the flue gas in the absorber column. Flue gas flow rate data are automatically logged into the data acquisition system and periodically recorded on data sheets as a backup. 
Table 6. LDDS Pressure Measurement Locations

\begin{tabular}{ll}
\hline Measurement Location & Pressure Measurement \\
\hline Absorber Inlet & Flue gas, static \\
Absorber Outlet & Flue gas, static \\
Absorber Column & Flue gas, differential \\
Absorber Inlet Annubar & Flue gas, differential \\
Absorber Outlet Annubar & Flue gas, differential \\
100-gal Tank Level & Desiccant solution, differential \\
500-gal Tank Level & Desiccant solution, differential \\
Desiccant Cooler & Desiccant solution, differential \\
Desiccant Cooler Outlet & Desiccant solution, static \\
Desiccant Heater & Desiccant solution, differential \\
Desiccant Heater Outlet & Desiccant solution, static \\
Flash Drum Vapor Outlet & Vacuum pressure \\
Product Water Condenser & Vapor, differential \\
\hline
\end{tabular}

Two continuous electronic monitors were installed to directly measure the moisture content of the flue gas at the inlet and outlet of the absorber column. Installation of the instruments was an attempt to directly measure flue gas moisture content and use those data in conjunction with flue gas flow rate data to document the amount of water recovered from the flue gas in the absorber column. Flue gas moisture data are automatically logged into the data acquisition system and periodically recorded on data sheets as a backup.

Desiccant flow rate is measured at three locations: 1) the exit of the absorber pump, 2) the exit of the regenerator pump, and 3) the inlet to the flash drum. Desiccant flow rate at the exit of the absorber pump is measured using a coriolis meter. As a result, desiccant solution density is measured resulting in mass and volumetric flow rate data. Magnetic flowmeters are used at the other two locations simply providing volumetric flow rate. The internals of these instruments, in contact with the desiccant solution, were fabricated from Hastelloy $\mathrm{C}$ materials. Desiccant solution $\mathrm{pH}$ is monitored continuously at the outlet of the regenerator pump using an existing online analyzer and probe. Desiccant solution flow rate, density, and $\mathrm{pH}$ data from these instruments are automatically logged into the data acquisition system and periodically recorded on data sheets as a backup.

Product water recovery rate was initially determined periodically by measuring the mass of the product recovery receiver and its contents at 30- to 60-minute intervals and calculating the rate for a given time interval. However, the scale used for this purpose failed toward the end of the Test Series I. Therefore, a new electronic platform scale, shown in Figure 10, was purchased for this purpose. The output signal from the electronic scale was input to the SFS data acquisition system to automatically log the mass data and permit online calculation of the product water recovery rate. These data are also periodically recorded on data sheets as a backup.

In order to support operation of the LDDS system, a number of modules were added to the existing SFS data acquisition system to handle the additional data points and control functions. One of the primary control loops for the LDDS is the total flow rate of desiccant solution through the 


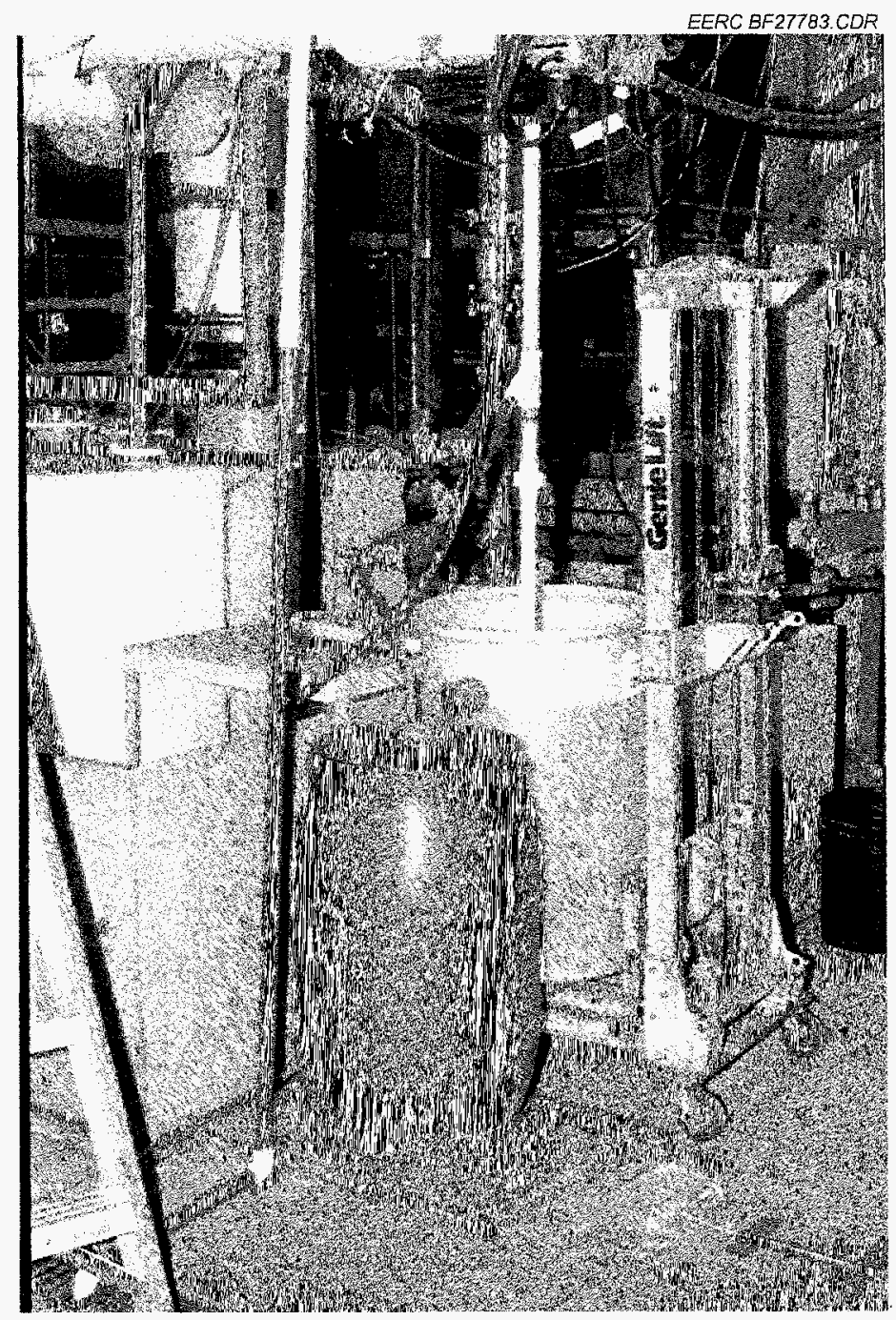

Figure 10. Photograph of the electronic platform scale and product water recovery drums.

LDDS. To date, absorber tests have been completed for desiccant flow rates of 6 to $44 \mathrm{gpm}$ ( 23 to $167 \mathrm{~L} / \mathrm{min}$ ). The desiccant flow control system is completely automated using flow control valves, online mass/volume flowmeters, and variable speed controllers for each of the two centrifugal pumps. As a result, desiccant flow rate control is typically $\pm 0.01 \mathrm{gpm}( \pm 0.01 \mathrm{~L} / \mathrm{min})$. Other control loops were programmed for the control of desiccant solution temperatures at the inlet of the absorber column and flash drum. Specifically, control valves are used to control the flow of cooling water to the desiccant cooler and steam to the desiccant heater based on temperature measurements and set points.

Many of the LDDS process data points are alarmed to inform personnel when corrective action should be considered or is absolutely necessary. Examples include desiccant solution levels in the two tanks, desiccant solution temperatures at the outlet of the desiccant cooler and heater, absorber and regenerator pump speed, flash drum vacuum pressure, liquid ring pump water temperature, and 
differential pressure across the absorber column, desiccant cooler and heater, and product water condenser. Most alarm conditions rely on personnel responses for corrective action. However, some alarms initiate preprogrammed corrective action, such as shutting down the pumps.

\subsection{Measurement and Sampling Procedures}

\subsubsection{Bench-Scale Desiccant Testing}

The following gas constituents were measured during the bench-scale desiccant testing:

- $\mathrm{SO}_{2}$

- $\mathrm{CO}_{2}$

- $\mathrm{NO}_{\mathrm{x}}$

- $\mathrm{CO}$

- $\mathrm{O}_{2}$

- $\mathrm{H}_{2} \mathrm{O}$

These gases were continuously monitored during the bench-scale testing and the data logged to disk. The $\mathrm{H}_{2} \mathrm{O}$ measurement probe was positioned after the CEPS FGD system. $\mathrm{SO}_{2}, \mathrm{CO}_{2}$, and $\mathrm{NO}_{\mathrm{x}}$ were measured before and after the CEPS FGD while the remaining gases were measured after the combustor only. Table 7 lists the instrumentation for these gas analysis systems.

Desiccant samples for the bench-scale tests were taken between the desiccant holding tank and the spray nozzles in quantities of approximately $250 \mathrm{~mL}$. Since this system had no desiccant regeneration system for water recovery, no water samples were obtained during this portion of the project. Desiccant samples were analyzed for the following:

- Sulfate

- $\mathrm{pH}$

- XRD analysis of precipitates

The precipitates formed posttest, and the desiccant solutions were filtered and dried to leave only the precipitate material.

Table 7. Measurement Methods for Continuously Measured Flue Gas Constituents in CEPS

\begin{tabular}{lcc}
\hline Gas & Company & Measurement Method \\
\hline $\mathrm{SO}_{2}$ & Rosemount & Nondispersive infrared (IR) \\
$\mathrm{CO}_{2}$ & Rosemount & Nondispersive infrared (IR) \\
$\mathrm{NO}_{\mathrm{x}}$ & Rosemount & Chemiluminescence \\
$\mathrm{CO}$ & Rosemount & Nondispersive infrared (IR) \\
$\mathrm{O}_{2}$ & Rosemount & Paramagnetic detection \\
$\mathrm{H}_{2} \mathrm{O}$ & MAC Instruments & $\mathrm{H}_{2} \mathrm{O}$ partial/total pressure (proprietary sensor) \\
\hline
\end{tabular}




\subsubsection{Pilot-Scale LDDS Tests}

The following flue gas constituents were measured during the pilot-scale LDDS tests:

- $\mathrm{SO}_{2}$

- $\mathrm{CO}_{2}$

- $\mathrm{NO}_{\mathrm{x}}$

- $\mathrm{CO}$

- $\mathrm{O}_{2}$

- $\mathrm{H}_{2} \mathrm{O}$

- $\mathrm{Hg}$

- Particulate matter (Hg, fluorides, sulfates, calcium, chlorides, and sodium)

It should be noted that all EPA methods discussed below can be found on the EPA Web site at www.epa.gov/ttn/emc. Table 8 outlines the sampling and analytical methods used in support of this project.

\subsubsection{1 $\mathrm{SO}_{2}, \mathrm{CO}_{2}, \mathrm{NO}_{x}, \mathrm{CO}, \mathrm{O}_{2}$, and $\mathrm{H}_{2} \mathrm{O}$}

During the pilot-scale tests, the EERC continuously monitored $\mathrm{O}_{2}, \mathrm{SO}_{2}, \mathrm{NO}_{\mathrm{x}}, \mathrm{CO}, \mathrm{CO}_{2}$, and $\mathrm{H}_{2} \mathrm{O}$ at two sample points (inlet and outlet of the LDDS absorber column) and periodically sampled for the same species, except $\mathrm{H}_{2} \mathrm{O}$, in the vapor stream exiting the product water condenser. The concentration values from all of the instruments were recorded continuously on the SFS data-logging system. In addition, backup data were manually recorded at set time intervals. The instrumentation used for each of these gases is shown in Table 9. Each of these analyzers, except the $\mathrm{H}_{2} \mathrm{O}$ analyzers, was regularly calibrated using certified calibration gases in the expected measurement range and maintained to provide accurate flue gas concentration measurements. The $\mathrm{H}_{2} \mathrm{O}$ analyzers have factory-calibrated sensors that cannot be changed. However, the zero point can be checked using dry gas.

Table 8. Sampling and Analytical Methods Used for the Test Program

\begin{tabular}{ll}
\hline Gas Constituent/Absorber Parameter & \multicolumn{1}{c}{ Method } \\
\hline $\mathrm{H}_{2} \mathrm{O}$ & $\mathrm{H}_{2} \mathrm{O}$ monitor/EPA Method 5 impinger train \\
Mercury & $\mathrm{Hg}$ CEM/EPA Method 5 filters and CVAA \\
Particulate Mass Loading & EPA Method 5 \\
Fluorides & EPA Method 5 filters and ion chromatography \\
Sulfates & EPA Method 5 filters and ion chromatography \\
Calcium & EPA Method 5 filters and inductively coupled plasma \\
Chlorides & EPA Method 5 filters and ion chromatography \\
Sodium & EPA Method 5 filters and inductively coupled plasma \\
pH & Online and grab-sample pH meter measurements \\
Specific Density & Gravimetric determination \\
Nitrates & Ion chromatography \\
\hline
\end{tabular}


Table 9. Measurement Methods for Continuously Measured Flue Gas Constituents

\begin{tabular}{lll}
\hline $\mathrm{Gas}$ & Company & Measurement Method \\
\hline $\mathrm{SO}_{2}$ & Ametek & UV (ultraviolet) photometric \\
$\mathrm{CO}_{2}$ & Rosemount & Nondispersive IR \\
$\mathrm{NO}_{\mathrm{x}}$ & Thermo Environmental & Chemiluminescence \\
$\mathrm{CO}$ & Rosemount & Nondispersive IR \\
$\mathrm{O}_{2}$ & Rosemount & Paramagnetic detection \\
$\mathrm{H}_{2} \mathrm{O}$ & MAC Instruments & $\mathrm{H}_{2} \mathrm{O}$ partial/total pressure (proprietary sensor) \\
\hline
\end{tabular}

\subsubsection{Flue Gas Hg Concentration}

To measure the concentration of elemental, oxidized, and total $\mathrm{Hg}$ in the flue gas, semicontinuous emission monitors (SCEMs) were employed to collect flue gas $\mathrm{Hg}$ concentration data simultaneously at the inlet and outlet of the absorber column. Specifically, two PS Analytical Sir Galahad Hg SCEMs were used. The PS Analytical instrument is based on the principle of atomic fluorescence, which provides an inherently more sensitive signal than atomic absorption. The system uses a gold-impregnated silica support for preconcentrating the mercury and separating it from potential interferences that degrade sensitivity.

The PS Analytical Sir Galahad Hg SCEM uses a wet-chemistry system to pretreat the flue gas and convert all forms of mercury to elemental mercury. Stannous chloride $\left(\mathrm{SnCl}_{2}\right)$ is used to convert the oxidized mercury to elemental prior to analysis. However, $\mathrm{SO}_{2}$ interferes with the ability of $\mathrm{SnCl}_{2}$ to reduce mercury. Therefore, pretreatment/conversion removes the $\mathrm{SO}_{2}$ using sodium hydroxide. To speciate mercury, the pretreatment conversion system has two sides. To measure only elemental mercury, a solution is used to remove all of the oxidized form of mercury. To measure total mercury, this step is bypassed. The oxidized mercury is then determined by difference.

A 4-step process is used to obtain a flue gas mercury measurement. In the first step, $0.07 \mathrm{ft}^{3}$ $(2 \mathrm{~L})$ of flue gas is pumped through a gold trap, which is maintained at a constant temperature. Before the mercury is desorbed from the gold trap, a flushing step is initiated to remove any flue gas that may be present, because it has a damping effect on the mercury fluorescence. When this is completed, the analysis step begins. The heating coil is activated, and the gold trap is heated to approximately $932^{\circ} \mathrm{F}\left(500^{\circ} \mathrm{C}\right)$. This desorbs the mercury from the trap, and the mercury is carried into the fluorescence detector. The gold trap is cooled rapidly by pumping argon over it in preparation for the next sample. The total time for the entire process is about 5 minutes.

The system is calibrated using $\mathrm{Hg}^{0}$ as the primary standard. The $\mathrm{Hg}^{0}$ is contained in a closed vial, which is held in a thermostatic bath. The temperature of the mercury is monitored, and the amount of mercury is measured using vapor pressure calculations. Typically, the calibration of the unit has proven stable over a 24-hour period. 


\subsubsection{Particulate Matter}

Particulate matter was sampled using the conventional bulk sampling procedure as defined by EPA Method 5. This method provided the total aerosol/particulate mass loading, and recovered samples were analyzed using ion chromatography to determine sulfate and chloride concentration. Inductively coupled plasma analyses were used to determine calcium and sodium concentration. Figure 11 illustrates the EPA Method 5 sample trains used simultaneously at the absorber inlet and outlet. Differences in nozzle and filter size related to differences in flue gas flow rates for the two test series. The use of DI water versus $3 \%$ hydrogen peroxide $\left(\mathrm{H}_{2} \mathrm{O}_{2}\right)$ solution in the first two impinger stages related to the presence or absence of $\mathrm{SO}_{2}$ in the flue gas stream.

\subsubsection{Desiccant Solution}

Desiccant solution samples were collected online from the process lines leading to the absorber column and flash drum. The following analyses were performed on the desiccant solution samples collected from the pilot-scale LDDS:

- Specific gravity

- $\mathrm{pH}$

- Total suspended solids

- Sulfate

- $\mathrm{Hg}$

\subsubsection{Product Water}

Product water samples were collected online from the process line between the product water condenser and collection drum. The following analyses were performed by the EERC on the product water samples collected from the pilot-scale LDDS:

- $\mathrm{pH}$

- Total dissolved solids

- Total suspended solids

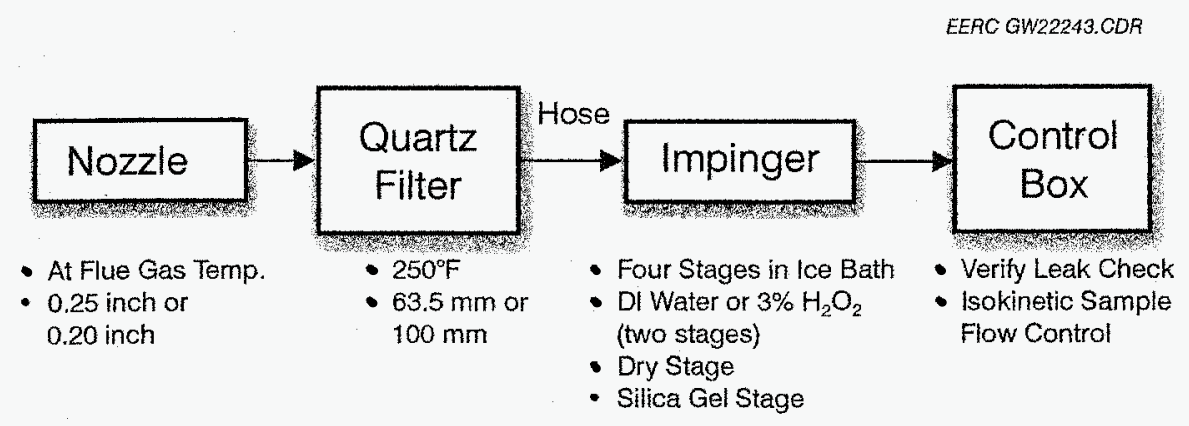

Figure 11. Schematic of the EPA Method 5 sample train used at the inlet and outlet of the absorber column. 
- Calcium

- Chlorides

- Sodium

- Sulfate

- Nitrate

- $\mathrm{Hg}$

More extensive analyses of the product water from both test series was completed by Nalco Analytical Resources.

\subsection{Technical Approach}

The overall objective of this program was to develop a liquid, desiccant-based flue gas dehydration process technology to reduce water consumption in coal-fired power plants. The specific objective of the program was to generate sufficient subscale test data and conceptual commercial power plant evaluations to assess the process feasibility and merits for commercialization. Through the dehumidification process, water in the flue gas can be recovered for use elsewhere in the power plant. The nominal power output and mass flow rate of water available in the flue gas of three selected power plant designs is shown in Table 10.

For these three designs, the available water flow rate ranges from 2.4 to $6.0 \times 10^{5} \mathrm{lb} / \mathrm{hr}(1.1$ to $2.7 \mathrm{~kg} / \mathrm{hr}$ ). This is a substantial water resource that is particularly attractive in regions where fresh water is in short supply or where government regulations limit the use of available water. The LDDS recovery scheme described here is a promising method of recovering a portion of this otherwise wasted resource.

The two primary options for removal of moisture from gas are condensation and desiccant dehumidification. Condensation involves cooling the gas below its dew point, causing the water to condense on the cooled surfaces. Desiccant technology employs chemical agents (i.e., desiccants) which possess a strong physicochemical affinity for water to extract water vapor. In both technologies, an energy flow may be required to power the separation process. Either process could employ waste heat from the flue gas and an ACC for heat rejection or ground-source heating and cooling. However in the LDDS process, the exothermic characteristic of the absorption of water by the desiccant in the absorber tower and the cooling effect of the water vapor loss in the regeneration step can provide the needed energy for the system to operate at minimum levels of water recovery. It was determined that commercial condensation systems already exist for flue gas moisture removal and that the quality of the water produced by condensation requires expensive cleanup operations to

Table 10. Selected Power Plant Designs with Available Water in the Flue Gas

\begin{tabular}{lccc}
\hline & $\begin{array}{c}\text { Natural Gas Fired } \\
\text { Combined Cycle }\end{array}$ & $\begin{array}{c}\text { Pulverized Coal Fired } \\
\text { Conventional Cycle }\end{array}$ & $\begin{array}{c}\text { Integrated } \\
\text { Gasification } \\
\text { Combined Cycle }\end{array}$ \\
\hline Nominal Output, $\mathrm{MW}$ & 500 & 600 & 300 \\
Mass Flow Rate $\mathrm{H}_{2} \mathrm{O}, \mathrm{bb} / \mathrm{hr}$ & 233,409 & 595,534 & 241,095 \\
\hline
\end{tabular}


be able to use the condensed water in most situations. Additionally, such systems would require massive and expensive heat rejection equipment, would be severely limited by high ambient temperatures, and would result in decreased gas turbine performance as a result of higher back pressure due to closed heat exchangers in the flow path. For these reasons, the LDDS process was the technology pursued under this project.

\subsubsection{Task 1-Desiccant Selection}

To facilitate the objectives of the project, a comprehensive literature review was conducted to assess the current state of the art in LDDSs and the potential liquid desiccants currently available. This also provided the characteristic physical, chemical, and performance properties of the assessed desiccants that were used in the ranking, evaluation, and selection process. Although no literature on the use of liquid desiccants to absorb water vapor from a flue gas stream was found, there are numerous published papers and patents on the application of liquid desiccants in building dehumidification, cooling, and natural gas dehydration. Figure 12 shows a summary of a literature search on the subject in the databases of EI (Engineering Index) and the U.S. patent office since the 1970s. The National Renewable Energy Laboratory (NREL) of the U.S. Department of Energy (DOE) has a web page on an advanced desiccant dehumidification and cooling program (www.nrel.gov/desiccantcool/tec.html). The NREL bibliography includes references on desiccantrelated publications up to the year 1997 and is shown in Figure 13. From Figures 12 and 13, it can be seen that research on solid desiccant systems reached a peak in the 1980s, while research on liquid desiccant systems peaked in the 1990s.

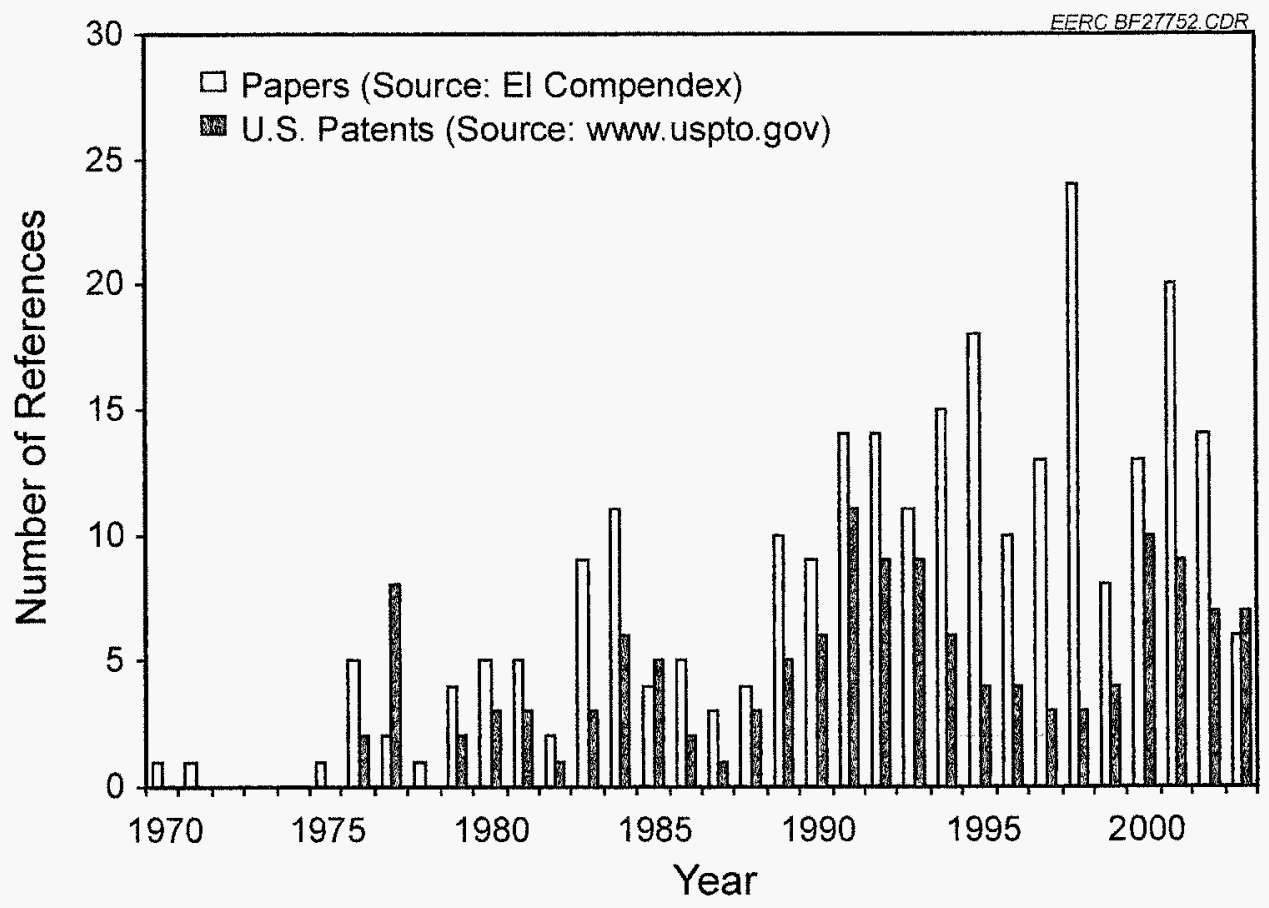

Figure 12. Number of publications and U.S. patents related to liquid desiccant systems. 


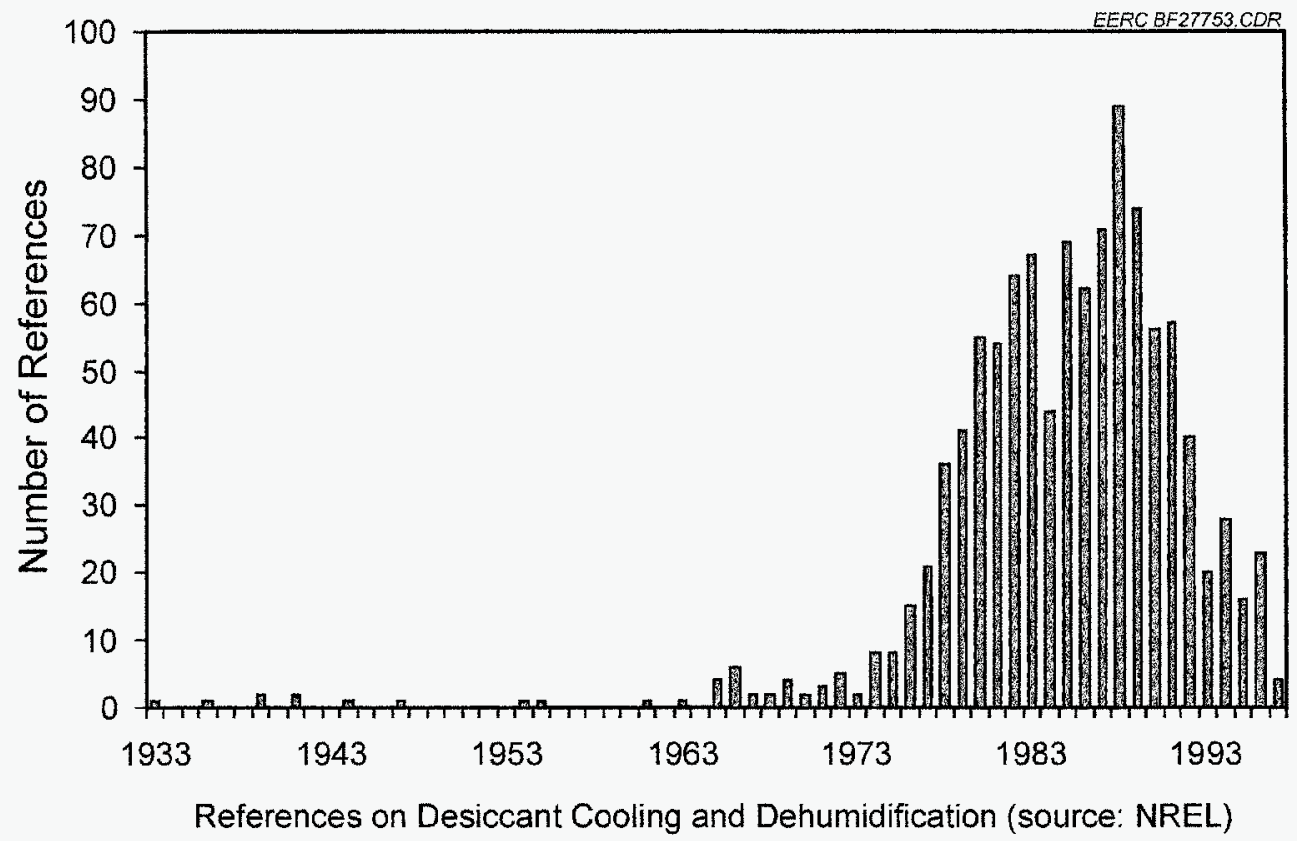

Figure 13. References on desiccant cooling and dehumidification (source: NREL. The bibliography include two sections. The first section contains 871 pieces of literature about desiccant cooling and dehumidification, and the second section contains 305 additional references covering the period from 1992 to 1997 . Both were compiled through open literature searches in the following databases: Engineering Index, 1970-June 1997; National Technical Information Service, 1964-June 1997; DOE Energy Database, 1974-June 1997; Dissertation Abstract Online, 1861-June 1997; Chemical Abstracts, 1967-June 1997).

Commonly used liquid desiccants are aqueous solutions of two basic classes: 1) inorganic salts (such as lithium chloride, lithium bromide, or calcium chloride) or 2) glycols (such as ethylene glycol, triethylene glycol, or propylene glycol). They are characterized by their strong affinity for water resulting in a low partial pressure of water above a saturated liquid. In general, the partial pressure of the desiccant is very low, so that the vapor pressure of the solution is dominated by the partial pressure of the water. The difference between the partial pressure of water in the gas stream and partial pressure of water in the desiccant is the driving force for dehumidification.

In order to choose between these liquid desiccants, the following issues must be considered:

- Ability of desiccant to remove water from flue gas stream (partial pressure of water)

- Heat-transfer properties (specific heat and thermal conductivity)

- Desiccant cost (capital and maintenance)

- Equipment corrosion

- Environmental effects of desiccant carryover

- Removal of combustion products other than water

- Flow characteristics when in solution with water (viscosity)

- Impact of desiccant selection on system operation and cost 
- Solubility limits (concentration range of desiccant)

- EPA/OSHA perception (for permitting purposes)

These issues are summarized in Table 11.

In addition to low partial pressure of water, liquid desiccants must have good heat and mass transfer characteristics. Properties affecting heat and mass transfer include viscosity, thermal conductivity, and surface tension/wetting characteristics. Low viscosity is needed to minimize liquid film thickness in packed bed-designs, and to allow effective mass diffusion in the liquid in spray tower designs, low viscosity is desirable to minimize pumping costs. Associated surface tension coupled with low viscosity allows for tailoring droplet size for effective gas-to-liquid contact and minimizing droplet carryover. High thermal conductivity enables heat transfer into and out of the liquid. For packed-bed designs, good wetting characteristics between the liquid desiccant and the packing material are critical for compact design. Some preferred properties of liquid desiccants are that they are noncorrosive, odorless, nontoxic, nonflammable, stable, readily available, and inexpensive.

The use of a liquid desiccant to strip water vapor from a flue gas stream appears to be a novel application based on the lack of literature found. One concern in this application is contamination of the liquid desiccant by constituents of the flue gas.

Table 11. Desiccant Selection Matrix

\begin{tabular}{|c|c|c|c|c|c|}
\hline & & & ortance R & ting & Must \\
\hline & Factor & Low & Medium & High & Have \\
\hline 1 & Environmental Effects of Desiccant Slip & & $\mathrm{X}$ & & \\
\hline 2 & Ability of Desiccant to Remove Water from Exhaust Stream & & & & $\mathrm{X}$ \\
\hline 3 & Corrosiveness & & & $\mathrm{X}$ & \\
\hline 4 & Heat-Transfer Properties (specific heat) & $\mathrm{X}$ & & & \\
\hline 5 & Desiccant Capital Cost & $\mathrm{X}$ & & & \\
\hline 6 & Removal of Combustion Products Other Than Water & $\mathrm{X}$ & & & \\
\hline 7 & Solubility Limits (concentration range of desiccant) & & $\mathrm{X}$ & & \\
\hline 8 & Permitability & & & & $\mathrm{X}$ \\
\hline 9 & Amount of Available Property Data & $X$ & & & \\
\hline 10 & Flow Characteristics When in Solution with Water & & $\mathrm{X}$ & & \\
\hline 11 & $\begin{array}{l}\text { Impact of Desiccant Selection on System Operation and Cost } \\
\text { (materials handling, makeup, part replacement, maintenance) }\end{array}$ & & & $\mathrm{X}$ & \\
\hline 12 & Adverse Impact of Flue Gas Constituents on Desiccant & & $\mathrm{X}$ & $\mathrm{X}$ & \\
\hline & Proposed Categories & & & & \\
\hline 1 & Removal of Water & & & & \\
\hline 2 & Environmental & & & & \\
\hline 3 & Desiccant Cost & & & & \\
\hline 4 & Desiccant Properties & & & & \\
\hline 5 & System Requirements & & & & \\
\hline
\end{tabular}


The major constituents of flue gas are $\mathrm{CO}_{2}, \mathrm{~N}_{2}, \mathrm{H}_{2} \mathrm{O}$, and ash with many trace constituents such as $\mathrm{SO}_{2}$ and $\mathrm{NO}_{\mathrm{x}}$. Their potential effects on the desiccant are outlined in Table 12.

In addition to the chemistry issues listed in Table 12, two pertinent issues are environmental release of the liquid desiccant and corrosion. For liquid desiccants such as brines, environmental release is considered a small issue because of the very low vapor pressure of the salt. The argument is that the amount of release is insignificant. However, this issue is considered to be potentially more significant for the glycols because of their relatively higher vapor pressure.

The second issue is the corrosivity of the desiccant. On this issue, the glycols have a distinct advantage because they cause essentially no corrosion. However, handling the brines requires carefully designed equipment to keep the corrosion under control. Careful material and design choices can minimize the impact of corrosion, such as fiber-reinforced plastic.

Trace amounts of air-borne chloride (and possibly other halogens) can cause significant corrosion problems over long time periods as shown in condensing furnace research where the chlorides came from the combustion process. The combination of the chloride plus electrolyte (condensate) on metal surfaces was found to be destructive to most common metals. With halidebased desiccant salts, there is a new source of these potent corrosive agents. This is a concern for the flue components downstream of the desiccant absorber. However, if liquid carryover is minimized by low flue gas velocities and mist eliminators, corrosion can be avoided by eliminating the electrolyte. In practice, it may be necessary to design the absorber sump and mist eliminators from polymer

Table 12. Chemistry Issues in Flue Gas Application

\begin{tabular}{ll}
\hline Constituent & Comments \\
\hline $\mathrm{N}_{2}$ & This should be inert. \\
$\mathrm{CO}_{2}$ & Increased $\mathrm{CO}_{2}$ levels may cause decreased $\mathrm{pH}$ with consequent increased \\
& corrosion concerns. Depending on the desiccant, $\mathrm{pH}$ control can be achieved \\
& by adding a strong base (such as $\mathrm{LiOH}$ if the desiccant salt is LiBr). \\
& The desiccant has a high affinity for $\mathrm{H}_{2} \mathrm{O}$. \\
$\mathrm{Ash}$ & Ash may be stripped from the flue gas stream by impact with the desiccant \\
& liquid. The ash may provide a buffer against the pH problems mentioned \\
& above since it tends to be basic when dissolved in water. If sufficient ash is \\
& entrained in the liquid desiccant, it will produce a sludge that may interfere \\
& with pumping and with the flow passages in the absorber and regenerator. A \\
& filter system will be required to deal with the ash. Filtration could be \\
& performed in the gas and/or liquid. If large amounts of ash are present, a \\
& liquid filter with an automatic flushing system would be required. \\
& Sulfur dioxide is expected to be somewhat soluble in the liquid desiccant. It \\
$\mathrm{SO}_{2}$ & would be expected to cause a shift in pH toward acid. Most of the sulfur \\
& should come out in the scrubber or water spray. If it gets in the desiccant, \\
& calcium hydroxide addition plus filtration should remove it. \\
& Nitrogen oxides are expected to have limited solubility in the liquid \\
& desiccant.
\end{tabular}


materials. Assuming zero liquid carryover, the stack materials should not be affected by the presence of the desiccant system as long as condensing conditions are avoided.

\subsubsection{Task 2-Bench-Scale Testing}

The desiccants selected in Task 1 of this project were tested in the CEPS under identical operating conditions. Two fuels, a Powder River Basin (PRB) coal and natural gas, were used to generate a flue gas for each of the desiccants. Flue gas temperature was maintained at $130^{\circ} \mathrm{F}\left(55^{\circ} \mathrm{C}\right)$, and desiccant solution temperatures were maintained at $140^{\circ} \mathrm{F}\left(60^{\circ} \mathrm{C}\right)$.

For each of the tests performed with the CEPS, the desiccant storage tank under the absorber was filled with 7.5 gallons $\left(28.4 \mathrm{~L}\right.$ ) of desiccant solution which was heated to approximately $140^{\circ} \mathrm{F}$ $\left(60^{\circ} \mathrm{C}\right)$. Tests were run for 3 hours with the desiccant circulating at a rate of $0.5 \mathrm{gpm}(1.9 \mathrm{Lpm})$. Every 30 minutes, a $250-\mathrm{mL}(0.07$-gal) sample of the desiccant was removed from the system for testing at a later date. At the end of each test, three tests with desiccant on gas and three tests with desiccant on coal, the system was flushed with 10 gallons $(38 \mathrm{~L})$ of hot tap water by filling the absorber tank and running the pump at a flow rate of $1 \mathrm{gpm}(4 \mathrm{Lpm})$ to circulate the wash water through the system. This water was then pumped out and the system dried by means of heat tape on the tank to dry the walls, vacuuming out the residual water in the bottom, breaking the pump lines, and vacuuming the water from the lines and pump. Compressed air also was used to blow-dry pump lines, and the pump. The system was reassembled and filled with the next desiccant for testing. At the end of the next 3-hour test, the same procedure was used for emptying the tank and cleaning as previously specified. Between test periods, the furnace was idled overnight at $1652^{\circ} \mathrm{F}\left(900^{\circ} \mathrm{C}\right)$ and the absorber tank left open and empty to dry.

\subsubsection{Task 7-Pilot-Scale Testing}

Two separate test series were completed over two nonconsecutive weeks of pilot-scale SFS and LDDS operation. The objective of the first test series (Test Series I) was to evaluate a range of LDDS operating parameters and general performance when attempting to recover water from a flue gas stream representing a natural gas-fired turbine. Key flue gas characteristics for Test Series I included high excess air (nominally $13 \mathrm{vol} \% \mathrm{O}_{2}$ in the flue gas) and a low moisture content

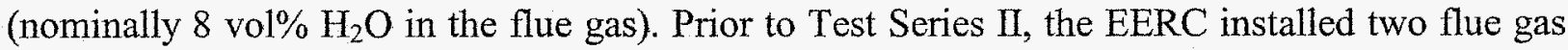
humidification systems, one at the exit of the furnace and the second near the exit of the SFS baghouse, well upstream of the LDDS absorber column. Both humidification systems used pressurized tap water and nitrogen in a dual-fluid nozzle and were operated at water flow rates of 5$6 \mathrm{gph}(19-23 \mathrm{~L} / \mathrm{hr}$ ). The purpose of the two humidification systems was to control the temperature of the flue gas immediately downstream of the furnace and the temperature and moisture content of the flue gas stream entering the absorber column. The Test Series II objective was to evaluate a range of LDDS operating parameters and general performance when attempting to recover water from a flue gas stream representing conditions downstream of a conventional wet FGD system. Key flue gas characteristics for Test Series II included low excess air (nominally 4-5 vol\% $\mathrm{O}_{2}$ in the flue gas), high moisture content (nominally $14-15$ vol\% $\mathrm{H}_{2} \mathrm{O}$ in the flue gas), low $\mathrm{SO}_{2}$ concentration $\left(<300\right.$ ppmv, dry basis), and low temperature $\left(130^{\circ}-135^{\circ} \mathrm{F}\left[55^{\circ}-58^{\circ} \mathrm{C}\right]\right)$. Total particulate mass and the mass contribution of $\mathrm{Hg}$, sulfate, calcium, chloride, and sodium species were documented at the 
inlet and outlet of the absorber column. Table 13 lists the sampling point locations for the pilot-scale LDDS tests.

The SFS combustor was fired using natural gas during Test Series I and natural gas and subbituminous coal during Test Series II. During SFS heatup, the desiccant solution was prepared to the desired concentration and loaded into the two LDDS tanks. Desiccant solution circulation was initiated between the two tanks and then through the absorber column and flash drum to verify that the piping/valve configurations were correct and to verify that there were no leaks prior to initiating flue gas flow through the absorber column. Both test series began with fresh desiccant solution. Once the SFS and LDDS were stabilized at desired operating conditions, each test series was initiated.

\subsubsection{Evaluation of LDDS Performance for a Gas Turbine System - Test Series I}

A 5-day pilot-scale test series was conducted to document the performance of the LDDS during the week of September 27-October 1, 2004. Tables 14 and 15 summarize the operating parameters for Test Series I. Test parameters summarized in Table 14 primarily address LDDS operating parameters and flue gas composition at the absorber column inlet. Several secondary test parameters were determined during the test series as a function of operating conditions required to achieve primary test parameters. Table 15 summarizes SFS operating parameters. Sampling activities were limited to 8-12 hours each day. However, the SFS and LDDS were operated 24 hours/day. Overnight activities focused on completion of specific tests and changing operating parameters in preparation for the next day's sampling activities.

The original sampling plan for Test Series I is summarized in Table 16. EPA Method 5 sample trains were run simultaneously at the inlet and outlet of the absorber column for a duration of 120 minutes. Although the concentration of sulfates, calcium, and chlorides and total particulate mass at the inlet of the absorber column were expected to be zero or nearly zero, sampling at this location was deemed necessary to confirm the expectation as well as validate the sampling and analytical methodology chosen. Backup filters were not included in sample trains used at the absorber column inlet and outlet sample locations because secondary aerosol formation was not anticipated. Recovery of the impingers in each sample train was important to document flue gas moisture content as a backup to the online flue gas moisture monitors.

A desiccant solution sample was collected at the inlet of the absorber column and flash drum for each test period as were product water samples. The types of sample analyses completed were summarized in Section 4 of this report. Once the analyses were completed, the individual samples were saved until completion of this report.

Table 13. Sampling Point Locations

\begin{tabular}{lc}
\hline Sampling Point No. & Sampling Point Location \\
\hline 1 & Outlet of the combustor \\
2 & Inlet of the LDDS absorber \\
3 & Outlet of the LDDS absorber \\
4 & Product water condenser outlet vapor \\
\hline
\end{tabular}


Table 14. Test Plan Summary for Test Series I*

\begin{tabular}{|c|c|c|c|c|c|c|c|c|}
\hline $\begin{array}{l}\text { Test No. } \\
\text { Absorber Configuration }\end{array}$ & $\begin{array}{c}1 \\
\mathrm{ST}^{1}\end{array}$ & $\begin{array}{l}2 \\
\text { ST }\end{array}$ & $\begin{array}{l}3 \\
\text { ST } \\
\end{array}$ & $\begin{array}{l}4 \\
\text { ST }\end{array}$ & $\begin{array}{l}5 \\
\text { ST }\end{array}$ & $\begin{array}{l}6 \\
\text { ST }\end{array}$ & $\begin{array}{l}7 \\
\text { ST }\end{array}$ & $\begin{array}{l}8 \\
\text { ST } \\
\end{array}$ \\
\hline Absorber Gas Outlet Temp.y ${ }^{\circ} \mathrm{F}$ & $\mathrm{TBD}^{2}$ & TBD & TBD & TBD & TBD & 121 & 121 & TBD \\
\hline Absorber Desiccant Inlet Temp., ${ }^{\circ} \mathrm{F}$ & 120 & 120 & 120 & 120 & 120 & 120 & 120 & 120 \\
\hline Absorber Desiccant Outlet Temp., ${ }^{\circ} \mathrm{F}$ & TBD & TBD & TBD & TBD & TBD & 131 & 131 & TBD \\
\hline Desiccant $\mathrm{pH}$ & TBD & TBD & TBD & TBD & TBD & TBD & TBD & TBD \\
\hline Desiccant Sp. Gr. & 1.51 & 1.51 & 1.51 & 1.51 & 1.51 & 1.51 & 1.51 & 1.51 \\
\hline Desiccant Concentration, wt $\%$ & 50 & 50 & 50 & 50 & 50 & 50 & 50 & 50 \\
\hline No. of Absorber Spray Levels & 6 & 5 & 4 & 3 & 2 & 1 & 1 & 1 \\
\hline Nozzle Size, Spray Angle $60^{\circ}$ & 82 & 82 & 82 & 82 & 82 & 82 & 82 & 164 \\
\hline Desiccant Flow Rate, gpm & 49 & 41 & 33 & 25 & 14.4 & 7.2 & 7.2 & 14.4 \\
\hline Desiccant Line Pressure, psig & $<20$ & $<20$ & $<20$ & $<20$ & $<15$ & $<15$ & $<15$ & $<15$ \\
\hline Absorber $L / G$, gal/1000 acfm & 109 & 91 & 73 & 56 & 32 & 16 & 16 & 32 \\
\hline Absorber Outlet $\mathrm{H}_{2} \mathrm{O}$ Conc., vol\% & TBD & TBD & TBD & TBD & TBD & TBD & TBD & TBD \\
\hline Regen. Desiccant Inlet Temp., ${ }^{\circ} \mathrm{F}$ & 154 & 154 & 154 & 154 & 154 & 154 & 154 & 154 \\
\hline Regen. Desiccant Outlet Temp., , $\mathrm{F}$ & TBD & TBD & TBD & TBD & TBD & 147 & 147 & TBD \\
\hline Regen. Desiccant Flow Rate, gpm & 49 & 41 & 33 & 25 & 14.4 & 7.2 & 7.2 & 14.4 \\
\hline Nozzle Size, Spray Angle $60^{\circ}$ & 470 & 470 & TBD & TBD & TBD & TBD & 82 & TBD \\
\hline Regen. Desiccant Line Pressure, psig & $<20$ & $<15$ & $<20$ & $<10$ & $<15$ & $<15$ & $<15$ & $<15$ \\
\hline Product Water Condenser Temp., ${ }^{\circ} \mathrm{F}$ & 80 & 80 & 80 & 80 & 80 & 80 & 80 & 80 \\
\hline Product Water Recovery Rate, gpm & TBD & TBD & TBD & TBD & TBD & TBD & TBD & TBD \\
\hline
\end{tabular}

Continued...

Table 14. Test Plan Summary for Test Series I (continued)*

\begin{tabular}{|c|c|c|c|c|c|c|c|c|}
\hline Test No. & 9 & 10 & 11 & 12 & 13 & 14 & 15 & 16 \\
\hline Absorber Configuration & $\mathrm{ST}^{1}$ & ST & ST & ST & $\overline{\mathrm{ST}}$ & $\mathrm{PB}^{3}$ & $\mathrm{~PB}$ & ST \\
\hline Absorber Gas Outlet Temp., ${ }^{\circ} \mathrm{F}$ & $\mathrm{TBD}^{2}$ & TBD & TBD & TBD & TBD & 121 & TBD & TBD \\
\hline Absorber Desiccant Inlet Temp., ${ }^{\circ} \mathrm{F}$ & 120 & 120 & 120 & 120 & 120 & 120 & 120 & 135 \\
\hline Absorber Desiccant Outlet Temp., ${ }^{\circ} \mathrm{F}$ & TBD & TBD & TBD & TBD & TBD & 131 & TBD & TBD \\
\hline Desiccant $\mathrm{pH}$ & TBD & TBD & TBD & TBD & TBD & TBD & TBD & TBD \\
\hline Desiccant Sp. Gr. & 1.51 & 1.51 & 1.51 & 1.51 & 1.51 & 1.51 & 1.51 & TBD \\
\hline Desiccant Concentration, wt $\%$ & 50 & 50 & 50 & 50 & 50 & 50 & 50 & 40.5 \\
\hline No. of Absorber Spray Levels & 1 & 2 & 3 & 3 & 3 & 1 & 1 & 3 \\
\hline Nozzle Size, Spray Angle $60^{\circ}$ & 164 & 164 & 164 & 53 & 53 & 82 & 164 & 53 \\
\hline Desiccant Flow Rate, gpm & 16 & 33 & 49 & 16 & 14.4 & 7.2 & 14.4 & 16 \\
\hline Desiccant Line Pressure, psig & $<20$ & $<20$ & $<20$ & $<20$ & $<20$ & $<15$ & $<15$ & $<15$ \\
\hline Absorber L/G, gal/1000 acfm & 36 & 73 & 109 & 36 & 32 & 16 & 32 & 36 \\
\hline Absorber Outlet $\mathrm{H}_{2} \mathrm{O}$ Conc., vol\% & TBD & TBD & TBD & TBD & TBD & TBD & TBD & TBD \\
\hline Regen. Desiccant Inlet Temp., ${ }^{\circ} \mathrm{F}$ & 154 & 154 & 154 & 154 & 154 & 154 & 154 & TBD \\
\hline Regen. Desiccant Outlet Temp., ${ }^{\circ} \mathrm{F}$ & TBD & TBD & TBD & TBD & TBD & TBD & $\mathrm{TBD}$ & TBD \\
\hline Regen. Desiccant Flow Rate, gpm & 16 & 33 & 49 & 16 & 14.4 & 7.2 & 14.4 & 16 \\
\hline Nozzle Size, Spray Angle $60^{\circ}$ & TBD & TBD & TBD & TBD & TBD & TBD & TBD & TBD \\
\hline Regen. Desiccant Line Pressure, psig & $<20$ & $<10$ & $<20$ & $<20$ & $<20$ & $<15$ & $<15$ & $<20$ \\
\hline Product Water Condenser Temp. ${ }^{\circ} \mathrm{F}$ & 80 & 80 & 80 & 80 & 80 & 80 & 80 & 80 \\
\hline Product Water Recovery Rate, gpm & TBD & TBD & TBD & TBD & TBD & TBD & TBD & TBD \\
\hline \multicolumn{9}{|c|}{$\begin{array}{l}{ }^{1} \text { Spray tower } \\
{ }^{2} \text { To be determined. } \\
\text { 3 Packed bed. } \\
\text { * Note: During this series of natural gas-fired tests, the absorber inlet flue gas conditions were to be } 203^{\circ} \mathrm{F}, 360 \mathrm{scfm} \text { or } \\
450 \mathrm{acfm}, 8.2 \mathrm{vol} \% \mathrm{H}_{2} \mathrm{O} \text {, and } 12.7 \mathrm{vol} \% \mathrm{O}_{2} \text {. Absorber velocity was to be } 10 \mathrm{ft} / \mathrm{s} \text {. Flash drum vacuum pressure was to } \\
\text { be } 1 \mathrm{psia} \text {. Tests } 1,7,13 \text {, and } 15 \text { were to involve a test duration of } 6 \text { hours or more. All other test periods were to be } \\
\text { limited to } 2 \text { hours of stable operation. }\end{array}$} \\
\hline
\end{tabular}


Table 15. Planned SFS Test Parameters for Test Series I

\begin{tabular}{ll}
\hline Parameter & Set Point \\
\hline Fuel & Natural gas \\
Furnace Temperature & TBD, ${ }^{\circ} \mathrm{F}$ \\
Furnace Pressure & Maintain -0.1 to $-0.3 \mathrm{in}$. W.C. in furnace \\
CAH Flue Gas Inlet Temperature & $1800^{\circ} \mathrm{F} \pm 50^{\circ} \mathrm{F}$ \\
Secondary Combustion Air (SCA) Temperature & $300^{\circ} \mathrm{F}$ \\
$\mathrm{O}_{2}$ in Flue Gas at Furnace Exit & $\mathrm{TBD} \pm 0.5$ vol\% (TBD excess air) \\
$\mathrm{O}_{2}$ in Flue Gas at Absorber Inlet & 12.5 to 13.0 vol\% (wet basis) \\
Main Burner Prim. $/$ Sec. Air Split & $50 \mathrm{scfm}$ primary combustion air (PCA)/290 scfm SCA @ TBD A/F ratio \\
CAH Process Air Inlet Temp. & $1000^{\circ} \mathrm{F} \pm 100^{\circ} \mathrm{F} @ 100 \mathrm{scfm} \pm 20 \mathrm{scfm}$ \\
CAH Process Air Outlet Temp. & $1300^{\circ} \mathrm{F}$ \\
Heat Exchanger Nos. 2-5 Outlet Air Temp. & $1275^{\circ} \mathrm{F} \pm 50^{\circ} \mathrm{F}$ \\
Baghouse Inlet Temperature & $250^{\circ}$ to $350^{\circ} \mathrm{F}$ \\
Baghouse Pulse Settings & Pressure: 60 psig \\
& Cleaning set point: 6 in. W.C. \\
Process Air Reheat Flow Rate & $100 \mathrm{scfm}$ \\
Process Air Reheat Temperature & TBD $\left(500^{\circ}\right.$ to $\left.600^{\circ} \mathrm{F}\right)$ \\
Absorber Inlet Temperature & $203^{\circ} \mathrm{F} \pm 5^{\circ} \mathrm{F}$ \\
Absorber Outlet Temperature & TBD \\
Absorber Inlet Flow Rate & $450 \pm 5$ acfm \\
\hline
\end{tabular}

Table 16. Sampling Activities for Test Series I*

\begin{tabular}{lccc}
\hline Test No. & $\begin{array}{c}\text { Sample Point No. 1 } \\
\text { Absorber Inlet }\end{array}$ & $\begin{array}{c}\text { Sample Point No. 2 } \\
\text { Absorber Outlet }\end{array}$ & $\begin{array}{c}\text { Sample Point 3 } \\
\text { Condenser Outlet Vapor }\end{array}$ \\
\hline & No. of M5 Trains & No. of M5 Trains & Group A or B Analyzers \\
1 & 2 & 2 & $60 \mathrm{~min}$ \\
7 & 2 & 2 & $60 \mathrm{~min}$ \\
13 & 2 & 2 & $60 \mathrm{~min}$ \\
15 & 2 & 2 & $60 \mathrm{~min}$ \\
\hline
\end{tabular}

* Notes: The M5 sample trains were run simultaneously at both sample locations for 120 minutes. M5 - EPA Method 5 (particulate mass loading, sulfate, calcium, and chlorides).

\subsubsection{Evaluation of LDDS Performance for a Coal-Fired Boiler/FGD System- Test Series II}

A 5-day pilot-scale test series was conducted to document the performance of the LDDS during the week of November 14-20,2004. Tables 17 and 18 summarize the operating parameters for Test Series II. Test parameters summarized in Table 17 primarily address LDDS operating parameters and flue gas composition at the absorber column inlet. Several secondary test parameters were determined during the test series as a function of operating conditions required to achieve primary test parameters. Table 18 summarizes SFS operating parameters. Sampling activities were limited to 8-12 hours each day. However, the SFS and LDDS were operated 24 hours/day. Overnight 
Table 17. Test Plan Summary for Test Series II*

\begin{tabular}{|c|c|c|c|c|c|c|c|c|}
\hline $\begin{array}{l}\text { Test No. } \\
\text { Fuel Fired } \\
\text { Absorber Configuration }\end{array}$ & $\begin{array}{c}1 \\
\mathrm{NG}^{1} \\
\mathrm{ST}^{2} \\
\end{array}$ & $\begin{array}{c}2 \\
\mathrm{NG} \\
\mathrm{ST} \\
\end{array}$ & $\begin{array}{c}3 \\
\text { NG } \\
\text { ST } \\
\end{array}$ & $\begin{array}{c}4 \\
\mathrm{NG} \\
\mathrm{ST} \\
\end{array}$ & $\begin{array}{r}5 \\
\mathrm{NG} \\
\mathrm{ST} \\
\end{array}$ & $\begin{array}{c}6 \\
\mathrm{NG} \\
\mathrm{ST} \\
\end{array}$ & $\begin{array}{c}7 \\
\mathrm{NG} \\
\mathrm{ST} \\
\end{array}$ & $\begin{array}{c}8 \\
\text { Coal } \\
\text { ST } \\
\end{array}$ \\
\hline Absorber Gas Outlet Temp., ${ }^{\circ} \mathrm{F}$ & TBD & TBD & TBD & TBD & TBD & $\mathrm{TBD}$ & TBD & TBD \\
\hline Absorber Desiccant Inlet Temp., ${ }^{\circ} \mathrm{F}$ & 120 & 120 & 120 & 120 & 120 & $\mathrm{TBD}$ & TBD & 120 \\
\hline Absorber Desiccant Outlet Temp., ${ }^{\circ} \mathrm{F}$ & TBD & TBD & TBD & $\mathrm{TBD}$ & $\mathrm{TBD}$ & TBD & TBD & TBD \\
\hline Desiccant $\mathrm{pH}$ & TBD & TBD & $\mathrm{TBD}$ & TBD & TBD & TBD & TBD & TBD \\
\hline Desiccant Sp. Gr. & TBD & TBD & TBD & TBD & TBD & TBD & TBD & TBD \\
\hline Desiccant Concentration, wt $\%$ & 46.7 & 46.7 & 46.7 & 46.7 & 46.7 & TBD & TBD & 46.7 \\
\hline No. of Absorber Spray Levels & 1 & 2 & 3 & 4 & 5 & 5 & 5 & 1 \\
\hline Nozzle Size, Spray Angle $60^{\circ}$ & 82 & 82 & 82 & 82 & 82 & 82 & 82 & 82 \\
\hline Desiccant Flow Rate, gpm & 7.2 & 14.4 & 25 & 33 & 41 & 25 & 25 & 7.2 \\
\hline Desiccant Line Pressure, psig & $<15$ & $<15$ & $<20$ & $<20$ & $<20$ & $<20$ & $<20$ & $<15$ \\
\hline Absorber $L / G$, gal $/ 1000 \mathrm{acfm}$ & 16 & 32 & 56 & 73 & 91 & 91 & 91 & 16 \\
\hline Absorber Outlet $\mathrm{H}_{2} \mathrm{O}$ Conc., vol\% & TBD & TBD & $\mathrm{TBD}$ & TBD & $\mathrm{TBD}$ & TBD & TBD & TBD \\
\hline Regen. Desiccant Inlet Temp., ${ }^{\circ} \mathrm{F}$ & $\mathrm{TBD}$ & TBD & $\mathrm{TBD}$ & TBD & TBD & TBD & TBD & TBD \\
\hline Regen. Desiccant Outlet Temp., ${ }^{\circ} \mathrm{F}$ & $\mathrm{TBD}$ & TBD & TBD & TBD & TBD & TBD & TBD & $\mathrm{TBD}$ \\
\hline Regen. Desiccant Flow Rate, gpm & 7.2 & 14.4 & 25 & 33 & 41 & 25 & 4.1 & 7.2 \\
\hline Nozzle Size, Spray Angle $60^{\circ}$ & 340 & 340 & 340 & 340 & 340 & 340 & 340 & 340 \\
\hline Regen. Desiccant Line Pressure, psig & $<10$ & $<10$ & $<15$ & $<20$ & $<20$ & $<20$ & $<10$ & $<10$ \\
\hline Product Water Condenser Temp., ${ }^{\circ} \mathrm{F}$ & 80 & 80 & 80 & 80 & 80 & 80 & 80 & 80 \\
\hline Product Water Recovery Rate, gpm & TBD & TBD & TBD & TBD & TBD & TBD & TBD & TBD \\
\hline
\end{tabular}

activities focused on completion of specific tests and changing operating parameters in preparation for the next day's sampling activities.

The original sampling plan for Test Series II is summarized in Table 19. EPA Method 5 sample trains were run simultaneously at the inlet and outlet of the absorber column for a duration of 120 minutes. Because of the baghouse located upstream of the absorber, the concentration of sulfates, calcium, sodium, and chlorides and total particulate mass at the inlet of the absorber column was expected to be near zero. However, sampling at this location was necessary to document the potential impact of these species on LDDS performance and their contribution to emissions downstream of the absorber column as well as contamination of the desiccant solution. Backup filters were not included in sample trains used at the absorber column inlet and outlet sample locations because secondary aerosol formation was not anticipated. Recovery of the impingers in each sample train was important to document flue gas moisture content as a backup to the online flue gas moisture monitors.

A desiccant solution sample was collected at the inlet of the absorber column and flash drum for each test period as were product water samples. The types of sample analyses completed were summarized in Section 4 of this report. Once the analyses were completed, the individual samples were saved until this report was completed for possible future analysis. Subsequently, Test Series I and II samples were disposed of in an appropriate manner. 
Table 17. Test Plan Summary for Test Series II* (continued)

\begin{tabular}{|c|c|c|c|c|c|}
\hline Test No. & 9 & 10 & 11 & 12 & 13 \\
\hline Fuel Fired & Coal & Coal & Coal & Coal & Coal \\
\hline Absorber Configuration & $\mathrm{ST}$ & ST & $\mathrm{PB}^{3}$ & $\mathrm{~PB}$ & PB \\
\hline Absorber Gas Outlet Temp., ${ }^{\circ} \mathrm{F}$ & $\mathrm{TBD}$ & TBD & TBD & TBD & TBD \\
\hline Absorber Desiccant Inlet Temp., ${ }^{\circ} \mathrm{F}$ & 120 & 120 & 120 & 120 & 120 \\
\hline Absorber Desiccant Outlet Temp., ${ }^{\circ} \mathrm{F}$ & TBD & TBD & TBD & TBD & TBD \\
\hline Desiccant $\mathrm{pH}$ & TBD & $\mathrm{TBD}$ & TBD & TBD & TBD \\
\hline Desiccant Sp. Gr. & TBD & TBD & TBD & TBD & TBD \\
\hline Desiccant Concentration, wt $\%$ & 46.7 & 46.7 & 46.7 & 46.7 & 46.7 \\
\hline No. of Absorber Spray Levels & 3 & 3 & 1 & 1 & 1 \\
\hline Nozzle Size, Spray Angle $60^{\circ}$ & 82 & 53 & 164 & 164 & 164 \\
\hline Desiccant Flow Rate, gpm & 25 & 14.4 & 7.2 & 7.2 & 14.4 \\
\hline Desiccant Line Pressure, psig & $<15$ & $<20$ & $<15$ & $<15$ & $<15$ \\
\hline Absorber $\mathrm{L} / \mathrm{G}$, gal./1000 acfm & 56 & 32 & 16 & 16 & 32 \\
\hline Absorber Outlet $\mathrm{H}_{2} \mathrm{O}$ Conc., vol\% & TBD & $\mathrm{TBD}$ & $\mathrm{TBD}$ & TBD & TBD \\
\hline Regen. Desiccant Inlet Temp. ${ }^{\circ} \mathrm{F}$ & TBD & TBD & $\mathrm{TBD}$ & TBD & TBD \\
\hline Regen. Desiccant Outlet Temp., ${ }^{\circ} \mathrm{F}$ & TBD & TBD & TBD & TBD & TBD \\
\hline Regen. Desiccant Flow Rate, gpm & 25 & 14.4 & 7.2 & 7.2 & 14.4 \\
\hline Nozzle Size, Spray Angle $60^{\circ}$ & 340 & 340 & 340 & 340 & 340 \\
\hline Regen. Desiccant Line Pressure, psig & $<15$ & $<15$ & $<15$ & $<15$ & $<15$ \\
\hline Product Water Condenser Temp., ${ }^{\circ} \mathrm{F}$ & 80 & 80 & 80 & 80 & 80 \\
\hline Product Water Recovery Rate, gpm & TBD & TBD & TBD & TBD & TBD \\
\hline
\end{tabular}

Natural gas.

2 Spray tower.

Packed bed.

* Note: During this series of natural gas- and coal-fired tests the absorber inlet flue gas conditions were to be $135^{\circ} \mathrm{F}$, $450 \mathrm{acfm}, 14-15 \mathrm{vol} \% \mathrm{H}_{2} \mathrm{O}$, and 4-5 vol\% (dry) $\mathrm{O}_{2}$. Absorber velocity was to be $10 \mathrm{ft} / \mathrm{s}$. Flash drum vacuum pressure was to be 1 psia. Tests $8-13$ were to involve a test duration of roughly 8 hours. All other test periods were to be limited to 2 hours of stable operation.

\subsection{Results and Discussion}

The overall objective of the project was to develop a liquid desiccant-based flue gas dehydration process technology to reduce water consumption in coal-fired power plants. Specific objectives included the generation of sufficient subscale test data and conceptual commercial power plant evaluations to permit assessment of process feasibility and its merits for commercialization. Results from the multitask effort are divided into three areas: 1) desiccant selection, 2) bench-scale desiccant testing, and 3) pilot-scale desiccant testing.

\subsubsection{Desiccant Selection}

As previously stated, commonly used liquid desiccants are aqueous solutions of inorganic salts or glycols and are characterized by their strong affinity for water, resulting in a low partial pressure of water above a saturated liquid. It is the difference between the partial pressure of water in the gas stream and partial pressure of water in the desiccant that is the driving force for dehumidification. 
Table 18. Planned SFS Test Parameters for Test Series II

\begin{tabular}{ll}
\hline Parameter & \multicolumn{1}{c}{ Set Point } \\
\hline Fuel & Natural gas or Belle Ayr subbit. coal \\
Furnace Temperature & TBD, ${ }^{\circ} \mathrm{F}$ \\
Furnace Exit Pressure & Maintain -0.1 to $-0.3 \mathrm{in} . \mathrm{H}_{2} \mathrm{O}$ in furnace \\
CAH Flue Gas Inlet Temperature & $\leq 1800^{\circ} \mathrm{F} \pm 50^{\circ} \mathrm{F}$ \\
SCA Temperature & $\geq 300^{\circ} \mathrm{F}$ \\
$\mathrm{O}_{2}$ in Flue Gas at Furnace Exit & $3.5 \pm 4.0 \%(\sim 20 \%$ excess air) \\
$\mathrm{O}_{2}$ in Flue Gas at Absorber Inlet & $4.0 \pm 5.0^{\circ} \%$ (dry basis) \\
Main Burner PCA/SCA Split & $50 \mathrm{scfm}$ primary combustion air $/ 290 \mathrm{SCA} @ 1.2 \mathrm{~A} / \mathrm{F}$ \\
CAH Process Air Inlet Temp. & $1000^{\circ} \mathrm{F} \pm 100^{\circ} \mathrm{F} @ 100 \mathrm{scfm} \pm 20 \mathrm{scfm}$ \\
CAH Process Air Outlet Temp. & $\leq 1300^{\circ} \mathrm{F}$ \\
Heat Exchanger Nos. 2-5 Outlet Air Temp. & $1275^{\circ} \mathrm{F} \pm 50^{\circ} \mathrm{F}$ \\
Baghouse Inlet Temperature & $200^{\circ}$ to $250^{\circ} \mathrm{F}$ \\
Baghouse Pulse Settings & Pressure 60 psig \\
& $\mathrm{Cleaning} \mathrm{set} \mathrm{point:} 6$ in. W.C. \\
Process Air Reheat Flow Rate & $100 \mathrm{scfm}$ \\
Process Air Reheat Temperature & $\mathrm{TBD}\left(500^{\circ}\right.$ to $\left.600^{\circ} \mathrm{F}\right)$ \\
Absorber Inlet Temperature & $135^{\circ} \mathrm{F} \pm 5^{\circ} \mathrm{F}$ \\
Absorber Outlet Temperature & $\mathrm{TBD}$ \\
Absorber Inlet Flow Rate & $450 \pm 5$ acfm
\end{tabular}

Table 19. Sampling Activities for Test Series II*

\begin{tabular}{lccccc}
\hline Test No. & \multicolumn{2}{c}{$\begin{array}{c}\text { Sample Point No. } 1 \\
\text { Absorber Inlet }\end{array}$} & \multicolumn{2}{c}{$\begin{array}{c}\text { Sample Point No. 2 } \\
\text { Absorber Outlet }\end{array}$} & $\begin{array}{c}\text { Sample Point No. 3 } \\
\text { Condenser Outlet Vapor }\end{array}$ \\
\hline & Hg CEM & No. of M5s & Hg CEM & No. of M5s & Group B Analyzers \\
4 & $2 \mathrm{hr}$ & 2 & $2 \mathrm{hr}$ & 2 & $60-120 \mathrm{~min}$ \\
8 & $4-6 \mathrm{hr}$ & 2 & $4-6 \mathrm{hr}$ & 2 & $60-120 \mathrm{~min}$ \\
10 & $4-6 \mathrm{hr}$ & 2 & $4-6 \mathrm{hr}$ & 2 & $60-120 \mathrm{~min}$ \\
13 & $4-6 \mathrm{hr}$ & 2 & $4-6 \mathrm{hr}$ & 2 & $60-120 \mathrm{~min}$ \\
\hline
\end{tabular}

* Notes: The M5 sample trains were run simultaneously at both sample locations. M5 - EPA Method 5 (particulate mass loading, sulfate, calcium, sodium, and chlorides). $\mathrm{Hg} \mathrm{CEM}-\mathrm{Hg}$ sampling with continuous emission monitors (CEMs) was conducted simultaneously at both sample locations.

Figure 14 shows the vapor pressures of some common liquid desiccants as a function of temperature with weight percent of the desiccant as a parameter.

A simple industrial liquid desiccant system, as shown in Figure 15, consists of an absorber (also called the conditioner), a regenerator, two pumps, and three heat exchangers. In the absorber, chilled and concentrated liquid desiccant is distributed over packing. A key aspect of the design of such packed-bed devices is the need to recirculate the desiccant from the sump to achieve sufficient liquid flow rate in the bed to provide wetting of the packing (uniform wetting of the packing provides a large vapor-liquid surface area for mass transfer). In the absorber, the partial pressure of 


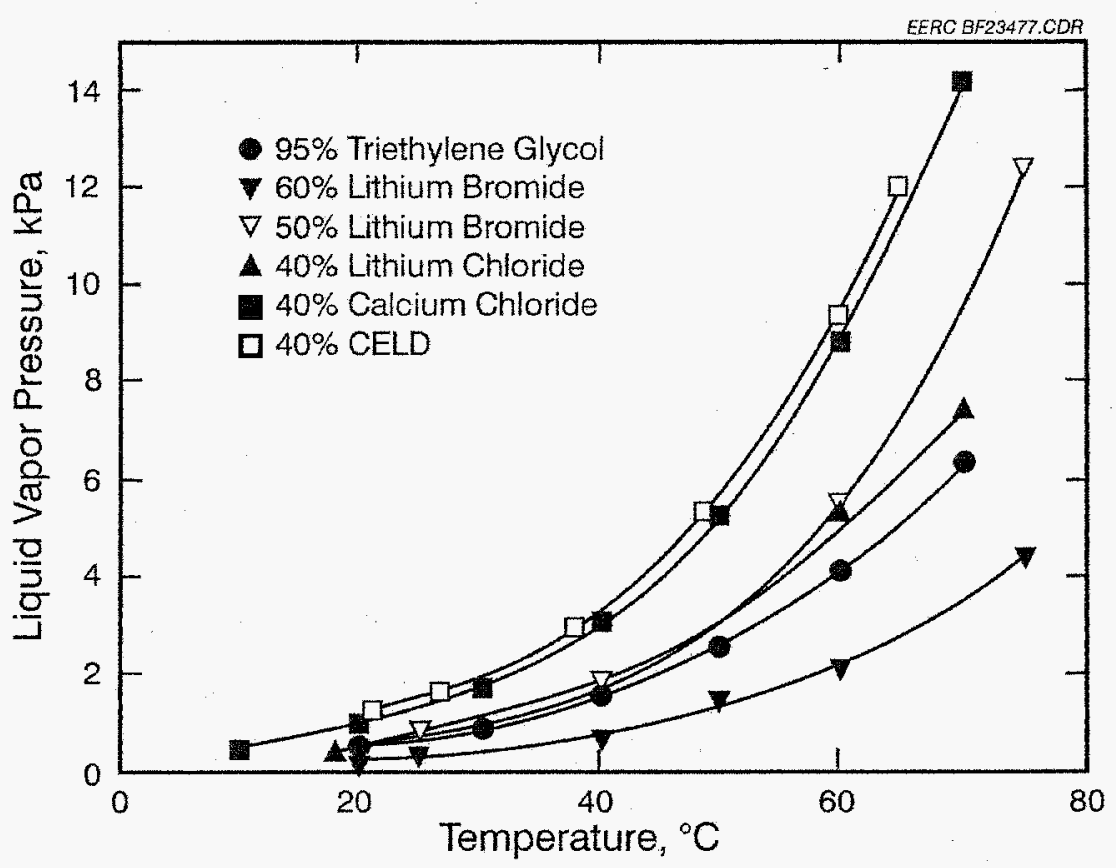

Figure 14. Vapor pressure of liquid desiccants (Oberg and Goswami, 1998) as a function of temperature for various concentrations of desiccant (CELD: cost-effective liquid desiccant, a mixture of calcium and lithium chloride).

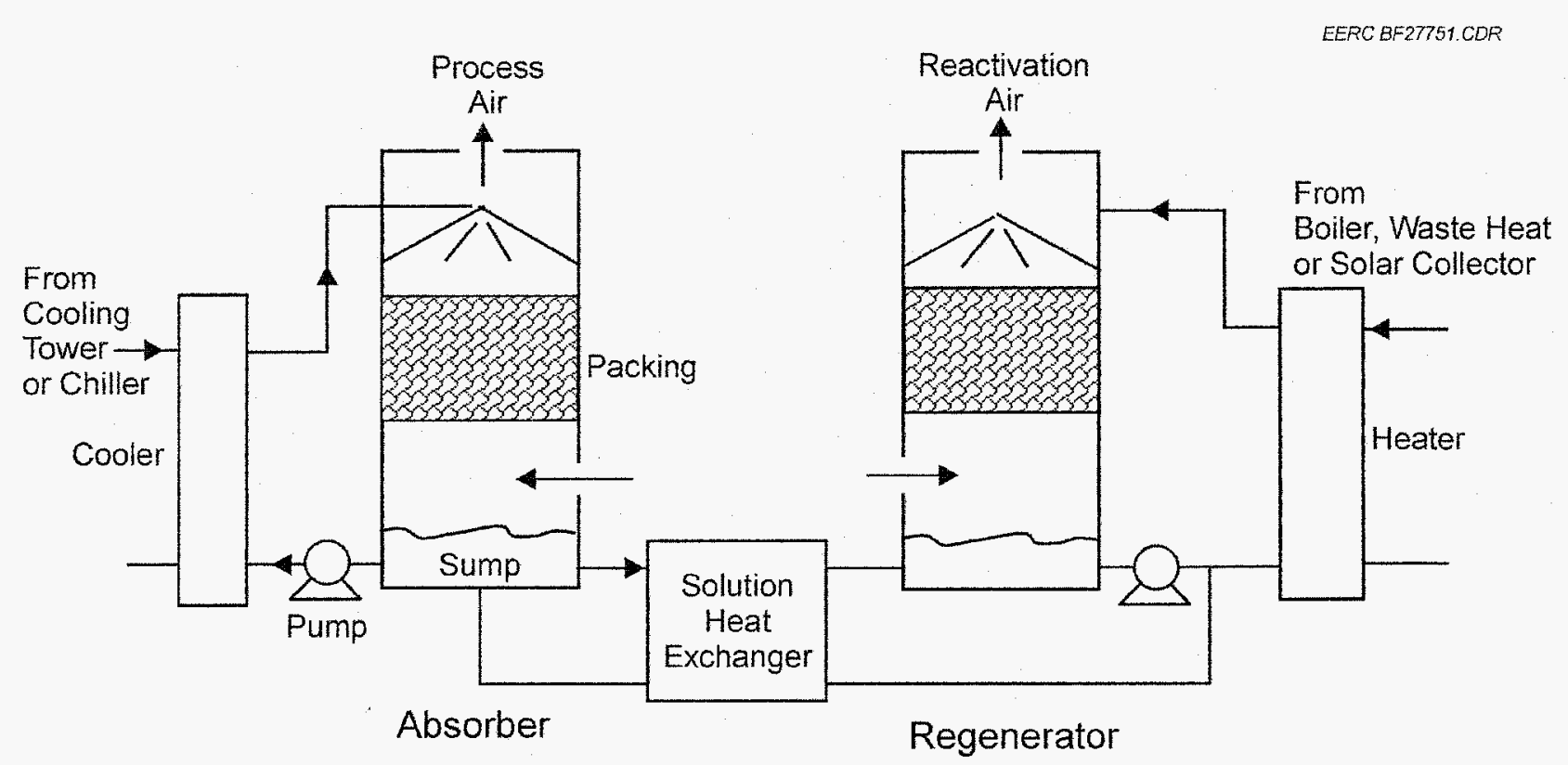

Figure 15. Schematic of a liquid desiccant system (Pesaran et al., 1992). 
the water in the desiccant is low, and water vapor from the counterflowing air stream (process air) is dehumidified. The desiccant recirculating around and through the absorber is cooled by a heat exchanger to reject the latent heat of the absorbed water vapor and the heat of mixing. A fraction of the dilute desiccant exits the absorber and passes through a regenerative heat exchanger on its way to the desiccant regenerator. The regenerator is a packed-bed design similar to the absorber, including a recirculation system. For the regenerator, a heat input is needed to cause the water to evaporate from the solution. The desiccant is distributed over the regenerator packed bed where its high vapor pressure forces the water out of the desiccant and into the passing air which is called reactivation air (Harriman, 1990).

When the desiccant exits from the regenerator, it is concentrated and warm. The regenerative heat exchanger is used to condition it before reintroduction to the absorber.

In the design of the absorber, a mist eliminator at the outlet is needed to prevent droplets of desiccant from leaving with the process air. This is important to conserve desiccant and to prevent a corrosive or otherwise undesirable chemical from leaving the system (Lowenstein, 1998).

The LDDS regenerator design is different because it does not utilize regeneration air. The regenerator in the LDDS system is more like a generator or an evaporator in a closed-cycle absorption chiller.

The flue gas inlet to the LDDS water retrieval system immediately follows the exit of the conventional heat recovery steam generator (HRSG) economizer in a gas-fired combined-cycle system or after a wet FGD system in a coal-fired plant. The primary components through which the flue gas passes are the desiccant absorber (ABS) and a heat recovery heat exchanger (EVAP) in the case of using low-grade heat to add additional heat to the desiccant going into the regenerator. The regenerator (SAR) operates at subatmospheric pressure, and a heat exchanger condenses the steam. In a field application, this would be an ACC to condense the steam. The EVAP extracts energy from the flue gas which is used to regenerate the desiccant in the SAR. In the absorber, the flue gas contacts the concentrated desiccant solution and most of the water vapor fraction is absorbed. During this process, the desiccant is heated because of the heat of sorption as the water is removed (the absorption of water into the desiccant is exothermic). The wet desiccant solution is then sent to the SAR where steam is boiled out and routed to an air-cooled condenser. The water extracted by the condenser is then available for use by the processes required to operate the power plant (such as evaporative cooling, make-up water for water/steam leakage, water injection for pollution control). Excess water may be sent to a storage tank for use when the ambient temperatures are too high to produce sufficient water to meet plant requirements. The regeneration process (for the desiccant solution) requires heat that is provided by the EVAP. Following the desiccant regeneration process, the dry desiccant solution is returned and sprayed into the absorber.

The driving force of dehumidification is the low partial pressure of water above the liquid desiccant. Low partial pressure of water means the solution has strong affinity for the water molecules. Lowenstein (1993) uses activity of the water to discuss the potential of a liquid desiccant. Activity of water in solution is equal to the ratio of the water partial pressure as part of a mixture to its vapor pressure as a pure substance; it is similar to the relative humidity of the water vapor in 
equilibrium with the solution. Table 20 lists the activity of water in solution with inorganic desiccants, while Table 21 lists the activity for selected glycols. A low value of activity, such as that for $\mathrm{LiBr}$, implies a low partial pressure of water and thus good water absorption potential. However, this property is only one of many properties that impact desiccant selection.

For all of the desiccant options, the vapor pressure is essentially equal to the partial pressure of water because the partial pressure of the desiccant is so low. For the glycol with the highest vapor pressure (propylene glycol), the partial pressure of the glycol is less than $1 \%$ of that of water. Therefore, it is reasonable to view the vapor phase as consisting of pure water for the purposes of interpreting the activity values. The relationship between activity and partial pressure of water is summarized in the captions with Tables 20 and 21 . This allows the pressures to be recovered from the activity data in a simple manner.

Activity values are tabulated at a particular temperature and concentration of the desiccant. The majority of the data in Table 20 come from a source (Lowenstein, 1993) that listed it at $25^{\circ} \mathrm{C}\left(77^{\circ} \mathrm{F}\right)$, and these data are retained here for comparison. However, since the temperature in the absorber for the LDDS application is expected to be higher, an additional column was added quoting activities for selected desiccants at $37.8^{\circ} \mathrm{C}\left(100^{\circ} \mathrm{F}\right)$. It is interesting to note that the basic trends seen at $25^{\circ} \mathrm{C}$ $\left(77^{\circ} \mathrm{F}\right)$ seem to also be reflected at $37.8^{\circ} \mathrm{C}\left(100^{\circ} \mathrm{F}\right)$. This observation is equivalent to observing the vapor pressure trends in Figure 14 and noting that the vapor pressure curves tend to follow parallel traces. This is important because the conclusion is that the effect of temperature on vapor pressure is well understood and thus we can do the comparison of desiccants at a nominal design temperature and then expect the conclusions to hold up when the actual temperature varies from that nominal value.

The effect of desiccant concentration on the activity is crucial to the interpretation of the data in Tables 20 and 21. The concentration is given as molality with mass fraction in parentheses for the most important desiccant options. The relationship between molality and mass fraction is given at the bottom of the table. In general, the activity of water decreases as the desiccant concentration increases (the nature of a desiccant is that it attracts water). In Table 20 , only a single concentration is listed for each of the inorganic desiccants, and the choice of that concentration can influence the comparison of activity values (and hence conclusions regarding the drying capability of a desiccant). The inorganic systems tend to exhibit a solubility limit where addition of more desiccant causes a solid phase to precipitate. The concentration values listed in Table 21 represent an approach to this solubility limit, and thus the activity values listed represent the maximum performance possible. In a liquid desiccant application, care must be exercised in the design to operate the system sufficiently far from the solubility limit as to avoid precipitation of solids and possible system failure that might be expected to result.

Activity values for various glycols are listed in Table 21 along with the vapor pressure of the anhydrous glycol. The glycols are soluble with water over the full range of possible concentrations. Thus with glycols there is no concern about precipitation of solids as discussed for the inorganics. The glycols can be dried to close to $100 \%$ in the regenerator. However, to avoid high glycol flow rates, the absorber is expected to see a change in concentration on the order of $10 \%$. To get an idea of 
Table 20. Activity of Water in Solution with Inorganic Desiccants. Most of the data are from Lowenstein (1993). To obtain vapor pressure from activity values, multiply activity by the vapor pressure of pure water at $77^{\circ} \mathrm{F}\left(\mathrm{P}_{\mathrm{w}}=3.17 \mathrm{kPa}=0.46 \mathrm{psi}\right)$ or at $100^{\circ} \mathrm{F}\left(\mathrm{P}_{\mathrm{w}}=6.56 \mathrm{kPa}=0.96 \mathrm{psi}\right)$.

\begin{tabular}{|c|c|c|c|c|c|c|}
\hline $\begin{array}{l}\text { Compound } \\
\text { (molecular } \\
\text { weight) }\end{array}$ & $\begin{array}{c}\text { Molal Conc. } \\
\text { (mass } \\
\text { fraction) }\end{array}$ & $\begin{array}{c}\text { Activity of } \\
\text { Water at } \\
25^{\circ} \mathrm{C} \\
\left(77^{\circ} \mathrm{F}\right) \\
\end{array}$ & $\begin{array}{c}\text { Compound } \\
\text { (molecular } \\
\text { weight) }\end{array}$ & $\begin{array}{c}\text { Molal Conc. } \\
\text { (mass } \\
\text { fraction) }\end{array}$ & $\begin{array}{c}\text { Activity of } \\
\text { Water at } \\
25^{\circ} \mathrm{C} \\
\left(77^{\circ} \mathrm{F}\right) \\
\end{array}$ & $\begin{array}{c}\text { Activity of } \\
\text { Water at } \\
37.8^{\circ} \mathrm{C} \\
\left(100^{\circ} \mathrm{F}\right) \\
\end{array}$ \\
\hline $\mathrm{HF}$ & 20.0 & 0.601 & $\mathrm{NH}_{4} \mathrm{NO}_{3}$ & 25.0 & 0.628 & \\
\hline $\mathrm{HCl}$ & 16.0 & 0.175 & $\begin{array}{c}\mathrm{LiCl} \\
(42.39)\end{array}$ & $19.0(0.45)$ & 0.122 & 0.138 \\
\hline $\mathrm{HBr}$ & 11.0 & 0.280 & $\begin{array}{c}\mathrm{LiBr} \\
(86.85)\end{array}$ & $20(0.635)$ & 0.054 & 0.061 \\
\hline $\mathrm{HI}$ & 10.0 & 0.311 & LiI & 3.0 & 0.853 & \\
\hline $\mathrm{HClO}_{4}$ & 16.0 & 0.070 & $\mathrm{LiOH}$ & 5.0 & 0.845 & \\
\hline $\mathrm{HNO}_{3}$ & 28.0 & 0.232 & $\mathrm{LiClO}_{4}$ & 4.5 & 0.761 & \\
\hline $\mathrm{NaF}$ & 1.0 & 0.969 & $\begin{array}{c}\mathrm{LiNO}_{3} \\
(68.9)\end{array}$ & $20.0(0.58)$ & 0.272 & 0.20 \\
\hline $\mathrm{NaCl}$ & 6.0 & 0.758 & $\mathrm{KF}$ & 17.5 & 0.292 & \\
\hline $\mathrm{NaBr}$ & 9.0 & 0.592 & $\mathrm{KCl}$ & 5.0 & 0.836 & \\
\hline $\mathrm{NaI}$ & 12.0 & 0.393 & $\mathrm{KBr}$ & 5.5 & 0.816 & \\
\hline $\mathrm{NaOH}$ & 29.0 & 0.063 & $\mathrm{KI}$ & 4.5 & 0.846 & \\
\hline $\mathrm{NaClO}_{3}$ & 3.0 & 0.909 & $\mathrm{KOH}$ & 20.0 & 0.109 & \\
\hline $\mathrm{NaClO}_{4}$ & 6.0 & 0.795 & $\mathrm{KClO}_{3}$ & 0.7 & 0.980 & \\
\hline $\mathrm{NaBrO}_{3}$ & 2.5 & 0.931 & $\mathrm{KBrO}_{3}$ & 0.5 & 0.985 & \\
\hline $\mathrm{NaNO}_{3}$ & 10.0 & 0.662 & $\mathrm{KNO}_{3}$ & 3.5 & 0.930 & \\
\hline $\mathrm{NaH}_{2} \mathrm{PO}_{4}$ & 6.5 & 0.844 & $\mathrm{KH}_{2} \mathrm{PO}_{4}$ & 1.8 & 0.958 & \\
\hline $\mathrm{NaH}_{2} \mathrm{AsO}_{4}$ & 1.3 & 0.963 & $\mathrm{KH}_{2} \mathrm{AsO}_{4}$ & 1.3 & 0.966 & \\
\hline NaCNS & 18.0 & 0.346 & $\mathrm{KCNS}$ & 5.0 & 0.847 & \\
\hline $\mathrm{RbF}$ & 3.5 & 0.874 & $\mathrm{CsF}$ & 3.5 & 0.861 & \\
\hline $\mathrm{RbCl}$ & 7.8 & 0.752 & $\mathrm{CsCl}$ & 11.0 & 0.668 & \\
\hline $\mathrm{RbBr}$ & 5.0 & 0.845 & $\mathrm{CsBr}$ & 5.0 & 0.850 & \\
\hline $\mathrm{RbI}$ & 5.0 & 0.844 & CsI & 3.0 & 0.915 & \\
\hline $\mathrm{RbNO}_{3}$ & 4.5 & 0.919 & $\mathrm{CsOH}$ & 1.2 & 0.957 & \\
\hline $\mathrm{NH}_{4} \mathrm{Cl}$ & 7.0 & 0.782 & $\mathrm{CsNO}_{3}$ & 1.5 & 0.963 & \\
\hline $\mathrm{NH}_{4} \mathrm{ClO}_{4}$ & 2.1 & 0.944 & $\begin{array}{c}\mathrm{CaCl}_{2} \\
(111)\end{array}$ & $7.4(0.45)$ & 0.291 & 0.28 \\
\hline
\end{tabular}

Relationship between molality, $\mathrm{m}$ (mol of solute/kg of water) and mass fraction, $\mathrm{x}$. $m=\frac{(x / M) 1000}{1-x}$ where $M$ is the molecular weight of the solute.

$x=\frac{m}{1000 / M+m}$ 
Table 21. Activity of Water in Solution with Organic Desiccants (data from Dow product literature). To obtain vapor pressure from activity values, multiply activity by the vapor pressure of pure water at $77^{\circ} \mathrm{F}\left(\mathrm{P}_{\mathrm{w}}=3.17 \mathrm{kPa}=0.46 \mathrm{psi}\right)$ or at $100^{\circ} \mathrm{F}\left(\mathrm{P}_{\mathrm{w}}=6.56 \mathrm{kPa}=0.96 \mathrm{psi}\right.$.

\begin{tabular}{lcccc}
$\begin{array}{l}\text { Glycol (molecular } \\
\text { weight) }\end{array}$ & $\begin{array}{c}\text { Molal Conc. } \\
\text { (mass fraction) }\end{array}$ & $\begin{array}{c}\text { Activity of } \\
\text { Water at } 25^{\circ} \mathrm{C} \\
\left(77^{\circ} \mathrm{F}\right)\end{array}$ & $\begin{array}{c}\text { Activity of } \\
\text { Water at } 37.8^{\circ} \mathrm{C} \\
\left(100^{\circ} \mathrm{F}\right)\end{array}$ & $\begin{array}{c}\text { Vapor Pressure } \\
(\mathrm{kPa}) \text { of Pure Glycol } \\
\text { at } 37.8^{\circ} \mathrm{C}\left(100^{\circ} \mathrm{F}\right)\end{array}$ \\
\hline Ethylene Glycol (62) & $145(0.9)$ & 0.27 & 0.30 & 0.037 \\
Diethylene Glycol & $1597(0.99)$ & 0.037 & 0.04 & \\
(106) & $85(0.9)$ & 0.35 & 0.36 & 0.0019 \\
Triethylene Glycol & $934(0.99)$ & 0.05 & 0.04 & \\
(150) & $60(0.9)$ & 0.33 & 0.36 & 0.000092 \\
Tetraethylene Glycol & $660(0.99)$ & 0.04 & 0.09 & \\
(194) & $46(0.9)$ & 1.04 & 0.76 & 0.0000049 \\
Propylene Glycol (76) & $510(0.99)$ & 0.21 & 0.12 & 0.05 \\
\hline
\end{tabular}

Relationship between molality, $\mathrm{m}$ (mol of solute/kg of water) and mass fraction, $\mathrm{x}$. $m=\frac{(x / M) 1000}{1-x}$ where $\mathrm{M}$ is the molecular weight of the solute.

$x=\frac{m}{1000 / M+m}$

the effect of this concentration range on the properties of the glycols, activity values are listed for two concentrations for each $(90 \%$ and $99 \%$ glycol). The molality values are also listed for consistency with Table 20 . It is observed that the activity is a strong function of concentration. This effect, which is also present when inorganic desiccants are used, is amplified with the glycols because they are used at concentrations approaching pure desiccant where the largest changes occur.

Viscosity, $\mu$, is key because of the role it plays in mass transfer through its effects on diffusion and its effects on system performance. A simple model of binary diffusion in a liquid results in $D_{A B} \propto \frac{1}{\mu}$. Thus higher viscosity tends to retard mass transfer significantly. Another negative effect of higher viscosity is the effect on film thickness, $\delta$, of the liquid on either heat-transfer surfaces or packing material. Film thickness varies as $\delta \propto \mu^{1 / 3}$. The film thickness plays a major role in the distribution of liquid within a packed bed. High viscosity tends to hold up liquid in the bed, which complicates design by promoting flooding at lower flow rates. For a spray tower configuration, the droplet size and film thickness on the heat-transfer tubes is dependent on viscosity. These effects can be significant, making viscosity a key design variable for any liquid desiccant system.

Corrosion is a major design stumbling block in the proposed LDDS design. Most of the saltbased desiccants (with the exception perhaps of lithium nitrate) are highly corrosive to steel and most other common metals. Lithium bromide is used successfully in absorption chillers only because they are hermetically sealed. Absorption chillers that undergo maintenance procedures that cause air introduction usually degrade rapidly because of corrosion. Lithium chloride liquid desiccant systems experience rapid corrosion of all metal parts exposed to the liquid. The most recent designs utilize 
polymer components to minimize these effects. Corrosion inhibitors are not expected to provide much help in the presence of excess oxygen as is the case in the LDDS design. There are two design options to deal with corrosion. The first is to choose a desiccant, such as lithium nitrate or triethylene glycol, that does not participate readily in corrosion. The drawback of this approach is that these desiccant choices have a relatively higher water vapor pressure (and in the case of the glycol, a nonnegligible partial pressure of the desiccant); therefore, the corrosion benefit must be weighed against the costs. The second design option is to use the best liquid desiccant (e.g., lithium bromide) and to put design resources into the task of minimizing or eliminating liquid carryover. The key design variable here is flue gas face velocity through the absorber. If the face velocity is kept low, then the entrained droplet size is small. If the absorber is designed so that splashing is minimized, then the creation of airborne droplets will be small. A combination of these features is needed to make the more corrosive salts practical for the LDDS.

Environmental release of chemicals is a concern whenever a new system is readied for permitting. For the salt-based systems, it can likely be argued that there would be zero release. However, for the glycol systems, the vapor pressure of the glycol in the absorber means that there will be continuous loss of glycol to the flue gas as it passes through the absorber. This is dependent on the vapor pressure of the glycol, and estimates of the expected release are included in the next section.

For the inorganic desiccant candidates, several choices are indicated in Table 20 that have low activity values. These include a number of strong acids $\left(\mathrm{HCl}, \mathrm{HBr}, \mathrm{HClO}_{4}\right)$ and strong bases $(\mathrm{NaOH}$, $\mathrm{KOH}$ ). For material handling considerations, the strong acids and strong bases are considered impractical in the LDDS application. Of the remaining choices with low activity values, $\mathrm{LiBr}, \mathrm{LiCl}$, $\mathrm{LiNO}_{3}$ and $\mathrm{CaCl}_{2}$ (in order of drying capability) appear to have promise:

- Lithium bromide (LiBr) - exhibits very low activity but high corrosivity and high cost. This choice would yield the largest amount of recovered water.

- Lithium chloride ( $\mathrm{LiCl}$ - - LiCl has a higher activity than $\mathrm{LiBr}$, but it is less corrosive. As such, $\mathrm{LiCl}$ is used in many liquid desiccant applications in the HVAC (heating, ventilating, and air-conditioning) industry.

- Lithium nitrate $\left(\mathrm{LiNO}_{3}\right)-\mathrm{LiNO}_{3}$ has significantly lower drying capability than $\mathrm{LiBr}$, but relatively high cost.

- Calcium chloride $\left(\mathbf{C a C l}_{2}\right)-\mathrm{CaCl}_{2}$ has similar drying capability as $\mathrm{LiNO}_{3}$, similar corrosion characteristics as $\mathrm{LiCl}$, but extremely low cost.

The family of ethyl and propyl glycols are the primary organic desiccant candidates because they have a good mix of properties, including 1) a strong affinity for water and, hence, a low partial pressure of water and 2) a low vapor pressure of the pure desiccant. In addition, the glycols have very low corrosivity, making them attractive, but high viscosity reduces performance. The main candidates along with their primary uses are: 
- Ethylene glycol - used for low-temperature applications such as frost elimination in freezers.

- Propylene glycol - used in food and pharmaceutical manufacturing because of its combination of low toxicity and acceptable performance.

- Triethylene glycol - used in high-temperature applications because it has a much lower vapor pressure than either of the two mentioned above while maintaining acceptable performance. Note that tetraethylene glycol has a lower vapor pressure than triethylene glycol, but its water activity is much higher, making it a poor choice as a desiccant.

One concern about the glycols is the amount of loss out the stack with the flue gas because of evaporation in the absorber. An estimate of this loss is provided in Table 22 . The calculation is based on the $100^{\circ} \mathrm{F}\left(38^{\circ} \mathrm{C}\right)$ vapor pressure data in Table 21 which is used to estimate the mole fraction of glycol in the gases leaving the absorber. The mole fraction is then used to estimate a mass fraction which is applied to the nominal flue gas flow rate taken from the natural gas column in Table 20 . The results show that the amount of glycol lost depends strongly on which glycol is being used. Triethylene glycol appears to represent a preferred choice since it exhibits both a low water activity and a low mass loss. Tetraethylene glycol has a lower vapor pressure and, hence, a lower mass loss, but it has poor water activity.

The issue of glycol loss has two facets. On the one hand, the cost of the glycol must be considered since any loss must be made up. At approximately $\$ 0.5 / \mathrm{lb}$, the cost issue might be significant for some of the glycols but appears to be in an acceptable range for triethylene glycol. The other side of the glycol loss issue is the potential for environmental damage because of the release. This issue is strongly connected to the amount of the release, and triethylene glycol looks like a reasonable candidate again.

Table 22. Estimate of Glycol Loss in Flue Gas

\begin{tabular}{lcccc}
\hline Glycol & Mole Faction & Molecular Weight & Mass Fraction & Mass Loss, lb/hr \\
\hline Ethylene & 0.00037 & 62 & 0.000793435 & 2931.7 \\
Diethylene & 0.0000186 & 106 & $6.82181 \mathrm{E}-05$ & 252.1 \\
Triethylene & 0.00000092 & 150 & $4.77507 \mathrm{E}-06$ & 17.6 \\
Tetraethylene & 0.000000049 & 194 & $3.28927 \mathrm{E}-07$ & 1.2 \\
Propylene & 0.0005 & 76 & 0.001313808 & 4854.5 \\
\hline
\end{tabular}

Calculate mole fraction ( $\mathrm{fg}$ - flue gas)

$x_{n, g l y c o l}=\frac{P_{g l y c o l}}{P_{f g}}$

Calculate mass fraction

$x_{m, g l y c o l}=\frac{x_{n, g l y c o l}}{x_{n, \text { glycol }}+\left(1-x_{n, \text { glycol }}\right) M_{f g} / M_{\text {glycol }}}$

Calculate mass loss

$\dot{m}_{g l y c o l}=\dot{m}_{f g} x_{m, g l y c o l}$ 
The choice of the best desiccant is dependent on a number of properties of the desiccant as already discussed. A summary of the key properties for the most promising candidates is presented in Table 23. To create a systematic selection process, these data were distilled into a set of "Design Factors" as shown in Table 24. The Design Factors represent an attempt to create a relative ranking, between the desiccant options, for each characteristic. This ranking is recognized as subjective. The ranking is used to arrive at a final desiccant selection by applying a weight to each factor and then summing the weighted factors for each desiccant option. The desiccant with the highest sum is, in some sense, the best desiccant choice. In addition to the subjective nature of the Design Factors, the choice of weights is subjective.

Three weighting scenarios are calculated and listed in the last three columns of Table 24 . The first uses uniform weights, and it results in the choice of calcium chloride as the best desiccant, although a more accurate interpretation of the uniform weighting result is that each of the desiccant choices included in Table 24 has one strong Design Factor, but none has a clear and overwhelming advantage when the Design Factors are treated uniformly.

The second weighting scenario puts a premium on the cost of the desiccant. This scenario, shown in the second-to-last column of Table 24, gives the desiccant cost factor a weight of 2 while keeping all of the other weights at 1 . Interestingly, calcium chloride rises to the top again, and this time the difference appears more significant. If desiccant cost is a major factor in the decision, then calcium chloride's low cost becomes a dominating decision point.

The third weighting scenario puts a premium on the drying potential/system size. This factor is meant to include the drying performance of the desiccant as well as the system size aspects associated with viscosity. In this case, the weighting factor on the drying potential/system size factor was set at 3 while the others were set at 1 . The interesting observation about this scenario is that the design choice does not seem to be very sensitive to the weight of this factor. This is apparently because of the choices made in assigning the values for the factors. Because of the subjective elements in this selection process, the significance of this observation is not very clear.

- Five candidate liquid desiccants were identified as showing promise in the LDDS application. These candidates, which are summarized in Tables 23 and 24, are lithium bromide, lithium chloride, lithium nitrate, calcium chloride, and triethylene glycol. Each of these candidates has clear strengths and weaknesses.

Table 23. Characteristics of Potential Liquid Desiccants at $37.8^{\circ} \mathrm{C}$

\begin{tabular}{lccccc}
\hline Desiccant & $\mathrm{P}(\mathrm{kPa})$ & $\mu .10^{3}\left(\mathrm{~N}-\mathrm{s} / \mathrm{m}^{2}\right)$ & Corrosivity & Cost $(\$ / \mathrm{b})$ & Environmental Impact \\
\hline 63.5\% Lithium Bromide & 0.4 & 7.8 & Severe & 2.5 & Minimal \\
45\% Lithium Chloride & 0.91 & 9 & Significant & 0.8 & Minimal \\
58\% Lithium Nitrate & 1.3 & $3.5^{1}$ & Mild & 0.8 & Minimal \\
45\% Calcium Chloride & 1.84 & 12 & Significant & 0.05 & Minimal \\
95\% Triethylene Glycol & 1.32 & 21 & Negligible & 0.5 & Minimal \\
\hline
\end{tabular}

'Extrapolated from available data.

${ }^{2}$ Corrosion characteristics of lithium nitrate extrapolated from its use as a corrosion inhibitor in absorption refrigeration. 


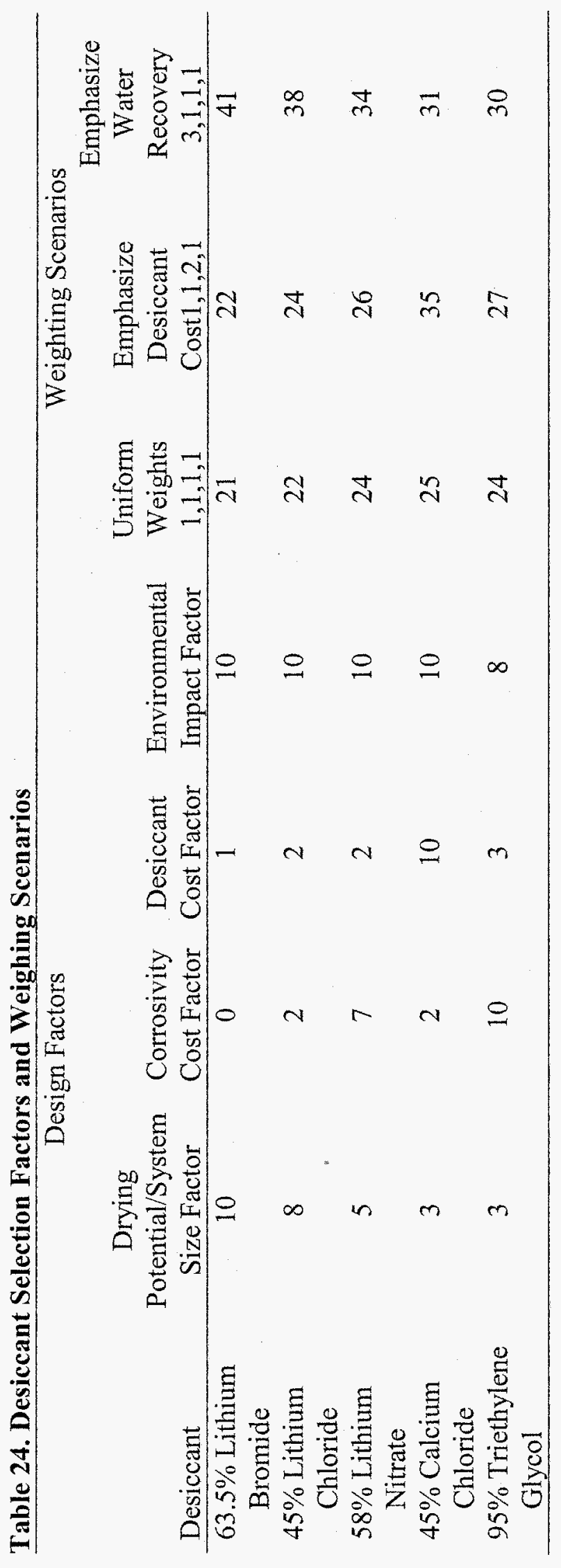


- Three of the salts $\left(\mathrm{LiBr}, \mathrm{LiCl}\right.$, and $\left.\mathrm{CaCl}_{2}\right)$ are expected to exhibit severe corrosion of all common metals. This aspect impacts cost through the need for low face velocity to reduce carryover and/or exotic materials to withstand corrosion. Although $\mathrm{LiBr}$ is probably the worst choice from a corrosion standpoint, the other two salts are also expected to aggressively attack most metals on contact.

- The strength of lithium bromide is its strong drying capability as the desiccant with the lowest partial pressure of water. This characteristic could have a significant impact on system performance and/or cost since it will allow more water recovery than other desiccant choices for the same equipment size or will allow smaller equipment size for the same water recovery rate. The weakness of lithium bromide is desiccant cost as it is the most expensive of all the desiccant materials.

- Based on the design factor analysis, lithium chloride appears very similar to lithium bromide as far as strengths and weaknesses.

- The strength of lithium nitrate is the potentially low corrosivity. This characteristic should be confirmed in bench-scale tests to clarify the potential of lithium nitrate. However, the cost of lithium nitrate is still a significant weakness. Thus if material cost is considered a major factor, then it may overwhelm the corrosion advantage.

- The strength of calcium chloride is its low material cost. At 1/20 of the cost of lithium chloride, the cost difference is very significant. Unfortunately, calcium chloride has weak drying potential, which implies a reduction in the cost advantage because of increases in system size to achieve a particular level of water recovery.

- The strength of triethylene glycol is on the corrosion issue. It has drying potential similar to or possibly a little better than calcium chloride but no corrosion. Thus overall system cost of a glycol-based system may be less since there is no need for exotic materials.

- A major issue in the design is zero carryover of desiccant liquid with the flue gas exiting the absorber. The major design variable that impacts carryover is flue gas velocity through the absorber. Typical absorber face velocities are in the range $250-500 \mathrm{ft} / \mathrm{min}$ or 4-8 ft/sec $(1.2-$ $2.4 \mathrm{~m} / \mathrm{sec}$ ), implying a very large absorber cross-sectional face area for the large flue gas flow rate from a power plant. On the positive side, the low face velocities imply very little pressure drop in the absorber.

The review of the available information on desiccants in conjunction with the weighting scheme led to the selection of three desiccants to be tested in the EERC CEPS. They were lithium bromide, calcium chloride, and triethylene glycol. The three desiccants have a good mix of qualities for the bench-scale testing. The lithium bromide has the lowest vapor pressure and greatest ability to recover water from the gas stream but is also the most expensive. The triethylene glycol is the best candidate of the glycols but may have carryover issues, and the calcium chloride is the least expensive while maintaining good recovery potential. The inorganic salt desiccants chosen for further evaluation have potential corrosion issues. Additives used in industry to reduce the 
corrosivity of these desiccants were investigated, but it was determined they would be ineffective in this application. All three desiccants chosen have unique beneficial qualities as well as challenges to overcome. System performance at the bench scale was used to aid in determining which desiccant would be best suited for further evaluation. The tests were performed with a recirculating spray of liquid desiccant in a flue gas generated in the CEPS and the desiccant assayed by $\mathrm{pH}$, specific gravity, and visual examination.

\subsubsection{Bench-Scale Desiccant Testing}

The purpose of the bench-scale testing was to evaluate at a coarse level the interaction of selected desiccants with actual flue gas and combustion ash. The information from this bench-scale testing was used to then make a final selection of a desiccant for testing in the larger pilot-scale system. The design of the pilot-scale system would depend to a limited degree on the particular desiccant selected.

\subsubsection{Water Removal}

Figures 16 and 17 illustrate the amount of moisture the desiccants were removing during the CEPS absorber testing of $\mathrm{CaCl}_{2}, \mathrm{TEG}$, and $\mathrm{LiBr}$ while combusting natural gas and a PRB coal. Each graph shows from 10 to 20 minutes of data prior to introducing the desiccant to the flue gas. This illustrates the amount of available moisture in the flue gas. In the $\mathrm{CaCl}_{2}$ and $\mathrm{LiBr}$ results for the natural gas testing at the end of the test period of 3 hours, the absorber was bypassed, and the graph shows the moisture levels climbing back to pretest levels. In the TEG natural gas test and for all three coal combustion tests, the fuel was shutdown at the end of the test, and the graph reflects this by approaching $0 \%$ moisture levels of the compressed air input. As expected, the lower the vapor pressure of the desiccant, the more moisture was removed from the flue gas. The two precipitous drops in the moisture values for the TEG test with natural gas in Figure 16 are when the system was open to atmosphere to remove and clean spray nozzles that became plugged during the test. As stated previously, nozzle plugging was determined to be oxidized Fe from the system. This occurred only during initial testing; after the oxidized Fe particles were removed, this was no longer an issue. The $\mathrm{CaCl}_{2}$ exhibits a $21 \%$ drop in moisture of the flue gas, the TEG a $50 \%$ reduction, and the $\mathrm{LiBr}$ shows a $70 \%$ reduction in the flue gas moisture content. Figure 17 shows the tests of the desiccants with coal combustion flue gas. It is presumed that the increase in the moisture content in the $\mathrm{CaCl}_{2}$ test at the start is from an increase in the moisture content of the feed coal. In general, the trend remains the same as seen in the natural gas runs with the moisture removal increasing in the expected progression of the desiccants.

\subsubsection{Gas Analysis}

The graph in Figure 18 shows the $\mathrm{CO}_{2}$ levels as a volume percent of the natural gas combustion flue gas at the outlet of the absorber. The combustion data reflect the flue gas without passing through the absorber. This occurred when the absorber was bypassed between tests of the $\mathrm{CaCl}_{2}$ and TEG to empty the absorber tank, rinse it, and refill with the new desiccant. The pre- $\mathrm{LiBr}$ comb. data reflect the combustion of natural gas on the second day of testing prior to passing the flue gas through the absorber. During this time, the desiccant was preheating, and instruments were being 


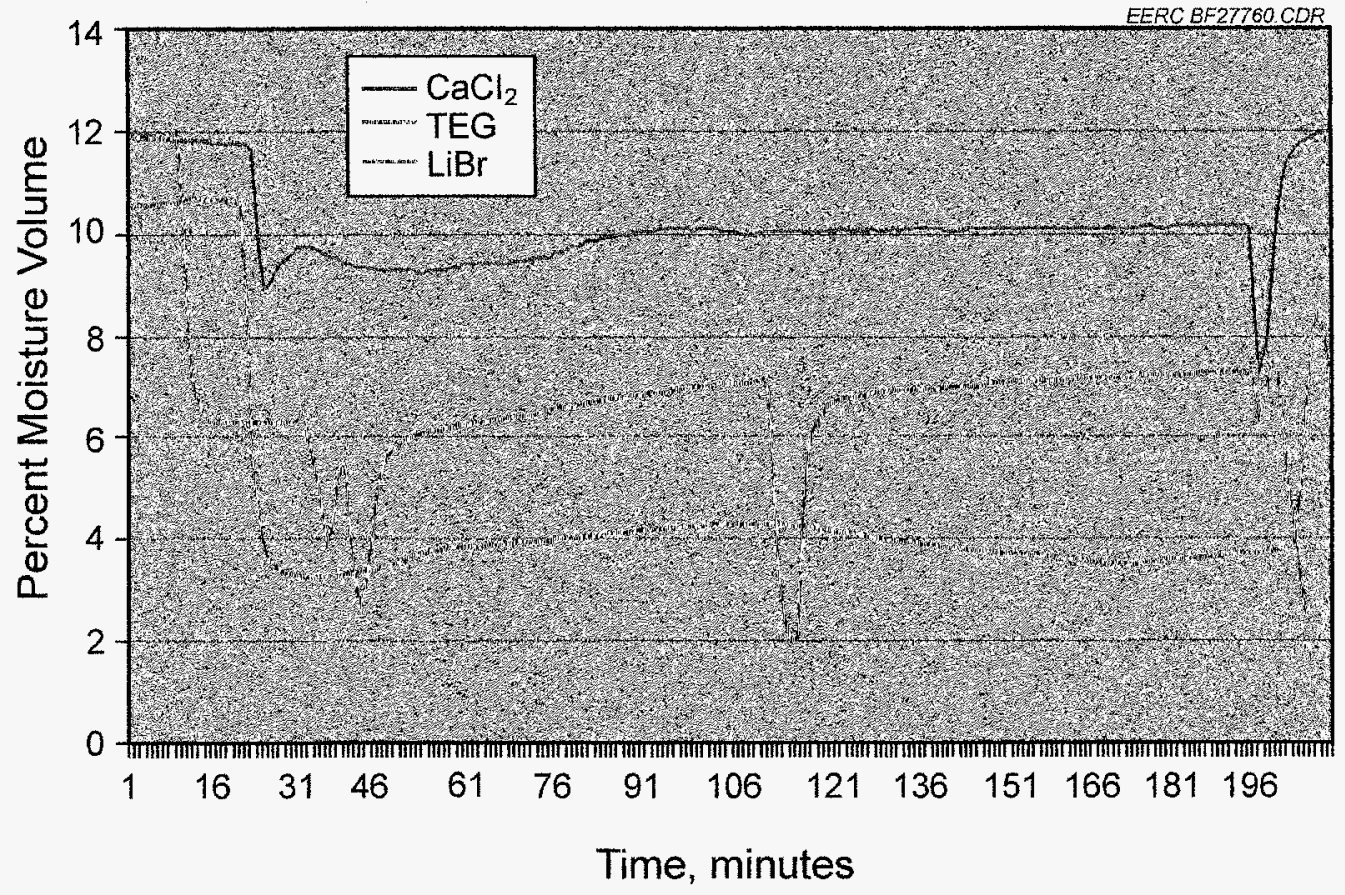

Figure 16. Percent moisture reduction using the CEPS absorber desiccant system combusting natural gas.

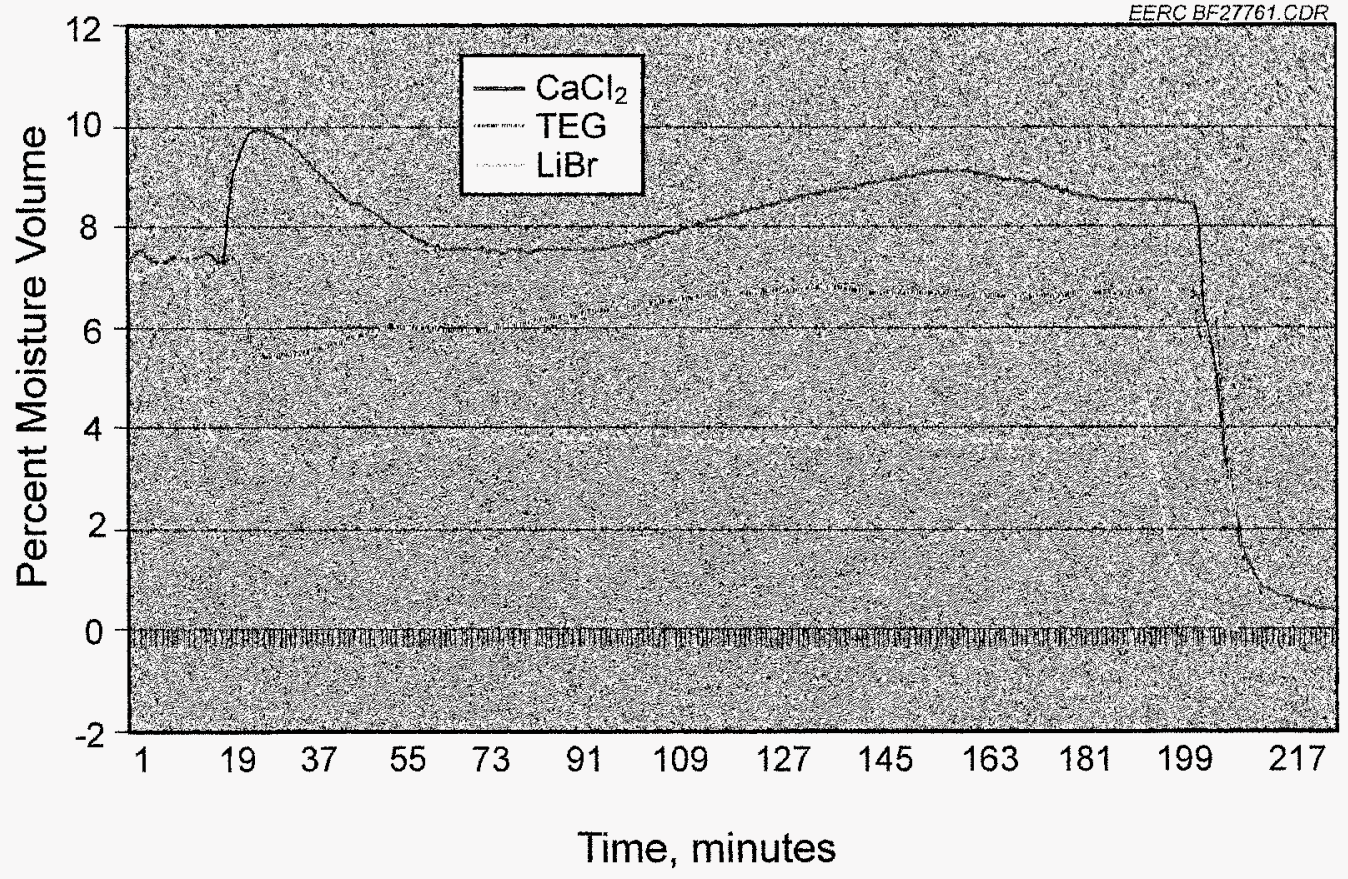

Figure 17. Percent moisture reduction using the CEPS absorber desiccant system combusting a PRB coal. 
calibrated. The large dips in the TEG data once again reflect the removal and cleaning of spray nozzles during the test, which open the absorber to the atmosphere. The data for the $\mathrm{CaCl}_{2}$ and TEG indicate little interaction of the desiccant with the flue gas from the natural gas combustion. $\mathrm{The} \mathrm{LiBr}$ data show a marked decrease in the $\mathrm{CO}_{2}$ levels upon introduction of the flue gas to the desiccant. It parallels the moisture curves in that it drops to a low upon introduction and then slowly climbs. Analysis of the desiccant described later in this report indicates that the interaction of the desiccant and the $\mathrm{CO}_{2}$ in the gas stream formed $\mathrm{Li}_{2} \mathrm{CO}_{3}$.

Figure 19 shows similar $\mathrm{CO}_{2}$ data from the coal combustion test of the desiccants. There is some variability in the system for all of the desiccants tested, with $\mathrm{CaCl}_{2}$ appearing to have a modest amount of interaction indicated by the rise of $\mathrm{CO}_{2}$ levels with time. This movement from a lower level of $\mathrm{CO}_{2}$ to a higher level over the course of the testing may be from the solution becoming less able to absorb $\mathrm{CO}_{2}$ as time goes on. This was confirmed based on pilot-scale pito data. The initially low numbers on the $\mathrm{CaCl}_{2}$ and TEG are most likely due to the system coming to equilibrium. Figure 20 shows the $\mathrm{CO}_{2}$ percentage in the flue gas when the absorber is bypassed. This gives an indication of a baseline with no contact with the desiccant stream. Prior to the $\mathrm{CaCl}_{2}$ test, the $\mathrm{CO}_{2}$ was fairly stable at $14 \%$. Once the flue gas starts running through the absorber, there is a drop in $\mathrm{CO}_{2}$ levels for a short time and then it rises to be slightly above the precombustion levels. The levels of $\mathrm{CO}_{2}$ for the TEG and $\mathrm{LiBr}$ desiccant tests appear to stay relatively the same between bypassing the absorber and passing through the absorber except for an initial drop in the case of the TEG.

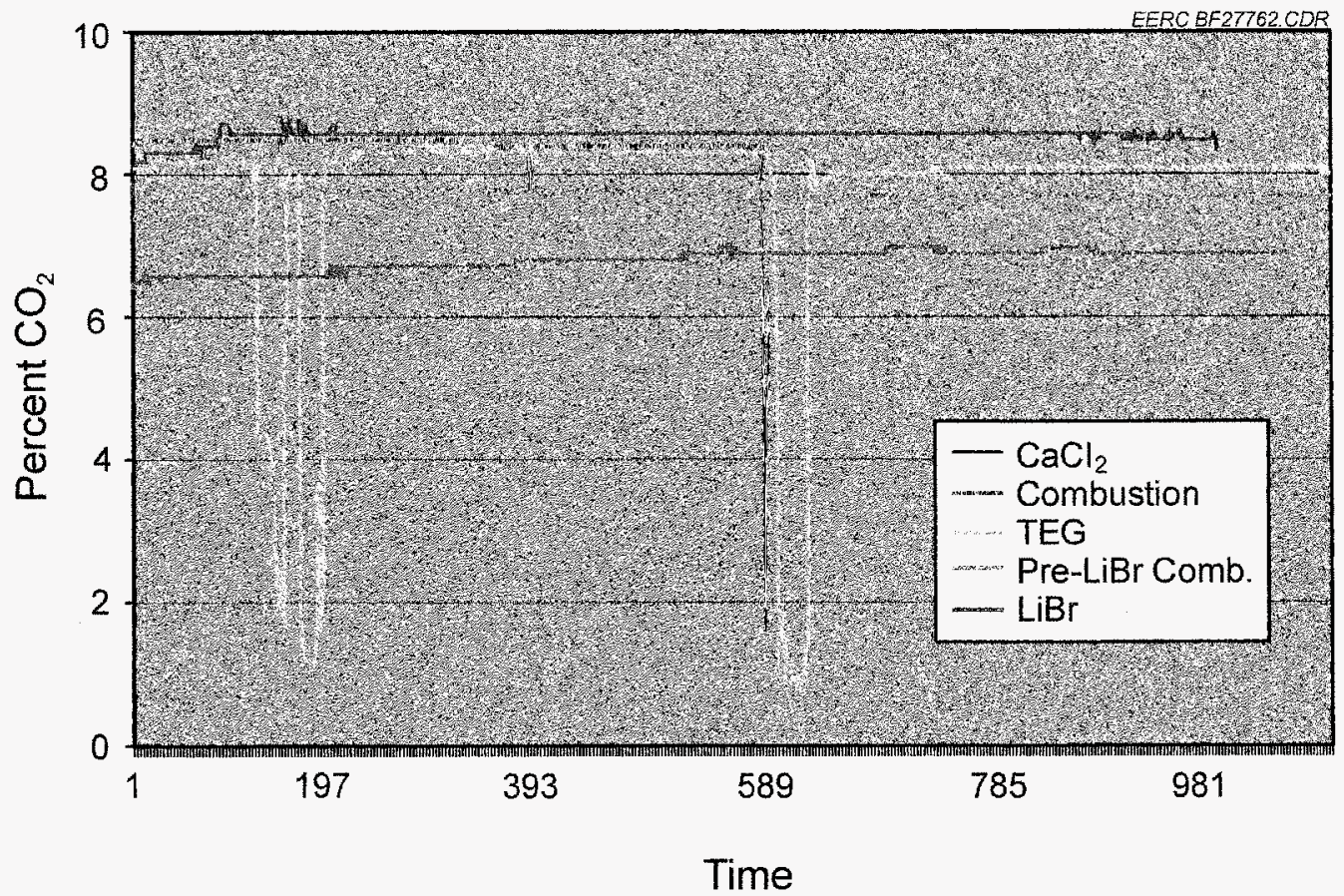

Figure $18 . \mathrm{CO}_{2}$ percent in the flue gas after the CEPS absorber when natural gas is combusted. 


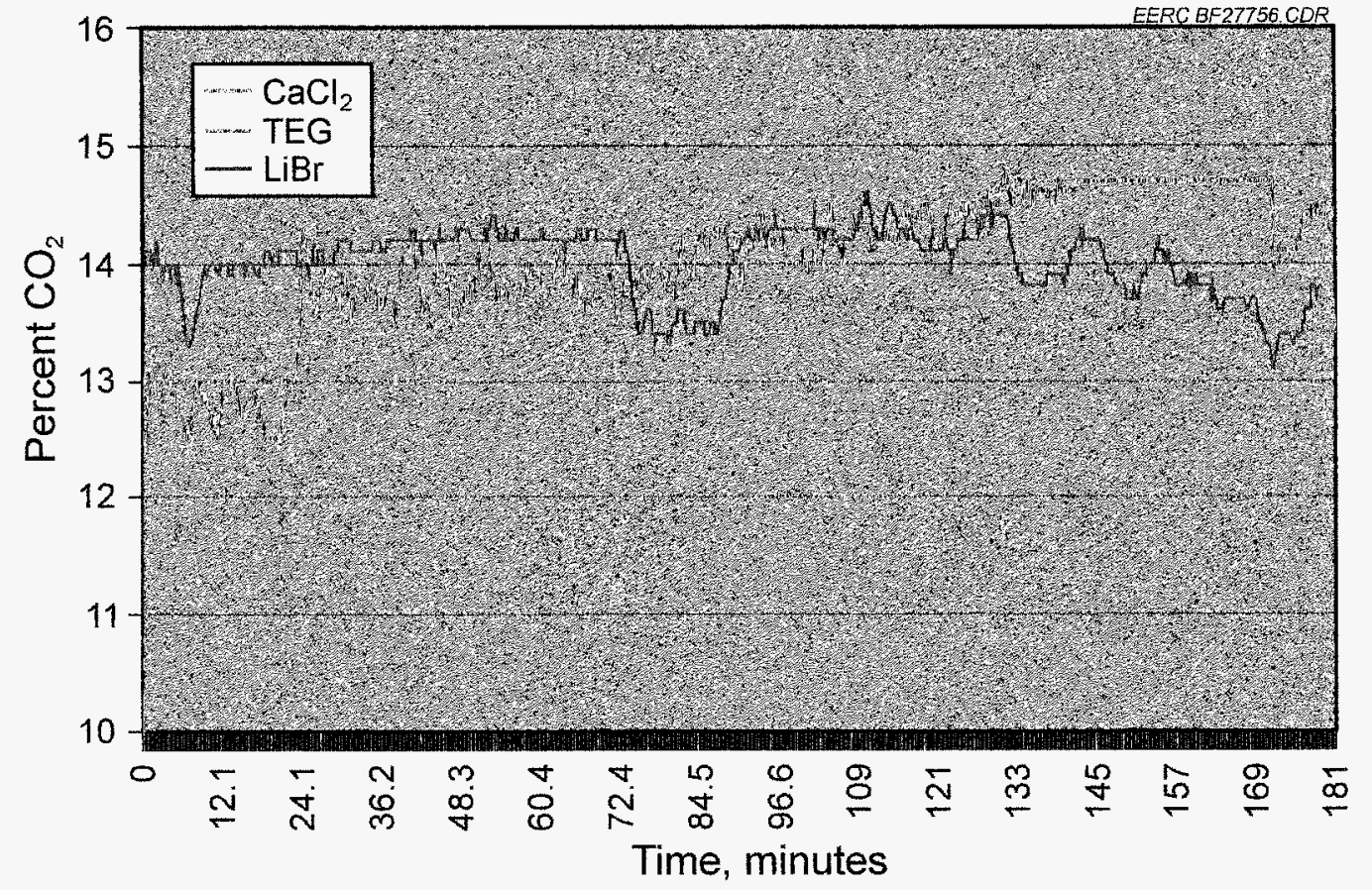

Figure 19. $\mathrm{CO}_{2}$ percent in the flue gas after the CEPS absorber when a PRB coal is combusted.

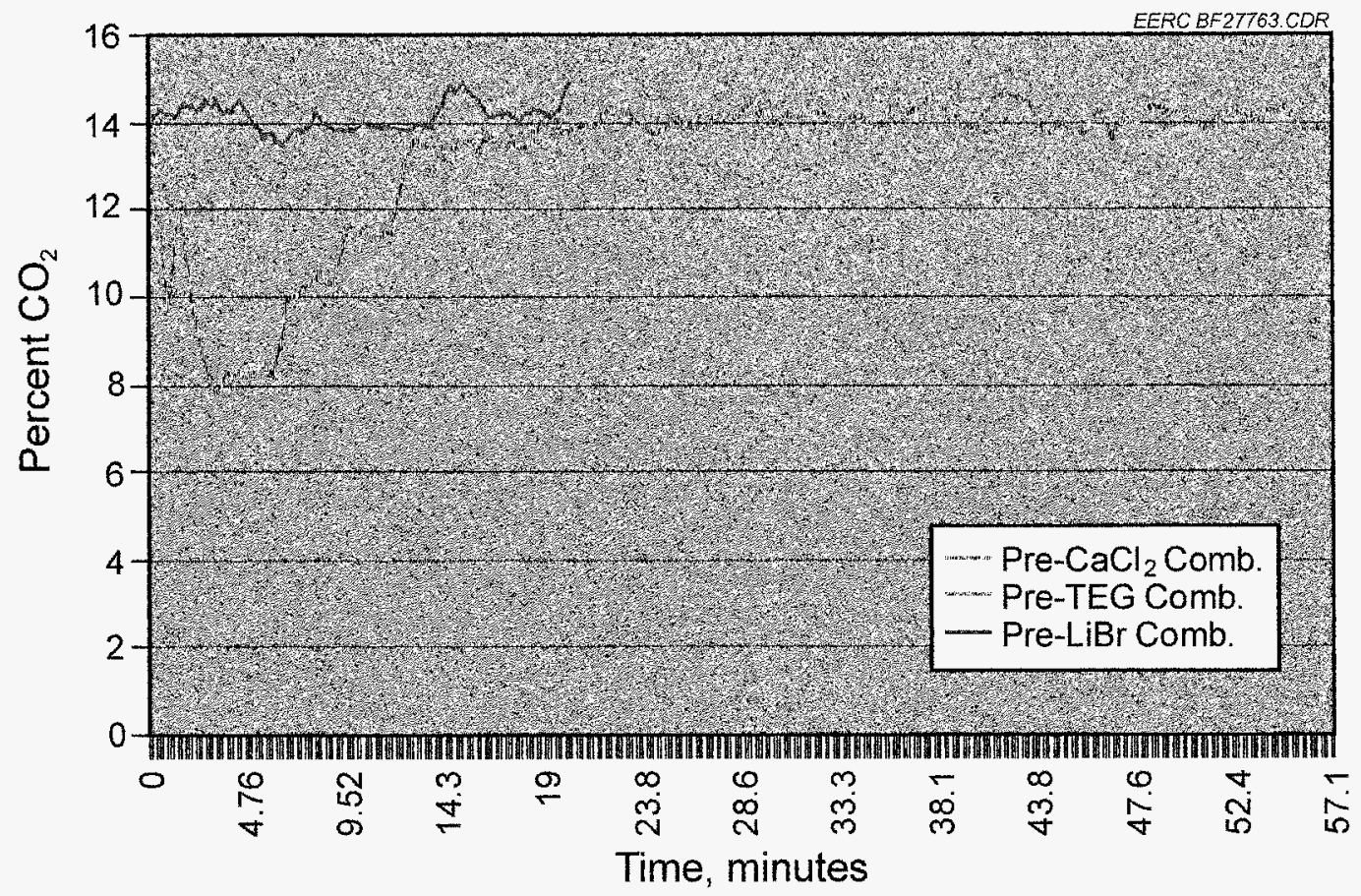

Figure 20. $\mathrm{CO}_{2}$ percent in the flue gas with no absorber when a PRB coal is combusted. 
Figures 21-23 are graphs of the $\mathrm{SO}_{2}$ levels before and after the absorber during the natural gas combustion testing. These graphs also only represent one data point every one-half hour. It was discovered after all of the testing that the $\mathrm{SO}_{2}$ monitor that sampled after the absorber was incorrectly connected to the CEPS computer, and the values posting on the display were not being logged electronically. The data shown in the figures came from records taken manually every half hour. There is some deviation between the three desiccants, but this is probably due to the variability of the $\mathrm{SO}_{2}$ as shown in Figure 24, which is the real time log of the $\mathrm{SO}_{2}$ levels in the flue gas before the absorber. There is typically very little sulfur in natural gas, and the levels being measured are very small. Desiccant solution testing explained later in this report indicates that no sulfur was absorbed in the solutions during the natural gas combustion tests.

\subsubsection{Desiccant Analysis}

Desiccant samples taken during the bench-scale combustion tests were analyzed for sulfate quantity, and those numbers are reported in Table 25. The natural gas combustion runs showed no sulfate species in the desiccant for all three desiccants as expected. The PRB coal combustion tests showed no sulfate species in the TEG but levels of $120 \mathrm{mg} / \mathrm{L}$ in the $\mathrm{CaCl}_{2}$ solution and $200 \mathrm{mg} / \mathrm{L}$ in the $\mathrm{LiBr}$ solution. Longer duration testing needs to occur to determine if this sulfated material will become problematic. The last desiccant samples taken at the end of the tests during coal combustion for the $\mathrm{LiBr}$ and $\mathrm{CaCl}_{2}$ formed precipitates after a day of inactivity on the laboratory bench. These precipitates were collected as a slurry in a ceramic boat and subsequently dried. X-ray diffraction of the $\mathrm{LiBr}$ precipitate showed a $\mathrm{CaS}$ phase, oldhamite, as the predominate phase other than lithium bromide hydrate. Several minor phases were also found. They were zaubuyelite $\left(\mathrm{Li}_{2} \mathrm{CO}_{3}\right)$, calcium

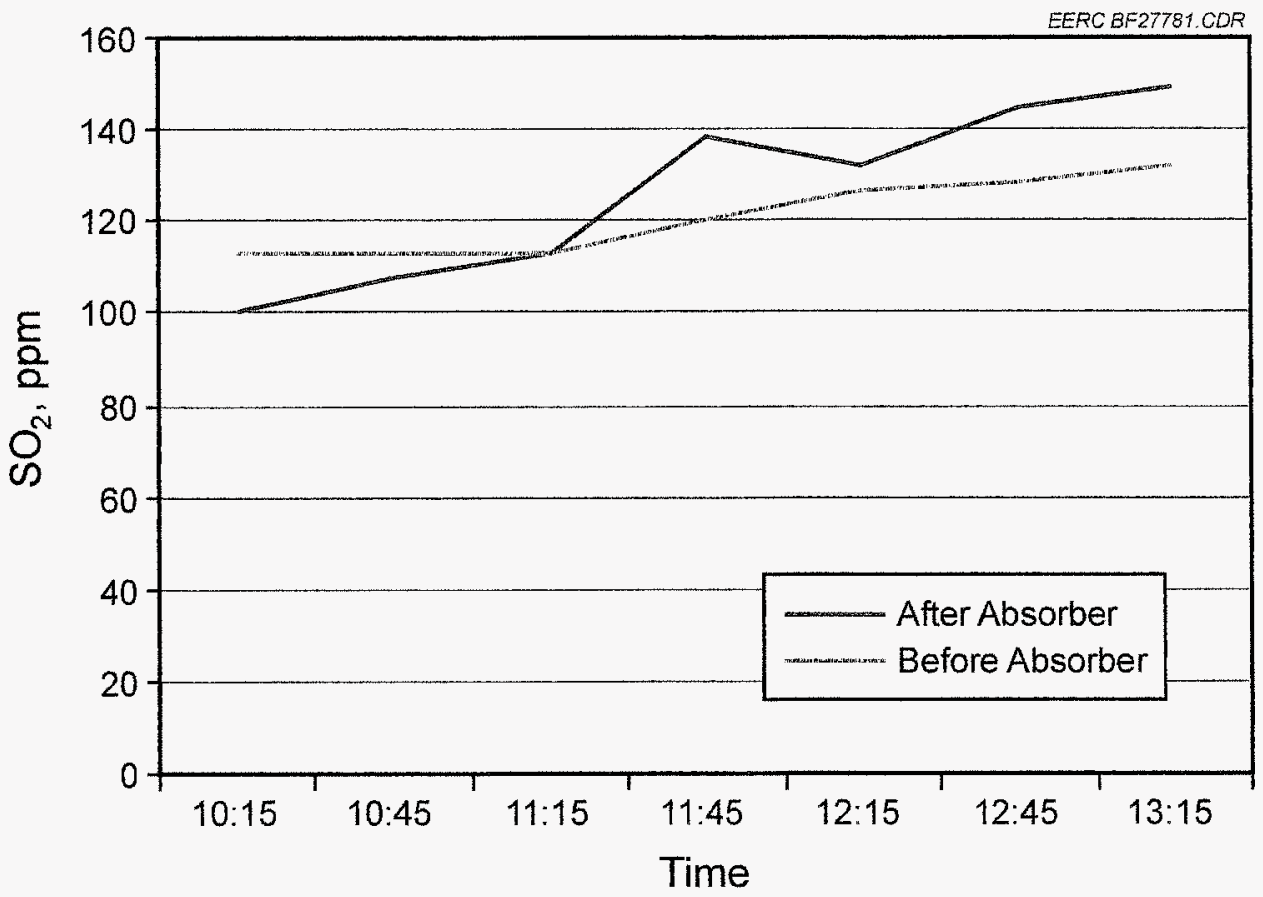

Figure 21. $\mathrm{SO}_{2}$ in the flue gas before and after the absorber with $\mathrm{CaCl}_{2}$. 


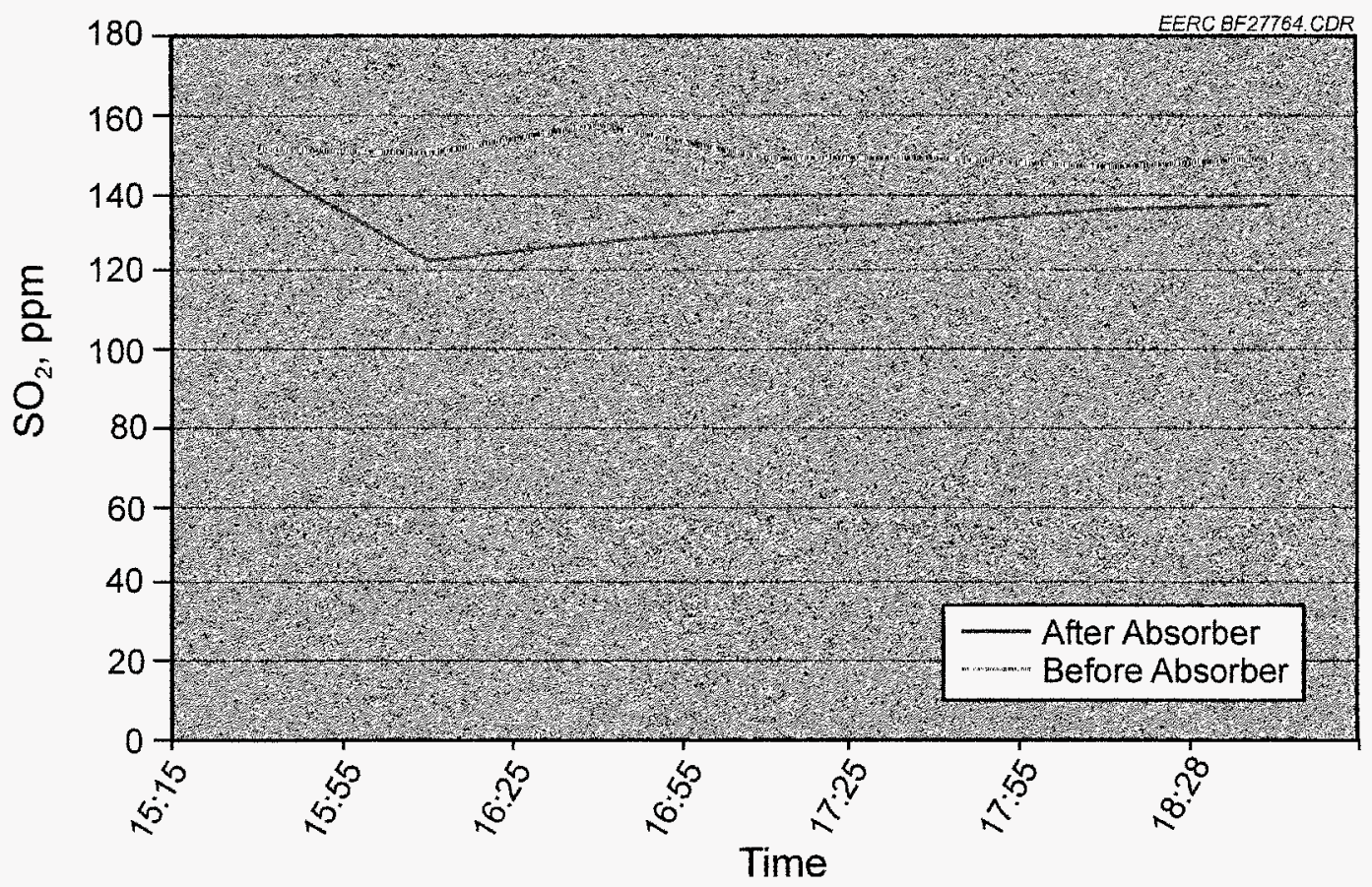

Figure $22 . \mathrm{SO}_{2}$ in the flue gas before and after the absorber with TEG.

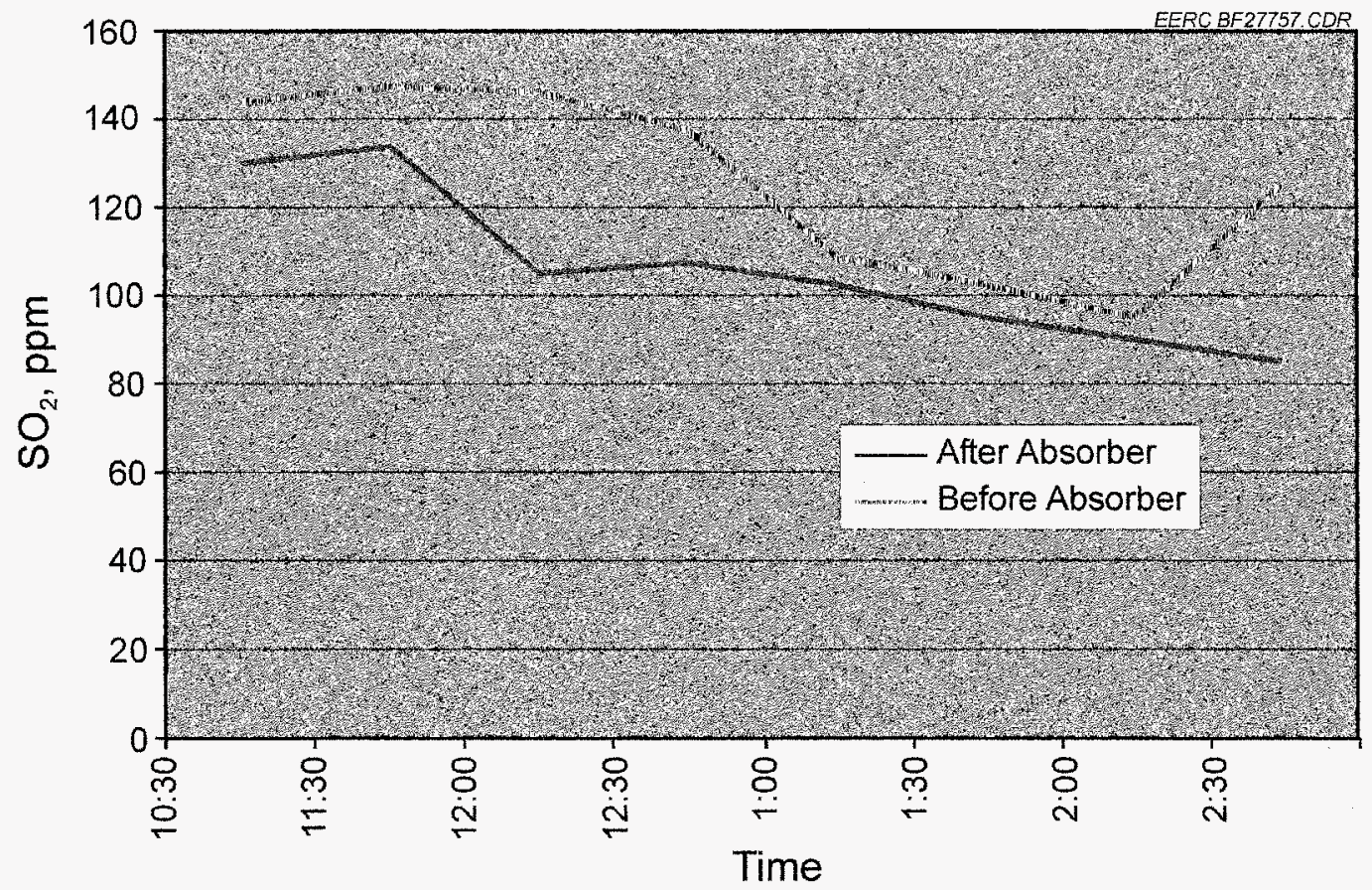

Figure $23 . \mathrm{SO}_{2}$ in the flue gas before and after the absorber with $\mathrm{LiBr}$. 


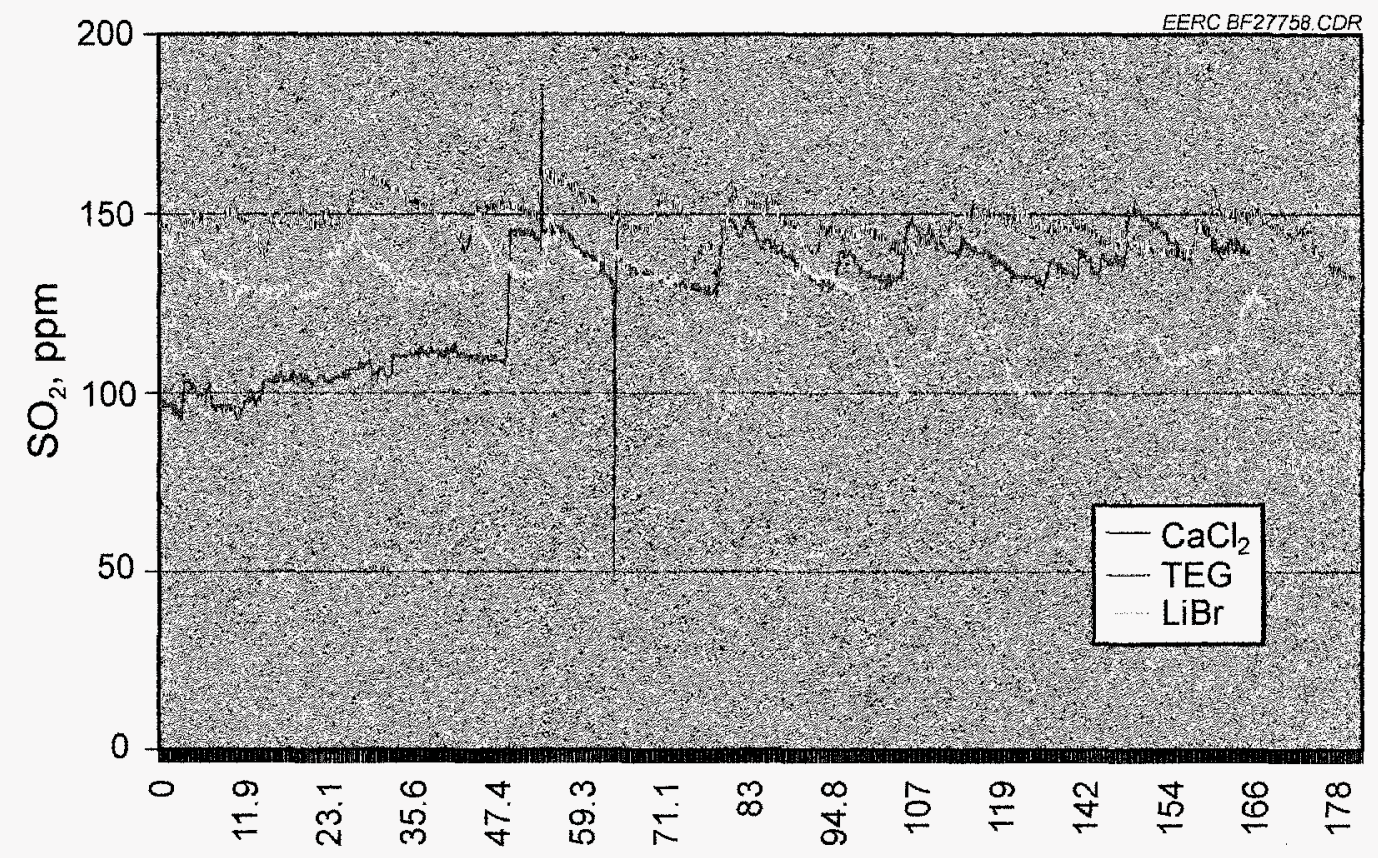

Time, minutes

Figure 24. $\mathrm{SO}_{2}$ levels in the flue gas prior to the absorber when natural gas is fired.

Table 25. Level of Sulfates in Solution for Combustion Tests, $\mathrm{mg} / \mathrm{L}$

\begin{tabular}{lccc} 
& $\mathrm{CaCl}_{2}$ & $\mathrm{TEG}$ & $\mathrm{LiBr}$ \\
\hline Natural Gas & $\mathrm{ND}^{*}$ & $\mathrm{ND}$ & $\mathrm{ND}$ \\
Antelope Coal & 120 & $\mathrm{ND}$ & 200 \\
\hline
\end{tabular}

* Not detectable.

silicate $\left(\mathrm{Ca}_{2} \mathrm{SiO}_{4}\right)$, and strontium sulfate $\left(\mathrm{SrSO}_{4}\right)$. The lithium carbonate phase was expected per conversations with desiccant industry personnel. The calcium silicate phase is a typical phase found in PRB coal combustion ash and is not unexpected. The strontium sulfate phase is the major sulfate species identified in the solution at $200 \mathrm{mg} / \mathrm{L}$. Antelope coal has a small level of strontium and strontium minerals in low-rank coals have been found as celestite $\left(\mathrm{SrSO}_{4}\right)(\mathrm{Zygarlicke}, 1987)$. The strontium sulfate in the precipitate may have been present as either the mineral celestite and passed through the combustion system unreacted or it may have occurred in the coal as some other form of strontium and reacted with the sulfur in the system to produce this phase. This strontium sulfate phase and the calcium silicate are probably captured ash particles from the flue gas and are only present as minor phases.

The $\mathrm{CaCl}_{2}$ desiccant was analyzed with a scanning electron microscope (SEM) and $\mathrm{x}$-ray diffraction (XRD). The composition of the matrix material for both the top and bottom of the dried precipitate material varies only slightly. The bottom of the dried precipitate, however, has two distinguishing features. It contains long slender crystals as shown in Figure 25 which have been identified as a strontium chloride crystalline material. This material is present in very small 


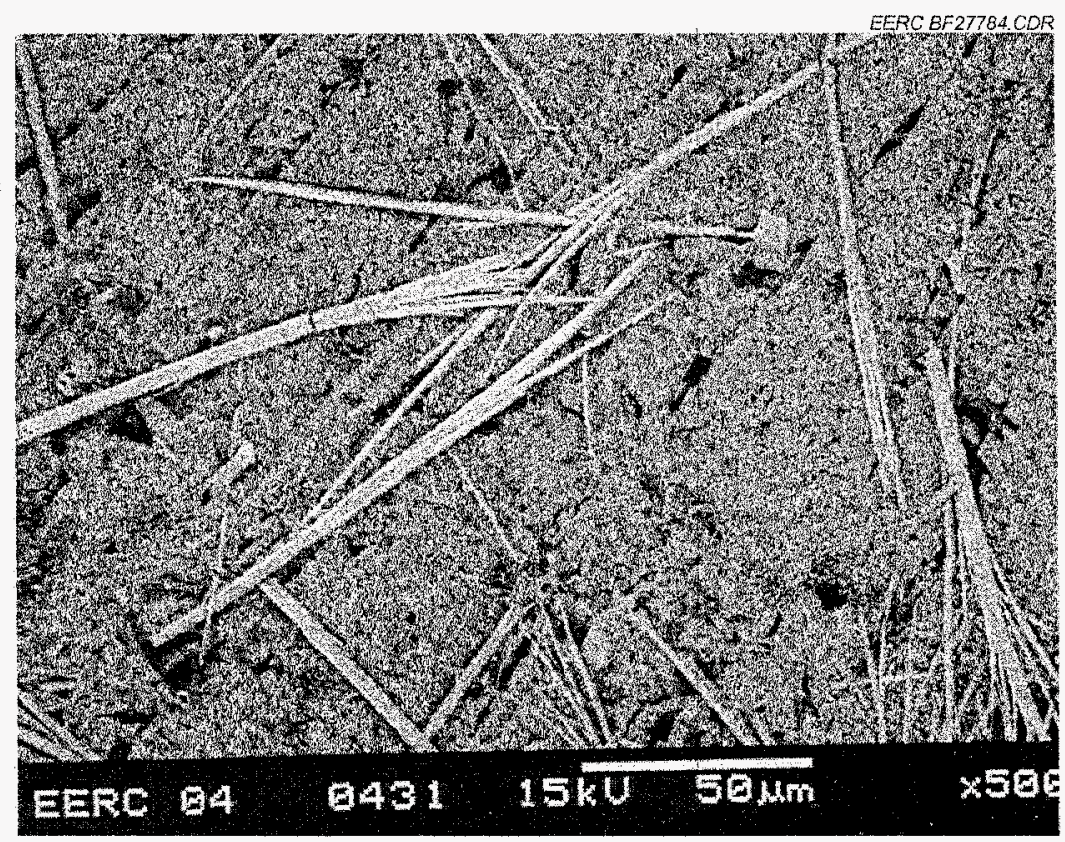

Figure 25. Low-magnification image showing strontium chloride crystals.

quantities in the analyzed precipitate. In addition, a strontium hydroxide hydrate phase $\left(\mathrm{Sr}[\mathrm{OH}]_{2} \bullet \mathrm{H}_{2} \mathrm{O}\right)$ and a strontium carbonate mineral $\left(\mathrm{SrCO}_{3}\right)$ were identified. The strontium carbonate is a low-temperature hydrothermal precipitate and can form in a solid solution series with $\mathrm{CaCO}_{3}$. The Antelope PRB coal used for this combustion test has a small amount of strontium associated with it as discussed above which has reacted with the carbon and oxygen in the solution to form this precipitate. This may or may not prove to be a problem depending on its rate of formation in solution. This was not observed in samples from Test Series I or II in pilot-scales tests. The rate of formation will not be well understood without longer-duration tests since the precipitate did not form until the solution sat undisturbed in a sample bottle and cooled.

The mercury content of the three desiccant solutions was analyzed to determine the capture level of mercury in the desiccants. The mercury levels in the three solutions for the coal and the natural gas combustion tests are listed in Table 26. Three things are quite unexpected in these results. TEG is an organic liquid that was not expected to have any capture capability for mercury from flue gas. The level of capture for the two desiccants that do sequester mercury is essentially all of the mercury that was present in the coal and, therefore, the flue gas stream. In a typical wet FGD system, which this system was designed to mimic, if the sulfur capture in the solution is $90 \%$, then the capture of the oxidized form of mercury will be approximately $90 \%$. Mercury will typically take either an oxidized form or an elemental form in the flue gas from coal combustion. The oxidized form of mercury can be controlled to a large degree using conventional control devices used in combustion systems such as wet FGD. The elemental form of mercury is much more difficult to sequester. Typically, in a PRB coal, $70 \%$ to $90 \%$ of the mercury present in the coal will be present as elemental mercury in the flue gas stream. It is, therefore, quite unusual for the system to capture essentially all of the mercury present in the coal and flue gas stream in the solutions. Upon further 
Table 26. Level of Mercury in Solution for Combustion Tests $(\mu \mathrm{g} / \mathrm{L})$

\begin{tabular}{lccl}
\hline & $\mathrm{CaCl}_{2}$ & TEG & $\mathrm{LiBr}$ \\
\hline Natural Gas & 8.03 & 6.52 & $\mathrm{ND}$ \\
Antelope Coal & 5.18 & 8.33 & $\mathrm{ND}$ \\
\hline
\end{tabular}

${ }^{\mathrm{ND}}$ Not Detectable

investigation, it was discovered that previous testing in the CEPS under a different project had been performed with mercury injection and that this mercury had condensed out in the unheated piping between the baghouse and the wet FGD. It was determined that upon heating during this test some of this deposited mercury was reemitted into the gas stream and captured in the desiccants. Therefore, no quantitative observations concerning the $\mathrm{Hg}$ data in Table 26 can be made.

The $\mathrm{pH}$ online monitoring system did not perform as well as expected in the experimental testing. The physical samples taken during the testing were analyzed for $\mathrm{pH}$ and the results shown in Figure 26 and 27 for the two combustion tests. In both combustion tests, similar results were found. The $\mathrm{CaCl}_{2}$ and the TEG pH changed little if at all during the duration of the tests while the $\mathrm{LiBr}$ started at fairly high levels and quickly equilibrated at a level similar to the other two desiccants. Because of the short duration of the test period, it is hard to determine if the $\mathrm{pH}$ can either be an indicator of solution changes that may lead to precipitation or changes in its ability to absorb moisture.

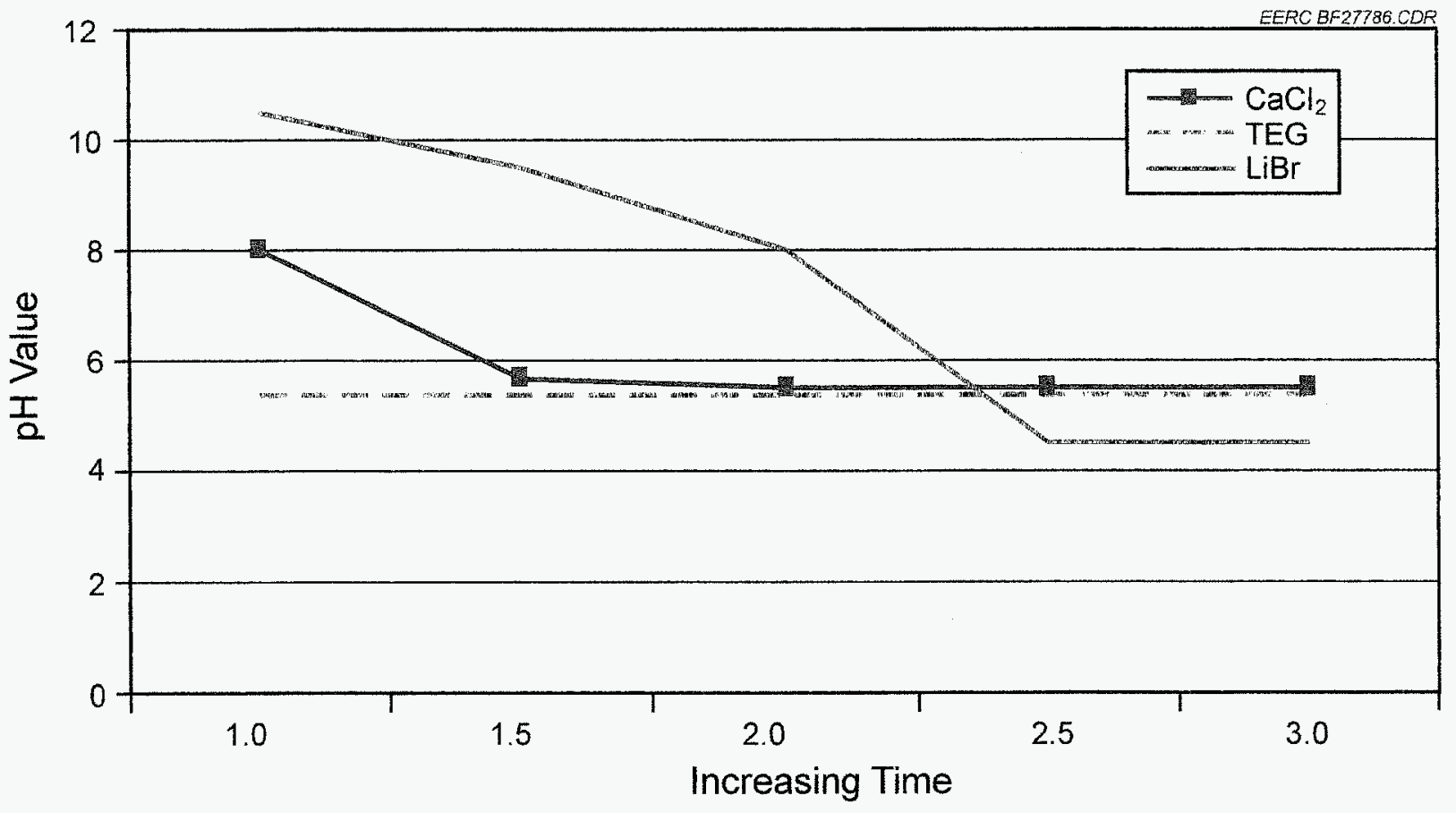

Figure 26. $\mathrm{pH}$ of desiccant samples taken during the natural gas combustion tests. 


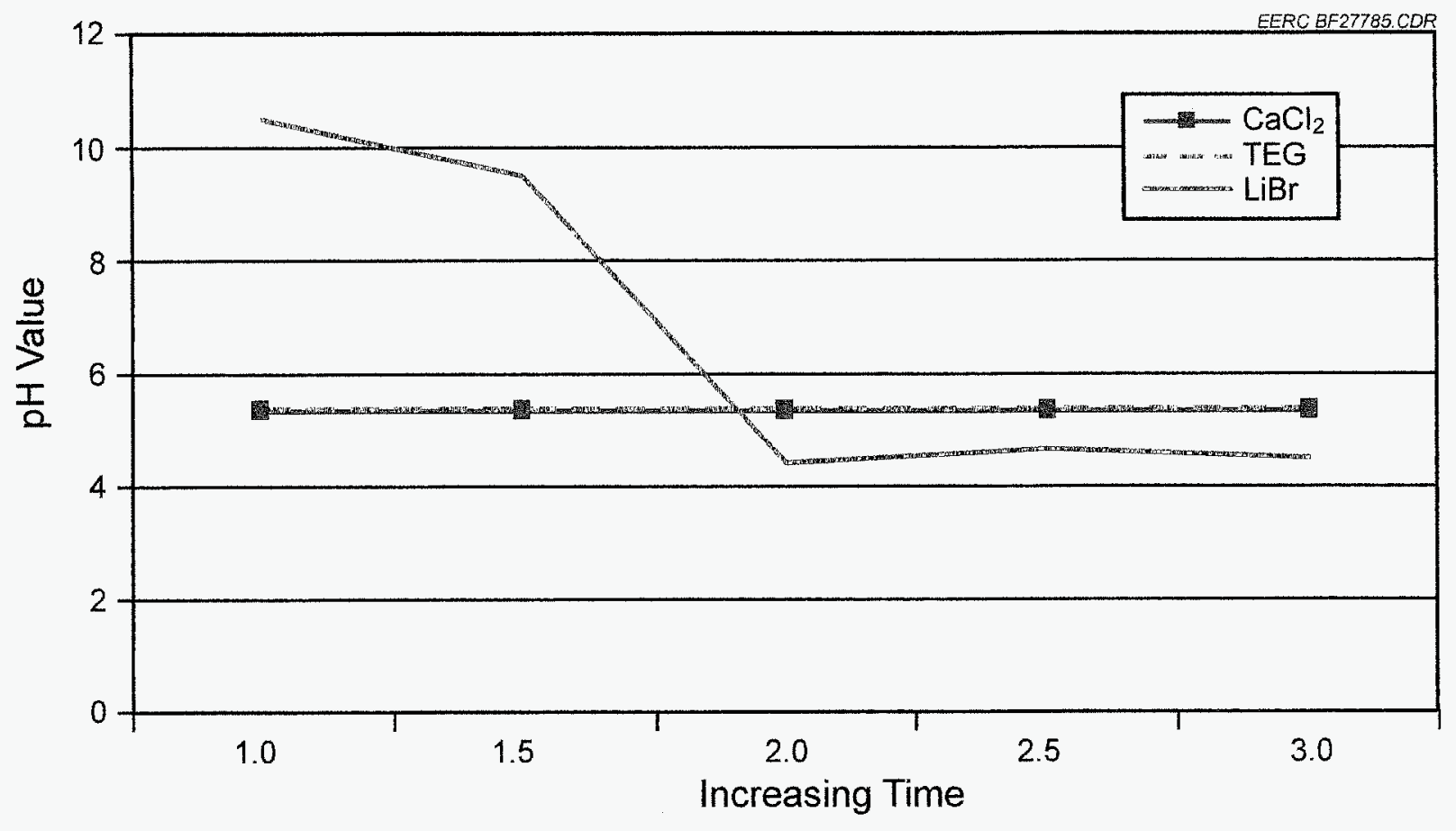

Figure 27. $\mathrm{pH}$ of desiccant samples taken during the Antelope coal combustion tests.

Analysis of the solutions for inorganics was difficult because of the high concentration of desiccant in solution. In typical analysis techniques used to analyze water solutions, the amount of solvent is generally much greater than the solute. In this case, the large amount of solute generates large peaks of intensity in the analysis that overshadowed the other much lesser amount of contaminates we were looking for such as calcium carbonate and calcium sulfate. Characteristic identification peaks of calcium carbonate and calcium chloride for instance are in very close proximity and when one is present in quantities orders of magnitude greater than another, the lesser amount of material will become difficult to identify. During the pilot-scale tests, rather than try to analyze the solutions, the desiccant will be circulated through a mechanical filter during the testing where fine particulates will be trapped and the filter will then be dried and analyzed for inorganic materials using $\mathrm{x}$-ray fluorescence (XRF) and diffractometry techniques.

The TEG solution was difficult to analyze because it is an organic fluid and to determine the amount of inorganic material present in the fluid, it would have to be ashed to drive off the organic matrix, leaving only the inorganic residue or ash material. However, because of the small volume of inorganic material in the TEG, the ashing procedure cannot produce enough material to be analyzed by conventional techniques. This may be overcome in any future testing by running the solution through a mechanical filter during testing as described above.

The desiccant materials all performed as expected with respect to the amount of moisture removed from the flue gas stream of both the natural gas and coal combustion tests. The lower the vapor pressure of the desiccant was, the more moisture it removed from the flue gas stream. The flow behavior of all of the desiccants was as expected for the duration of the tests, although during 
the first test, the spray nozzles had to be removed and cleaned because of inadequate spray pattern and volume. This partial plugging was attributable to small particulate that was entrained in the solution from the absorber system and was not a reflection of the desiccant flow characteristics. The probable source of the particulate is oxidation of components of the wet FGD when sitting idle, producing small particles which then became entrained in the solution.

Sulfur absorption by the desiccants was minimal, with no absorption of sulfur in the natural gas tests and only two of the desiccants absorbing small amounts in the coal combustion tests. The interaction of the flue gas nitrogen with the desiccants also appeared to be minimal, with no nitrate crystalline species detected in precipitate material removed from the solutions. Longer-term tests will be needed to confirm desiccant flue gas interactions.

No precipitates were formed in situ during the testing; however, these tests were short in duration, and longer-term testing will be needed to determine if precipitation will need to be addressed. Precipitates did form in desiccant samples taken from the coal combustion tests after removal from the absorber and cooling of the desiccant material. These precipitates were found in the samples taken near the end of the test for the two desiccants. This precipitate material in the desiccant was analyzed and found to consist of primarily carbonate, sulfate, and some coal combustion ash material. The third desiccant showed no precipitation during or after the testing.

\subsubsection{Pilot-Scale Desiccant Testing}

As discussed in Section 5 of this report, pilot-scale evaluation of the LDDS concept involved the completion of two nonconsecutive weeks of testing. Flue gas data are presented on an asmeasured and a 3 vol $\% \mathrm{O}_{2}$ dry basis so that valid comparisons can be made because of the potential for some air leakage across the LDDS absorber column and the change in flue gas moisture content as a result of water recovery in the desiccant solution. Data and observations resulting from Test Series I and II are presented in this section of the report.

\subsubsection{Evaluation of LDDS Performance-Pilot-Scale Test Series I}

Test Series I was a weeklong effort beginning September 27 and continuing through October 1 , 2004. Natural gas was fired in the SFS in support of this test series in order to simulate flue gas conditions representing gas turbine exhaust, high excess oxygen $\left(12.7 \mathrm{vol} \% \mathrm{O}_{2}\right.$, dry basis), and low moisture content $\left(8.2\right.$ vol\% $\left.\mathrm{H}_{2} \mathrm{O}\right)$. Flue gas temperature and flow rate at the inlet of the LDDS absorber column were nominally $203^{\circ} \mathrm{F}\left(95^{\circ} \mathrm{C}\right)$ and $450 \mathrm{acfm}\left(12.7 \mathrm{~m}^{3} / \mathrm{min}\right)$, respectively. These flue gas conditions were achieved as a result of furnace firing conditions and the use of heat exchangers between the furnace and LDDS absorber column. Sixteen individual test periods were completed. Fourteen test periods involved operation of the LDDS absorber in a spray tower configuration with two tests evaluating a packed-bed configuration. During the tests, primary independent variables included number of spray levels, desiccant circulation rate, desiccant concentration, and absorber desiccant temperature. The primary dependent variable was product water recovery. 


\subsection{SFS Operating Parameters}

SFS operating parameters were selected to achieve desired operating conditions at the inlet of the LDDS absorber column, specifically, flue gas flow rate, moisture and $\mathrm{O}_{2}$ content, and temperature. Table 27 summarizes the furnace firing rate, primary and secondary combustion air flow rates, and several SFS flue gas temperatures. Average furnace firing rate ranged from 0.65 to $0.73 \mathrm{MMBtu} / \mathrm{hr}(0.69$ to $0.78 \mathrm{~kJ} / \mathrm{hr})$ with standard deviations of typically $<0.006 \mathrm{MMBtu} / \mathrm{hr}$ $(<0.006 \mathrm{~kJ} / \mathrm{hr})$. Test periods resulting in higher standard deviations, Test No. 2, 7.1, and 14.1, were the result of firing rate changes made during the individual test periods. Firing rate changes were made during individual test periods to increase or decrease the flue gas flow rate and moisture content at the inlet of the LDDS absorber. Flow rate data are summarized for both primary (PCA) and secondary combustion air (SCA) flow rate. PCA flow rate represented nominally $22 \%$ of the total combustion air flow rate and averaged $70 \mathrm{scfm}\left(2 \mathrm{~m}^{3} / \mathrm{min}\right)$ for all test periods with typical standard deviations of $<1.5 \mathrm{scfm}\left(0.04 \mathrm{~m}^{3} / \mathrm{min}\right)$. SCA flow rate represented nominally $78 \%$ of the total combustion air flow rate and averaged $245 \mathrm{scfm}\left(7 \mathrm{~m}^{3} / \mathrm{min}\right)$ for all test periods with typical standard deviations of $<1.5 \mathrm{scfm}\left(0.04 \mathrm{~m}^{3} / \mathrm{min}\right)$. Average furnace exit flue gas temperatures ranged from $1334^{\circ}$ to $1428^{\circ} \mathrm{F}\left(724^{\circ}\right.$ to $\left.776^{\circ} \mathrm{C}\right)$ with typical standard deviations of $<3^{\circ} \mathrm{F}\left(<1.7^{\circ} \mathrm{C}\right)$. Furnace exit temperatures observed were a function of the natural gas firing rate and the high excess combustion air levels. In general, furnace exit temperature increased during Test Series I as furnace firing rate was increased and furnace refractory approached thermal equilibrium.

Baghouse inlet and outlet flue gas temperatures were nominally $204^{\circ}$ and $207^{\circ} \mathrm{F}\left(96^{\circ}\right.$ to $\left.98^{\circ} \mathrm{C}\right)$, respectively, with standard deviations of typically $0.4^{\circ} \mathrm{F}\left(0.2^{\circ} \mathrm{C}\right)$ or less. Baghouse outlet flue gas temperatures were slightly higher than inlet temperatures because the baghouse is electrically heattraced and the controllers were intentionally set to increase flue gas temperature in order to ensure that flue gas moisture was not condensing in the baghouse. Flue gas piping between the baghouse and the absorber column was also electrically heat-traced to prevent flue gas moisture condensation

on surfaces. These data indicate that desired SFS temperature control for Test Series I was achieved using a combination of SFS heat exchangers and the baghouse heaters.

Flue gas composition at the furnace exit was not monitored continuously in order to continuously monitor flue gas composition at the inlet and outlet of the absorber column. However, based on measurements made during a 1 -hour period immediately prior to initiating absorber tests, flue gas $\mathrm{O}_{2}$ and $\mathrm{CO}_{2}$ concentrations at the furnace exit were $15.5 \pm 0.1 \mathrm{vol} \%$ and $4.3 \pm 0.1 \mathrm{vol} \%$, respectively. Flue gas $\mathrm{CO}$ concentration was 0 ppmv. These data are reported on a dry flue gas basis and are very similar to initial Test Series I data for the absorber inlet sample location. Differences were the result of air in-leakage between the furnace exit and absorber inlet. Specifically, the oxygen content at the furnace exit was slightly lower with the $\mathrm{CO}_{2}$ concentration slightly higher than that measured at the absorber inlet. Because natural gas was fired in the slagging furnace in support of Test Series I, flue gas $\mathrm{SO}_{2}$ concentrations were not measured. Measurement of $\mathrm{NO}_{\mathrm{x}}$ concentration at the furnace exit was not possible during Test Series I because the analyzer was not working properly. 


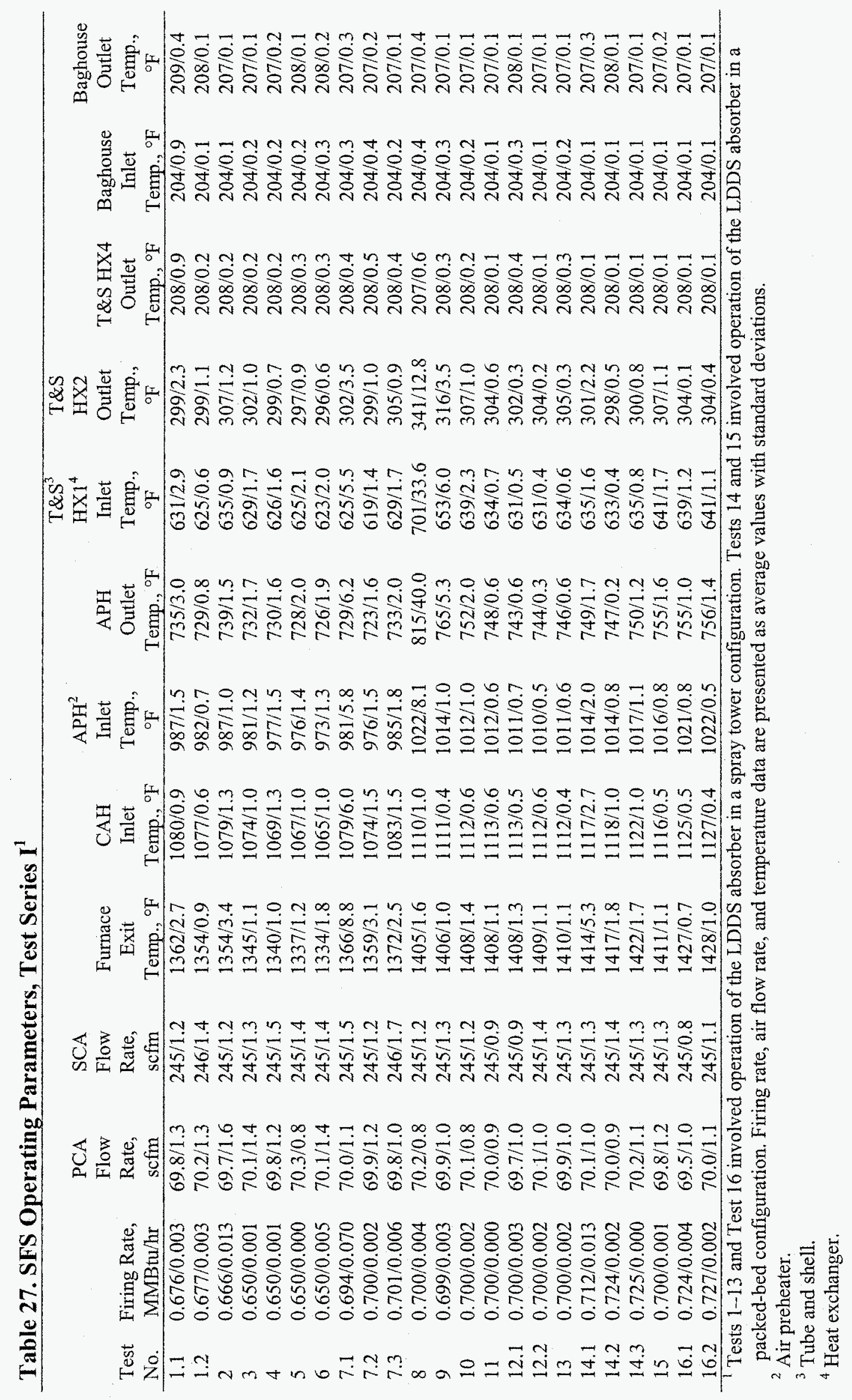




\subsection{LDDS Operating Parameters}

Table 28 summarizes LDDS absorber operating parameters for Test Series I. Process data include 1) flue gas inlet and outlet temperatures; 2) desiccant concentration, circulation rate, and temperature; and 3) absorber flue gas flow rate and $\mathrm{L} / \mathrm{G}$ (liquid-to-gas) ratio. Average flue gas temperatures at the LDDS absorber inlet ranged from $202^{\circ}$ to $205^{\circ} \mathrm{F}\left(95^{\circ}\right.$ to $96^{\circ} \mathrm{C}$ ) with standard deviations of typically $0.4^{\circ} \mathrm{F}\left(0.2^{\circ} \mathrm{C}\right)$ or less. Absorber outlet flue gas temperatures ranged from $123^{\circ}$ to $145^{\circ} \mathrm{F}\left(51^{\circ}\right.$ to $\left.63^{\circ} \mathrm{C}\right)$ with typical standard deviations of $\angle 1^{\circ} \mathrm{F}\left(<0.6^{\circ} \mathrm{C}\right)$. These data indicate that desired absorber flue gas temperatures were achieved and temperature control during Test Series I was very good.

Desiccant concentration values at the inlet of the absorber column ranged from 41.0 to $47.1 \mathrm{wt} \%$, but were typically $>46 \mathrm{wt} \%$, with typical standard deviations of $\leq 0.1 \mathrm{wt} \%$ for most test periods. These values are less than the $50 \mathrm{wt} \%$ desiccant concentration originally planned for Test Series I. The EERC determined, during initial circulation tests, that a $50 \mathrm{wt} \%$ desiccant concentration would result in operational problems. Specifically, a $50 \mathrm{wt} \%$ desiccant concentration did not permit operation at the range of desiccant temperatures desired without encountering crystallization and line plugging problems. In addition, even at appropriate operating conditions, the $50 \mathrm{wt} \%$ desiccant concentration allowed for no margin of error; any operational upset resulted in crystallization and line plugging problems. Therefore, the EERC elected to reduce the desiccant concentration to nominally $46.5 \mathrm{wt} \%$. For two test periods, the desiccant concentration was intentionally reduced to $41 \mathrm{wt} \%$. Measured desiccant specific gravity values for select samples ranged from 1.480 to 1.496.

Desiccant temperatures at the inlet of the LDDS absorber through the nozzles ranged from $120^{\circ}$ to $135^{\circ} \mathrm{F}\left(49^{\circ}\right.$ to $\left.58^{\circ} \mathrm{C}\right)$ with typical standard deviations of $\leq 0.7^{\circ} \mathrm{F}\left(0.4^{\circ} \mathrm{C}\right)$. Desiccant temperatures exiting the LDDS absorber into the tank ranged from $124^{\circ}$ to $140^{\circ} \mathrm{F}\left(51^{\circ}\right.$ to $\left.60^{\circ} \mathrm{C}\right)$ with typical standard deviations of $50.8^{\circ} \mathrm{F}\left(0.4^{\circ} \mathrm{C}\right)$. Inlet and outlet standard deviations $>0.7^{\circ} \mathrm{F}\left(0.4^{\circ} \mathrm{C}\right)$ or $>0.8^{\circ} \mathrm{F}\left(0.4^{\circ} \mathrm{C}\right)$ represented very short duration test periods, 30 minutes or less. Desiccant circulation rates ranged from 7.1 to $48.5 \mathrm{gpm}(26.9$ to $183.6 \mathrm{Lpm})$ with the number and size of the nozzles selected to match the desired rate. Circulation rate variations during individual test periods were typically $\leq 0.2 \mathrm{gpm}(\leq 0.8 \mathrm{Lpm})$.

Flue gas flow rates ranged from 430 to $438 \mathrm{acfm}\left(12.2\right.$ to $\left.12.4 \mathrm{~m}^{3} / \mathrm{min}\right)$, resulting in absorber velocities of 9.5 to $9.6 \mathrm{ft} / \mathrm{s}(2.4-2.5$ to $3.2 \mathrm{~m} / \mathrm{s})$. Calculated $\mathrm{L} / \mathrm{G}$ ratios ranged from 16.3 to $112.3 \mathrm{gal} / 1000 \mathrm{acf}$. LDDS absorber differential pressure ranged from 0.7 to $2.2 \mathrm{in}$. W.C. (1.3 to 4.1 $\mathrm{mmHg}$ ) depending on desiccant circulation rates and absorber configuration: spray tower versus packed bed. The lower end of the differential pressure range represented a spray tower configuration and a low desiccant circulation rate with the high end of the range representing a packed-bed configuration and a low desiccant circulation rate. In general, the desired LDDS absorber operating parameters were achieved, and operational stability was good as indicated by the low standard deviation values reported for individual parameters.

Table 29 summarizes LDDS flash drum operating parameters for Test Series I. Flash drum process data include 1) desiccant inlet and outlet temperatures, 2) desiccant circulation rate and $\mathrm{pH}$, 3) flash operating drum pressure, and 4) desiccant nozzle size. Average desiccant temperatures at the 


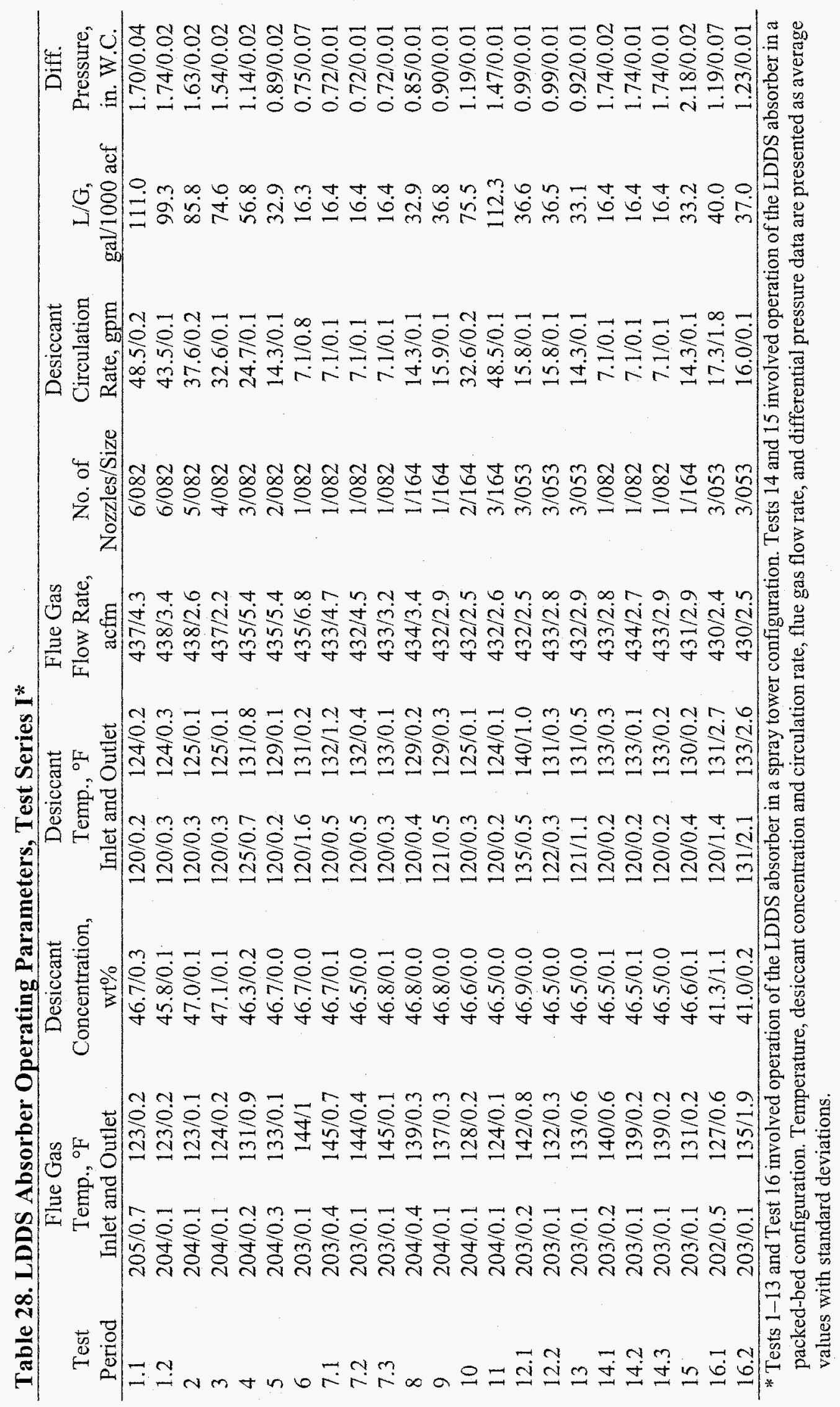


Table 29. LDDS Flash Drum Operating Parameters, Test Series I*

\begin{tabular}{lcccccc}
\hline $\begin{array}{l}\text { Test } \\
\text { Period }\end{array}$ & \multicolumn{2}{c}{$\begin{array}{c}\text { Desiccant } \\
\text { Temp., }\end{array}$ Inlet and Outlet } & $\begin{array}{c}\text { Desiccant } \\
\text { Specific } \\
\text { Gravity }\end{array}$ & $\begin{array}{c}\text { Desiccant } \\
\text { pH }\end{array}$ & $\begin{array}{c}\text { Flash Drum } \\
\text { Vac. Press., } \\
\text { psia }\end{array}$ & $\begin{array}{c}\text { Desiccant } \\
\text { Circulation } \\
\text { Rate, gpm }\end{array}$ \\
\hline 1.1 & $162 / 3.3$ & $143 / 1.2$ & NA & $6.2 / 0.3$ & $0.91 / 0.04$ & $10.0 / 0.1$ \\
1.2 & $159 / 0.8$ & $139 / 0.2$ & 1.465 & $3.7 / 0.0$ & $0.85 / 0.02$ & $9.0 / 0.1$ \\
2 & $155 / 1.1$ & $139 / 0.4$ & NA & $3.5 / 0.0$ & $0.80 / 0.02$ & $9.0 / 0.1$ \\
3 & $154 / 1.1$ & $139 / 0.3$ & NA & $3.4 / 0.0$ & $0.78 / 0.02$ & $9.0 / 0.1$ \\
4 & $145 / 1.8$ & $137 / 1.0$ & NA & $3.6 / 0.0$ & $0.96 / 0.28$ & $24.9 / 0.1$ \\
5 & $140 / 0.2$ & $134 / 0.2$ & NA & $3.5 / 0.0$ & $0.71 / 0.01$ & $14.4 / 0.1$ \\
6 & $140 / 1.1$ & $132 / 0.3$ & 1.464 & $3.5 / 0.0$ & $0.68 / 0.02$ & $7.3 / 0.3$ \\
7.1 & $147 / 6.3$ & $139 / 4.1$ & NA & $3.6 / 0.0$ & $0.86 / 0.15$ & $7.3 / 0.1$ \\
7.2 & $151 / 1.1$ & $143 / 2.8$ & NA & $3.6 / 0.0$ & $0.93 / 0.09$ & $7.3 / 0.1$ \\
7.3 & $144 / 8.0$ & $136 / 1.6$ & NA & $3.6 / 0.0$ & $0.74 / 0.03$ & $7.3 / 0.1$ \\
8 & $146 / 1.2$ & $139 / 0.4$ & 1.482 & $3.7 / 0.0$ & $0.81 / 0.01$ & $14.4 / 0.2$ \\
9 & $143 / 1.2$ & $137 / 0.7$ & NA & $3.6 / 0.0$ & $0.77 / 0.01$ & $16.0 / 0.1$ \\
10 & $145 / 2.7$ & $135 / 0.4$ & NA & $3.6 / 0.0$ & $0.73 / 0.01$ & $9.0-0.1$ \\
11 & $148 / 0.4$ & $135 / 0.2$ & NA & $3.6 / 0.0$ & $0.72 / 0.01$ & $9.0 / 0.1$ \\
12.1 & $146 / 0.8$ & $141 / 1.4$ & NA & $3.5 / 0.0$ & $0.91 / 0.10$ & $16.0 / 0.1$ \\
12.2 & $147 / 0.9$ & $141 / 0.5$ & NA & $3.6 / 0.0$ & $0.89 / 0.01$ & $16.0 / 0.1$ \\
13 & $147 / 0.2$ & $141 / 1.8$ & NA & $3.6 / 0.0$ & $0.90 / 0.10$ & $14.5 / 0.1$ \\
14.1 & $144 / 2.9$ & $135 / 2.2$ & 1.472 & $3.6 / 0.0$ & $0.76 / 0.06$ & $7.3 / 0.2$ \\
14.2 & $140 / 2.0$ & $134 / 0.8$ & NA & $3.6 / 0.0$ & $0.73 / 0.01$ & $7.3 / 0.2$ \\
14.3 & $142 / 0.6$ & $133 / 0.5$ & NA & $3.6 / 0.0$ & $0.70 / 0.01$ & $7.3 / 0.2$ \\
15 & $146 / 1.1$ & $139 / 1.9$ & 1.473 & $3.6 / 0.0$ & $0.84 / 0.09$ & $14.5 / 0.1$ \\
16.1 & $132 / 3.3$ & $123 / 2.8$ & NA & $4.3 / 0.1$ & $0.76 / 0.07$ & $17.4 / 1.8$ \\
16.2 & $144 / 4.9$ & $133 / 2.0$ & NA & $4.2 / 0.0$ & $1.07 / 0.09$ & $16.0 / 0.1$ \\
\hline
\end{tabular}

* Tests 1-13 and Test 16 involved operation of the LDDS absorber in a spray tower configuration. Tests 14 and 15 involved operation of the LDDS absorber in a packed-bed configuration. Temperature and desiccant $\mathrm{pH}$ and circulation rate data are presented as average values with standard deviations. Nozzle sizes were 470 for Tests 1-6, 082 for Test 7 , and 340 or 164 for Tests 8-16.

LDDS flash drum inlet ranged from $132^{\circ}$ to $162^{\circ} \mathrm{F}\left(56^{\circ}\right.$ to $\left.73^{\circ} \mathrm{C}\right)$ with standard deviations of $0.2^{\circ}$ to $8.0^{\circ} \mathrm{F}\left(0.1^{\circ}\right.$ to $\left.4.4^{\circ} \mathrm{C}\right)$. The range of flash drum inlet temperatures was a result of selected set points. However, the range of standard deviations resulted from regulator problems controlling steam flow to the desiccant heater. Therefore, one of the recommended modifications to the LDDS prior to any future work is the replacement of the desiccant heater steam control regulator. Flash drum outlet desiccant temperatures ranged from $123^{\circ}$ to $143^{\circ} \mathrm{F}\left(51^{\circ}\right.$ to $\left.62^{\circ} \mathrm{C}\right)$ with standard deviations of $0.2^{\circ}$ to $4.1^{\circ} \mathrm{F}\left(0.1^{\circ}\right.$ to $\left.2.3^{\circ} \mathrm{C}\right)$.

Desiccant concentration values were not measured continuously at the inlet of the flash drum. Specific gravity measurements for selected samples showed that the desiccant concentration decreased as a result of water being absorbed into the desiccant solution from the flue gas in the absorber column. Measured desiccant specific gravity values for select samples ranged from 1.464 to 1.482. Flash drum desiccant circulation rates ranged from 7.3 to $24.9 \mathrm{gpm}$ ( 27.6 to $94.2 \mathrm{Lpm}$ ). For this range of circulation rates, the desiccant circulation rate from the regeneration pump is slightly 
higher than the rate from the absorber pump. The reason for this difference is the control philosophy employed in the pilot-scale system (regeneration tank level and pump discharge rate), the fact that water recovered in the absorber contributed to the desiccant circulation rate to the flash drum, and the potential for slight variations in meter measurement performance for the two desiccant streams. Flash drum circulation rates were intentionally set lower than absorber circulation rates for rates $>25 \mathrm{gpm}(94.6 \mathrm{Lpm})$. Desiccant circulation rates to the flash drum did not match high desiccant circulation rates to the absorber because that was the intent for specific test periods. However, for other test periods planned higher desiccant circulation rates to the flash drum could not be achieved because of the combination of desiccant concentration, the 37-ft $(11-\mathrm{m})$ elevation differential between the regeneration pump and flash drum nozzle, and pump capacity. Flash drum circulation rate variations during individual test periods were typically $0.1 \mathrm{gpm}(0.4 \mathrm{Lpm})$.

Flash drum operating pressure ranged from 0.68 to 1.07 psia ( 35 to $55 \mathrm{mmHg}$ ) with typical standard deviations $\leq 0.1 \mathrm{psia}(\leq 5.2 \mathrm{mmHg})$. Higher standard deviations were the result of moisture condensation and accumulation in the pressure transmitter line attached to the vapor discharge line exiting the flash drum. In general, flash drum vacuum pressure was less than the $1.0 \mathrm{psia}(52 \mathrm{mmHg})$ value planned. This occurred because of the moisture condensation previously mentioned and the difficulty encountered when attempting to manually set the pressure regulator controlling vacuum pressure. Prior to any future pilot-scale tests, the EERC intends to relocate the pressure transmitter measuring vacuum pressure to eliminate the accumulation of moisture in the pressure transmitter line. Options will also be considered for improving vacuum pressure regulator performance and control.

Sulfate content in the flash drum desiccant samples was below detection limits for Test Series $\mathrm{I},<3 \mathrm{mg} / \mathrm{L}$, consistent with the absorber desiccant samples. Again, this observation is consistent with the fuel fired, natural gas, and the absence of $\mathrm{SO}_{2}$ in the flue gas. Flash drum desiccant $\mathrm{pH}$ was measured continuously during Test Series I. Values typically ranged from 3.4 to 3.7 with standard deviations of 0.0 for most test periods. The first test period had a desiccant $\mathrm{pH}$ value of 6.2 , and the last two test periods had desiccant $\mathrm{pH}$ values of 4.3 and 4.2 . The high $\mathrm{pH}$ value was observed during the first test period because carbon dioxide dissolution in the desiccant had not reached equilibrium. The increase in desiccant $\mathrm{pH}$ from Test 15 to 16 resulted from a decrease in desiccant concentration and a resulting change in the equilibrium of carbon dioxide dissolution. Desiccant $\mathrm{pH}$ was measured for select absorber column inlet samples, ranging from 3.61 to 4.00 . These values were consistently lower than the corresponding values measured for the desiccant solution after exposure to flue gas in the absorber column. This is consistent with the dilution effect of the water recovered from the flue gas in the absorber column.

Table 30 summarizes product water condenser operating parameters for Test Series I. Process data include 1) vapor inlet temperature, 2) product water outlet temperature, 3) condenser vacuum and differential pressure, and 4) ring pump temperature. Condenser operating conditions were a function of vapor temperature and flow rate, cooling water temperature and flow rate, and vacuum pressure. Average vapor temperature at the condenser inlet ranged from $137^{\circ}$ to $156^{\circ} \mathrm{F}\left(59^{\circ}\right.$ to $\left.69^{\circ} \mathrm{C}\right)$ with standard deviations ranging from $0.4^{\circ}$ to $7.0^{\circ} \mathrm{F}\left(0.2^{\circ}\right.$ to $\left.3.9^{\circ} \mathrm{C}\right)$. The range of vapor temperatures and standard deviations were a direct result of desiccant temperature set points and variability at the inlet of the flash drum. 
Table 30. LDDS Product Water Condenser Operating Parameters, Test Series I*

\begin{tabular}{|c|c|c|c|c|c|}
\hline $\begin{array}{l}\text { Test } \\
\text { Period }\end{array}$ & $\begin{array}{l}\text { Condenser } \\
\text { Inlet Vapor } \\
\text { Temp., }{ }^{\circ} \mathrm{F}\end{array}$ & $\begin{array}{c}\text { Condenser } \\
\text { Product Water } \\
\text { Outlet Temp., }{ }^{\circ} \mathrm{F}\end{array}$ & $\begin{array}{c}\text { Condenser } \\
\text { Vacuum Pressure, } \\
\text { psia }\end{array}$ & $\begin{array}{l}\text { Condenser } \\
\text { Diff. Press., } \\
\text { in. W.C. }\end{array}$ & $\begin{array}{c}\text { Ring Pump } \\
\text { Temperature, }{ }^{\circ} \mathrm{F}\end{array}$ \\
\hline 1.1 & $144 / 3.7$ & $91 / 1.9$ & $0.81 / 0.04$ & $2.8 / 0.7$ & $67 / 0.2$ \\
\hline 1.2 & $141 / 0.4$ & $89 / 0.4$ & $0.74 / 0.02$ & $3.0 / 0.6$ & $67 / 0.2$ \\
\hline 2 & $144 / 0.6$ & $86 / 0.6$ & $0.73 / 0.02$ & $2.0 / 0.6$ & $68 / 0.1$ \\
\hline 3 & $142 / 1.7$ & $86 / 0.4$ & $0.71 / 0.02$ & $2.0 / 0.4$ & $68 / 0.1$ \\
\hline 4 & $142 / 1.0$ & $87 / 1.9$ & $0.86 / 0.28$ & $2.7 / 0.3$ & $68 / 0.2$ \\
\hline 5 & $143 / 0.8$ & $80 / 0.2$ & $0.66 / 0.01$ & $1.5 / 0.2$ & $67 / 0.1$ \\
\hline 6 & $142 / 6.1$ & $78 / 0.6$ & $0.64 / 0.02$ & $1.1 / 0.5$ & $67 / 0.1$ \\
\hline 7.1 & $149 / 6.4$ & $85 / 8.6$ & $0.79 / 0.15$ & $2.0 / 2.4$ & $68 / 0.6$ \\
\hline 7.2 & $155 / 1.4$ & $96 / 5.3$ & $0.89 / 0.09$ & $1.1 / 1.0$ & $68 / 0.8$ \\
\hline 7.3 & $143 / 7.0$ & $81 / 5.4$ & $0.69 / 0.03$ & $1.3 / 0.4$ & $68 / 0.2$ \\
\hline 8 & $156 / 1.3$ & $86 / 1.1$ & $0.77 / 0.01$ & $1.2 / 0.1$ & $68 / 0.2$ \\
\hline 9 & $153 / 0.5$ & $84 / 0.9$ & $0.73 / 0.01$ & $1.2 / 0.1$ & $68 / 0.1$ \\
\hline 10 & $149 / 1.8$ & $83 / 0.7$ & $0.68 / 0.01$ & $1.3 / 0.3$ & $67 / 0.1$ \\
\hline 11 & $144 / 0.6$ & $84 / 0.2$ & $0.66 / 0.01$ & $1.7 / 0.1$ & $67 / 0.1$ \\
\hline 12.1 & $148 / 1.0$ & $85 / 2.4$ & $0.86 / 0.10$ & $1.5 / 0.1$ & $67 / 0.1$ \\
\hline 12.2 & $151 / 0.5$ & $88 / 0.8$ & $0.84 / 0.01$ & $1.3 / 0.1$ & $67 / 0.1$ \\
\hline 13 & $148 / 1.2$ & $87 / 1.1$ & $0.84 / 0.10$ & $1.6 / 0.1$ & $68 / 0.1$ \\
\hline 14.1 & $146 / 2.2$ & $80 / 2.3$ & $0.72 / 0.06$ & $1.2 / 0.6$ & $66 / 0.3$ \\
\hline 14.2 & $144 / 0.6$ & $77 / 2.1$ & $0.69 / 0.01$ & $1.0 / 0.1$ & $66 / 0.1$ \\
\hline 14.3 & $144 / 1.5$ & $80 / 0.4$ & $0.66 / 0.01$ & $1.2 / 0.1$ & $66 / 0.1$ \\
\hline 15 & $144 / 3.4$ & $86 / 1.7$ & $0.79 / 0.09$ & $1.3 / 0.4$ & $67 / 0.3$ \\
\hline 16.1 & $137 / 3.5$ & $87 / 2.7$ & $0.68 / 0.07$ & $2.3 / 0.2$ & $67 / 0.5$ \\
\hline 16.2 & $138 / 1.6$ & $94 / 3.8$ & $0.96 / 0.09$ & $3.0 / 0.1$ & $67 / 0.4$ \\
\hline
\end{tabular}

* Tests 1-13 and Test 16 involved operation of the LDDS absorber in a spray tower configuration. Tests 14 and 15 involved operation of the LDDS absorber in a packed-bed configuration. Temperature and pressure data are presented as average values with standard deviations.

Condenser product water temperatures ranged from $77^{\circ}$ to $96^{\circ} \mathrm{F}\left(25^{\circ}\right.$ to $\left.36^{\circ} \mathrm{C}\right)$ with standard deviations of $0.2^{\circ}$ to $8.6^{\circ} \mathrm{F}\left(0.1^{\circ}\right.$ to $\left.4.8^{\circ} \mathrm{C}\right)$. Condenser product water temperatures were a function of the condenser cooling water temperature and flow rate as well as the vapor temperature and flow rate. Cooling water temperature was nominally $62^{\circ} \mathrm{F}\left(17^{\circ} \mathrm{C}\right)$ at flow rates exceeding $10 \mathrm{gpm}$ (38 Lpm). Condenser operating pressure was not directly measured, but calculated from flash drum outlet pressure and the condenser differential pressure. Condenser operating pressure ranged from 0.64 to 0.96 psia ( 35 to $55 \mathrm{mmHg}$ ) with typical standard deviations $\leq 0.1$ psia $(\leq 5.2 \mathrm{mmHg}$ ). Because condenser operating pressure data were calculated based on flash drum data, average and standard deviation values directly follow flash drum operating data. In general, condenser vacuum pressure was less than 0.9 psia $(47 \mathrm{mmHg})$. Condenser differential pressure ranged from 1.0 to $3.0 \mathrm{in}$. W.C. (1.9 to $5.6 \mathrm{mmHg}$ ). Ring pump outlet water temperatures ranged from $66^{\circ}$ to $68^{\circ} \mathrm{F}\left(19^{\circ}\right.$ to $\left.20^{\circ} \mathrm{C}\right)$ with standard deviations of $0.1^{\circ}$ to $0.5^{\circ} \mathrm{F}\left(0.06^{\circ}\right.$ to $\left.0.3^{\circ} \mathrm{C}\right)$ as a result of a nominal inlet temperature of $62^{\circ} \mathrm{F}\left(17^{\circ} \mathrm{C}\right)$ and a flow rate of $5 \mathrm{gpm}(19 \mathrm{Lpm})$. 


\subsection{Flue Gas Sampling Data}

Table 31 summarizes the $\mathrm{O}_{2}, \mathrm{CO}_{2}, \mathrm{SO}_{2}, \mathrm{CO}$, and $\mathrm{NO}_{x}$ flue gas data on an as-measured dry volume basis for Test Series I as well as flue gas moisture concentration data. Average values are presented for each test period along with standard deviations. Measured $\mathrm{O}_{2}$ concentration at the inlet and outlet of the absorber ranged from 14.1 to $16.1 \mathrm{vol} \%$ and 14.3 to 15.2 vol\%, respectively, with typical standard deviations of $\leq 0.1 \mathrm{vol} \%$. For Tests 1 through $12, \mathrm{O}_{2}$ concentration at the absorber outlet was less than the $\mathrm{O}_{2}$ concentration at the absorber inlet. This observation was surprising for a balanced-draft system with the potential for air in-leakage. A review of the operations log for Test Series I indicated that an air leak was observed for the sample system supporting the absorber inlet location. Over the course of the test series, several small leaks were found and corrected. In addition, an instrument calibration correction was also found to be necessary. The end result was a $0.1-$ 0.2 vol\% difference between the absorber inlet and outlet sampling locations indicating $1.5 \%-3 \%$ air in-leakage across the absorber.

Measured $\mathrm{CO}_{2}$ concentration at the inlet and outlet of the absorber ranged from 3.9 to $5.0 \mathrm{vol} \%$ and 5.8 to 7.8 vol\%, respectively, with typical standard deviations of $\leq 0.2$ vol\%. For Tests 1 through 7 , the $\mathrm{CO}_{2}$ concentration measured at the absorber inlet is believed to be less than the actual concentration because of the sample system air in-leakage problem previously discussed. Absorber inlet data are not available for Tests 8 through 16 because of an instrument failure resulting from a power bump that occurred during Test Series I.

As expected $\mathrm{CO}$ concentrations in the flue gas were $0.0 \mathrm{ppmv}$ for essentially all test periods. Two test periods resulted in measurable CO concentrations, Test $1.1(0.14 \pm 0.82$ ppmv $)$ and Test 7.1 $(2.6 \pm 27$ ppmv). However, in both cases, the average values were small, and standard deviations were significantly larger indicating $\mathrm{CO}$ spikes as a function of momentary system upsets. Pressure fluctuations in the system, affecting furnace pressure, are the most likely momentary system upset. These likely occurred when flue gas sample probes were inserted and removed.

Because only one analyzer was available, $\mathrm{NO}_{\mathrm{x}}$ data were only reported for the absorber outlet sample location. The data indicate that the flue gas $\mathrm{NO}_{\mathrm{x}}$ concentration at the absorber outlet typically averaged 34 to $44 \mathrm{ppmv}$ for individual test periods with standard deviations of 3 ppmv. These low flue gas $\mathrm{NO}_{\mathrm{x}}$ concentrations are consistent with the firing of natural gas in the slagging furnace at high excess $\mathrm{O}_{2}$ concentrations $\left(>14\right.$ vol\%) and low furnace temperatures $\left(<1430^{\circ} \mathrm{F}\left[<777^{\circ} \mathrm{C}\right]\right)$. Because natural gas was fired in the slagging furnace in support of Test Series I, flue gas $\mathrm{SO}_{2}$ concentrations were not measured.

Measured $\mathrm{H}_{2} \mathrm{O}$ concentration at the inlet and outlet of the absorber, as summarized in Table 612 , ranged from 7.5 to 8.6 vol\% and 2.5 to 5.8 vol\%, respectively, with typical standard deviations of $\leq 0.1 \mathrm{vol} \%$. Standard deviations never exceeded 0.3 vol $\%$, indicating stable absorber operation. The results indicate that $\mathrm{H}_{2} \mathrm{O}$ recovery across the LDDS absorber was highly variable, ranging from $27 \%$ to $69 \%$ of the available $\mathrm{H}_{2} \mathrm{O}$ in the flue gas stream. Factors influencing $\mathrm{H}_{2} \mathrm{O}$ recovery in the LDDS absorber include desiccant concentration, temperature, and circulation rate, as well as absorber operation in a spray tower versus packed-bed configuration. However, these data are not corrected for air in-leakage and are, therefore, nominal values. A detailed summary of the water recovery data for Test Series I is presented later in this report in Section 3.4.3.1.4. 


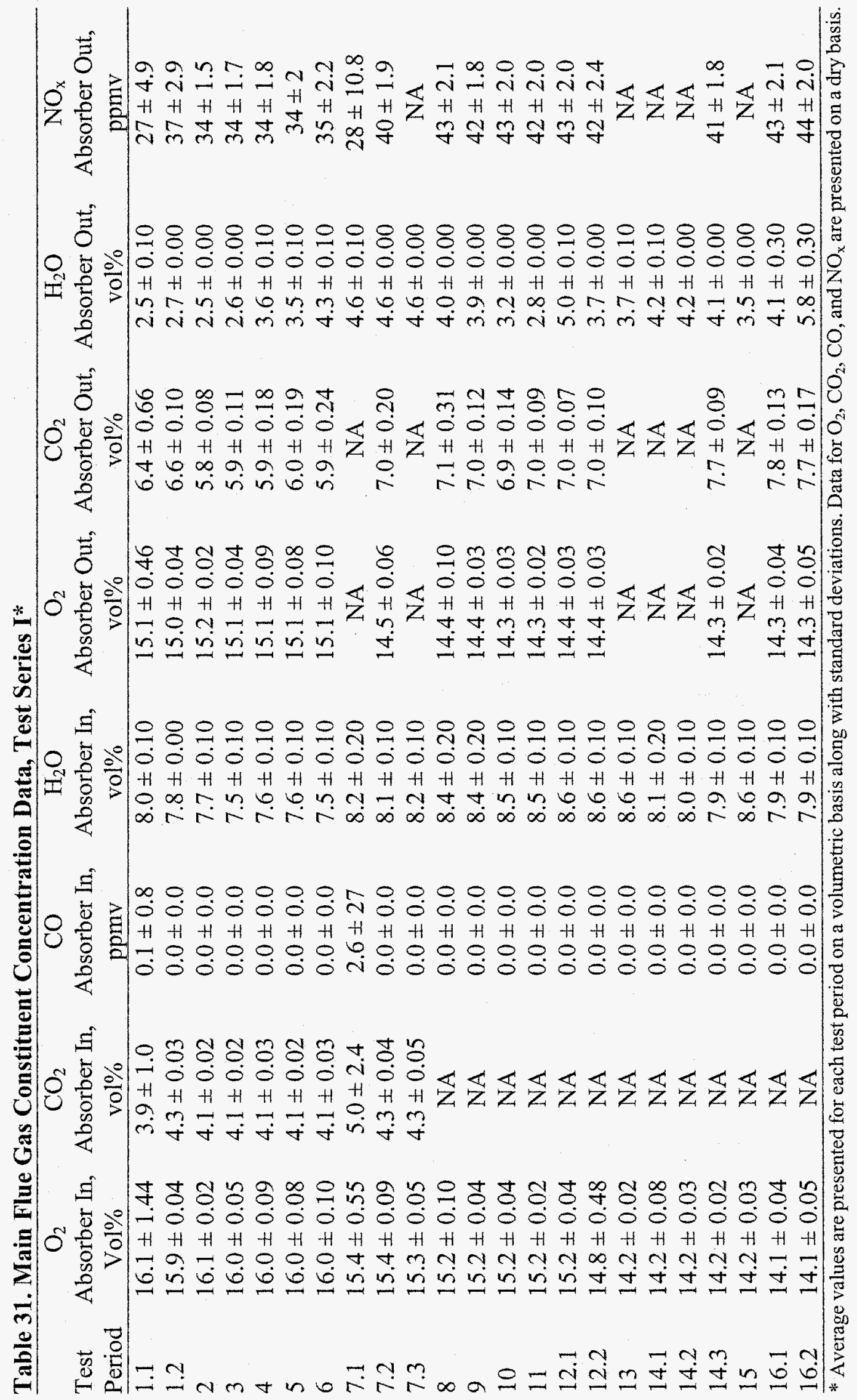


Gas concentration measurements were made periodically in the vapor stream at the outlet of the product water condenser. Specifically, measurements (dry basis) were made for $\mathrm{O}_{2}, \mathrm{CO}_{2}, \mathrm{CO}$, and $\mathrm{NO}_{\mathrm{x}}$ for Test Series I during Tests 7.1, 7.3, 13, 14.1, 14.2, and 15. Measurement results for $\mathrm{CO}_{2}$ (vol\%) and $\mathrm{CO}$ (ppmv) concentrations were essentially 0.0 . Average $\mathrm{O}_{2}$ concentrations ranged from $17.1 \pm 2.10$ to $20.8 \pm 0.01 \mathrm{vol} \%$. These data indicate the vapor stream is essentially air. Because of the high vacuum pressure in the flash drum, product water condenser, and interconnecting piping, this gas stream may be dominated by air in-leakage. Average $\mathrm{NO}_{\mathrm{x}}$ concentrations ranged from $17 \pm 5$ to $28 \pm 11 \mathrm{ppmv}$. These values are lower than what was measured in the combustion flue gas and represent a very small volume. Therefore, the data may indicate a small amount of flue gas was dissolved in the desiccant solution and then released in the flash drum or the analyzer zero was off.

Flue gas particulate mass loading data for the pilot-scale absorber inlet and outlet sample locations are summarized in Table 32. Sampling activities were completed for Tests 1.1, 1.2, 7.1, 7.2, 14.1, and 14.2. As previously discussed in Section 4, the data are the result of EPA Method 5 sampling. Sampling results at the absorber inlet indicated a mass loading of $0.0000 \mathrm{gr} / \mathrm{scf}$ $\left(0.0000 \mathrm{~g} / \mathrm{m}^{3}\right)$. Because natural gas was fired in the SFS combustor for Test Series I, the mass loading at the inlet of the absorber was expected to be zero.

Absorber outlet mass loading, based on EPA Method 5 sample trains, ranged from 0.0000 $0.0009 \mathrm{gr} / \mathrm{scf}\left(0.0000-0.0021 \mathrm{~g} / \mathrm{m}^{3}\right)$. For most sampling periods, although small, the mass measured at the absorber outlet was greater than the mass measured at the absorber inlet. The most likely mechanism responsible for the increased mass across the absorber is simply mist eliminator carryover, specifically desiccant solution aerosol droplets. Analysis of the outlet filter for Test 1.2 indicated the presence of $0.0147 \mathrm{gr}(956 \mu \mathrm{g})$ of calcium and $0.0286 \mathrm{gr}(1850 \mu \mathrm{g})$ of chloride. Sulfate was less than the detection limit, $<0.0003 \mathrm{gr}(<20 \mu \mathrm{g})$. The total mass recovered on the filter was $0.0749 \mathrm{gr}(0.00486 \mathrm{~g})$. Therefore, calcium and chloride combined represented $58 \%$ of the total mass collected on the filter. A similar analysis of the outlet filter for Test 14.2 showed that calcium and

Table 32. Particulate Sampling Data, Test Series I*

\begin{tabular}{l|cccc|cc}
$\begin{array}{l}\text { Test } \\
\text { Period }\end{array}$ & $\begin{array}{c}\text { Sampling } \\
\text { Method }\end{array}$ & $\begin{array}{c}\text { Absorber Inlet, } \\
\text { gr/scf }\end{array}$ & $\begin{array}{c}\text { Absorber } \\
\text { Outlet, Gr/scf }\end{array}$ & \multicolumn{2}{c}{ Removal, } & \multicolumn{2}{c}{ Flue Gas } & \multicolumn{2}{c}{$\begin{array}{c}\text { Average Stack } \\
\text { O O Content, vol\% }\end{array}$} & Temp., ${ }^{\circ}$ F \\
\hline 1.1 & EPA M5 & 0.0000 & - & - & 6.7 & 204 \\
1.2 & EPA M5 & - & 0.0002 & - & 3.3 & 120 \\
7.1 & EPA M5 & 0.0000 & - & - & 6.6 & 204 \\
& EPA M5 & - & 0.0009 & - & 3.2 & 119 \\
7.2 & EPA M5 & 0.0000 & - & - & 6.8 & 203 \\
14.1 & EPA M5 & - & 0.0000 & - & 5.3 & 140 \\
& EPA M5 & 0.0000 & - & - & 7.0 & 203 \\
14.2 & EPA M5 & - & 0.0002 & - & 5.3 & 141 \\
& EPA M5 & 0.0000 & - & - & 6.8 & 203 \\
& EPA M5 & - & 0.0000 & - & 4.9 & 135 \\
& EPA M5 & 0.0000 & - & - & 6.7 & 203 \\
\hline
\end{tabular}

* Mass loading data are presented on a dry basis. 
chloride represented $51 \%$ of the total mass collected on the filter. Based on the data, mist eliminator carryover is the most probable source of the mass collected at the outlet of the absorber. The $42 \%-$ $49 \%$ of the mass that remained undocumented is likely water chemically bound to the calcium chloride. As many as six moles of water can be chemically bound to calcium chloride representing a nearly $50 \mathrm{wt} \%$ contribution. Free water would not be a contributing factor because of the $250^{\circ} \mathrm{F}$ $\left(121^{\circ} \mathrm{C}\right)$ filter temperature employed and the method for measuring filter mass involved oven drying of filters at $212^{\circ} \mathrm{F}\left(100^{\circ} \mathrm{C}\right)$ and cooling the filter in a desiccated container prior to determining a final weight.

\subsection{Desiccant and Product Water Analyses Results}

Desiccant samples were collected from the inlet of the absorber and flash drum for each test period for Test Series I and select samples were analyzed. Table 33 summarizes the analytical results for ten desiccant samples representing five test periods. Desiccant $\mathrm{pH}$ for the samples collected at the absorber inlet ranged from 3.61 to 4.00 . Values for flash drum inlet samples ranged from 3.95 to 4.16. These data show an increase in desiccant solution $\mathrm{pH}$ as a function of exposure to flue gas in the absorber column and the absorption of water vapor. Continuous $\mathrm{pH}$ measurement data summarized in Table 29 are consistently lower than the data presented for select desiccant solution samples in Table 33. The primary reason for this difference is a temperature effect, as temperature increases $\mathrm{pH}$ decreases. The data in Table 29 represent an online measurement of heated desiccant

Table 33. Desiccant Analyses Results, Test Series I

\begin{tabular}{|c|c|c|c|c|c|c|c|}
\hline Test No. & $\mathrm{pH}$ & $\begin{array}{l}\text { Specific } \\
\text { Gravity }\end{array}$ & $\begin{array}{l}\text { Sulfate, } \\
\mathrm{mg} / \mathrm{L}\end{array}$ & $\begin{array}{c}\text { Desiccant } \\
\text { Circulation Rate, } \\
\text { gpm }\end{array}$ & $\begin{array}{l}\text { L/G Ratio, } \\
\mathrm{gal} / 1000 \mathrm{acf}\end{array}$ & $\begin{array}{l}\text { Desiccant } \\
\text { Conc., wt } \%\end{array}$ & $\begin{array}{c}\mathrm{H}_{2} \mathrm{O} \\
\text { Recovery, } \\
\text { lb/hr }\end{array}$ \\
\hline Test No. 1.2 & 3.61 & 1.496 & $<3$ & 43.5 & 99.3 & 45.8 & 51.2 \\
\hline Abs. Inlet & & & & Six nozzles & & & \\
\hline $\begin{array}{l}\text { Test No. } 1.2 \\
\text { Abs. Outlet }\end{array}$ & 3.95 & 1.465 & $<3$ & & & & \\
\hline $\begin{array}{l}\text { Test No. } 6 \\
\text { Abs. Inlet }\end{array}$ & 4.00 & 1.489 & $<3$ & $\begin{array}{c}7.1 \\
\text { One nozzle }\end{array}$ & 16.3 & 46.7 & 32.4 \\
\hline $\begin{array}{l}\text { Test No. } 6 \\
\text { Abs. Outlet. }\end{array}$ & 4.09 & 1.464 & $<3$ & & & & \\
\hline $\begin{array}{l}\text { Test No. } 8 \\
\text { Abs. Inlet }\end{array}$ & 3.87 & 1.493 & $<3$ & $\begin{array}{c}14.3 \\
\text { One nozzle }\end{array}$ & 32.9 & 46.8 & 43.8 \\
\hline $\begin{array}{l}\text { Test No. } 8 \\
\text { Abs. Outlet }\end{array}$ & 3.95 & 1.482 & $<3$ & & & & \\
\hline $\begin{array}{l}\text { Test No. } 14 \\
\text { Abs. Inlet }\end{array}$ & 3.93 & 1.480 & $<3$ & $\begin{array}{c}7.1 \text { One } \\
\text { nozzle/packing }\end{array}$ & 16.4 & 46.5 & $\begin{array}{l}37.8- \\
38.4\end{array}$ \\
\hline $\begin{array}{l}\text { Test No. } 14 \\
\text { Abs. Outlet }\end{array}$ & 4.16 & 1.472 & $<3$ & & & & \\
\hline $\begin{array}{l}\text { Test No. } 15 \\
\text { Abs. Inlet }\end{array}$ & 3.95 & 1.492 & $<3$ & $\begin{array}{c}\text { 14.3 One } \\
\text { nozzle/packing }\end{array}$ & 33.2 & 46.6 & 50.8 \\
\hline $\begin{array}{l}\text { Test No. } 15 \\
\text { Abs. Outlet }\end{array}$ & 4.07 & 1.473 & $<3$ & & & & \\
\hline
\end{tabular}


solution. The data in Table 33 represent samples collected and analyzed at a later date. Also, the potential for $\mathrm{CO}_{2}$ offgassing during sample handling may be a contributing factor. Carbon dioxide offgassing would result in an increase in measured $\mathrm{pH}$.

Specific gravity data show a consistent trend with respect to water absorption in the absorber column. Specifically, the specific gravity of the desiccant solution at the inlet of the absorber is greater than the specific gravity of the desiccant solution pumped to the flash drum. This is consistent with the dilution affect of water absorption. However, the specific gravity data for the absorber inlet samples are not consistent with the online desiccant concentration measurement data resulting from the Coriolis meter. The reason for this difference is primarily a temperature effect; the desiccant concentration data in Table 28 represent an online measurement of the heated desiccant solution, and the specific gravity measurement data in Table 33 represent samples collected and analyzed at a later date.

Water production was a function of several variables including desiccant temperature, desiccant concentration, flow rates, desiccant/gas contact method, and flash drum pressure. Figure 28 illustrates desiccant flow rate and water production during this test series. Figure 29 is a comparison of the water quality produced in the LDDS during this test series and that of reverse osmosis (RO)treated water. This produced water would require little or no treatment prior to use in many plant applications.

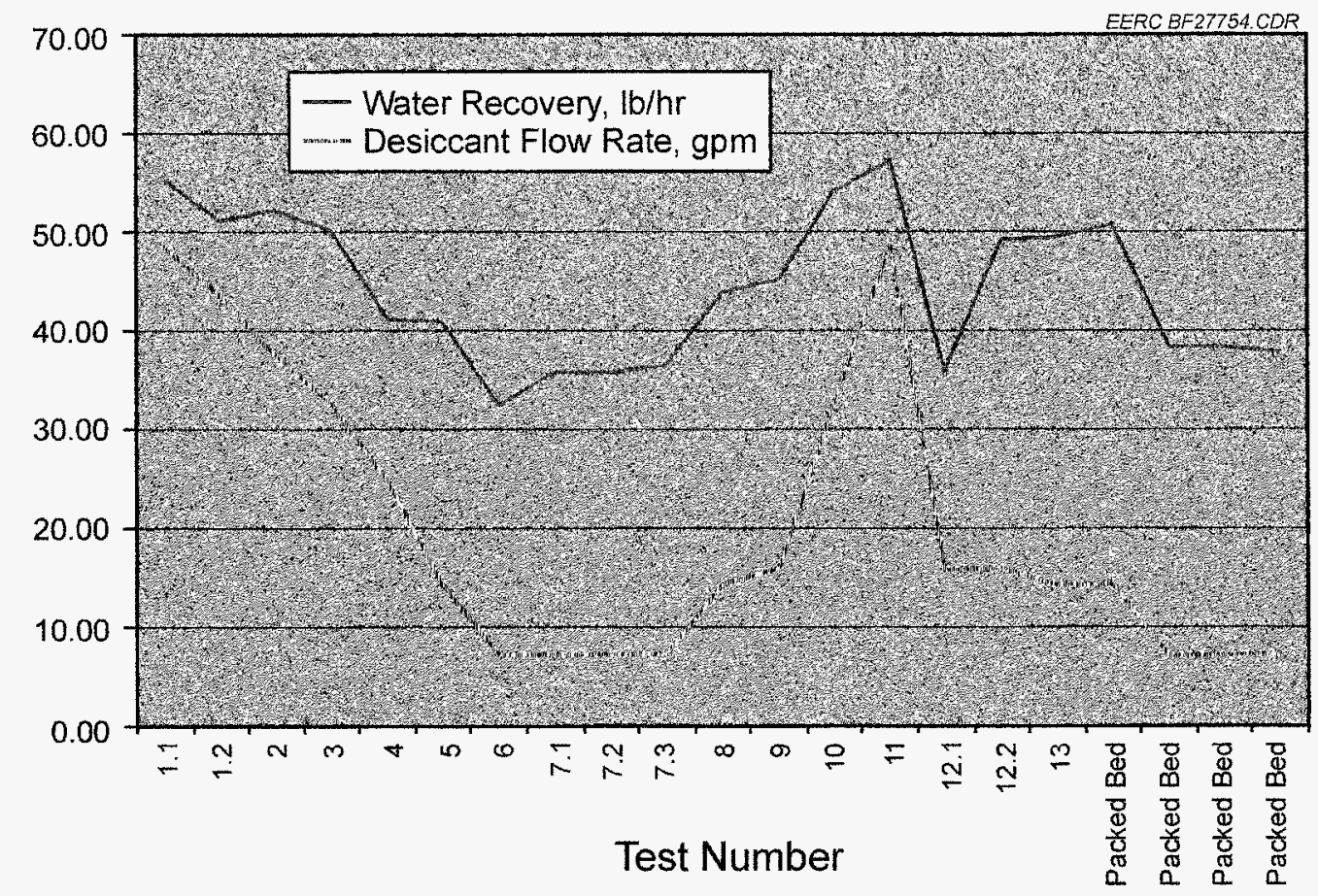

Figure 28. Average absorber water recovery rate versus absorber desiccant circulation rate and absorber configuration, Test Series I. 


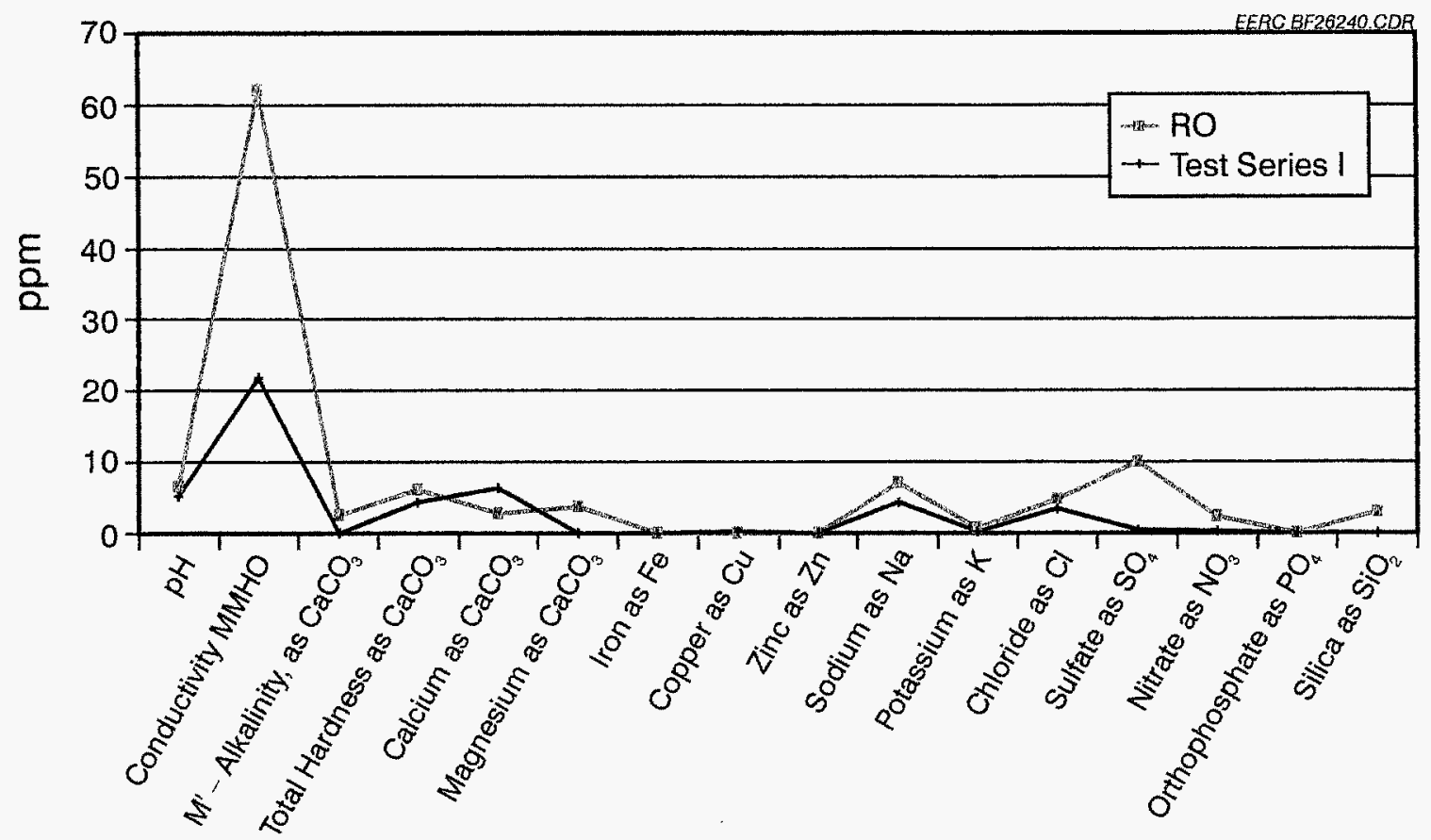

Figure 29. Water quality from the LDDS compared to RO-treated water.

Product water samples were collected for each test period for Test Series I, and select samples were analyzed for water quality. Table 34 summarizes the analytical results for five product water samples and compares the data with similar measurements for deionized (DI) and city tap water. Product water $\mathrm{pH}$ values were similar to the $\mathrm{DI}$ water $\mathrm{pH}$ value, consistent with the vaporization and condensation methodologies used to produce these samples. The higher $\mathrm{pH}$ of the city tap water is consistent with its calcium and sulfate content. TDS levels for the product water samples were greater than the DI water sample and less than the city tap water sample. Although the calcium, chloride, and sulfate content of the product water is a partial explanation for the differences, the analysis results reported in Table 34 do not document all of the constituents contributing to the TDS content of the samples.

Table 35 summarizes product water analyses for a Test Series I sample submitted to Nalco Analytical Resources. The water $\mathrm{pH}$ reported is on the high end of the EERC data range. Calcium, chloride, nitrate, and sulfate concentration data are consistent with the EERC data. Other cations, metals, and anions found to be at or greater than detection limits included boron, copper, iron, lithium, manganese, potassium, sodium, strontium, zinc, nitrate, nitrite, and sulfate. Based on the analyses completed, the product water generated during Test Series I would require minimal upgrading for use in a utility station steam cycle.

Figure 30 illustrates the quality of the water produced in the LDDS in Test Series I compared to water quality from a typical power plant reverse osmosis system output (ROO). With the exception of a slightly higher concentration of the calcium as $\mathrm{CaCO}_{3}$ value, the produced water from the LDDS in Test Series I is equal to or better than that of the water from ROO in a typical power 
Table 34. Product Water Analyses Results, Test Series I

\begin{tabular}{lccccccc}
\hline Test No. & $\mathrm{pH}$ & $\begin{array}{c}\text { TDS, } \\
\mathrm{mg} / \mathrm{L}\end{array}$ & $\begin{array}{c}\mathrm{TSS}^{2}{ }^{2} \mathrm{mg} / \mathrm{L} \\
\text { Test No. 1B }\end{array}$ & $\begin{array}{c}\text { Calcium, } \\
\mathrm{mg} / \mathrm{L}\end{array}$ & $\begin{array}{c}\text { Chloride, } \\
\mathrm{mg} / \mathrm{L}\end{array}$ & $\begin{array}{c}\text { Nitrate, } \\
\mathrm{mg} / \mathrm{L}\end{array}$ & $\begin{array}{c}\text { Sulfate, } \\
\mathrm{mg} / \mathrm{L}\end{array}$ \\
\hline Test No. 6 & 5.35 & 16 & $<10$ & 1.71 & 3.2 & $<1$ & $<1$ \\
Test No. 8 & 4.50 & 18 & $<10$ & 0.85 & 2.0 & $<1$ & $<1$ \\
Test No. 14 & 4.79 & 16 & $<10$ & 2.15 & 3.2 & $<1$ & $<1$ \\
Test No. 15 & 4.30 & 20 & $<10$ & 0.59 & 1.3 & $<1$ & $<1$ \\
DI Water & 4.32 & 18 & $<10$ & 0.43 & 1.2 & $<1$ & $<1$ \\
City Tap Water & 4.31 & $<1$ & $<10$ & $<0.09$ & $<1$ & $<1$ & $<1$ \\
\hline
\end{tabular}

${ }^{\mathrm{I}}$ Total dissolved solids.

${ }^{2}$ Total suspended solids.

plant. Water from the ROO is generally near boiler make-up water ready with potentially a degassing step prior to introduction into the steam cycle. This illustrates the potential high quality of the produced water from the LDDS process.

Absorber and flash drum desiccant solution and product water samples collected during Test Series I were selectively analyzed. However, all of the samples collected were retained until this report was completed and approved to accommodate further analyses if desired. Subsequently, the samples were disposed of in an appropriate manner.

\subsubsection{Evaluation of LDDS Performance - Pilot-Scale Test Series II}

Test Series II was a weeklong effort beginning November 14 and continuing through November 20, 2004. Natural gas was fired in the SFS in support of several test periods. However, pulverized subbituminous coal was the primary fuel for this test series in order to simulate flue gas conditions downstream of a particulate control device and FGD system supporting a coal-fired utility boiler, low excess oxygen ( $4-5 \mathrm{vol} \% \mathrm{O}_{2}$, dry basis), low $\mathrm{SO}_{2}$ concentration ( $<300$ ppmv, dry basis), low temperature $\left(135^{\circ} \mathrm{F}\left[58^{\circ} \mathrm{C}\right]\right)$, and high moisture content $\left(14-15 \mathrm{vol} \% \mathrm{H}_{2} \mathrm{O}\right)$. Flue gas flow rate at the inlet of the LDDS absorber column was nominally $450 \mathrm{acfm}\left(12.7 \mathrm{~m}^{3} / \mathrm{min}\right)$. These flue gas conditions were achieved as a result of furnace firing conditions and the use of heat exchangers and two dual-fluid humidification nozzles between the furnace and LDDS absorber column.

Thirteen individual test conditions were planned. However, only nine test conditions were completed, during fourteen individual test periods (six natural gas-fired and eight coal-fired), because of desiccant solution holdup in the flash drum and the need to modify the desiccant discharge piping to correct the problem. Desiccant holdup in the flash drum appeared to be the result of product water flashing from the desiccant solution in the flash drum as well as the $2-\mathrm{in} .(5-\mathrm{cm})$ CPVC discharge line to the 100-gal (378-L) tank. The problem was solved by replacing $12-\mathrm{ft}(3.7-\mathrm{m})$ of 2-in. (5-cm) CPVC pipe with $12 \mathrm{ft}(3.7 \mathrm{~m})$ of 4-in. (10-cm) 304 SS pipe, used because it was available. The increased volume of the $4-\mathrm{in} .(10-\mathrm{cm})$ pipe allowed the product water to evolve from the desiccant solution without liquid holdup in the flash drum. Seven of the nine test conditions completed involved operation of the LDDS absorber in a spray tower configuration with two 
Table 35. Nalco Analytical Resources Product Water Analyses

Results, Test Series I

\begin{tabular}{|c|c|c|}
\hline Cations/Metals & Filtered, mg/L & Total, $\mathrm{mg} / \mathrm{L}$ \\
\hline Aluminum (Al) & $<0.1$ & $<0.1$ \\
\hline Barium $(\mathrm{Ba})$ & $<0.1$ & $<0.1$ \\
\hline Boron $(B)$ & 0.1 & 0.1 \\
\hline Cadmium (Cd) & $<0.01$ & $<0.01$ \\
\hline Calcium (Ca) & 1.8 & 2.4 \\
\hline Chromium (Cr) & $<0.01$ & $<0.01$ \\
\hline Copper $(\mathrm{Cu})$ & 0.15 & 0.15 \\
\hline Iron $(\mathrm{Fe})$ & 0.02 & 0.05 \\
\hline Lead $(\mathrm{Pb})$ & $<0.1$ & $<0.1$ \\
\hline Lithium (Li) & $<0.01$ & 0.01 \\
\hline Magnesium (Mg) & $<0.1$ & $<0.1$ \\
\hline Manganese (Mn) & 0.02 & 0.02 \\
\hline Molybdenum (Mo) & $<0.1$ & $<0.1$ \\
\hline Nickel (Ni) & $<0.1$ & $<0.1$ \\
\hline Phosphorus (P) & $<1.0$ & $<1.0$ \\
\hline Phosphorus $\left(\mathrm{PO}_{4}\right)$ & $<3.1$ & $<3.1$ \\
\hline Potassium (K) & $<0.2$ & 0.3 \\
\hline Silica $\left(\mathrm{SiO}_{2}\right)$ & $<0.2$ & $<0.2$ \\
\hline Sodium (Na) & 0.4 & 0.4 \\
\hline Strontium (Sr) & 0.03 & 0.04 \\
\hline Vanadium (V) & $<0.01$ & $<0.01$ \\
\hline Zinc $(\mathrm{Zn})$ & 0.01 & 0.01 \\
\hline Calcium $\left(\mathrm{CaCO}_{3}\right)$ & 4.4 & 6.0 \\
\hline Magnesium ( reported as $\mathrm{CaCO}_{3}$ ) & $<0.4$ & $<0.4$ \\
\hline Sodium (reported as $\mathrm{CaCO}_{3}$ ) & 0.8 & 0.8 \\
\hline Calculated Hardness $\left(\mathrm{CaCO}_{3}\right)$ & 4.4 & 6.0 \\
\hline \multicolumn{3}{|l|}{ Anions } \\
\hline Bromide $(\mathrm{Br})$ & - & $<0.20$ \\
\hline Chloride (Cl) & - & 3.5 \\
\hline Nitrate $\left(\mathrm{NO}_{3}\right)$ & - & 0.26 \\
\hline Nitrite $\left(\mathrm{NO}_{2}\right)$ & - & 0.96 \\
\hline Sulfate $\left(\mathrm{SO}_{4}\right)$ & - & 0.41 \\
\hline Chloride $\left(\mathrm{CaCO}_{3}\right)$ & - & 5.0 \\
\hline Nitrate $\left(\mathrm{CaCO}_{3}\right)$ & - & 0.21 \\
\hline Sulfate $\left(\mathrm{CaCO}_{3}\right)$ & - & 0.42 \\
\hline \multicolumn{3}{|l|}{ Alkalinity } \\
\hline Bicarbonate $\left(\mathrm{CaCO}_{3}\right)$ & - & 20 \\
\hline Methyl Orange $\left(\mathrm{CaCO}_{3}\right)$ & - & 20 \\
\hline Phenolphthalein $\left(\mathrm{CaCO}_{3}\right)$ & - & $<1$ \\
\hline \multicolumn{3}{|l|}{ Others } \\
\hline $\mathrm{pH}$ & - & 5.3 pH units \\
\hline Conductivity & - & $22 \mu \mathrm{S} / \mathrm{cm}$ \\
\hline
\end{tabular}




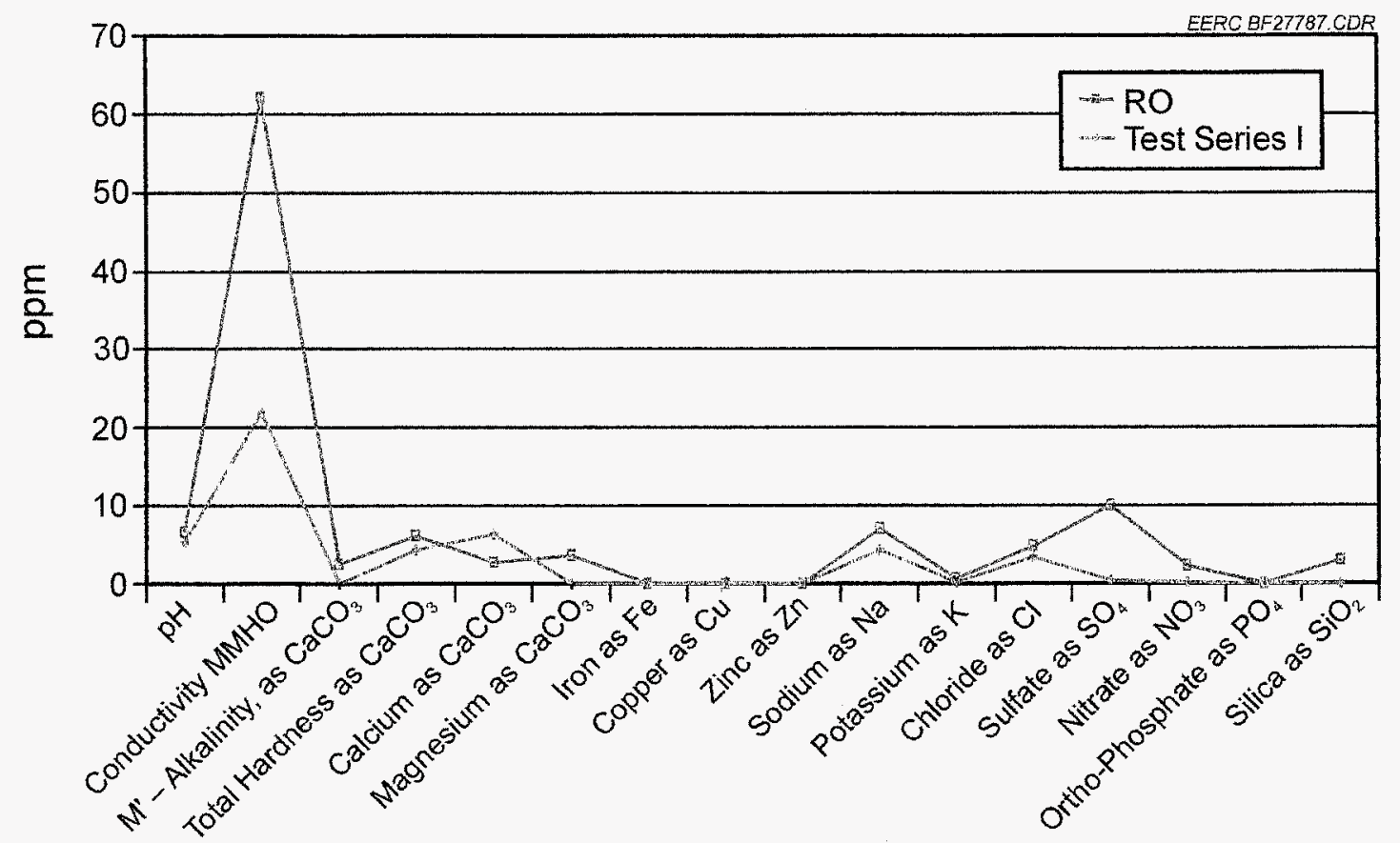

Figure 30. Produced water quality from Test Series I compared to ROO water.

evaluating a packed-bed configuration. Five of the nine test conditions completed involved coal firing, including the two tests using the packed-bed configuration. During the spray tower and packed-bed configuration tests, primary independent variables included number of spray levels, desiccant circulation rate, desiccant concentration, and absorber desiccant temperature. The primary dependent variable was product water recovery.

Table 36 summarizes analytical results for the Belle Ayr subbituminous coal fired during Test Series II. This fuel was selected because it represented a coal type of general commercial interest and it was available in sufficient quantities in the EERC's inventory. During the coal-fired test periods, fuel feed rate ranged from 154 to $160 \mathrm{lb} / \mathrm{hr}$ (70 to $73 \mathrm{~kg} / \mathrm{hr}$ ) with adjustments made to control flue gas oxygen concentrations and flue gas flow rate to the absorber column. Generally, the coal feed rate was quite stable except for a few minor spikes (high and low) associated with coal hopper refill cycles.

Analyses of the composite Belle Ayr subbituminous coal sample collected during individual test periods indicated that the as-fired fuel contained $14.2 \mathrm{wt} \%$ moisture, $6.0 \mathrm{wt} \%$ ash, and $0.4 \mathrm{wt} \%$ sulfur. The heating value was $9602 \mathrm{Btu} / \mathrm{lb}(22,313 \mathrm{~kJ} / \mathrm{kg})$ on an as-fired basis. Coal ash was analyzed for ash fusion properties under oxidizing conditions. Results indicate a softening temperature of $2256^{\circ} \mathrm{F}\left(1236^{\circ} \mathrm{C}\right)$ and a fluid temperature of $2311^{\circ} \mathrm{F}\left(1266^{\circ} \mathrm{C}\right)$. Moisture levels for subbituminous coals are typically in the range of $20-30 \mathrm{wt} \%$. The Belle Ayr coal fired in support of this project was dryer than anticipated. Therefore, it was necessary to increase water injection through the dual-fluid nozzles to achieve the desired flue gas moisture content at the inlet of the absorber column. 
Table 36. Results of Coal and Coal Ash Analyses for Test Series II

\begin{tabular}{|c|c|}
\hline & $\begin{array}{c}\text { Belle Ayr } \\
\text { Subbituminous Coal }\end{array}$ \\
\hline \multicolumn{2}{|l|}{ Proximate Analysis, wt $\%$} \\
\hline Moisture & 14.2 \\
\hline Volatile Matter & NA \\
\hline Fixed Carbon & NA \\
\hline Ash & 6.0 \\
\hline \multicolumn{2}{|l|}{ Ultimate Analysis, wt \% } \\
\hline Hydrogen & 5.3 \\
\hline Carbon & 56.7 \\
\hline Nitrogen & 1.0 \\
\hline Sulfur & 0.4 \\
\hline Oxygen & 30.6 \\
\hline Ash & 6.0 \\
\hline Heating Value, Btu/lb & 9602 \\
\hline Mercury, $\mu \mathrm{g} / \mathrm{g}$ & 0.12 \\
\hline \multicolumn{2}{|l|}{ Percent as Oxides, wt $\%$} \\
\hline $\mathrm{SiO}_{2}$ & 28.1 \\
\hline $\mathrm{Al}_{2} \mathrm{O}_{3}$ & 14.3 \\
\hline $\mathrm{Fe}_{2} \mathrm{O}_{3}$ & 6.1 \\
\hline $\mathrm{TiO}_{2}$ & 1.5 \\
\hline $\mathrm{P}_{2} \mathrm{O}_{5}$ & 1.0 \\
\hline $\mathrm{CaO}$ & 26.3 \\
\hline $\mathrm{MgO}$ & 5.0 \\
\hline $\mathrm{Na}_{2} \mathrm{O}$ & 1.5 \\
\hline $\mathrm{K}_{2} \mathrm{O}$ & 0.1 \\
\hline $\mathrm{SO}_{3}$ & 15.9 \\
\hline \multicolumn{2}{|l|}{ Ash Fusion Temp., ${ }^{\circ} \mathrm{F}$} \\
\hline Initial & 2241 \\
\hline Softening & 2256 \\
\hline Hemisphere & 2279 \\
\hline Fluid & 2311 \\
\hline \multicolumn{2}{|l|}{ Sieve Analysis } \\
\hline \multicolumn{2}{|l|}{ Screen Mesh Size } \\
\hline 100 & 9.6 \\
\hline 140 & 13.3 \\
\hline 200 & 12.2 \\
\hline 230 & 8.3 \\
\hline 270 & 1.8 \\
\hline 325 & 11.3 \\
\hline Pan & 43.4 \\
\hline Total \% & 99.9 \\
\hline
\end{tabular}


Dry-sieve analysis indicated that the pulverized Belle Ayr subbituminous coal was 65 wt $\%$ -200 mesh $(74 \mu \mathrm{m})$. Typically, the EERC attempts to achieve at least $70 \mathrm{wt} \%-200 \mathrm{mesh}(74 \mu \mathrm{m})$. Occasionally, poor pulverization performance can be attributed to excessive fuel surface moisture, damaged pulverizer screens, worn pulverizer hammers, or a combination of these factors. The EERC investigated possible reasons for the marginal pulverizer performance but could not find an obvious explanation. However, because of the high furnace operating temperature, combustion efficiency was not affected by fuel particle size. The carbon content of the fly ash collected in the baghouse was low for Test Series II, $0.24 \mathrm{wt} \%$.

XRF analysis results for the ashed fuel is summarized in Table 36 and reported as wt $\%$ oxides. Analysis of the coal ash indicates that the primary components are silica $\left(28.1 \mathrm{wt} \% \mathrm{SiO}_{2}\right)$, calcium $(26.3 \mathrm{wt} \% \mathrm{CaO})$, alumina $\left(14.3 \mathrm{wt} \% \mathrm{Al}_{2} \mathrm{O}_{3}\right)$, and iron $\left(6.1 \mathrm{wt} \% \mathrm{Fe}_{2} \mathrm{O}_{3}\right)$. Alkaline-earth and alkali components $\left(\mathrm{CaO}, \mathrm{MgO}, \mathrm{Na}_{2} \mathrm{O}\right.$, and $\left.\mathrm{K}_{2} \mathrm{O}\right)$ combined represent $33 \mathrm{wt} \%$ in the ash. These ash properties are representative of subbituminous coals and are consistent with the ash fusion temperatures observed.

\subsection{SFS Operating Parameters}

SFS operating parameters were selected to achieve desired operating conditions at the inlet of the LDDS absorber column, specifically, flue gas flow rate, moisture and $\mathrm{O}_{2}$ content, and temperature. Table 37 summarizes the furnace firing rate, primary and secondary combustion air flow rates, and several SFS flue gas temperatures. Average furnace firing rate during the natural gasfired tests was $1.62 \mathrm{MMBtu} / \mathrm{hr}(1.70 \mathrm{~kJ} / \mathrm{hr})$ with standard deviations $<0.006 \mathrm{MMBtu} / \mathrm{hr}$ $(<0.006 \mathrm{~kJ} / \mathrm{hr})$. Average furnace firing rates during the coal-fired test periods ranged from 1.51 to $1.58 \mathrm{MMBtu} / \mathrm{hr}(1.59$ to $1.67 \mathrm{~kJ} / \mathrm{hr})$ with standard deviations typically $<0.02 \mathrm{MMBtu} / \mathrm{hr}$ $(<0.02 \mathrm{~kJ} / \mathrm{hr})$. Test periods resulting in higher standard deviations, Test Nos. 1, 6.2, and 8 , were the result of firing rate changes made during the individual test periods. Firing rate changes were made during individual test periods to adjust the flue gas flow rate and $\mathrm{O}_{2}$ content at the inlet of the LDDS absorber. Furnace firing rate for Tests 1 through 6.1 and 6.2 through 13.2 were a direct function of the natural gas and coal feed rates, respectively. Average coal feed rates ranged from 154.8 to $160.5 \mathrm{lb} / \mathrm{hr}(70.3$ to $72.9 \mathrm{~kg} / \mathrm{hr})$ with typical standard deviations of $<2.0 \mathrm{lb} / \mathrm{hr}(<0.9 \mathrm{~kg} / \mathrm{hr})$.

Data are summarized for both PCA and SCA flow rate in Table 37. PCA flow rate represented $25 \%$ to $28 \%$ of the total combustion air flow rate and averaged 76 to $80 \mathrm{scfm}$ ( 2.2 to $\left.2.3 \mathrm{~m}^{3} / \mathrm{min}\right)$ with typical standard deviations of $1.0 \mathrm{scfm}\left(0.03 \mathrm{~m}^{3} / \mathrm{min}\right)$. SCA flow rate represented $72 \%$ to $75 \%$ of the total combustion air flow rate and averaged 200 to $240 \mathrm{scfm}\left(5.7\right.$ to $\left.6.8 \mathrm{~m}^{3} / \mathrm{min}\right)$ for individual test periods with typical standard deviations of $<1.6 \mathrm{scfm}\left(0.05 \mathrm{~m}^{3} / \mathrm{min}\right)$. Average furnace exit flue gas temperatures ranged from $2259^{\circ}$ to $2589^{\circ} \mathrm{F}\left(1238^{\circ}\right.$ to $\left.1421^{\circ} \mathrm{C}\right)$ with typical standard deviations of $<8^{\circ} \mathrm{F}\left(<4.4^{\circ} \mathrm{C}\right)$. Furnace exit temperatures observed were a function of the natural gas or coal firing rate and the low excess combustion air levels. In general, furnace exit temperature increased during Test Series $\Pi$ as fuel firing switched from natural gas to coal and the furnace refractory approached thermal equilibrium.

CAH inlet flue gas temperatures were not available for Tests 13.1 and 13.2 because of a failed thermocouple. In addition, flue gas temperature measurements at the outlet of tube-and-shell heat 


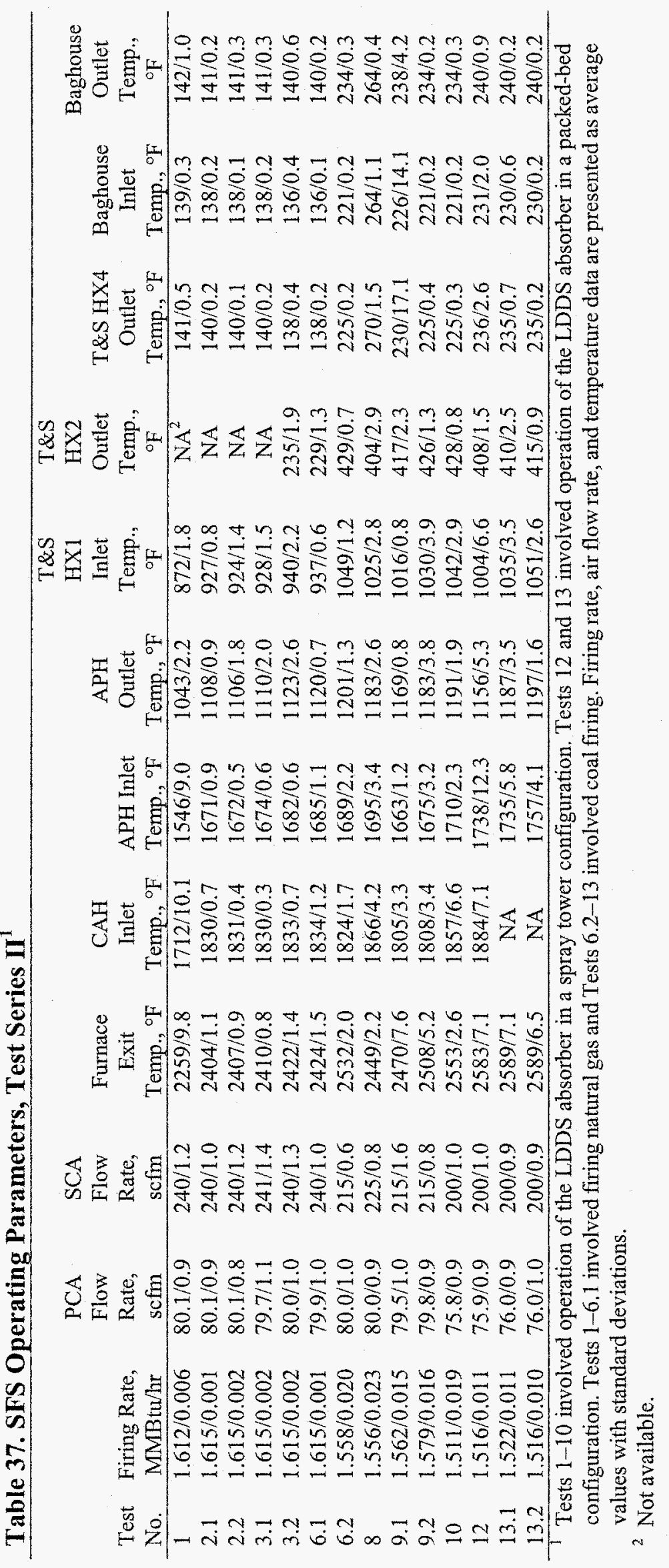


exchanger No. 2 are not reported for Tests 1,2.1,2.2, and 3.1 because the thermocouple was measuring the temperature of accumulated condensed moisture rather than flowing flue gas.

Baghouse flue gas temperatures (inlet and outlet) were nominally $136^{\circ}$ to $142^{\circ} \mathrm{F}\left(58^{\circ}\right.$ to $61^{\circ} \mathrm{C}$ ) and $221^{\circ}$ to $240^{\circ} \mathrm{F}\left(105^{\circ}\right.$ to $\left.116^{\circ} \mathrm{C}\right)$ for the natural gas- and coal-fired test periods, respectively. Standard deviations for baghouse flue gas temperatures were typically $<1.0^{\circ} \mathrm{F}\left(<0.6^{\circ} \mathrm{C}\right)$. Higher values were the result of changes to furnace firing rate and combustion air flow rate. Baghouse outlet flue gas temperatures were slightly higher than inlet temperatures because the baghouse is electrically heat-traced, and the controllers were intentionally set to increase flue gas temperature in order to ensure that flue gas moisture was not condensing in the baghouse. Flue gas piping between the baghouse and the absorber column was also electrically heat-traced to promote vaporization of water injected through a dual-fluid atomizer and prevent flue gas moisture condensation on surfaces. These data indicate that desired SFS temperature control for Test Series II was achieved using a combination of SFS heat exchangers, the baghouse and downstream piping electrical heaters, and the dual-fluid atomizer.

Flue gas composition at the furnace exit was not monitored continuously in order to continuously monitor flue gas composition at the inlet and outlet of the absorber column. However, based on measurements made during a 1-hour period immediately prior to initiating absorber tests, flue gas $\mathrm{O}_{2}$ and $\mathrm{CO}_{2}$ concentrations at the furnace exit were $6.0 \pm 0.1 \mathrm{vol} \%$ and $10.4 \pm 0.2 \mathrm{vol} \%$, respectively. Flue gas CO concentration was 0 ppmv. These data are reported on a dry flue gas basis and are similar to initial Test Series II data for the absorber inlet sample location. Differences were the result of air in-leakage between the furnace exit and absorber inlet. Specifically, the oxygen content at the furnace exit was lower with the $\mathrm{CO}_{2}$ concentration higher than that measured at the absorber inlet. Because natural gas was fired in the slagging furnace during the first six test periods, flue gas $\mathrm{SO}_{2}$ concentrations were not initially measured. Flue gas $\mathrm{NO}_{\mathrm{x}}$ concentration at the furnace exit was $180 \pm 7$ ppmv during initial natural gas firing.

\subsection{LDDS Operating Parameters}

Table 38 summarizes LDDS absorber operating parameters for Test Series II. Process data include 1) flue gas inlet and outlet temperatures; 2) desiccant concentration, circulation rate, and temperature; and 3) absorber flue gas flow rate and L/G ratio. Average flue gas temperatures at the LDDS absorber inlet ranged from $134^{\circ}$ to $137^{\circ} \mathrm{F}\left(57^{\circ}\right.$ to $\left.59^{\circ} \mathrm{C}\right)$ with typical standard deviations of $<0.5^{\circ} \mathrm{F}\left(<0.3^{\circ} \mathrm{C}\right)$. Absorber outlet flue gas temperatures ranged from $134^{\circ}$ to $149^{\circ} \mathrm{F}\left(57^{\circ}\right.$ to $\left.65^{\circ} \mathrm{C}\right)$ with standard deviations of $\angle 2^{\circ} \mathrm{F}\left(<1.1^{\circ} \mathrm{C}\right)$. These data indicate that desired absorber flue gas temperatures were achieved and temperature control during Test Series II was very good.

Desiccant concentration values at the inlet of the absorber column ranged from 42.6 to $50.7 \mathrm{wt} \%$, but were typically $>45 \mathrm{wt} \%$ with standard deviations of $\leq 0.5 \mathrm{wt} \%$, for most test periods. With the exception of one test period, these values are consistent with or slightly less than the $46.7 \mathrm{wt} \%$ desiccant concentration originally planned for Test Series II. For two test periods, the desiccant concentration was intentionally reduced to $<43 \mathrm{wt} \%$. Measured desiccant specific gravity values for select samples ranged from 1.4744 to 1.4894 . 


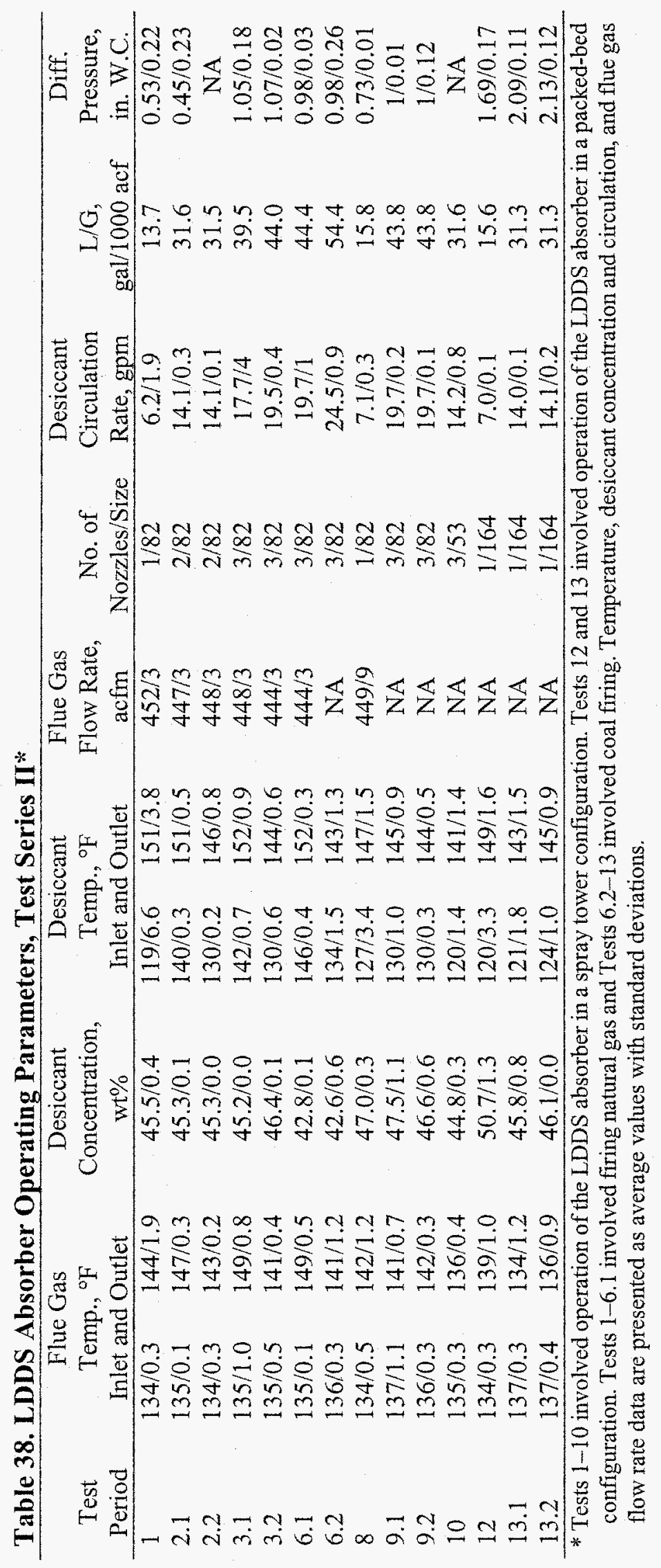


Desiccant temperatures entering the LDDS absorber through the nozzles and exiting the LDDS absorber into the tank ranged from $119^{\circ}$ to $146^{\circ} \mathrm{F}\left(49^{\circ}\right.$ to $\left.64^{\circ} \mathrm{C}\right)$ and from $141^{\circ}$ to $152^{\circ} \mathrm{F}\left(61^{\circ}\right.$ to $67^{\circ} \mathrm{C}$ ), respectively. Typical standard deviations for these desiccant temperatures were $\leq 2.0^{\circ} \mathrm{F}$ $\left(1.1^{\circ} \mathrm{C}\right)$. Desiccant circulation rates ranged from 6.2 to $24.5 \mathrm{gpm}(23.5$ to $92.7 \mathrm{Lpm})$ with the number and size of the nozzles selected to match the desired rate. Circulation rate variations during individual test periods were typically 0.1 to $1 \mathrm{gpm}(0.4$ to $3.8 \mathrm{Lpm})$. Standard deviations $>1.0 \mathrm{gpm}$ $(>3.8 \mathrm{Lpm})$ were the result of occasional nozzle plugging during individual test periods.

Flue gas flow rates ranged from 444 to $452 \mathrm{acfm}\left(12.6\right.$ to $\left.12.8 \mathrm{~m}^{3} / \mathrm{min}\right)$, resulting in absorber velocities of 9.8 to $10.0 \mathrm{ft} / \mathrm{s}(3.0 \mathrm{~m} / \mathrm{s})$. Calculated $\mathrm{L} / \mathrm{G}$ ratios ranged from 13.7 to $54.4 \mathrm{gal} / 1000 \mathrm{acf}$. LDDS absorber differential pressure ranged from 0.5 to 2.1 in. W.C. (0.9 to $3.9 \mathrm{mmHg}$ ) depending on desiccant circulation rates and absorber configuration, spray tower versus packed bed. The lower end of the differential pressure range represented a spray tower configuration and a low desiccant circulation rate with the high end of the range representing a packed-bed configuration and a low desiccant circulation rate. Absorber flue gas flow rate data are not reported for Tests 6.2, 9.1, 9.2, 10, $12,13.1$, and 13.2 because of an annubar failure. Prior to any future tests, the EERC would recommend replacing the annubar at the absorber inlet with a venturi, $v$-cone, or orifice plate measurement device. Absorber differential pressure data are not reported for Tests 2.2 and 10 because of variable data resulting from pressure tap plugging. In general, the desired LDDS absorber operating parameters were achieved, and operational stability was good as indicated by the low standard deviation values reported for individual parameters.

Table 39 summarizes LDDS flash drum operating parameters for Test Series II. Flash drum process data include 1) desiccant inlet and outlet temperatures, 2) desiccant circulation rate and $\mathrm{pH}$, and 3) flash drum operating pressure. Average desiccant temperatures at the LDDS flash drum inlet ranged from $142^{\circ}$ to $171^{\circ} \mathrm{F}\left(61^{\circ}\right.$ to $\left.78^{\circ} \mathrm{C}\right)$ with typical standard deviations of $0.2^{\circ}$ to $5.0^{\circ} \mathrm{F}\left(0.1^{\circ}\right.$ to $2.8^{\circ} \mathrm{C}$ ). The range of flash drum inlet temperatures was a result of selected set points. However, the range of standard deviations resulted from regulator problems controlling steam flow to the desiccant heater. Therefore, one of the recommended modifications to the LDDS prior to any future work is the replacement of the desiccant heater steam control regulator. Flash drum outlet desiccant temperatures ranged from $133^{\circ}$ to $152^{\circ} \mathrm{F}\left(56^{\circ}\right.$ to $\left.67^{\circ} \mathrm{C}\right)$ with standard deviations of $0.2^{\circ}$ to $8.3^{\circ} \mathrm{F}$ $\left(0.1^{\circ}\right.$ to $\left.4.6^{\circ} \mathrm{C}\right)$.

Desiccant concentration values were not measured continuously at the inlet of the flash drum. Specific gravity measurements for selected samples showed that the desiccant concentration decreased as a result of water being absorbed into the desiccant solution from the flue gas in the absorber column. Measured desiccant specific gravity values for select samples ranged from 1.4588 to 1.5084 . Flash drum desiccant circulation rates ranged from 7.3 to $24.8 \mathrm{gpm}$ (27.6 to $93.9 \mathrm{Lpm}$ ). For this range of circulation rates, the desiccant circulation rate from the regeneration pump is slightly higher than the rate from the absorber pump. The reason for this difference is the control philosophy employed in the pilot-scale system (regeneration tank level and pump discharge rate), the fact that water recovered in the absorber contributed to the desiccant circulation rate to the flash drum, and the potential for slight variations in meter measurement performance for the two desiccant streams. Flash drum circulation rate variations during individual test periods were typically $\leq 0.2$ gpm ( $\leq 0.8 \mathrm{Lpm})$. 
Table 39. LDDS Flash Drum Operating Parameters, Test Series II*

\begin{tabular}{|c|c|c|c|c|c|c|}
\hline $\begin{array}{c}\text { Test } \\
\text { Period }\end{array}$ & $\begin{array}{r}\text { Des } \\
\text { Ten } \\
\text { Inlet a1 }\end{array}$ & $\begin{array}{l}\text { ant } \\
{ }^{\circ} \mathrm{F} \\
\text { Outlet }\end{array}$ & $\begin{array}{c}\text { Desiccant } \\
\text { Specific } \\
\text { Gravity }\end{array}$ & $\begin{array}{c}\text { Desiccant } \\
\mathrm{pH}\end{array}$ & $\begin{array}{c}\text { Flash Drum } \\
\text { Vac. Press., } \\
\text { psia }\end{array}$ & $\begin{array}{l}\text { Desiccant } \\
\text { Circulation } \\
\text { Rate, gpm }\end{array}$ \\
\hline 1 & $166 / 4.2$ & $152 / 8.3$ & NA & $6.2 / 0.0$ & $0.93 / 0.04$ & $7.3 / 0.5$ \\
\hline 2.1 & $154 / 0.5$ & $140 / 0.2$ & NA & $4.6 / 0.4$ & $1.08 / 0.01$ & $14.4 / 0.1$ \\
\hline 2.2 & $155 / 0.2$ & $139 / 0.3$ & $\mathrm{NA}$ & $4.0 / 0.1$ & $0.91 / 0.00$ & $14.4 / 0.1$ \\
\hline 3.1 & $153 / 3.0$ & $141 / 3.4$ & NA & $3.9 / 0.0$ & $1.14 / 0.10$ & $17.6 / 6.3$ \\
\hline 3.2 & $160 / 2.2$ & $145 / 1.8$ & 1.4746 & $3.8 / 0.0$ & $1.20 / 0.11$ & $20.0 / 0.1$ \\
\hline 6.1 & $152 / 1.1$ & $145 / 0.5$ & NA & $4.1 / 0.0$ & $1.36 / 0.03$ & $20.0 / 0.1$ \\
\hline 6.2 & $142 / 1.4$ & $133 / 1.6$ & NA & $2.2 / 0.1$ & $1.01 / 0.04$ & $24.8 / 0.2$ \\
\hline 8 & $167 / 1.4$ & $133 / 0.9$ & 1.4853 & $3.4 / 0.0$ & $0.69 / 0.02$ & $7.3 / 0.1$ \\
\hline 9.1 & $163 / 2.1$ & $147 / 1.1$ & NA & $3.2 / 0.0$ & $1.11 / 0.02$ & $20.0 / 0.1$ \\
\hline 9.2 & $162 / 0.7$ & $146 / 0.4$ & 1.4678 & $2.7 / 0.1$ & $1.02 / 0.03$ & $20.0 / 0.1$ \\
\hline 10 & $163 / 2.3$ & $141 / 1.5$ & 1.5084 & $2.4 / 0.3$ & $1.01 / 0.12$ & $14.4 / 0.2$ \\
\hline 12 & $165 / 0.6$ & $133 / 2.3$ & 1.4663 & $2.0 / 0.0$ & $0.76 / 0.11$ & $7.3 / 0.1$ \\
\hline 13.1 & $168 / 5.0$ & $145 / 3.1$ & NA & $2.8 / 0.1$ & $1.20 / 0.09$ & $14.4 / 0.2$ \\
\hline 13.2 & $171 / 0.8$ & $148 / 1.4$ & 1.4588 & $2.5 / 0.1$ & $1.18 / 0.50$ & $14.4 / 0.2$ \\
\hline
\end{tabular}

* Tests 1-10 involved operation of the LDDS absorber in a spray tower configuration. Tests 12 and 13 involved operation of the LDDS absorber in a packed-bed configuration. Desiccant temperature, $\mathrm{pH}$, and desiccant circulation rate and flash drum vacuum pressure data are presented as average values with standard deviations.

Flash drum operating pressure ranged from 0.69 to $1.36 \mathrm{psia}$ ( 36 to $70 \mathrm{mmHg}$ ) with typical standard deviations $\leq 0.1 \mathrm{psia}$ ( $\leq 5.2 \mathrm{mmHg}$ ). Higher standard deviations were the result of moisture condensation and accumulation in the pressure transmitter line attached to the vapor discharge line exiting the flash drum. In general, the measured flash drum vacuum pressure was greater than the $1.0 \mathrm{psia}(52 \mathrm{mmHg})$ value planned. This occurred because of the moisture condensation previously mentioned and the difficulty encountered when the pressure regulator controlling vacuum pressure was manually set. Prior to any future pilot-scale tests, the EERC intends to relocate the pressure transmitter measuring vacuum pressure to eliminate the accumulation of moisture in the pressure transmitter line. Options will also be considered for improving vacuum pressure regulator performance and control.

Flash drum desiccant $\mathrm{pH}$ was measured continuously during Test Series II. Values ranged from 2.0 to 6.2 with standard deviations of 0.1 or less for most test periods. The first test period had a desiccant $\mathrm{pH}$ value of 6.2 with $\mathrm{pH}$ decreasing to 3.8 for Test Period 3.2. Desiccant $\mathrm{pH}$ decreased during these initial natural gas-fired test periods as carbon dioxide dissolution in the desiccant approached equilibrium. Desiccant $\mathrm{pH}$ was slightly higher during Test Period 6.1 because of an intentional decrease in desiccant concentration resulting in a change in the dissolution equilibrium of carbon dioxide. Coal-fired tests actually began with Test Period 8 and Test Period 6.2 actually occurred between Test Periods 9.2 and 10. Therefore, the desiccant $\mathrm{pH}$ value, 2.2, observed for Test Period 6.2 is consistent with the general decrease in desiccant $\mathrm{pH}$ during the coal-fired test periods. Desiccant $\mathrm{pH}$ was intentionally adjusted to a value of 4 using hydrated lime as the neutralizing agent between Test Periods 12 and 13.1. However, desiccant solution pH quickly decreased to $<3$ as a 
result of carbon dioxide and likely some $\mathrm{SO}_{2}$ dissolution. Based on the Test Series II desiccant $\mathrm{pH}$ data, application of a LDDS to a coal-fired boiler system will require the implementation of a desiccant solution $\mathrm{pH}$ control strategy including a filtration system to recover precipitated solids. Desiccant solution $\mathrm{pH}$ control may offer an opportunity to further reduce $\mathrm{SO}_{2}$ emission downstream of existing control technology or possibly include $\mathrm{SO}_{2}$ emission control as part of the design basis for an LDDS. The potential for $\mathrm{SO}_{2}$ emission control in an LDDS is discussed further with respect to flue gas $\mathrm{SO}_{2}$ measurements later in this report.

Table 40 summarizes product water condenser operating parameters for Test Series II. Process data include 1) vapor inlet temperature, 2) product water outlet temperature, 3) condenser vacuum and differential pressure, and 4) ring pump temperature. Condenser operating conditions were a function of vapor temperature and flow rate, cooling water temperature and flow rate, and vacuum pressure. Average vapor temperature at the condenser inlet ranged from $127^{\circ}$ to $141^{\circ} \mathrm{F}\left(53^{\circ}\right.$ to $\left.61^{\circ} \mathrm{C}\right)$ with standard deviations ranging from $0.4^{\circ}$ to $4.8^{\circ} \mathrm{F}\left(0.2^{\circ}\right.$ to $\left.2.7^{\circ} \mathrm{C}\right)$. The range of vapor temperatures and standard deviations was a direct result of desiccant temperature set points and variability at the inlet of the flash drum.

Condenser product water temperatures ranged from $74^{\circ}$ to $89^{\circ} \mathrm{F}\left(24^{\circ}\right.$ to $\left.32^{\circ} \mathrm{C}\right)$ with standard deviations of $0.4^{\circ}$ to $4.8^{\circ} \mathrm{F}\left(0.2^{\circ}\right.$ to $\left.2.7^{\circ} \mathrm{C}\right)$. Condenser product water temperatures were a function of the condenser cooling water temperature and flow rate as well as the vapor temperature and flow rate. However, the duration of Test Period 1 was cut short because of desiccant solution carryover from the flash drum into the condenser. Cooling water temperature at the inlet of the condenser was nominally $46^{\circ} \mathrm{F}\left(8^{\circ} \mathrm{C}\right)$ at flow rates exceeding $10 \mathrm{gpm}(38 \mathrm{Lpm})$.

\begin{tabular}{|c|c|c|c|c|c|}
\hline $\begin{array}{l}\text { Test } \\
\text { Period }\end{array}$ & $\begin{array}{l}\text { Condenser } \\
\text { Inlet Vapor } \\
\text { Temp., }{ }^{\circ} \mathrm{F} \\
\end{array}$ & $\begin{array}{c}\text { Condenser } \\
\text { Product Water } \\
\text { Outlet Temp., }{ }^{\circ} \mathrm{F}\end{array}$ & $\begin{array}{c}\text { Flash Drum/ Condenser } \\
\text { Vacuum Pressure, } \\
\text { psia }\end{array}$ & $\begin{array}{c}\text { Condenser } \\
\text { Differential } \\
\text { Pressure, in. W.C. }\end{array}$ & $\begin{array}{c}\text { Ring Pump } \\
\text { Temperature, } \\
\text { of }\end{array}$ \\
\hline 1 & $139 / 2.4$ & $85 / 1.3$ & $0.84 / 0.04$ & $2.5 / 0.1$ & $53 / 1.1$ \\
\hline 2.1 & $131 / 1.5$ & $86 / 0.4$ & $0.84 / 0.02$ & $6.7 / 0.5$ & $51 / 0.2$ \\
\hline 2.2 & $127 / 4.8$ & $87 / 0.7$ & $0.80 / 0.01$ & $3.0 / 0.2$ & $53 / 0.2$ \\
\hline 3.1 & $132 / 1.3$ & $86 / 3.7$ & $0.87 / 0.10$ & $7.4 / 2.6$ & $51 / 0.2$ \\
\hline 3.2 & $138 / 1.1$ & $89 / 3.8$ & $0.77 / 0.20$ & $11.8 / 4.2$ & $54 / 0.6$ \\
\hline 6.1 & $134 / 3.9$ & $88 / 4.8$ & $1.23 / 0.06$ & $3.7 / 1.8$ & $51 / 0.1$ \\
\hline 6.2 & $130 / 1.6$ & $81 / 0.8$ & $0.81 / 0.05$ & $5.6 / 1.5$ & $51 / 0.1$ \\
\hline 8 & $129 / 1.0$ & $74 / 0.4$ & $0.56 / 0.02$ & $3.5 / 0.2$ & $52 / 0.3$ \\
\hline 9.1 & $140 / 1.3$ & $84 / 1.2$ & $0.85 / 0.03$ & $7.1 / 0.9$ & $52 / 0.4$ \\
\hline 9.2 & $140 / 0.4$ & $83 / 0.4$ & $0.80 / 0.03$ & $6.1 / 0.7$ & $52 / 0.1$ \\
\hline 10 & $135 / 3.9$ & $81 / 1.1$ & $0.69 / 0.12$ & $8.8 / 2.6$ & $52 / 0.4$ \\
\hline 12 & $129 / 1.2$ & $74 / 1.8$ & $0.58 / 0.11$ & $5.0 / 0.1$ & $51 / 0.2$ \\
\hline 13.1 & $138 / 4.5$ & $82 / 2.5$ & $0.74 / 0.17$ & $12.6 / 4.6$ & $52 / 0.6$ \\
\hline 13.2 & $141 / 4.0$ & $84 / 0.6$ & $1.00 / 0.50$ & $5.1 / 0.7$ & $51 / 0.5$ \\
\hline
\end{tabular}

* Tests 1-10 involved operation of the LDDS absorber in a spray tower configuration. Tests 12 and 13 involved operation of the LDDS absorber in a packed-bed configuration. Natural gas was fired during Tests 1-6.1 and coal was fired during tests 6.2-13. Temperature and pressure data are presented as average values with standard deviations. 
Condenser operating pressure was not directly measured, but calculated from flash drum outlet pressure and the condenser differential pressure. Calculated condenser operating pressure ranged from 0.56 to 1.23 psia (29 to $64 \mathrm{mmHg}$ ) and was generally less than 0.9 psia ( $47 \mathrm{mmHg}$, with typical standard deviations $\leq 0.1 \mathrm{psia}(\leq 5.2 \mathrm{mmHg})$. Because condenser operating pressure data were calculated based on flash drum data, average and standard deviation values directly follow flash drum operating data and are influenced by any errors in the data resulting from moisture condensation in static or differential pressure lines. Condenser differential pressure ranged from 2.5 to 12.6 in W.C. $(4.7$ to $23.5 \mathrm{mmHg}$ ). Values $>5$ in W.C. ( $>9 \mathrm{mmHg}$ ) were likely impacted by moisture condensation in tubing between the pressure tap and pressure transmitters. Ring pump outlet water temperatures ranged from $51^{\circ}$ to $54^{\circ} \mathrm{F}\left(11^{\circ}\right.$ to $\left.13^{\circ} \mathrm{C}\right)$ with standard deviations of $0.1^{\circ}$ to $1.1^{\circ} \mathrm{F}\left(0.06^{\circ}\right.$ to $\left.0.6^{\circ} \mathrm{C}\right)$ as a result of a nominal inlet temperature of $46^{\circ} \mathrm{F}\left(8^{\circ} \mathrm{C}\right)$ and a flow rate of $5 \mathrm{gpm}(19 \mathrm{Lpm})$.

\subsubsection{Flue Gas-Sampling Data for Test Series II}

Table 41 summarizes the $\mathrm{O}_{2}, \mathrm{CO}_{2}, \mathrm{SO}_{2}$, and $\mathrm{NO}_{\mathrm{x}}$ flue gas data, on an as-measured dry volume basis, for Test Series II as well as flue gas moisture concentration data. Except for flue gas moisture data, absorber outlet data are not available for Test Period 3.1 because of a sample system failure. Average values are presented for each test period along with standard deviations. Measured $\mathrm{O}_{2}$ concentration at the inlet and outlet of the absorber ranged from nominally 4.6 to $6.8 \mathrm{vol} \%$ and 5.1 to 6.8 vol\%, respectively, with typical standard deviations of $\leq 0.3 \mathrm{vol} \%$. The upper half of each range represents natural gas-fired tests, 1-6.1, and the lower half of each range represents coal-fired tests, 6.2-13.2. For all test periods $\mathrm{O}_{2}$ concentration at the absorber outlet was greater than the $\mathrm{O}_{2}$ concentration at the absorber inlet. This observation is consistent for a balanced-draft system with the potential for air in-leakage. Based on the data, a $0.2-0.7$ vol\% difference between the absorber inlet and outlet sampling locations was observed indicating $1.4 \%-4.5 \%$ air in-leakage across the absorber.

Measured $\mathrm{CO}_{2}$ concentration at the inlet and outlet of the absorber ranged from 8.5 to $14.7 \mathrm{vol} \%$ and 6.3 to $14.0 \mathrm{vol} \%$, respectively, with typical standard deviations of $\leq 0.3 \mathrm{vol} \%$. Concentrations $\leq 10$ vol\% represented natural gas firing and concentrations $>13$ vol\% represented coal firing. For all test periods, $\mathrm{CO}_{2}$ concentration at the absorber outlet was less than the $\mathrm{CO}_{2}$ concentration at the absorber inlet. This observation is consistent for a balanced-draft system with the potential for air in-leakage. Carbon monoxide data have not been included because carbon monoxide was not detected at the furnace exit.

Sulfur dioxide was measured in the flue gas at the inlet and outlet of the absorber during the coal-fired test periods, 6.2 through 13.2. Flue gas $\mathrm{SO}_{2}$ concentration data, corrected to a dry 3 vol\% $\mathrm{O}_{2}$ basis, are summarized in Table 42 along with absorber operating parameters. Concentrations at the absorber inlet ranged from $236 \pm 11$ to $290 \pm 12$ ppmv (dry basis) while outlet values ranged from $122 \pm 4$ to $302 \pm 6 \mathrm{ppmv}$. The results indicate that $\mathrm{SO}_{2}$ capture across the LDDS absorber was highly variable, ranging from 0 to $58 \%$. Factors potentially impacting $\mathrm{SO}_{2}$ capture in the LDDS absorber include desiccant $\mathrm{pH}$, concentration, temperature, and circulation rate. Based on the limited data available from Test Series II, desiccant $\mathrm{pH}$ appears to be the primary factor influencing $\mathrm{SO}_{2}$ capture in the LDDS absorber. During test periods when the absorber was operated in a spray tower 


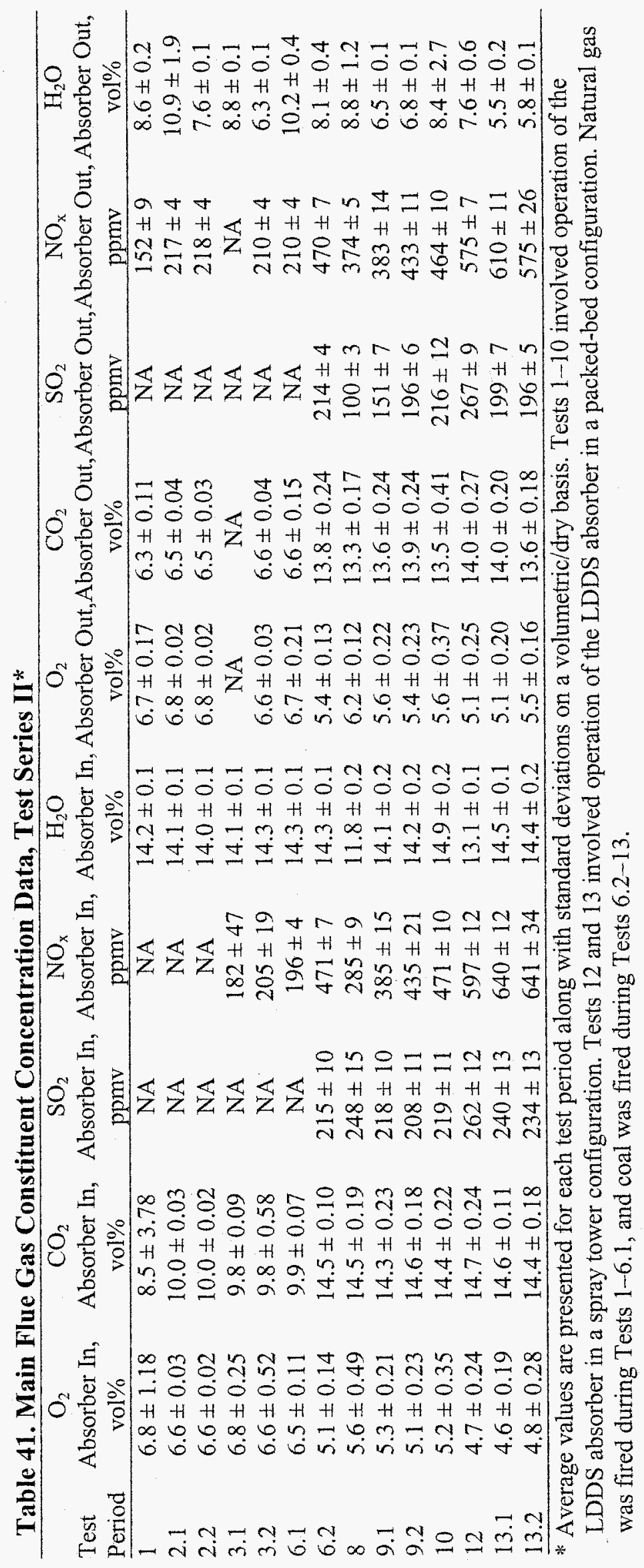


Table 42. $\mathrm{SO}_{2}$ Removal Efficiency Across the Absorber, Test Series II*

\begin{tabular}{|c|c|c|c|c|c|c|c|c|}
\hline $\begin{array}{l}\text { Test } \\
\text { Period }\end{array}$ & $\begin{array}{c}\mathrm{SO}_{2} \\
\text { Absorber In, } \\
\text { ppmv }\end{array}$ & $\begin{array}{c}\mathrm{SO}_{2} \\
\text { Absorber Out, } \\
\text { ppmv }\end{array}$ & $\begin{array}{c}\mathrm{SO}_{2} \\
\text { Removal, } \\
\%\end{array}$ & $\begin{array}{c}\text { Absorber } \\
\text { Desiccant } \\
\text { pH/Temp., }{ }^{\circ} \mathrm{F}\end{array}$ & $\begin{array}{l}\text { Absorber } \\
\text { Outlet } \\
\text { Temp., }{ }^{\circ} \mathrm{F}\end{array}$ & $\begin{array}{c}\text { Desiccant } \\
\text { Recycle Rate, } \\
\text { gpm }\end{array}$ & $\begin{array}{c}\text { Absorber } \\
\text { Velocity, } \\
\text { ft/s }\end{array}$ & $\begin{array}{l}\text { Absorber L/G, } \\
\mathrm{gal} / 1000 \mathrm{acf}\end{array}$ \\
\hline 1 & NA & $\mathrm{NA}$ & -- & $6.2 / 119$ & 151 & $6.2 / 1.9$ & 9.9 & 13.7 \\
\hline 2.1 & NA & NA & - & $4.6 / 140$ & 151 & $14.1 / 0.3$ & 9.8 & 31.6 \\
\hline 2.2 & NA & NA & - & $4.0 / 130$ & 146 & $14.1 / 0.1$ & 9.9 & 31.5 \\
\hline 3.1 & NA & NA & - & $3.9 / 142$ & 152 & $17.7 / 4$ & 9.9 & 39.5 \\
\hline 3.2 & NA & NA & - & $3.8 / 130$ & 144 & $19.5 / 0.4$ & 9.8 & 44.0 \\
\hline 6.1 & NA & NA & - & $4.1 / 146$ & 152 & $19.7 / 1$ & 9.8 & 44.4 \\
\hline 6.2 & $244 \pm 11$ & $247 \pm 5$ & 0 & $2.9 / 134$ & 143 & $24.5 / 0.9$ & NA & 54.4 \\
\hline 8 & $290 \pm 12$ & $122 \pm 4$ & 58 & $3.4 / 127$ & 147 & $7.1 / 0.3$ & 9.9 & 15.8 \\
\hline 9.1 & $249 \pm 11$ & $177 \pm 7$ & 29 & $3.2 / 130$ & 145 & $19.7 / 0.2$ & NA & 43.8 \\
\hline 9.2 & $236 \pm 11$ & $226 \pm 6$ & 4 & $2.7 / 130$ & 144 & $19.7 / 0.1$ & NA & 43.8 \\
\hline 10 & $250 \pm 11$ & $252 \pm 15$ & 0 & $2.4 / 120$ & 141 & $14.2 / 0.8$ & NA & 31.6 \\
\hline 12 & $289 \pm 12$ & $302 \pm 6$ & 0 & $2.0 / 120$ & 149 & $7.0 / 0.1$ & NA & 15.6 \\
\hline 13.1 & $263 \pm 13$ & $225 \pm 7$ & 14 & $2.8 / 121$ & 143 & $14.0 / 0.1$ & NA & 31.3 \\
\hline 13.2 & $254 \pm 11$ & $227 \pm 7$ & 11 & $2.5 / 124$ & 145 & $14.1 / 0.2$ & NA & 31.3 \\
\hline
\end{tabular}

* Flue gas $\mathrm{SO}_{2}$ data are corrected to a dry 3 vol\% $\mathrm{O}_{2}$ basis. Average values are presented with standard deviations.

configuration, significant levels of $\mathrm{SO}_{2}$ capture were observed for desiccant $\mathrm{pH}$ levels $>3$. When the absorber was operated in a packed-bed configuration, a minimal level of $\mathrm{SO}_{2}$ capture was observed for desiccant $\mathrm{pH}$ levels of 2.5 to 2.8 .

If $\mathrm{SO}_{2}$ capture in the LDDS absorber is of interest as a flue gas polishing step or as an integrated design feature, specific pilot-scale tests will be required to determine the impact of primary independent and dependent variables. In addition, a desiccant solution $\mathrm{pH}$ control strategy and filtration system will be required. One $\mathrm{pH}$ control option would involve the controlled addition of calcium hydroxide $\left(\mathrm{Ca}[\mathrm{OH}]_{2}\right)$ to the desiccant solution. The EERC demonstrated, at the conclusion of Test Series II, that $\mathrm{Ca}(\mathrm{OH})_{2}$ addition to the desiccant solution can be used effectively to neutralize $\mathrm{pH}$ : the desiccant solution $\mathrm{pH}$ was increased from 2.3 to 6.5 . Calcium oxide $(\mathrm{CaO})$ would not be appropriate for $\mathrm{pH}$ control because of its highly exothermic properties when exposed to water, and calcium carbonate $\left(\mathrm{CaCO}_{3}\right)$ may not react at an adequate rate to effectively control desiccant solution $\mathrm{pH}$. In one case (between Test Periods 12 and 13.1), the desiccant solution was circulated through a bed of $\mathrm{CaCO}_{3}$ with the $\mathrm{pH}$ increasing from 2.0 to nominally 4.0. Although other $\mathrm{pH}$ neutralization agents may be appropriate, the fact that the desiccant is a $\mathrm{CaCl}_{2}$ solution suggests that a calcium-based alkali source may be the best choice.

The use of any reagent to control desiccant solution $\mathrm{pH}$ will require the use of a filtration system to remove precipitated sulfur species and possibly precipitated carbonates. Addition of $\mathrm{Ca}(\mathrm{OH})_{2}$ would likely result in a combination of calcium sulfite $\left(\mathrm{CaSO}_{3}\right)$ and calcium sulfate $\left(\mathrm{CaSO}_{4}\right)$ being precipitated as hydrates depending on available dissolved $\mathrm{O}_{2}$. In order to minimize $\mathrm{CaSO}_{3}$ formation and promote the precipitation of hydrated $\mathrm{CaSO}_{4}$, air sparging would be necessary in the tank collecting desiccant solution from the absorber column to ensure that adequate dissolved $\mathrm{O}_{2}$ was available. Protection of the desiccant regeneration pump (supporting the flash drum) from precipitated solids may require the location of the filtration system upstream of this pump and the use 
of a third tank located between the filtration system and the pump. Actual requirements will depend on the quantity of $\mathrm{SO}_{2}$ removed from the flue gas in the absorber and the resulting precipitated solids. If the quantity of precipitated solids is limited, the required filtration system may simply be a circulation loop removing desiccant solution from and returning it to the tank recovering desiccant solution from the absorber column and supporting the regeneration pump.

Because only one analyzer was available, flue gas $\mathrm{NO}_{\mathrm{x}}$ concentration data were only reported for the absorber outlet sample location for Test Periods 1 through 2.2. Subsequently, an analyzer was repaired and placed in service to support Test Periods 3.1 through 13.2. Flue gas $\mathrm{NO}_{\mathrm{x}}$ concentration data, corrected to a dry 3 vol\% $\mathrm{O}_{2}$ basis, are summarized in Table 43 along with absorber operating parameters. Concentrations at the absorber inlet ranged from $248 \pm 47$ to $721 \pm 34 \mathrm{ppmv}$ (dry basis) while outlet values ranged from $205 \pm 9$ to $703 \pm 11$ ppmv. This range of flue gas $\mathrm{NO}_{\mathrm{x}}$ concentrations are consistent with the firing of natural gas and coal in the slagging furnace at typical excess $\mathrm{O}_{2}$ concentrations $\left(<7\right.$ vol $\%$ ) and furnace temperatures $\left(>2200^{\circ} \mathrm{F}\left[>1205^{\circ} \mathrm{C}\right]\right.$ and $<2600^{\circ} \mathrm{F}$ $\left[<1427^{\circ} \mathrm{C}\right]$ ). Absorber inlet $\mathrm{NO}_{\mathrm{x}}$ concentrations of $<300$ ppmv represent natural gas firing, and values $>300$ ppmv represent coal firing. The results indicate that there was no change in $\mathrm{NO}_{\mathrm{x}}$ concentration across the LDDS absorber. Therefore, no $\mathrm{NO}_{\mathrm{x}}$ removal occurred.

Measured $\mathrm{H}_{2} \mathrm{O}$ concentration at the inlet and outlet of the absorber, as summarized in Table 624 , ranged from 11.8 to $14.9 \mathrm{vol} \%$ and 5.5 to $10.9 \mathrm{vol} \%$, respectively, with typical standard deviations of $\leq 0.2 \mathrm{vol} \%$. Standard deviations $>0.2$ vol\% represent short test periods or test periods during which system adjustments were required. The results indicate that $\mathrm{H}_{2} \mathrm{O}$ recovery across the LDDS absorber was highly variable, ranging from 22 to $62 \%$ of the available $\mathrm{H}_{2} \mathrm{O}$ in the flue gas stream. Factors influencing $\mathrm{H}_{2} \mathrm{O}$ recovery in the LDDS absorber include desiccant concentration,

Table 43. NO ${ }_{\mathrm{x}}$ Removal Efficiency Across the Absorber, Test Series II*

$\begin{array}{lllll} & & \text { Absorber } & & \text { Absorber } \\ \mathrm{NO}_{\mathrm{x}} & \mathrm{NO}_{\mathrm{x}} & \mathrm{NO}_{\mathrm{x}} & \text { Desiccant Absorber Desiccant } & \text { Absorber } \\ \mathrm{L} / \mathrm{G},\end{array}$

Test Absorber In, Absorber Out, Removal, pH/Temp., Outlet Recycle Rate, Velocity, gal/1000

\begin{tabular}{lcccccccc} 
Period & ppmv & ppmv & $\%$ & ${ }^{\circ} \mathrm{F}$ & Temp., ${ }^{\circ} \mathrm{F}$ & gpm & $\mathrm{ft} / \mathrm{s}$ & acf \\
\hline 1 & NA & $192 \pm 11$ & NA & $6.2 / 119$ & 151 & $6.2 / 1.9$ & 9.9 & 13.7 \\
2.1 & NA & $275 \pm 5$ & NA & $4.6 / 140$ & 151 & $14.1 / 0.3$ & 9.8 & 31.6 \\
2.2 & NA & $276 \pm 5$ & NA & $4.0 / 130$ & 146 & $14.1 / 0.1$ & 9.9 & 31.5 \\
3.1 & $230 \pm 60$ & NA & NA & $3.9 / 142$ & 152 & $17.7 / 4$ & 9.9 & 39.5 \\
3.2 & $255 \pm 21$ & $263 \pm 6$ & 0 & $3.8 / 130$ & 144 & $19.5 / 0.4$ & 9.8 & 44.0 \\
6.1 & $244 \pm 5$ & $264 \pm 7$ & 0 & $4.1 / 146$ & 152 & $19.7 / 1$ & 9.8 & 44.4 \\
6.2 & $534 \pm 7$ & $544 \pm 8$ & 0 & $2.9 / 134$ & 143 & $24.5 / 0.9$ & NA & 54.4 \\
8 & $334 \pm 6$ & $456 \pm 5$ &.- & $3.4 / 127$ & 147 & $7.1 / 0.3$ & 9.9 & 15.8 \\
9.1 & $442 \pm 18$ & $448 \pm 17$ & 0 & $3.2 / 130$ & 145 & $19.7 / 0.2$ & NA & 43.8 \\
9.2 & $493 \pm 24$ & $499 \pm 15$ & 0 & $2.7 / 130$ & 144 & $19.7 / 0.1$ & NA & 43.8 \\
10 & $536 \pm 11$ & $541 \pm 12$ & 0 & $2.4 / 120$ & 141 & $14.2 / 0.8$ & NA & 31.6 \\
12 & $658 \pm 18$ & $652 \pm 15$ & 0 & $2.0 / 120$ & 149 & $7.0 / 0.1$ & NA & 15.6 \\
13.1 & $703 \pm 15$ & $689 \pm 15$ & 0 & $2.8 / 121$ & 143 & $14.0 / 0.1$ & NA & 31.3 \\
13.2 & $689 \pm 25$ & $668 \pm 26$ & 0 & $2.5 / 124$ & 145 & $14.1 / 0.2$ & NA & 31.3 \\
\hline
\end{tabular}

* Flue gas $\mathrm{NO}_{x}$ data are corrected to a dry 3 vol\% $\mathrm{O}_{2}$ basis. Average values are presented with standard deviations. 
temperature, and circulation rate, as well as absorber operation in a spray tower versus packed-bed configuration. However, these data are not corrected for air in-leakage and are, therefore, nominal values. A detailed summary of the water recovery data for Test Series II is presented later in this report.

Gas concentration measurements were made once in the vapor stream at the outlet of the product water condenser. Specifically, measurements (dry basis) were made for $\mathrm{O}_{2}, \mathrm{CO}_{2}, \mathrm{CO}, \mathrm{SO}_{2}$, and $\mathrm{NO}_{\mathrm{x}}$ for Test Series $I I$ during Test Period 13.2. Measurement results for $\mathrm{CO}_{2}(\mathrm{vol} \%), \mathrm{CO}$ (ppmv), and $\mathrm{SO}_{2}$ (ppmv) concentrations were essentially zero. Average $\mathrm{O}_{2}$ concentrations were $>10$ vol\% and likely ranged between 17 and 21 vol\%, based on Test Series I data previously discussed. Specific $\mathrm{O}_{2}$ concentration data are not available because of an instrument ranging error. However, these data indicate the vapor stream is essentially air. Because of the high vacuum pressure in the flash drum, product water condenser, and interconnecting piping, this gas stream may be dominated by air in-leakage. Average $\mathrm{NO}_{\mathrm{x}}$ concentrations were $110 \pm 15 \mathrm{ppmv}$. These values are $81 \%$ lower than what was measured in the combustion flue gas, consistent with Test Series I data, and represent a very small volume. Therefore, the data indicate a small amount of flue gas was dissolved in the desiccant solution and then released in the flash drum.

Mercury measurements for Test Series II were performed to determine if the calcium chloride would have any effect on conversion of elemental mercury to an oxidized form. It is well documented that wet FGD systems will capture available oxidized species of mercury at approximately the same efficiency as sulfur capture. If a wet FGD is $85 \%$ efficient at capturing the available sulfur in the gas stream, it will also capture $85 \%$ of the oxidized mercury in the gas stream. Based on sampling data, the LDDS captured approximately $100 \%$ of the available oxidized species of mercury entering the absorber tower and concentrated the mercury in the desiccant as the test continued. The levels of mercury in the desiccant at the end of the test period were at the lower end of other FGD and ash samples analyzed in previous pilot-scale testing at the EERC. It appeared that no beneficial oxidation of the mercury occurred across the absorber tower, allowing capture of more mercury than would be expected in a wet FGD system.

Flue gas particulate mass loading data for the pilot-scale absorber inlet and outlet sample locations are summarized in Table 44. Sampling activities were completed for Tests 3.1, 3.2, 9.1, 9.2, 13.1, and 13.2. As previously discussed in Section 4, the data are the result of EPA Method 5 sampling. Sampling results at the absorber inlet indicated a mass loading of $0.0000 \mathrm{gr} / \mathrm{scf}$ $\left(0.0000 \mathrm{~g} / \mathrm{m}^{3}\right)$ when natural gas was fired and 0.0013 to $0.0035 \mathrm{gr} / \mathrm{scf}\left(0.0030\right.$ to $\left.0.0080 \mathrm{~g} / \mathrm{m}^{3}\right)$ when coal was fired. Because a baghouse was used for particulate control upstream of the LDDS absorber during Test Series II, the mass loading at the inlet of the absorber was expected to be near zero. However, most if not all of the mass observed at the inlet of the absorber was likely the result of flue gas humidification, between the baghouse and absorber, used during the coal-fired test periods. No flue gas humidification was used during Test Periods 3.1 and 3.2. The water used for flue gas humidification was city tap water with a nominal TDS loading of $250 \mathrm{mg} / \mathrm{L}$. Therefore, assuming a water flow rate of $0.083 \mathrm{gpm}(0.315 \mathrm{Lpm})$ and a flue gas flow rate of $390 \mathrm{scfm}\left(11.0 \mathrm{~m}^{3} / \mathrm{min}\right)$, the mass loading at the inlet of the absorber attributable to the humidification system was nominally $0.0031 \mathrm{gr} / \mathrm{scf}\left(0.0071 \mathrm{~g} / \mathrm{m}^{3}\right)$. 
Table 44. Particulate Sampling Data, Test Series II*

\begin{tabular}{|c|c|c|c|c|c|c|}
\hline $\begin{array}{l}\text { Test } \\
\text { Period }\end{array}$ & $\begin{array}{l}\text { Sampling } \\
\text { Method }\end{array}$ & $\begin{array}{c}\text { Absorber } \\
\text { Inlet, gr/scf }\end{array}$ & $\begin{array}{c}\text { Absorber Outlet, } \\
\mathrm{gr} / \mathrm{scf} \\
\end{array}$ & $\begin{array}{c}\text { Removal, } \\
\% \\
\end{array}$ & $\begin{array}{c}\text { Flue Gas } \\
\mathrm{H}_{2} \mathrm{O} \text { Content, vol\% }\end{array}$ & $\begin{array}{c}\text { Average Stack } \\
\text { Temp., }{ }^{\circ} \mathrm{F} \\
\end{array}$ \\
\hline \multirow[t]{2}{*}{3.1} & EPA M5 & 0.0000 & - & - & 13.7 & 135 \\
\hline & EPA M5 & - & 0.0005 & - & 9.0 & 148 \\
\hline \multirow[t]{2}{*}{3.2} & EPA M5 & 0.0000 & - & 一 & 13.7 & 135 \\
\hline & EPA M5 & - & 0.0008 & - & 6.2 & 140 \\
\hline \multirow[t]{2}{*}{9.1} & EPA M5 & 0.0035 & - & - & 14.3 & 135 \\
\hline & EPA M5 & - & 0.0012 & 65.7 & 6.6 & 140 \\
\hline \multirow[t]{2}{*}{9.2} & EPA M5 & 0.0016 & - & - & 14.6 & 136 \\
\hline & EPA M5 & - & 0.0012 & 25.0 & 7.1 & 140 \\
\hline \multirow[t]{2}{*}{13.1} & EPA M5 & 0.0013 & - & - & 15.0 & 137 \\
\hline & EPA M5 & - & 0.0012 & 7.7 & 5.6 & 134 \\
\hline \multirow[t]{2}{*}{13.2} & EPA M5 & 0.0022 & - & - & 15.0 & 137 \\
\hline & EPA M5 & - & 0.0012 & 45.4 & 6.2 & 136 \\
\hline
\end{tabular}

* Mass loading data are presented on a dry basis.

Analysis results for absorber inlet filters are summarized in Table 45 along with estimated potential contributions from the humidification water. Based on these data, it appears that all of the particulate mass on the absorber inlet filters observed as calcium, sodium, and sulfate likely originated with the humidification water. Chloride and fluoride particulate mass at the inlet of the absorber was likely a flue gas constituent resulting from coal combustion that passed through the baghouse fabric filters as particulate or vapor species. Chloride and fluoride vapor species are likely hydrogen chloride $(\mathrm{HCl})$ and hydrogen fluoride $(\mathrm{HF})$. Exposure of water-soluble species such as $\mathrm{HCl}$ and $\mathrm{HF}$ to the flue gas humidification system would likely transfer a percentage of the $\mathrm{HCl}$ and $\mathrm{HF}$ to any alkali particulate present in the gas stream. Mercury present as an aerosol or vapor species could have contributed to the mercury mass observed on the absorber inlet filters. The filter analyses completed do not account for all of the mass collected on the absorber inlet filters. Magnesium is a likely component of the humidification water contributing to the absorber inlet mass as the sulfate is likely present as calcium and magnesium sulfate.

Absorber outlet mass loading, based on EPA Method 5 sample trains, ranged from 0.0005 to $0.0012 \mathrm{gr} / \mathrm{scf}\left(0.0011\right.$ to $\left.0.0027 \mathrm{~g} / \mathrm{m}^{3}\right)$. For Test Periods 3.1 and 3.2 , although small, the mass measured at the absorber outlet was greater than the mass measured at the absorber inlet. The most likely mechanism responsible for the increased mass across the absorber is simply mist eliminator carryover, specifically desiccant solution aerosol droplets. Analysis of the outlet filter for Test Period 3.1 indicated the presence of $0.0068 \mathrm{gr}(0.440 \mathrm{mg})$ of calcium, $0.0074 \mathrm{gr}(0.480 \mathrm{mg})$ of chloride, and $0.0015 \mathrm{gr}(0.098 \mathrm{mg})$ of sodium. Sulfate was less than the detection limit, $<0.0008 \mathrm{gr}(<0.050 \mathrm{mg})$. The total mass recovered on the filter was $0.0267 \mathrm{gr}(1.73 \mathrm{mg})$. Therefore, calcium and chloride combined represented $53 \%$ of the total mass collected on the filter. Adding sodium to the total, likely present as sodium chloride, increases the percent mass identified to $59 \%$. Based on the data, mist eliminator carryover is the most probable source of the mass collected at the outlet of the absorber during Test Period 3.1 . The $41 \%$ of the mass that remained undocumented is likely water chemically bound to the calcium chloride. As many as six moles of water can be chemically bound 
Table 45. Absorber Inlet EPA Method 5 Sample Filter Analyses Results, Test Series II

\begin{tabular}{lccccccc}
\hline Sample Type & $\begin{array}{c}\text { Calcium, } \\
\mathrm{mg}\end{array}$ & $\begin{array}{c}\text { Chloride, } \\
\mathrm{mg}\end{array}$ & $\begin{array}{c}\text { Fluoride, } \\
\mathrm{mg}\end{array}$ & $\begin{array}{c}\text { Sodium, } \\
\mathrm{mg}\end{array}$ & $\begin{array}{c}\text { Sulfate, } \\
\mathrm{mg}\end{array}$ & $\begin{array}{c}\text { Mercury, } \\
\mu \mathrm{g}\end{array}$ & $\begin{array}{c}\text { Total } \\
\text { Mass, mg }\end{array}$ \\
\hline Humid. Water & $1.728-$ & $<0.039$ & $0.055-$ & $0.870-$ & 3.650 & $0.0031-$ & $6.342-$ \\
& 1.968 & & 0.062 & 0.991 & 4.158 & 0.0036 & 7.128 \\
9.1, Abs. Inlet & 1.240 & 0.590 & 0.310 & 0.895 & 2.860 & 0.249 & 11.21 \\
9.2, Abs. Inlet & 0.845 & 0.420 & 0.270 & 0.640 & 1.500 & 0.0638 & 5.15 \\
13.1 Abs. Inlet & 0.825 & 0.180 & 0.555 & 0.545 & 1.360 & 0.0600 & 4.48 \\
13.2 Abs. Inlet & 0.825 & 0.140 & 0.542 & 0.520 & 1.330 & 0.0712 & 7.60 \\
\hline
\end{tabular}

Test periods 9.1, 9.2, 13.1, and 13.2 represent coal-fired tests. "Total Mass" represents total filter mass estimated based on humidification water analyses or measured mass on each sample filter.

to calcium chloride, representing a nearly $50 \mathrm{wt} \%$ contribution. Free water would not be a contributing factor because of the $250^{\circ} \mathrm{F}\left(121^{\circ} \mathrm{C}\right)$ filter temperature employed, and the method for measuring filter mass involved oven drying of filters at $212^{\circ} \mathrm{F}\left(100^{\circ} \mathrm{C}\right)$ and cooling the filter in a desiccated container prior to determining a final weight.

For the coal-fired test periods, sampling data in Table 44 indicate that particulate mass removal across the absorber column was highly variable. However, the outlet mass loading was constant $\left(0.0012 \mathrm{gr} / \mathrm{scf}\left[0.0027 \mathrm{~g} / \mathrm{m}^{3}\right]\right)$ for Test Periods $9.1,9.2,13.1$, and 13.2. Therefore, the particulate removal variability across the absorber was a direct result of the variable inlet mass loading. Analyses results for absorber outlet filters are summarized in Table 46. Based on the data in Tables 45 and 46, it appears that the particulate mass on the absorber outlet filters is a combination of the particulate in the flue gas entering the absorber and mist eliminator carryover of desiccant solution aerosol droplets. The contribution of mist eliminator carryover is evident in the fact that, in all cases, the mass of chloride observed on the outlet filters was greater than the mass of chloride observed on the inlet filters. This was also true for calcium for all but one absorber outlet filter. For Test Periods $9.1,9.2,13.1$, and 13.2 , the calcium and chloride represented $35 \%-41 \%$ of the total mass collected on the absorber outlet filters. Filter mass values for fluoride, sodium, sulfate, and mercury all decreased across the absorber, indicating a degree of removal from the flue gas stream. Again, the filter analyses completed do not account for all of the mass collected on the absorber outlet filters. Magnesium as a sulfate and chemically bound water are likely components contributing to the absorber outlet mass for the reasons previously stated.

Table 46. Absorber Outlet EPA Method 5 Sample Filter Analyses Results, Test Series II

\begin{tabular}{lccccccc}
\hline Test Period & Calcium, $\mathrm{mg}$ & $\begin{array}{c}\text { Chloride, } \\
\mathrm{mg}\end{array}$ & $\begin{array}{c}\text { Fluoride, } \\
\mathrm{mg}\end{array}$ & $\begin{array}{c}\text { Sodium, } \\
\mathrm{mg}\end{array}$ & $\begin{array}{c}\text { Sulfate, } \\
\mathrm{mg}\end{array}$ & $\begin{array}{c}\text { Mercury, } \\
\mu \mathrm{g}\end{array}$ & $\begin{array}{c}\text { Total Mass } \\
\text { Measured, mg }\end{array}$ \\
\hline 3.1 & 0.440 & 0.480 & $<0.050$ & 0.098 & $<0.050$ & $<0.0006$ & 1.73 \\
9.1 & 1.010 & 0.600 & 0.170 & 0.480 & 1.480 & 0.0350 & 3.97 \\
9.2 & 0.890 & 0.510 & 0.150 & 0.450 & 1.180 & 0.0356 & 3.80 \\
13.1 & 0.960 & 0.470 & 0.320 & 0.440 & 1.270 & 0.0531 & 3.72 \\
13.2 & 0.925 & 0.430 & 0.340 & 0.400 & 1.210 & 0.117 & 3.86 \\
\hline
\end{tabular}

Test Period 3.1 represents a natural gas-fired test. Test periods 9.1,9.2, 13.1, and 13.2 represent coal-fired tests. "Total Mass Measured" represents total mass accumulated on each sample filter. 


\subsection{Desiccant and Product Water Analyses Results}

Desiccant samples were collected from the inlet of the absorber and flash drum for each test period for Test Series II, and select samples were analyzed. Table 47 summarizes the analytical results for twelve desiccant samples representing six test periods. Desiccant $\mathrm{pH}$ for the samples collected at the absorber inlet ranged from 1.27 to 3.94. Values for absorber outlet samples ranged from 1.23 to 3.85 . These data show variation in desiccant solution $\mathrm{pH}$ as a function of exposure to flue gas in the absorber column and the absorption of water vapor. In some cases, desiccant solution $\mathrm{pH}$ decreased with exposure to flue gas, and in other cases, there was no change or a small increase. Factors influencing desiccant solution $\mathrm{pH}$ include $\mathrm{CO}_{2}$ dissolution and water absorption independent of fuel type and acid gas dissolution when firing coal. Continuous $\mathrm{pH}$ measurement data summarized in Table 39 (an online measurement of heated desiccant solution pumped to the flash drum) are generally consistent with the data presented for select desiccant solution samples in Table 47 (samples collected and analyzed at a later date). However, significant differences are observed for Test Periods 12 and 13.2. One explanation for $\mathrm{pH}$ differences is a temperature effect-as temperature increases, $\mathrm{pH}$ decreases - a likely explanation for Test Period 12 data. Also, the potential for $\mathrm{CO}_{2}$ offgassing during sample handling may be a contributing factor. Carbon dioxide offgassing would result in an increase in measured $\mathrm{pH}$. The low desiccant solution $\mathrm{pH}$ value observed in Table 47 for Test Period 13.2 may be a function of acid dissolution in the desiccant solution and equilibrium achieved as a function of time or temperature. Because it was necessary to reheat the samples in the lab prior to analyses, temperature effects and equilibrium changes are likely. Ultimately, the online desiccant $\mathrm{pH}$ measurement, Table 39 data, best represents the desiccant characteristics as a function of LDDS absorber and flash drum operating conditions.

Specific gravity data show a consistent trend with respect to water absorption in the absorber column. Specifically, the specific gravity of the desiccant solution at the inlet of the absorber is greater than the specific gravity of the desiccant solution pumped to the flash drum. This is consistent with the dilution affect of water absorption. However, the measured specific gravity data for the absorber inlet samples are not consistent with the calculated values based on online desiccant density measurement data resulting from the Coriolis meter. The reason for this difference is likely a temperature effect. The calculated desiccant concentration data in Table 38 is based on an online measurement of the heated desiccant solution density, and the specific gravity measurement data in Table 47 represent samples collected and reheated and analyzed at a later date.

Sulfate content in the flash drum desiccant samples was below detection limits for Test Series $\mathrm{II},<10 \mathrm{mg} / \mathrm{L}$, natural gas-fired test periods as well as Test Periods 10,12 , and 13 when coal was fired. Measurable sulfate concentrations were observed in the desiccant for Test Periods 8 and 9, $106 \mathrm{mg} / \mathrm{L}$ for absorber inlet samples, and 39 to $44 \mathrm{mg} / \mathrm{L}$ for absorber outlet samples. Measurable sulfate levels in the desiccant solution are a function of two factors. First, coal firing resulted in $\mathrm{SO}_{2}$ in the flue gas. Second, desiccant $\mathrm{pH}$ determined the degree of $\mathrm{SO}_{2}$ solubility in the desiccant and the resulting sulfate concentration. Specifically, sulfate concentrations in the desiccant solution were less than detection limits when the desiccant $\mathrm{pH}$ measurement was $<3$. Measurable sulfate concentrations were observed for desiccant solution $\mathrm{pH}$ levels of $>3$. This observation was based on the $\mathrm{pH}$ data from the continuous monitor upstream of the flash drum. 


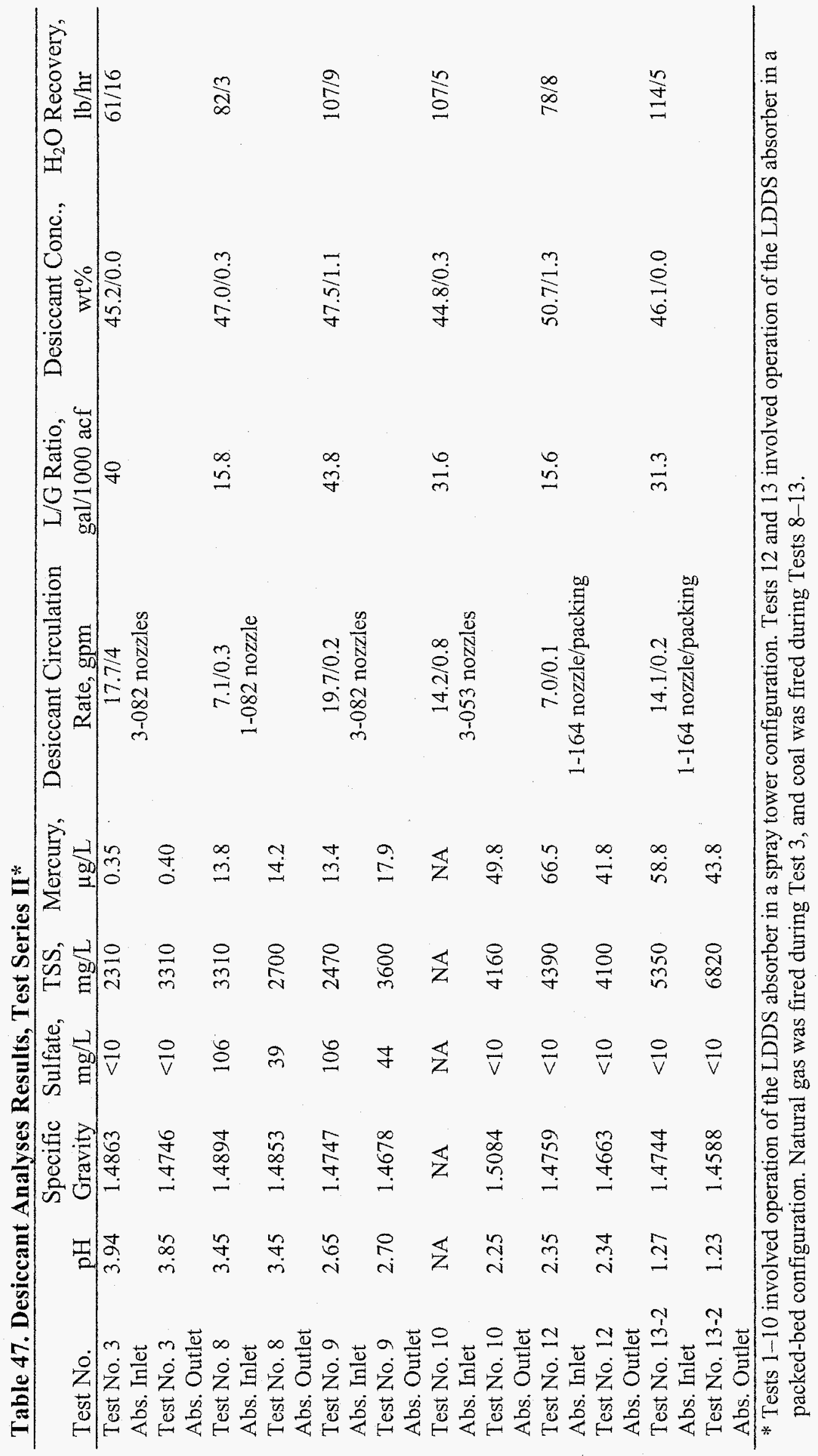


TSS concentration in the desiccant solution, as shown in Table 47, generally increased during Test Series II, indicating accumulation with time. Sources of suspended solids include fine particulate passing through the fabric filter, solids resulting from the flue gas humidification system previously discussed, carbonate precipitation, and sulfate formation as a result of $\mathrm{SO}_{2}$ removal from the flue gas. Although solids resulting from the flue gas humidification system are a characteristic specific to system configuration used in support of this project, the other sources identified demonstrate the need for a filtration system or a setting tank to remove TSS from the desiccant solution.

Mercury concentration in the desiccant solution generally increased as a function of time during Test Series II. Low mercury concentrations, $<0.5 \mu \mathrm{g} / \mathrm{L}$, were observed during the natural gasfired test with mercury concentration increasing by two orders of magnitude by the end of the coalfired tests. These data indicate that the LDDS absorber will remove oxidized mercury species from the flue gas. Whether use of a filtration system would remove mercury species from the desiccant solution along with suspended solids is uncertain and would have to be determined. This is consistent with wet FGD mercury capture which will capture the majority of the oxidized species of mercury passing through the absorber tower. Elemental forms of mercury will be unaffected to a large degree and pass through the absorber.

Figure 31 shows the water recovery rate as a function of desiccant circulation rate through the absorber tower and absorber configuration. The large difference in water recovery between Test 3-2 and Test 6 illustrates the ability of the system to be tailored for different levels of water recovery. The drop in water recovery is due to an increase in desiccant temperature entering the absorber from 144 to 152 and a decrease in desiccant concentration from 46.4 to 42.8 , respectively. Figure 32 illustrates the effect of a change in desiccant temperature and a slight increase in desiccant flow rate through the absorber. Water recovery increases significantly with a $10^{\circ} \mathrm{F}\left(6^{\circ} \mathrm{C}\right)$ decrease in temperature of the desiccant to the absorber from $140^{\circ}$ to $130^{\circ} \mathrm{F}\left(60^{\circ}\right.$ to $\left.54^{\circ} \mathrm{C}\right)$ with an additional slight increase in $\mathrm{L} / \mathrm{G}$.

Product water samples were collected for each test period for Test Series II, and select samples were analyzed for water quality. Table 48 summarizes the analytical results for six product water samples and compares the data with similar measurements for DI and city tap water. Product water $\mathrm{pH}$ values when natural gas was fired were similar to the $\mathrm{DI}$ water $\mathrm{pH}$ value, consistent with the vaporization and condensation methodologies used to produce these samples.

However, when coal was fired, product water $\mathrm{pH}$ generally followed desiccant solution $\mathrm{pH}$ to lower values. Implementation of a desiccant solution $\mathrm{pH}$ control system, as previously discussed, would be expected to mitigate the impact of flue gas constituents, from coal firing, on product water $\mathrm{pH}$ as well as desiccant solution $\mathrm{pH}$, resulting in a product water $\mathrm{pH}$ comparable to DI water regardless of flue gas composition and fuel type fired. The higher $\mathrm{pH}$ of the city tap water is consistent with its calcium, magnesium, and sulfate content.

TDS levels for the product water samples were highly variable, greater than the DI water sample and for most samples greater than the city tap water sample. Although the calcium, chloride, and sulfate content of the product water is a partial explanation for the differences, the analysis 


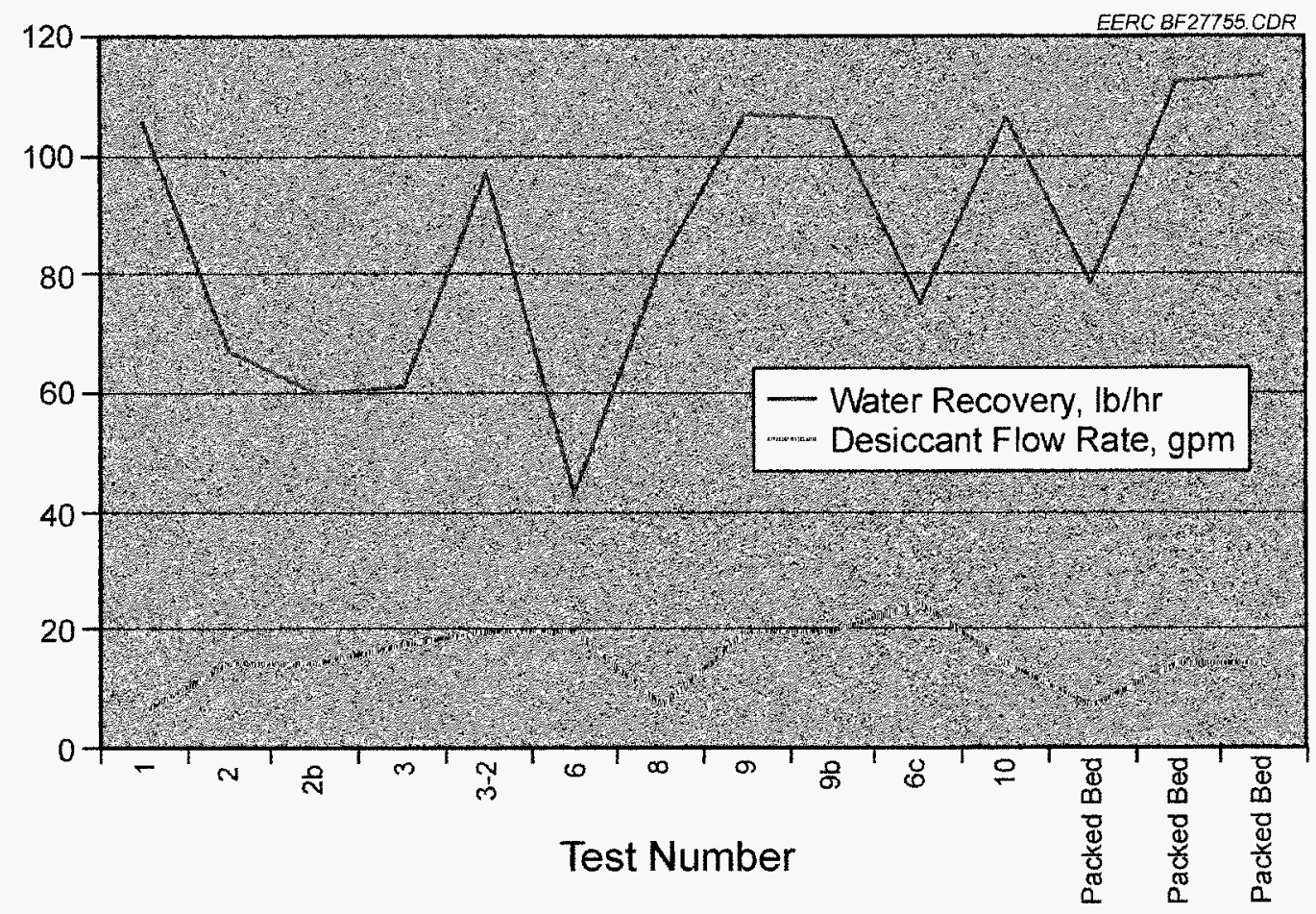

Figure 31. Average absorber water recovery rate versus absorber desiccant circulation rate and absorber configuration, Test Series II.

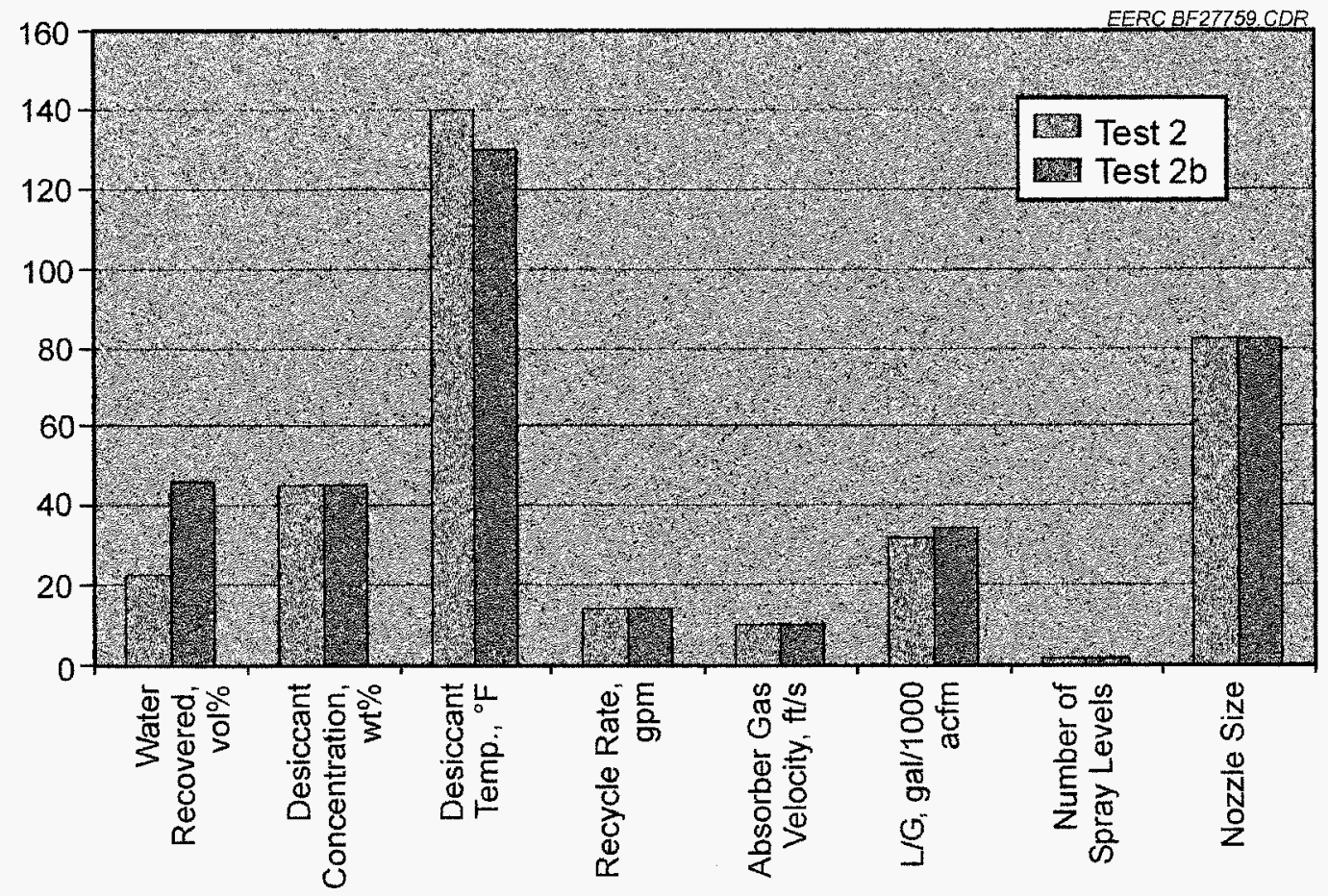

Figure 32. Average product water recovery rate varying desiccant temperature and $L / G$, Test Series II. 
Table 48. Product Water Analyses Results, Test Series II

\begin{tabular}{lcccccccc}
\hline Test No. & $\mathrm{pH}$ & $\begin{array}{c}\text { TDS, } \\
\mathrm{mg} / \mathrm{L}\end{array}$ & $\begin{array}{c}\text { TSS, } \\
\mathrm{mg} / \mathrm{L}\end{array}$ & $\begin{array}{c}\text { Calcium, } \\
\mathrm{mg} / \mathrm{L}\end{array}$ & $\begin{array}{c}\text { Chloride, } \\
\mathrm{mg} / \mathrm{L}\end{array}$ & $\begin{array}{c}\text { Nitrate, } \\
\mathrm{mg} / \mathrm{L}\end{array}$ & $\begin{array}{c}\text { Sulfate, } \\
\mathrm{mg} / \mathrm{L}\end{array}$ & $\begin{array}{c}\text { Sodium, } \\
\mathrm{mg} / \mathrm{L}\end{array}$ \\
\hline Test No. 3 & 4.22 & 1230 & $<10$ & 309 & 673 & $<1$ & $<1$ & 6.8 \\
Test No. 8 & 4.05 & 266 & $<10$ & 4 & 7 & $<1$ & $<1$ & 1.4 \\
Test No. 9 & 3.00 & 251 & $<10$ & 56 & 118 & $<1$ & 58 & 2.5 \\
Test No. 10 & 2.77 & 9320 & 30 & 3040 & 7150 & $<1$ & 120 & 54.4 \\
Test No. 12 & 2.71 & 1310 & $<10$ & 343 & 810 & $<1$ & 95 & 7.6 \\
Test No. 13-2 & 2.74 & 74 & $<10$ & 4 & 16 & $<1$ & 68 & 1.4 \\
DI Water & 4.31 & $<1$ & $<10$ & $<0.09$ & $<1$ & $<1$ & $<1$ & $\mathrm{NA}$ \\
City Water & 8.47 & 251 & $<10$ & 44 & $<1$ & 2.0 & 94 & 22.3 \\
\hline
\end{tabular}

results reported in Table 48 does not document all of the constituents contributing to the TDS content of the samples. However, the reason for the variable nature of the product water TDS, calcium, chloride, sulfate, and sodium data was contamination of the product water recovery system with desiccant solution because of the operating problems with the flash drum previously discussed. If the contamination had not occurred, the EERC expects that the product water quality for Test Series II would have been identical to Test Series I. Analysis of the Test Series II product water samples for mercury determined concentrations were less than detection limits $(<0.01 \mu \mathrm{g} / \mathrm{L})$ in all cases.

Table 49 summarizes product water analyses for a Test Series II sample submitted to Nalco Analytical Resources. The water $\mathrm{pH}$ reported is on the high end of the EERC data range. Calcium, chloride, sodium, and sulfate concentration data are within the range of data observed by the EERC. Nitrate concentration data are consistent with the EERC data. Other cations, metals, and anions found to be at or greater than detection limits included boron, copper, iron, lithium, magnesium, manganese, potassium, silica, sodium, strontium, zinc, chloride, and sulfate. Based on the analyses completed, the product water generated during Test Series II would require upgrading for use in a utility station steam cycle. However, as previously stated, if desiccant solution contamination of the product water recovery system had not occurred, the EERC expects that the product water quality for Test Series II would have been identical to Test Series I. Therefore, only a minimal upgrading requirement for use in a utility station steam cycle is anticipated.

Absorber and flash drum desiccant solution and product water samples collected during Test Series II were selectively analyzed. However, all of the samples collected have been retained until this report is completed and approved to accommodate further analyses if desired. Subsequently, the samples will be disposed of in an appropriate manner.

\subsubsection{Desiccant-Based Absorber Performance Data-Background or Basis for Absorber Performance Results}

The performance of the absorber was analyzed using theory developed for mass transfer occurring in gas absorption applications. In gas absorption, typically a liquid is used to dissolve a gas component from a gas mixture, thereby performing a separation. This method is usually applied to 
Table 49. Nalco Analytical Resources Product Water Analyses Results, Test Series II

\begin{tabular}{|c|c|c|}
\hline Cations/Metals & Filtered, $\mathrm{mg} / \mathrm{L}$ & Total, mg/L \\
\hline Aluminum (Al) & $<0.1$ & $<0.1$ \\
\hline Barium (Ba) & $<0.1$ & $<0.1$ \\
\hline Boron (B) & 0.6 & 0.6 \\
\hline Cadmium (Cd) & $<0.01$ & $<0.01$ \\
\hline Calcium (Ca) & 220 & 220 \\
\hline Chromium (Cr) & $<0.01$ & $<0.01$ \\
\hline Copper $(\mathrm{Cu})$ & 0.06 & 0.06 \\
\hline Iron $(\mathrm{Fe})$ & 1.9 & 2.0 \\
\hline Lead $(\mathrm{Pb})$ & $<0.1$ & $<0.1$ \\
\hline Lithium (Li) & 0.17 & 0.17 \\
\hline Magnesium (Mg) & 0.2 & 0.4 \\
\hline Manganese (Mn) & 0.05 & 0.05 \\
\hline Molybdenum (Mo) & $<0.1$ & $<0.1$ \\
\hline Nickel (Ni) & $<0.1$ & $<0.1$ \\
\hline Phosphorus (P) & $<1.0$ & $<1.0$ \\
\hline Phosphorus $\left(\mathrm{PO}_{4}\right)$ & $<3.1$ & $<3.1$ \\
\hline Potassium (K) & 9.6 & 9.8 \\
\hline Silica $\left(\mathrm{SiO}_{2}\right)$ & $<0.2$ & 0.3 \\
\hline Sodium $(\mathrm{Na})$ & 3.9 & 4.3 \\
\hline Strontium (Sr) & 3.4 & 3.4 \\
\hline Vanadium (V) & $<0.01$ & $<0.01$ \\
\hline Zinc $(\mathrm{Zn})$ & 0.02 & 0.02 \\
\hline Calcium (reported as $\mathrm{CaCO}_{3}$ ) & 540 & 540 \\
\hline Magnesium (reported as $\mathrm{CaCO}_{3}$ ) & 0.7 & 1.6 \\
\hline Sodium (reported as $\mathrm{CaCO}_{3}$ ) & 8.5 & 9.5 \\
\hline Calculated Hardness $\left(\mathrm{CaCO}_{3}\right)$ & 540 & 540 \\
\hline \multicolumn{3}{|l|}{ Anions } \\
\hline Bromide (Br) & - & $<2.0$ \\
\hline Chloride (Cl) & - & 400 \\
\hline Nitrate $\left(\mathrm{NO}_{3}\right)$ & - & $<2.0$ \\
\hline Nitrite $\left(\mathrm{NO}_{2}\right)$ & - & $<2.0$ \\
\hline Sulfate $\left(\mathrm{SO}_{4}\right)$ & - & 31 \\
\hline Chloride $\left(\mathrm{CaCO}_{3}\right)$ & - & 570 \\
\hline Nitrate $\left(\mathrm{CaCO}_{3}\right)$ & - & $<1.6$ \\
\hline Sulfate $\left(\mathrm{CaCO}_{3}\right)$ & - & 33 \\
\hline Alkalinity & - & - \\
\hline \multicolumn{3}{|l|}{ Others } \\
\hline $\mathrm{pH}$ & - & 3.2 \\
\hline Conductivity & - & $1700 \mu \mathrm{S} / \mathrm{cm}$ \\
\hline Acidity - Free Mineral $\left(\mathrm{CaCO}_{3}\right)$ & - & 33 \\
\hline Acidity - Total $\left(\mathrm{CaCO}_{3}\right)$ & - & 49 \\
\hline
\end{tabular}


packed columns, but it also is representative of the mass transfer occurring within a spray tower as well. Since both packed-bed and spray tower methods were utilized to absorb water from flue gas during the experimental evaluation, identical theoretical treatment was applied for both cases. The primary physical differences between the packed beds and spray towers are 1) the interfacial area for absorption to occur is fixed and determined by the packing used in a packed bed, while a spray tower utilizes droplet size to affect interfacial area, and is mobile throughout the tower and 2) the absorbing liquid is typically applied to the top of the packed bed and removed from the bottom of the bed, whereas a spray tower may utilize multiple spray levels where only a portion of the total liquid mass flow may be applied to any one level.

A simplified method of calculating an overall transfer unit rather than an individual or overall mass-transfer unit is especially well suited to experimental data for which an absorber process is being designed. The method is even more robust when the equilibrium and operating lines from the absorber are nearly linear, as is the case with most of the experimental conditions observed during this testing. Figure 33 shows a typical equilibrium diagram for the water/desiccant absorber operation. The upper line in the figure is the operating line and is determined by the inlet and outlet conditions for flue gas moisture. These data points were measured experimentally with continuous moisture analyzers. Since the mass flux and temperature at any point in the packed bed (or spray tower) is difficult to determine, an assumption of linear absorption of the gas component (water) across the length of the bed was made.

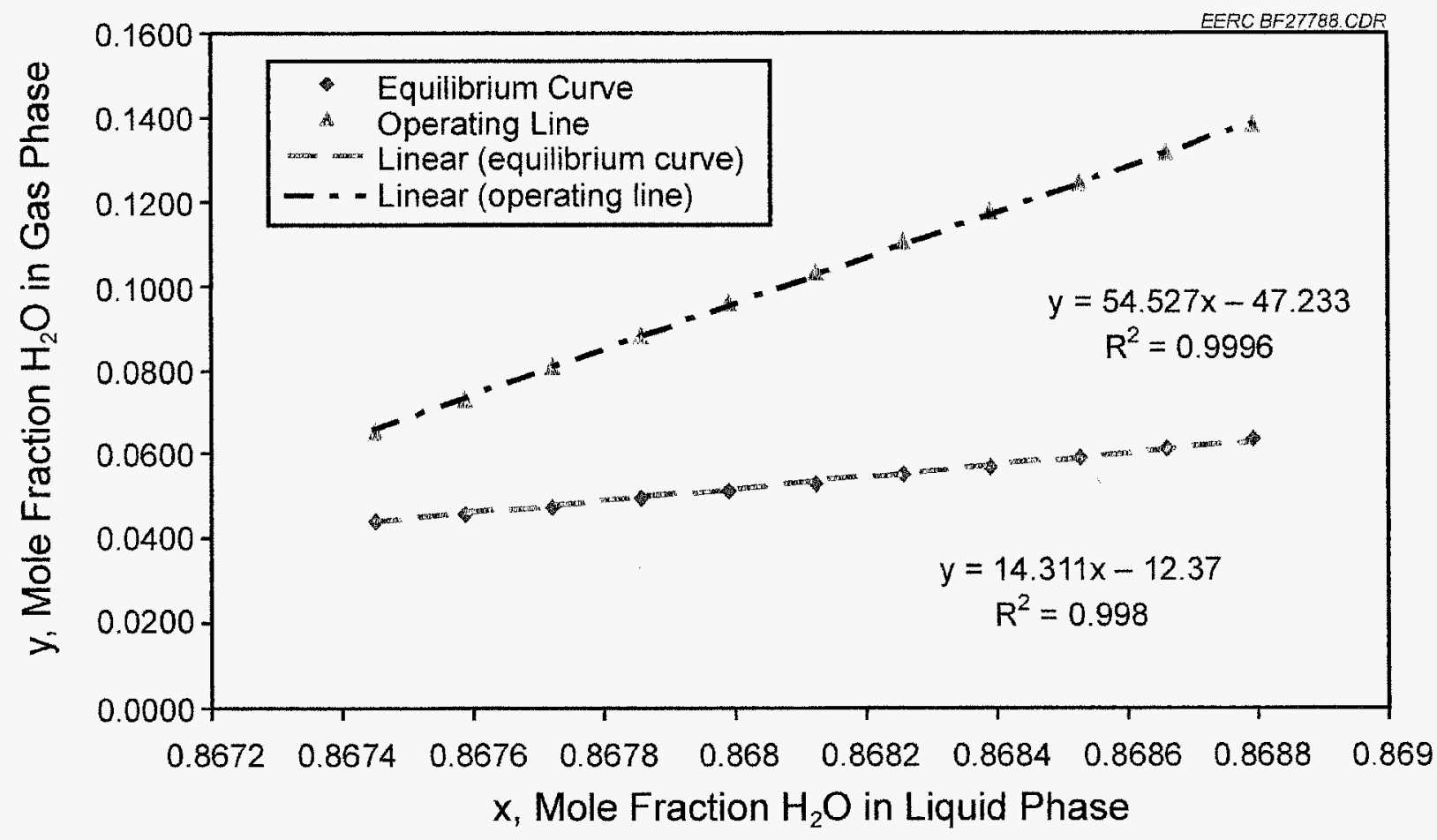

Figure 33. Operating and equilibrium lines for the flue gas $\mathrm{CaCl}_{2}$ desiccant system. 
The lower line represents the equilibrium of the gas and liquid phases at the desiccant concentration and temperature for which they were calculated. Likewise, these values are calculated assuming that the moisture is absorbed linearly as the desiccant travels across the absorber, and the temperature changes from water absorption occur linearly as well. Although these assumptions are not necessarily true, they are believed to be adequate for the analysis of the data, especially at the higher desiccant flow rates seen in the spray-tower configuration.

When a packed bed is designed, the height, given as $Z$, is equal to the number of transfer units (NTU) multiplied times the height of an individual transfer unit (HTU) or:

$$
\mathrm{Z}=\mathrm{NTU} \times \mathrm{HTU}
$$

The NTU is dimensionless, with the HTU having units of feet. The NTUs are calculated from numerically integrating factors derived from the plot of the desiccant equilibrium line and the absorber operating line. The equation derived for the overall NTUs based upon the gas-side mass transfer is as follows:

$$
\mathbf{d}(\mathbf{N T U})=\mathbf{d y} /\left[(1-\mathbf{y}) \times\left(\mathbf{y}-\mathbf{y}^{*}\right)\right]
$$

Where $y$ is the bulk gas moisture concentration at any point in the absorber, and $y^{*}$ is the equilibrium value of the desiccant at the same location. Referring to Figure 33, $y$ is found from the operating line, and $y^{*}$ is found directly below it from the equilibrium line. By integrating Equation 2 from the inlet to the outlet of the absorber, the total NTUs are calculated. Figure 34 shows the curves generated as a function of a change in the bulk moisture concentration versus the factors $1 /(1-y)$ and $1 /\left(y-y^{*}\right)$. The area under the curve gives the total NTUs. Note that one curve is generated from the single factor, $1 /\left(y-y^{*}\right)$. This factor can be integrated when the moisture levels are low, and the value $1-$ $\mathrm{y}$ can be assumed to be unity. Under these circumstances, the equation can be solved analytically for calculating NTUs directly or used as an approximation for the more rigorous treatment of the data. This equation is given as:

$$
\mathbf{N T U}=\left(\mathbf{y}_{\text {in }}-\mathbf{y}_{\text {out }}\right) /\left(\mathbf{y}-\mathbf{y}^{*}\right) \mathbf{L}
$$

Where $y_{\text {in }}$ is the moisture concentration at the inlet of the absorber, $y_{\text {out }}$ is the moisture concentration at the outlet of the absorber, and $\left(y-y^{*}\right)_{L}$ is the logarithmic mean of the difference between the operating and equilibrium curves at the inlet and the outlet to the absorber.

As seen from Equation 3, an NTU is mathematically the ratio of the water removed (y) by the absorber divided by the log mean difference between the two curves. The vertical distance between the two curves at the midpoint concentration can approximate this difference, or driving force. For the data shown in Figure 33, there are 1.46 NTU, i.e., $(0.138-0.065) /(0.103-0.053)=1.46$. The result of the numerical integration gives 1.89 NTUs by comparison.

The NTU can be thought of as the number of equilibrium stages required to affect the transfer or simply the amount of moisture absorbed per unit of average driving force. The NTUs are determined by the end point conditions of the physical process and the mass and energy balances. 


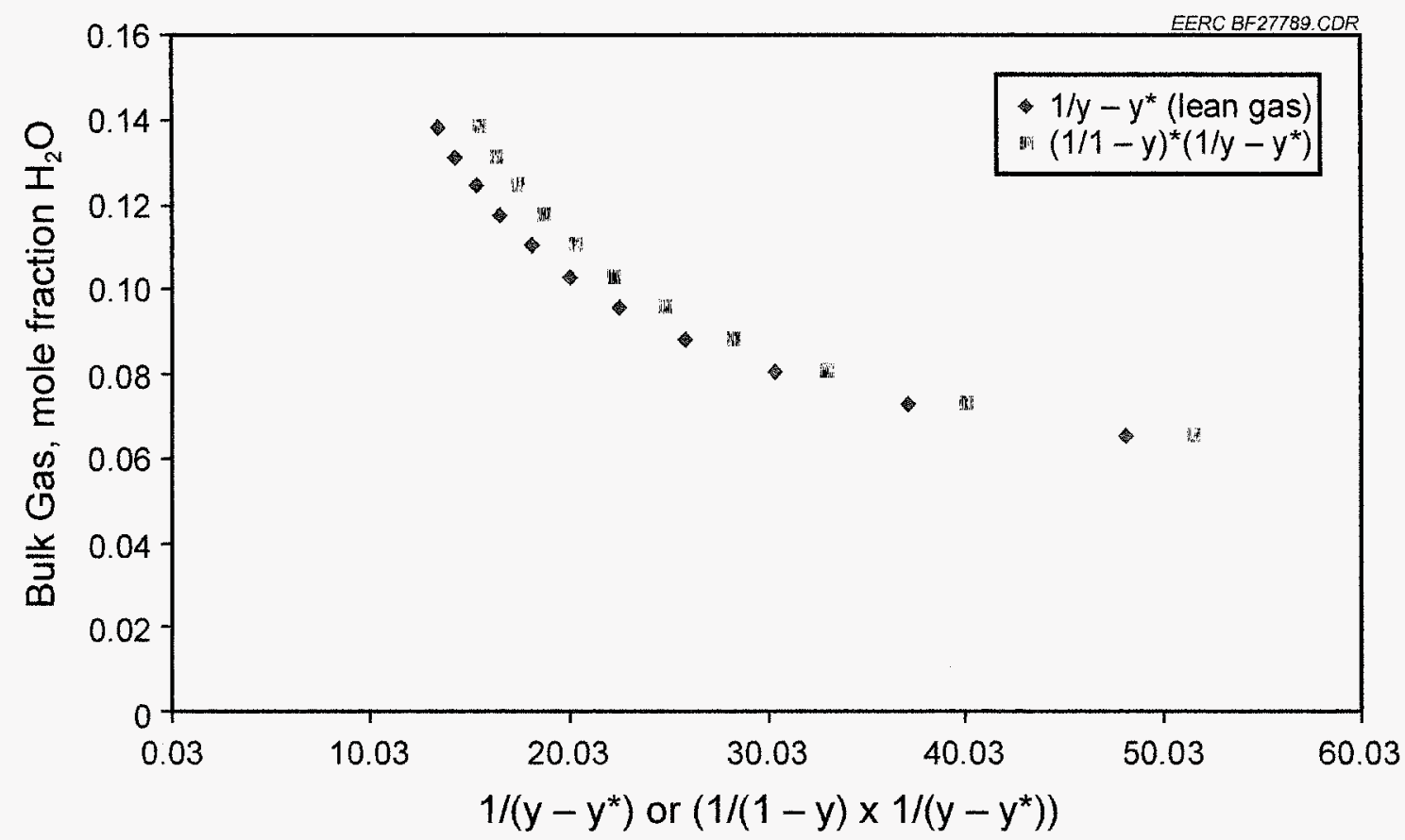

Figure 34 . The bulk moisture concentration versus the numerical integration factors: $1 /(1-\mathrm{y})$ and $1 /\left(y-y^{*}\right)$.

Almost any condition can physically exist provided the operating and equilibrium lines do not intersect and adequate time and interfacial area are available for mass transfer. However, it would be unwise to go beyond the limits of the experimental range for scale-up.

After the NTU is calculated, HTU can be calculated through Equation 1. The HTU is closely related to the overall mass transfer unit, $\mathrm{K}_{\mathrm{y}}$, by the equation:

$$
\mathrm{HTU}=\left[\mathrm{G}_{\mathrm{My}} / \mathrm{K}_{\mathrm{y}} \mathrm{a}\right]
$$

where $G_{M y}$ is the mean molal mass flux in the absorber, $K_{y}$ is the mean overall mass transfer coefficient, and $\mathrm{a}$ is the interfacial area per unit volume of absorber. As seen from Equation 4, an HTU is inversely related to the mass transfer coefficient, provided that the molal gas flux and area are constant. The quantities in brackets are averaged values across the absorber. Although an HTU is calculated from the known height of the absorber and the NTU, an HTU is actually an independent quantity. NTUs are dependent upon the driving force for mass transfer, while the height necessary to effectively transfer this mass is a result of hydrodynamics within the absorber, related to "effective" interfacial area and local mass transfer.

\subsubsection{Absorber Performance Results - Calculated NTU}

Tests were performed firing either natural gas or coal, with moisture levels simulating the operation of a gas turbine or the outlet from a typical wet scrubber following a utility boiler. From the perspective of absorber design, there should be little difference in its operation whether the unit is 
fired by coal or gas, but more importantly, the temperature, pressure and moisture content of the flue gas stream, the concentration and temperature of the desiccant as well as the specific absorber design utilized. A summary of the data from all the pilot-scale tests were combined and identified by factors most likely to affect the performance of the absorber. The default independent test parameters included the spray tower configuration, a $120^{\circ} \mathrm{F}\left(49^{\circ} \mathrm{C}\right)$ desiccant temperature, and a nominal $48.5 \%$ $\mathrm{CaCl}_{2}$ desiccant concentration. Notable exceptions are denoted in figure legends and applicable text. In addition, desiccant mass flow rate, tower height, and nozzle size were the primary absorber independent design variables.

Figure 35 shows a summary of the NTU data broken down by nozzle, temperature, packed bed, or a notable change in desiccant concentration. Since NTUs are calculated from post run data, the NTUs were not target values, but rather reflective of actual performance from preliminary design criteria. The greater the value of the calculated NTU is, the better the absorber performance, since more of the moisture is being absorbed per unit driving force. The NTUs are seen to vary linearly with desiccant flow rate, with the slope being dependent upon nozzle size or the use of a packed bed. In addition, since the curves do not intersect zero, it shows that there may be "end effects" that could be offsetting the data, i.e., at $0 \mathrm{lb} / \mathrm{hr}$ the $\mathrm{NTU} \neq 0$. This could also result from experimental noise or from absorption activity occurring above or below the absorber flue gas entrance/exit on the surface of the walls or entrained droplets. As suspected, there appears to be no distinction between coalversus gas-fired data with respect to absorber performance.

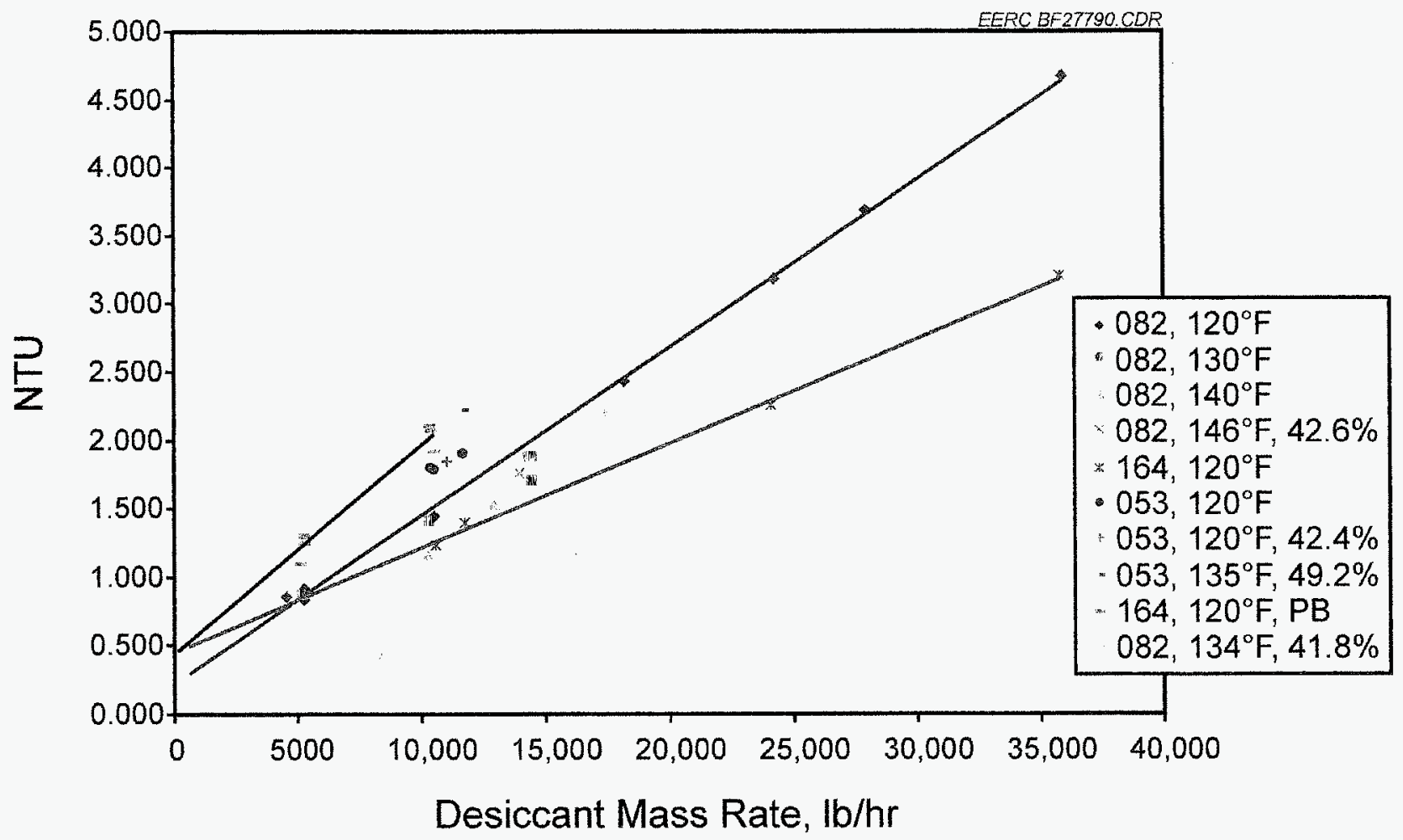

Figure 35. NTU as a function of desiccant mass flow rate. 
It should also be mentioned that tower height was not constant for the tests and was really a function of mass flow rate. As desiccant flow rate was increased, another spray level was added to manage the capacity. In order to reduce potential wall effects, it was decided to operate the absorber from the bottom up, where the shortest tower would be at the first spray level and the tallest would be at the sixth spray level. The alternate approach would have been to start the first spray level at the tallest tower configuration and add additional levels below the first, maintaining a constant tower height. However, since the tower has a severe aspect ratio, the initial design tests were intended to reduce the wall effects. Future work should address potential wall affects by quantifying and comparing these results with "tall-tower" results.

The primary factors affecting the absorber performance shown in Figure 35 are the nozzle specification and the desiccant flow rate. The larger the nozzle number is, the greater its flow capacity, but also the larger the particle size. Because mass transfer is dependent upon the surface area, the particle size is extremely important for absorber performance. The figure clearly shows an improvement in performance with smaller nozzles. For example, at a level of 2 NTUs, the 164 nozzles required a desiccant flow rate of $20,000 \mathrm{lb} / \mathrm{hr}(9080 \mathrm{~kg} / \mathrm{hr})$, the 082 nozzles required $14,000 \mathrm{lb} / \mathrm{hr}(6356 \mathrm{~kg} / \mathrm{hr})$, and the 053 only required about $11,000 \mathrm{lb} / \mathrm{hr}(4994 \mathrm{~kg} / \mathrm{hr})$. Because of the surface area of the packing, the packed bed only required about $10,000 \mathrm{lb} / \mathrm{hr}(4540 \mathrm{~kg} / \mathrm{hr})$. This comparison could only be made because the desiccant temperature and concentration were approximately the same for all of these tests. The mass flow rate was also shown to affect the absorber performance directly, with differing slopes for each nozzle configuration. The linear relationship is probably only applicable over a narrow range and is otherwise meaningless except for the fact that it delineates nozzle performance trends. The fact that performance improves with increased desiccant flow rate is somewhat intuitive and is consistent with mass transfer theory, especially if the liquid phase is providing considerable resistance to the mass transfer. In the case of the spray tower, added mass flow directly affects mass transfer by increasing available surface area.

\subsection{Absorber Performance Results - Calculated HTU}

Figure 33 presents the calculated HTU for each test as a function of desiccant mass flow rate. Similar to the data presented in Figure 35, the data in Figure 36 is divided by groups of nozzles and desiccant temperature and concentration where applicable. The HTU is inversely proportional to the mass transfer coefficient, which provides an indication of the maximum obtainable velocity for transferring mass from one phase to the other. An HTU can be thought of as the height required to attain a local equilibrium or one transfer unit in the absorber tower. The units of an HTU are given as feet (meters) and are representative of the actual height in the absorber required to provide one unit of mass transfer.

The data in Figure 36 show that the greatest mass transfer rates (smallest HTUs) are provided by the packed bed, followed by the 164, 082, and 053 nozzles. In the case of the packed bed, the 164 nozzle was used to distribute the liquid across the top of the packing. This may seem counterintuitive because the 053 nozzles produce the smallest droplets, while the 164 produced the largest. However, the HTU is indicative of absorption rate not quantity. Because the absorber mass rate variable is confounded with tower height, as discussed previously, it is difficult to make absolute comparisons between mass transfer rates and absorber performance. For example, at a nominal mass flow rate of 


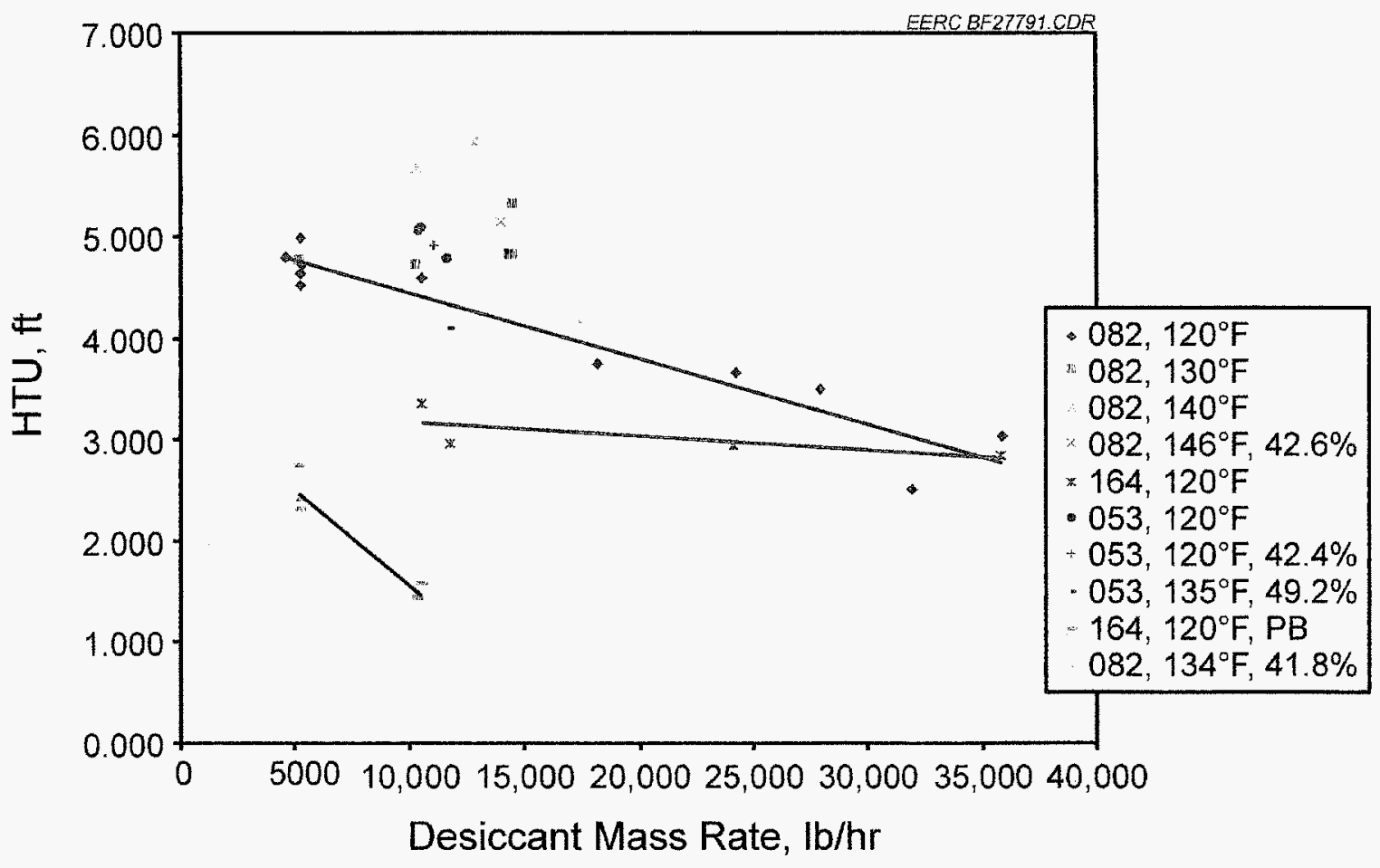

Figure 36. Height of transfer unit as a function of desiccant mass flow rate.

$10,000 \mathrm{lb} / \mathrm{hr}(4540 \mathrm{~kg} / \mathrm{hr})$ desiccant, the height of the absorber was operated using one level with the 164 nozzle, two levels with the 082 , and three levels with the 053 nozzle. Another way to look at this is to observe that for the same desiccant mass rate, the 164 nozzle produced 1.2 NTUs, the 082 produced 1.5 NTUs, and the 053 produced 1.75 NTUs. The end result is that the 053 removed more moisture over a longer distance, but at a slower rate. In addition, the packed bed had only one level but produced 2 NTUs at the lowest HTU of 1.5 .

If all spray tower tests were conducted at the same overall absorber height, then the measured NTU and the calculated HTU results could be totally different. The data shown in Figure 36 were recalculated assuming that the tower height was $10 \mathrm{ft}(3 \mathrm{~m})$ for all tests. This representation is fictitious because the experimentally determined water absorption rates, and thus the measured NTUs, may be different because of changes in residence time and contact area. However, if doing this did not substantially change the absorber performance, then the curves shown in Figure 37 would result. The trends shown in this figure provide what is believed to be a more realistic functional relationship between desiccant mass flow rate and the calculated HTU. As the mass flow approaches zero, the HTU will approach infinity, suggesting an enormous absorber height would be required to effectively transfer gas-phase moisture into the desiccant. In addition, the relationship to the observed HTUs falls in line with the differing nozzles, i.e., packed bed $<053<082<164$. One must assume that the desiccant mass flow rate, and not absorber height, is the controlling mechanism for mass transfer for these data to be believable. 


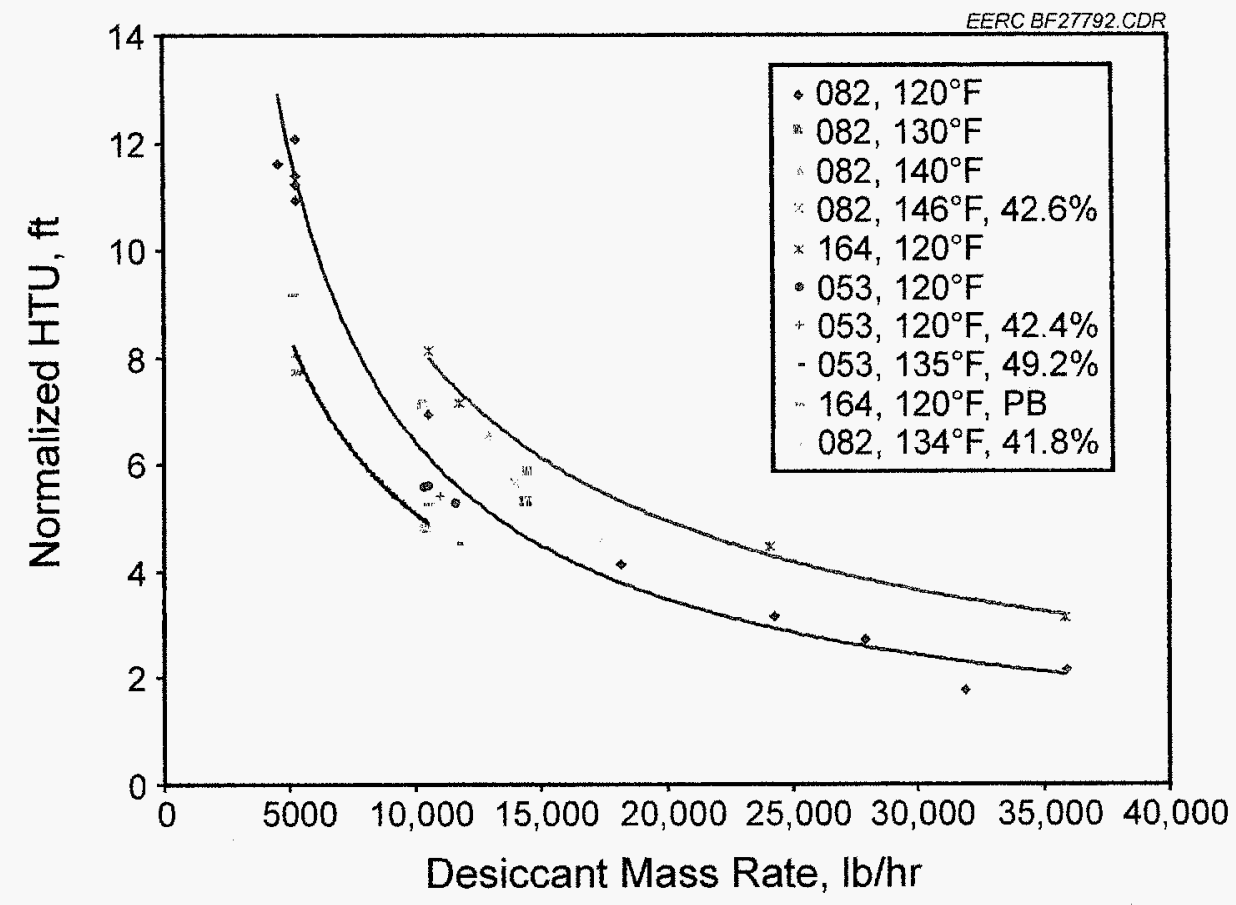

Figure 37. HTU data recalculated for a constant absorber height of 10 feet.

\subsection{Equilibrium Relationships in Mass Transfer Process}

The driving force for mass transfer in the absorber is the difference in concentration of the moisture in the bulk gas entering the absorber and that of the gas-desiccant interface. Specifically, the difference in concentration is the result of the partial pressure of water in the bulk gas or $y=$ $\mathrm{P}_{\mathrm{H} 2 \mathrm{O}} / \mathrm{P}_{\text {Tot }}$ versus that of the water in the desiccant, $\mathrm{y}^{*}=\mathrm{P}_{\mathrm{H} 20, \mathrm{Des}} / \mathrm{P}_{\text {Tot }}$, where $\mathrm{P}_{\text {Tot }}$ is the absolute pressure for absorber operation. Since the partial pressure for water in the desiccant is a function of temperature and $\mathrm{CaCl}_{2}$ concentration, the desiccant properties limit the performance and the maximum achievable moisture recovery. Figure 38 presents the equilibrium moisture levels of the flue gas over the desiccant at various temperatures and $\mathrm{CaCl}_{2}$ concentrations. For example, the minimum flue gas moisture attainable from the exit of the absorber at $120^{\circ} \mathrm{F}\left(49^{\circ} \mathrm{C}\right)$ and $50 \% \mathrm{CaCl}_{2}$ is $3 \%$ and $5.5 \%$ at $140^{\circ} \mathrm{F}\left(60^{\circ} \mathrm{C}\right)$.

The equilibrium moisture shown in Figure 38 represents a condition where the flue gas moisture leaving the absorber is in equilibrium with the desiccant entering the absorber. This condition would represent a $100 \%$ approach to equilibrium. If the flue gas entering the absorber leaves at the same moisture concentration, then this scenario would represent $0 \%$ approach to equilibrium (assuming that the desiccant was not at equilibrium with the flue gas moisture). This concept of "approach to equilibrium" will be shown to be useful for comparing absorber performance data at differing temperatures and desiccant concentrations. 


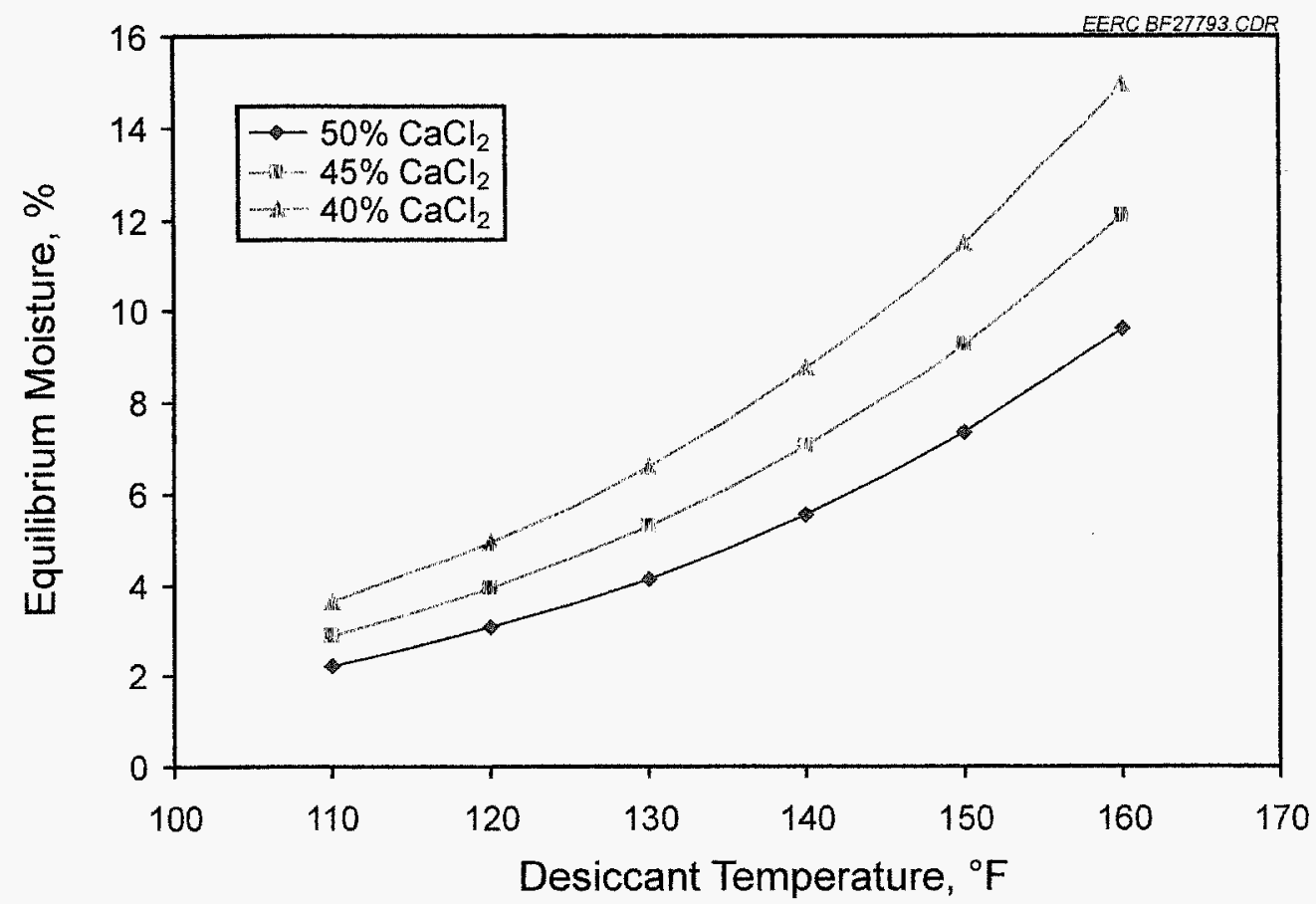

Figure 38. Desiccant equilibrium moisture as a function of desiccant temperature and $\mathrm{CaCl}_{2}$ concentration.

A plot of the flue gas water removal by the absorber as a function of desiccant mass flow rate is shown in Figure 39. Although there is a clear trend of increased water removal with increasing desiccant flow rate, there is a wide disparity in the values at any given flow rate, mostly between high-moisture coal and low-moisture gas conditions, but also with changes in desiccant temperature and concentration. Unless the tests are run under identical desiccant conditions and absorber configuration, it is difficult to relate the data on the basis of changes in flue gas moisture. In addition, attempts to correlate water removal as a function of NTUs or HTUs produced similarly poor results. Referring to Figure 38, it was shown that the equilibrium moisture level with respect to the desiccant is a moving target based upon temperature and concentration. By correlating the approach to equilibrium with desiccant mass flow rate, rather than the percent change in moisture removal, it effectively normalizes the data with respect to desiccant properties. The approach is defined as:

$$
\text { \%Approach }=\left(y, i-y_{, 0}\right) /\left(y, i-y^{*}, \text { Des, } 0\right) \times 100 \%
$$

where $y_{, i}$ is the molar flue gas inlet concentration to the absorber, $y_{, o}$ is the molar flue gas outlet concentration from the absorber, and $y^{*}$, Des,o is the equilibrium moisture concentration of the desiccant at the absorber outlet. The value for $y^{*}$ can be taken from Figure 38 for the representative desiccant conditions. As seen from this relationship, the water removed by the absorber is relative to the maximum attainable under the operating conditions, rather than on the basis of the inlet flue gas moisture concentration. 


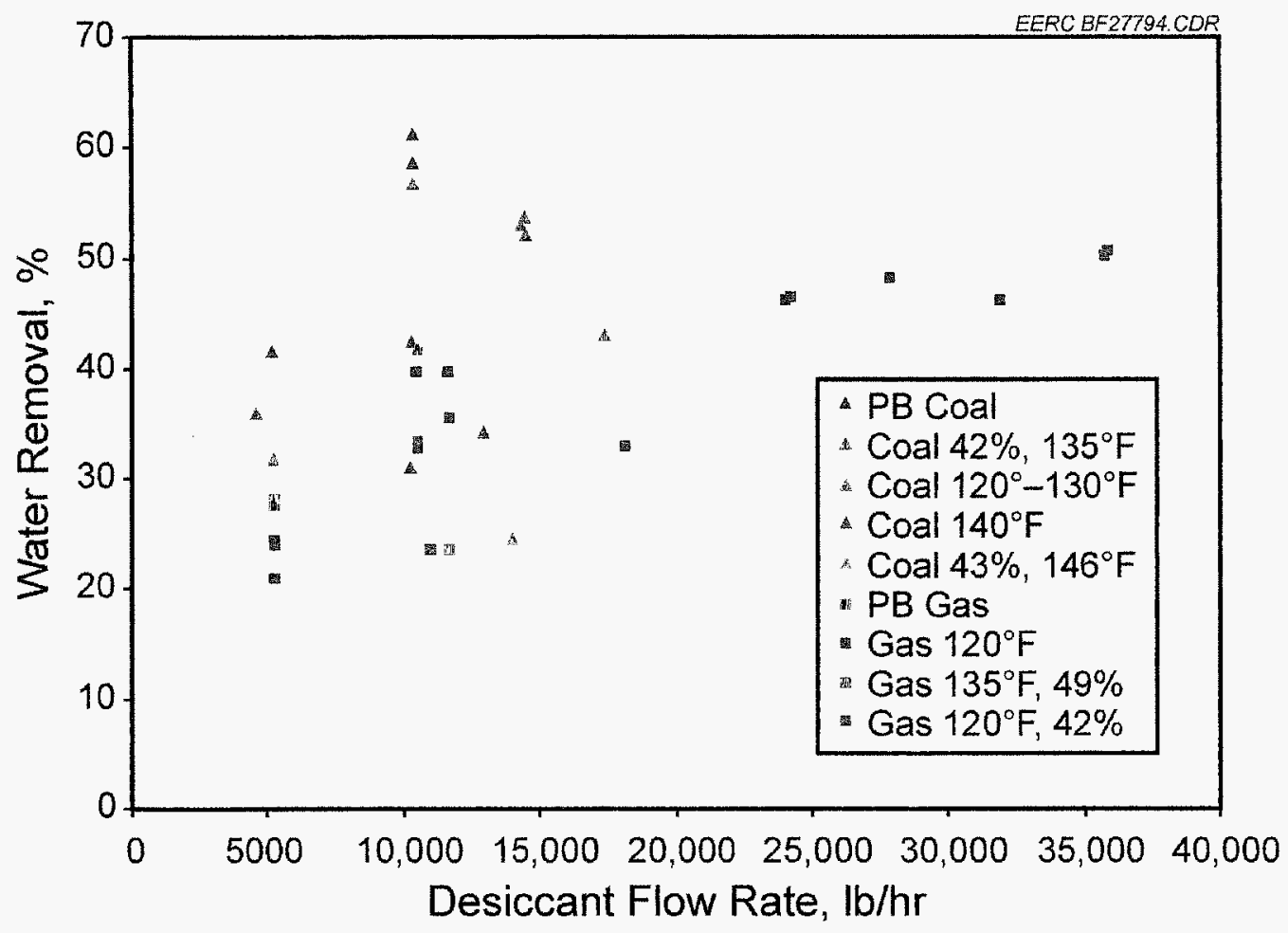

Figure 39. Flue gas water removal by the absorber as a function of desiccant mass flow rate.

The data in Figure 39 were recalculated and presented on the \% approach basis and plotted as a function of desiccant mass flow rate in Figure 38. Presentation of data on the approach basis shows a marked improvement with the correlation to desiccant mass flow rate. In addition, the data was fitted with the curve defined by the equation:

$$
f(\text { mass })=100[1-\exp (- \text { mass } / \mathrm{k})]
$$

where mass is the desiccant mass flow rate and $\mathrm{k}$ is a constant used to scale the equation to the approach data. This equation is the solution to a first-order differential equation typically describing a step change to a continuously stirred reactor, with the boundary conditions of the approach $=100 \%$ when mass flow approaches infinity, and the approach $=0 \%$ when the mass flow rate is equal to 0 . Normally in the time domain, the constant $\mathrm{k}$ is characteristic to the mass flow rate into the reactor, the volume of the reactor, and any change in mass associated with a reaction and is referred to as the time constant for the system. In this case, the value of $k=10,000$ was found iteratively to give the best fit to the data. The physical significance of this relationship is unknown, but seems to describe the experimental data quite well.

From Figure 40, it can be shown that the desiccant mass flow rate impacts the approach-toequilibrium, but it says nothing about the differences in the absorber hydrodynamics affecting efficiency at any given desiccant flow rate. For example, the data points for the packed bed show higher approaches for a given desiccant mass flow rate than do the spray tower data points. This is consistent with the data presented in Figure 35, where more transfer units were observed for a given 


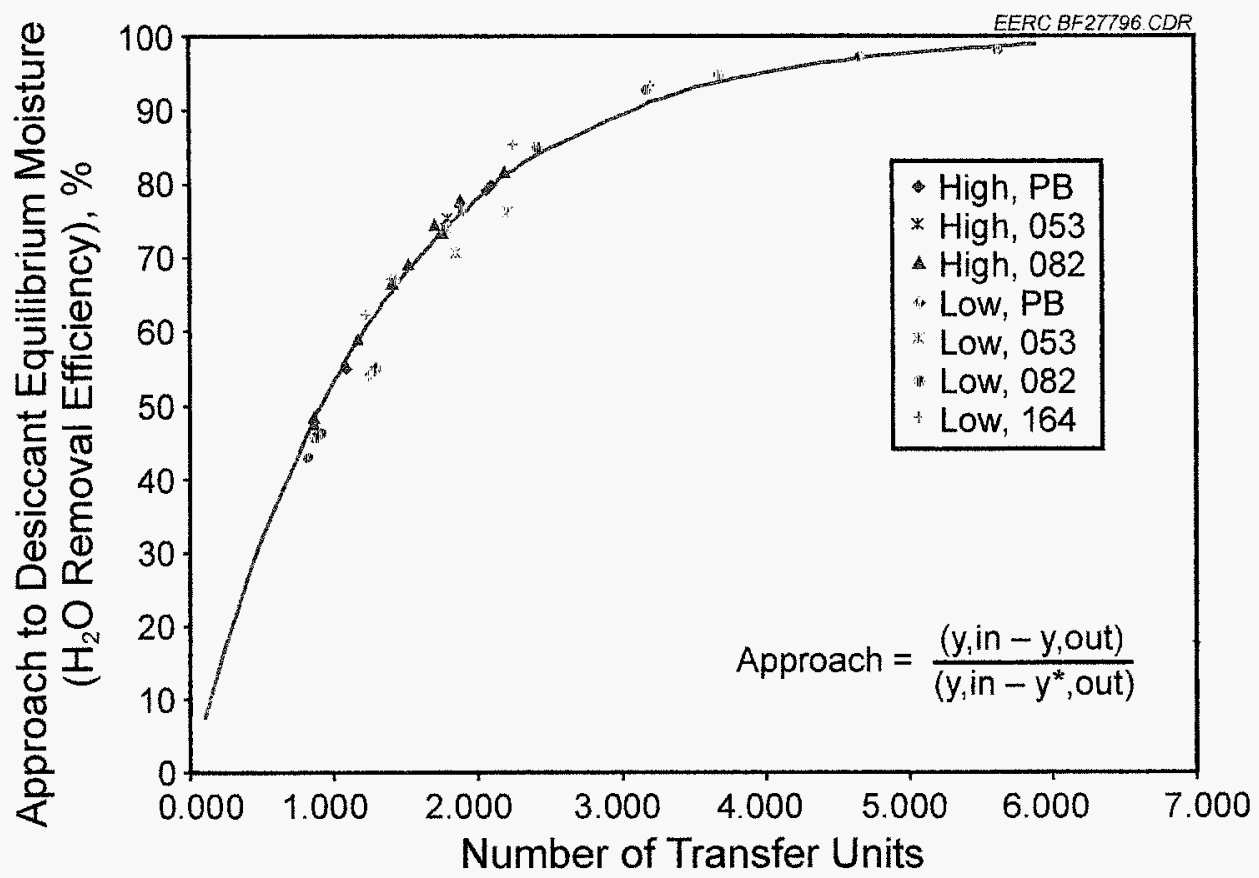

Figure 40. Approach to desiccant equilibrium moisture as a function of desiccant mass flow rate.

desiccant mass flow rate. Figure 35 data also give an indication that the NTU effectively normalizes the data with respect to hydrodynamics in the absorber. Figure 41 presents the data in Figure 40, except the respective NTUs were substituted for the desiccant mass flow rates. Another way to state this relationship is that for any given NTU, the absorber will perform at the same approach to equilibrium. The function correlating the NTU and the approach to equilibrium takes the same form as Equation 6, $\mathrm{f}(\mathrm{NTU})$, except for the constant: $\mathrm{k}=1.32$. Attempts to make similar correlations with the HTU data were not as successful, probably because of the fact that the HTU data were confounded by the inconsistent tower height with mass flow rate.

From a practical standpoint, the data presented in Figures 35 through 41 do not necessarily lend themselves to scale-up, but it does provide a window into the numerous modes of operation that are achievable based upon acceptable desiccant mass flow rates, concentrations, temperatures, and allowable absorber tower heights. In addition, the desiccant specification can be based upon required water recovery, mode of recovery (packed bed or spray tower), or the necessary driving force required to perform the recovery. Probably the most important factor in design, however, is the cost of water recovery. The next section will address absorber operation and design specifications that directly influence the cost of water recovery.

\subsubsection{Absorber Operation and Water Recovery}

The performance of the absorber is only one facet of the entire process for water recovery from flue gas. Once the desired quantity of water has been extracted via the absorber, the desiccant has to be regenerated by separating the water from the desiccant. However there are energy penalties to be paid for this process, which can be prohibitively expensive if operated under the wrong 


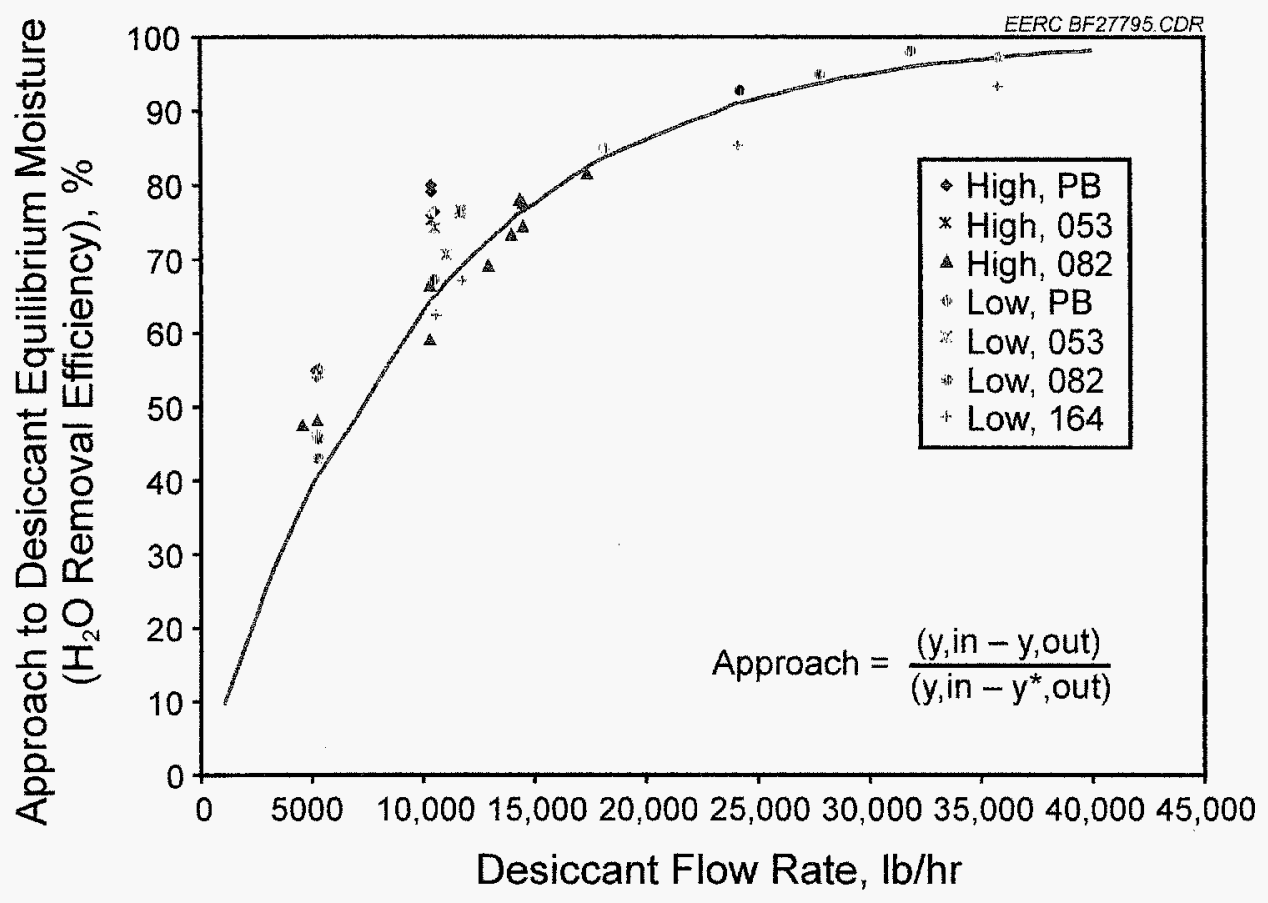

Figure 41. Approach to desiccant equilibrium moisture as a function of NTUs.

conditions. For the purposes of this discussion, the major energy consumption steps include the heating of the desiccant to flash off the water, the cooling of the regenerated desiccant to restore it to the proper temperature for operating the absorber, the condensation of the flashed water vapor, and the desiccant/recovered-water pumping cost. Relative to the other costs, the pumping will be assumed minor for this analysis. Likewise, the cost of condensing the recovered water will be the same regardless of how the water absorption/desiccant regeneration stages are accomplished and will be ignored. In the following figures, the effects of desiccant concentration, temperature and flow rate, the flash-tank pressure, the quantity of water absorbed, and the quantity of the desiccant stream that is regenerated are illustrated.

The energy required to regenerate the desiccant as a function of desiccant temperature, concentration and flow rate, and flash pressure is illustrated in Figure 42. Energy for both heating and cooling was summed and normalized on a Btu/hr per pound produced water basis. Calculated energy data are based upon $13.5 \%$ flue gas inlet moisture and $8 \%$ absorber exit flue gas moisture. In all cases, the absorber is operated at a nominal $10 \mathrm{ft} / \mathrm{s}(3 \mathrm{~m} / \mathrm{s})$ inlet velocity, or about $1775 \mathrm{lb} / \mathrm{hr}$ $(806 \mathrm{~kg} / \mathrm{hr})$ flue gas. The main trends noted in Figure 42 for regeneration energy requirements include a decrease as the temperature of the desiccant increases or the concentration of desiccant decreases, an increase as the flash-vessel pressure increases, and generally greater energy for the spray tower configuration simply because it is less efficient and requires additional mass to be heated and cooled. It should be noted that although all the data represented in Figure 42 are possible to attain, they might be impractical since the tower height may become prohibitively large. For example, at a $10,000 \mathrm{lb} / \mathrm{hr}(4540 \mathrm{~kg} / \mathrm{hr})$ desiccant flow rate, a temperature of $135^{\circ} \mathrm{F}\left(58^{\circ} \mathrm{C}\right)$, and a concentration of $40 \%$, a spray tower would have to function at an approach of $93 \%$. Referring to 


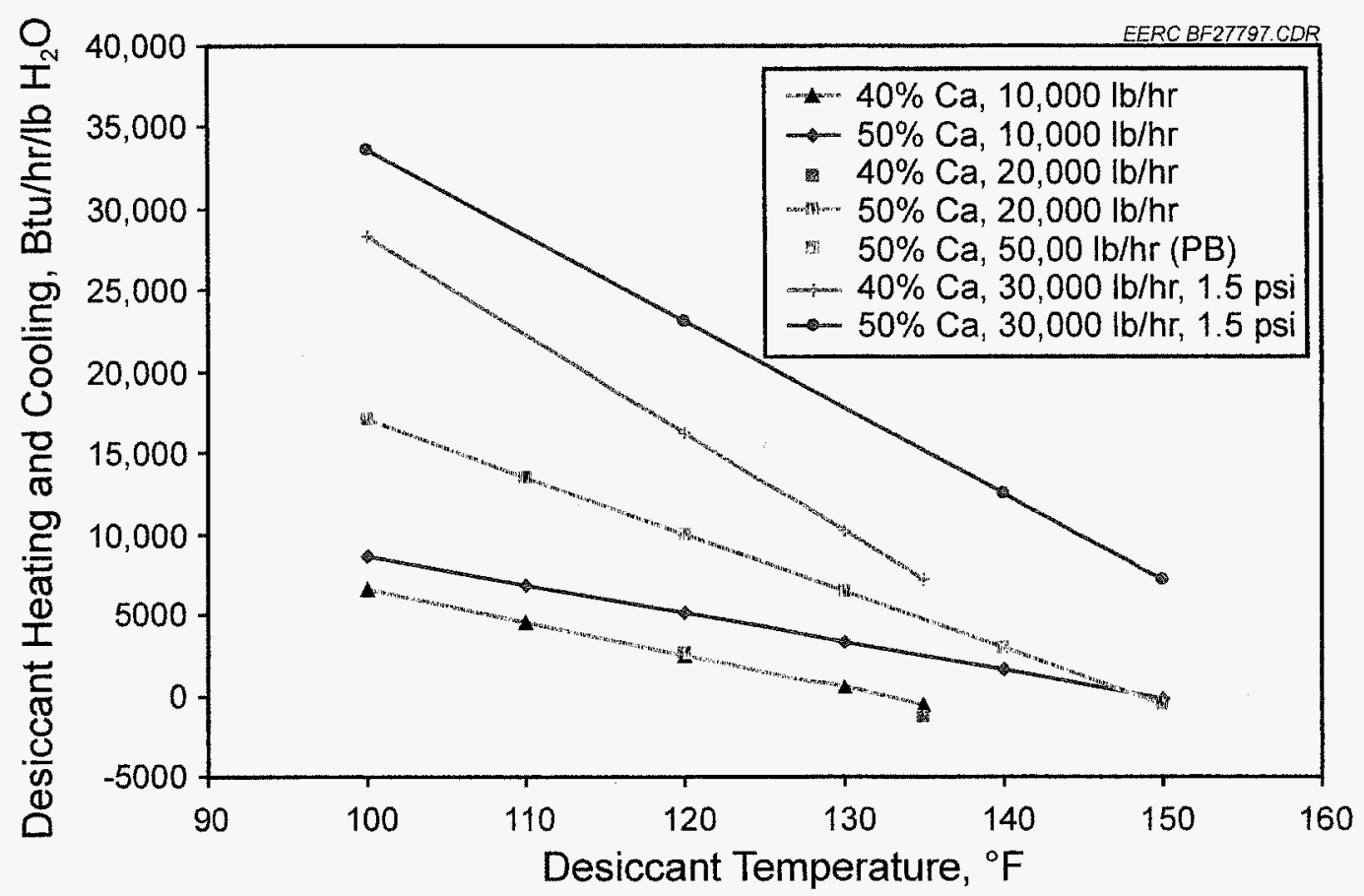

Figure 42. Energy required to regenerate desiccant as a function of design parameters.

Figure 40 , it can be seen that only flow rates nearing $25,000 \mathrm{lb} / \mathrm{hr}(11,350 \mathrm{~kg} / \mathrm{hr})$ can deliver that kind of efficiency. However, a single data point for a rate of $20,000 \mathrm{lb} / \mathrm{hr}(9080 \mathrm{~kg} / \mathrm{hr})$ is plotted on Figure 42 , and basically gives the same result for energy requirements. The reason for this is that the pumping energy is not included in the analysis.

Other important observations about the data in Figure 42 are that the curves are intentionally truncated because of the fact that the equilibrium moisture level, or $100 \%$ approach level, was attained, making it impossible to reduce the flue gas moisture below 8\%. In addition, there is a unique point for a given desiccant temperature and concentration, where the energy required for heating the desiccant equals the energy absorbed during flashing without additional input. In this scenario, the heat of absorption is sufficient to provide energy to flash the same amount of water, provided that the flash vessel can be maintained at a low enough pressure. As seen in Figure 42, raising the pressure from $1.0 \mathrm{psia}(52 \mathrm{mmHg})$ to $1.5 \mathrm{psia}(78 \mathrm{mmHg})$ causes the "no heat/no cool" option to become theoretically impossible and creates a tremendous energy penalty. A single point representing a packed bed shows that it is a very energy-efficient method to absorb water, and because it operates at a low desiccant flow rate, the energy cost of regenerating the desiccant is less. However, the low flow rates associated with a packed bed may be potentially problematic for use in a coal-fired system, where particulate could become difficult to wash from the system. Long-term testing will be required to assure that this is a reasonable option.

Because spray towers are inherently less efficient than a packed bed, greater masses of desiccant are required to absorb the same quantity of moisture from the flue gas. One way of reducing energy requirements associated with treating large desiccant masses is to fractionally treat 
the stream. Under this scenario, a desiccant is regenerated after bypassing a portion of the stream, then heating and flashing the remaining portion. The two streams are then recombined and cooled to the starting temperature for the absorber. The energy savings result from heating a smaller mass before flashing. Because all of the moisture is removed from a much smaller stream, the temperature is raised much higher to release the same quantity of water. Although the energy requirements are less, this could have implications regarding materials of construction and long-term life expectancy of equipment.

Figure 43 shows the effect of bypassing various mass fractions of the desiccant stream for flashing on the calculated energy requirements per pound of produced water. The basis for these data is a $13.5 \%$ and $8 \%$, respectively, absorber inlet and outlet moisture values, with $30,000 \mathrm{lb} / \mathrm{hr}$ $(13,620 \mathrm{~kg} / \mathrm{hr})$ of the desiccant being used to capture the water from the flue gas. This flow rate represents a liquid-to-gas ratio of about 92 gal/1000 acf and an approach of only $69 \%$ for the hightemperature desiccant case. These conditions are achievable and representative of rates used in utility flue gas scrubbers for $\mathrm{SO}_{2}$ control. The packed-bed option is displayed as a relative comparison of energy requirements. The data in Figure 43 show that the lowest energy requirements occur when the smallest desiccant mass is treated and when the desiccant is closest to its respective equilibrium moisture level. This result seems intuitive since it is the same principle that makes the packed bed more efficient. In addition, using a desiccant that has an equilibrium vapor pressure that is closer to the absorber exit moisture concentration requires less energy in the form of heat to overcome the water's attraction to the desiccant during the regeneration process.

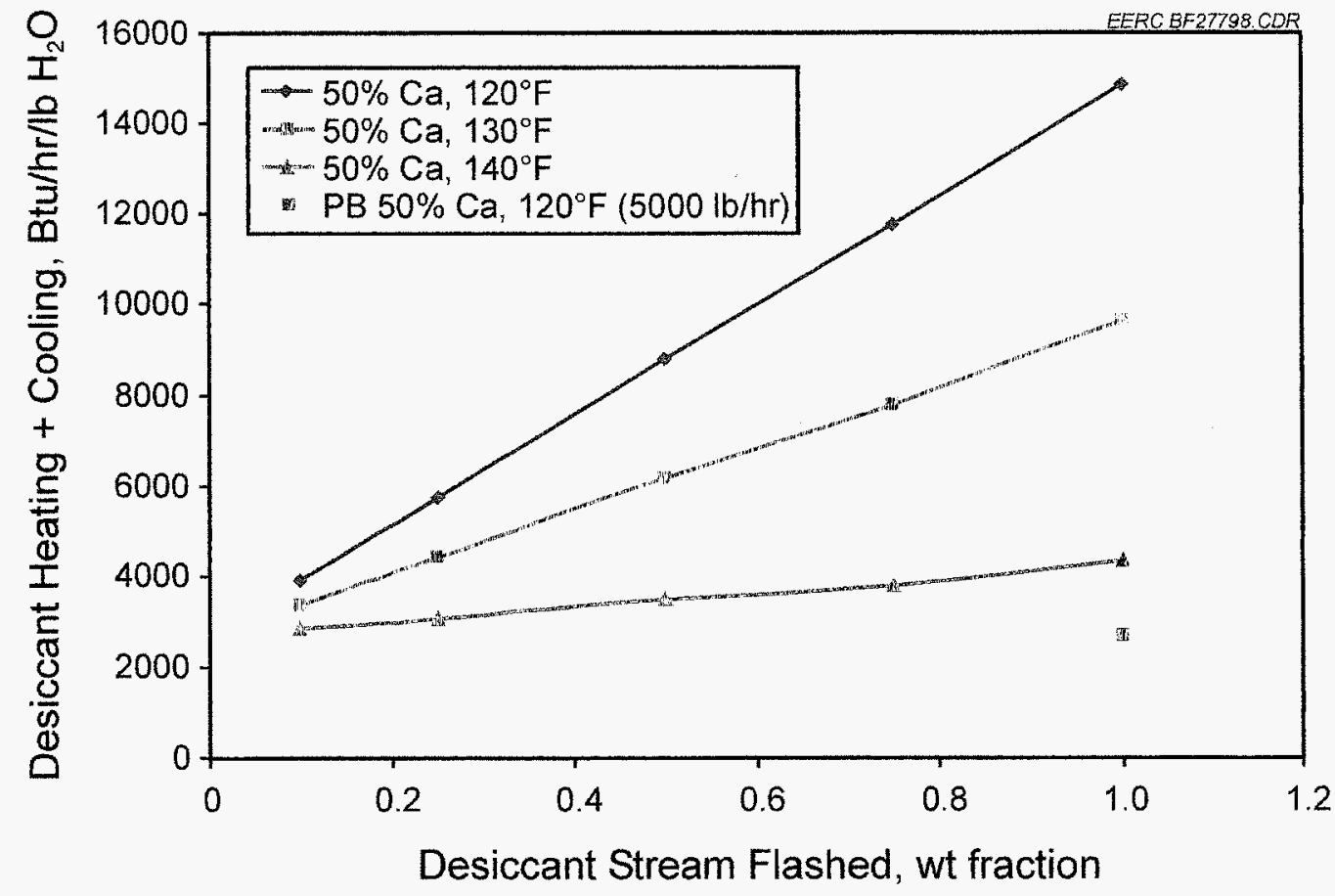

Figure 43. Desiccant regeneration energy requirements as a function of temperature and weight fraction of total stream treated. 
The previous two figures assumed an absorber inlet moisture of $13.5 \%$ and an outlet value of $8 \%$. The energy requirements presented for those cases would have totally different outcomes if more or less water were removed from the flue gas by the absorber. Figure 44 illustrates how varying the flue gas moisture at the outlet of the absorber affects the required energy for regenerating the desiccant. In all cases the absorber inlet moisture was maintained at $13.5 \%$. The data show that when the entire desiccant stream is regenerated, there is some economy in removing as much moisture as possible from the flue gas. This is observed from the bottom two curves in Figure 44, where 15,000 $\mathrm{lb} / \mathrm{hr}(6810 \mathrm{~kg} / \mathrm{hr})$ is utilized to perform the absorption. However, it is unlikely that the lower outlet moisture levels could actually be achieved at this low desiccant rate. An increase in flash pressure greatly affects the regeneration energy requirements. The top two curves represent a more likely scenario, where $30,000 \mathrm{lb} / \mathrm{hr}(13,620 \mathrm{~kg} / \mathrm{hr})$ desiccant at $120^{\circ} \mathrm{F}\left(49^{\circ} \mathrm{C}\right)$ and $50 \% \mathrm{CaCl}_{2}$ concentration is used to absorb the moisture, and through the use of a desiccant bypass the regeneration is performed. As seen from these data, the economy of removing more water from the flue gas or using a lower flash pressure has less of an effect than the desiccant bypass on regeneration (note scaling change). Two data points for the packed-bed option were also included on the figure for the single value of $8 \%$ moisture. These values show some improvement in economy over the spray tower operation with bypass.

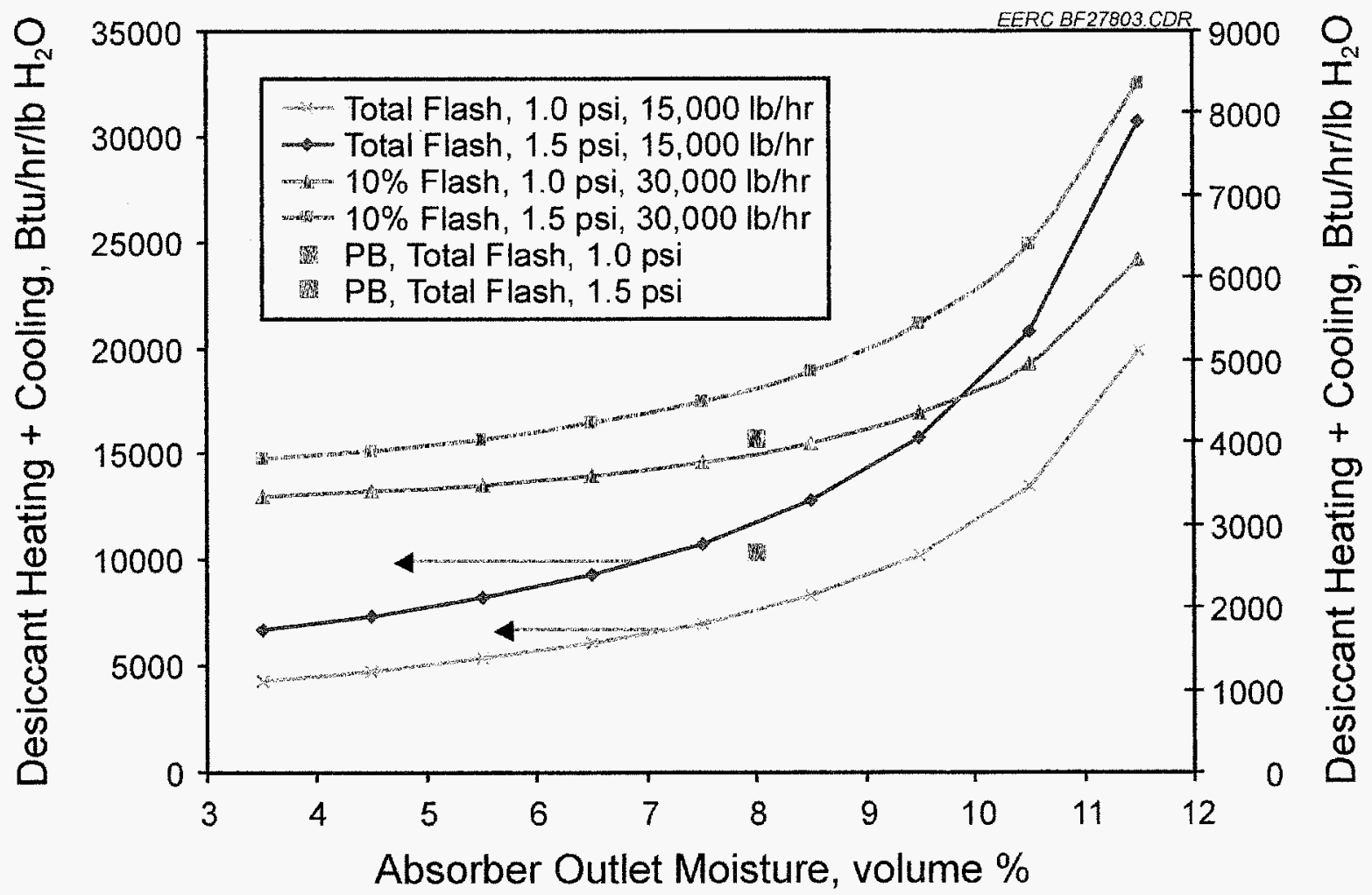

Figure 44. The effect of absorber exit flue gas moisture on desiccant regeneration energy requirements. 


\subsubsection{Commercial Power Plant Evaluation}

\subsubsection{LDDS Commercial and Economic Potential-Commercial System Discussion}

Based on the study of the LDDS's commercial and economic potential, it was concluded that two base configurations of this system are applicable. The first configuration is denoted as the fullflow (FF) LDDS, and the second is denoted as the slipstream (SS) LDDS as depicted in Figures 45 and 46, respectively. Both the FF-LDDS and the SS-LDDS would be capable of recovering a portion of the water that is contained in the flue gas stream of conventional coal-based power generation and combined-cycle (CC) power generation that is based on natural gas (NG-CC), fuel oil (FO-CC), and integrated gasification (IG-CC) operation.

As depicted in Figure 45, the FF-LDDS would be designed such that $100 \%$ of the flue gas is passed through the absorber section much like a wet FGD system.

Figure 46 depicts the SS-LDDS. In this configuration, a portion of the flue gas is extracted from the main flue gas path. After the water content within the extracted flue gas is recovered, the dryer flue gas is reintroduced to the main flue gas steam before exiting the stack. This application would be tailored to achieve the required water recovery rates by balancing the cost of the parasitic power loads, the cost and value of the water, and any site-specific conditions such as available space. An opportune use for an SS-LDDS would be a power plant in a water-limited region that is utilizing an $\mathrm{ACC}$ for steam condensation. A power plant utilizing an $\mathrm{ACC}$ will typically be derated during high ambient temperature periods because of inability of the ACC to condense the steam efficiently to maintain a good turbine backpressure. A potential scenario for utilizing the LDDS would be to provide misting water for the $\mathrm{ACC}$ to allow the plant to operate at maximum efficiency and output. This would not require large amounts of water, and water could be accumulated in storage facilities during off-peak times or during cooler conditions for use during peak temperatures. A small-scale SS-LDDS would also allow a smaller capital and operational cost when compared to an FF-LDDS.

Figure 47 illustrates the essential components of a typical LDDS system which would be applicable to either an FF-LDDS or an SS-LDDS.

The determination of the applicable system, either FF or SS, and the sizing of the applicable system will be determined by the system design inputs listed below.

- Greenfield or retrofit application

- Overall water recovery requirement

- Space availability

- Site-specific ambient conditions 


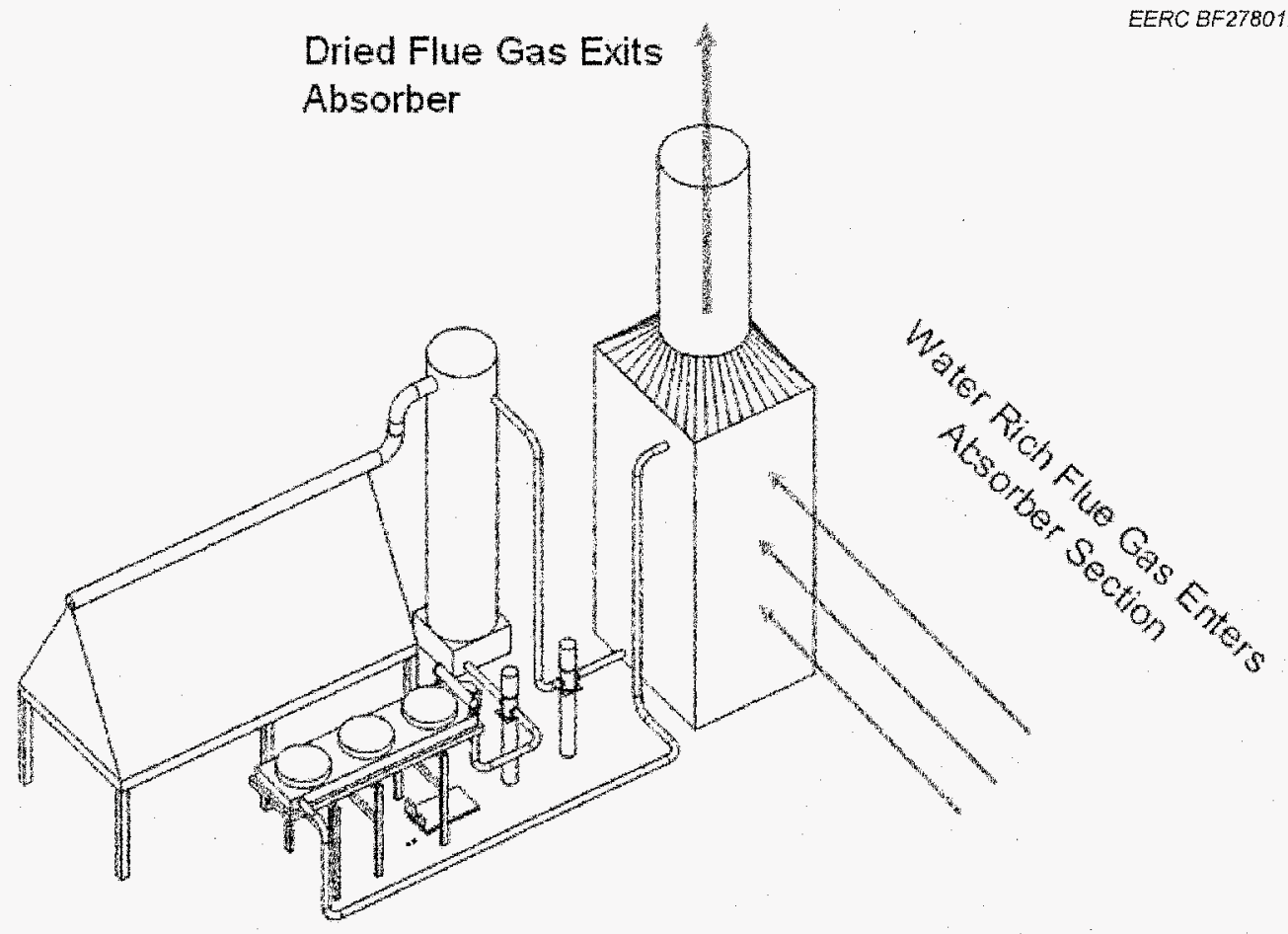

Figure 45. Conceptual diagram of a full-flow LDDS.

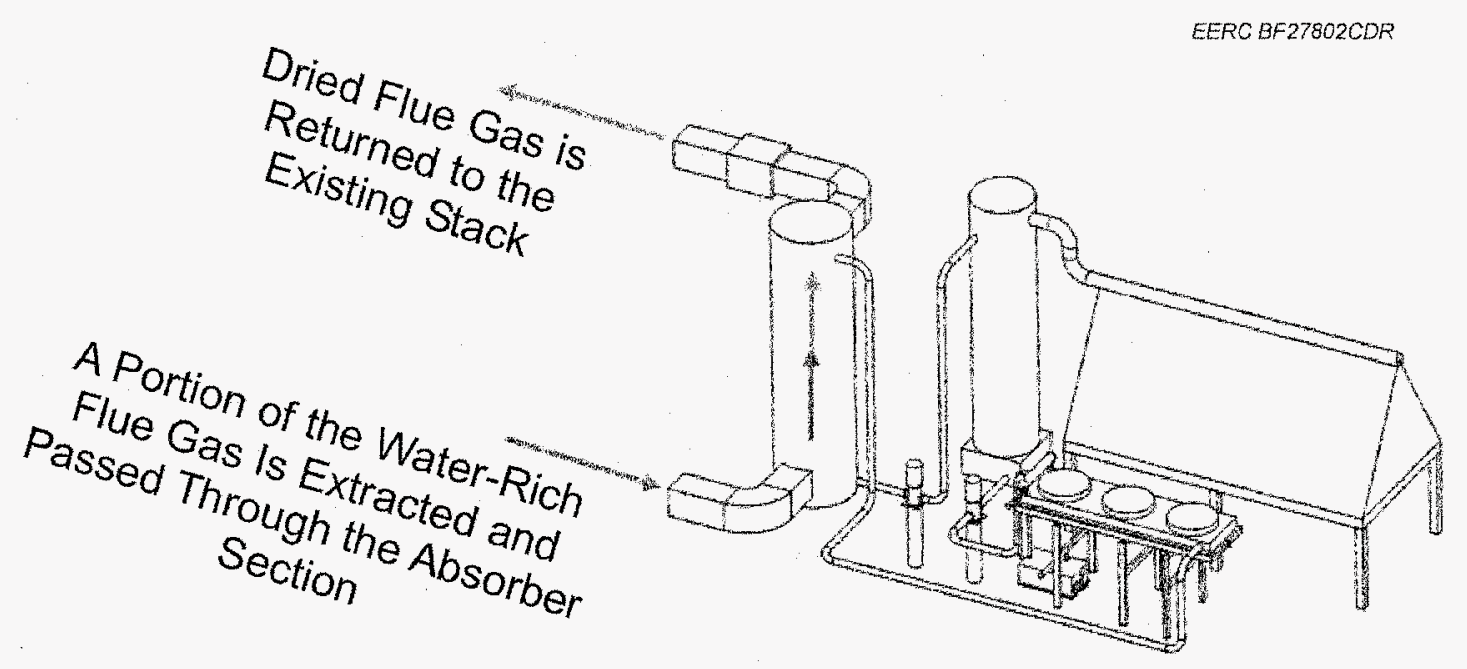

Figure 46. Conceptual diagram of a slipstream LDDS. 


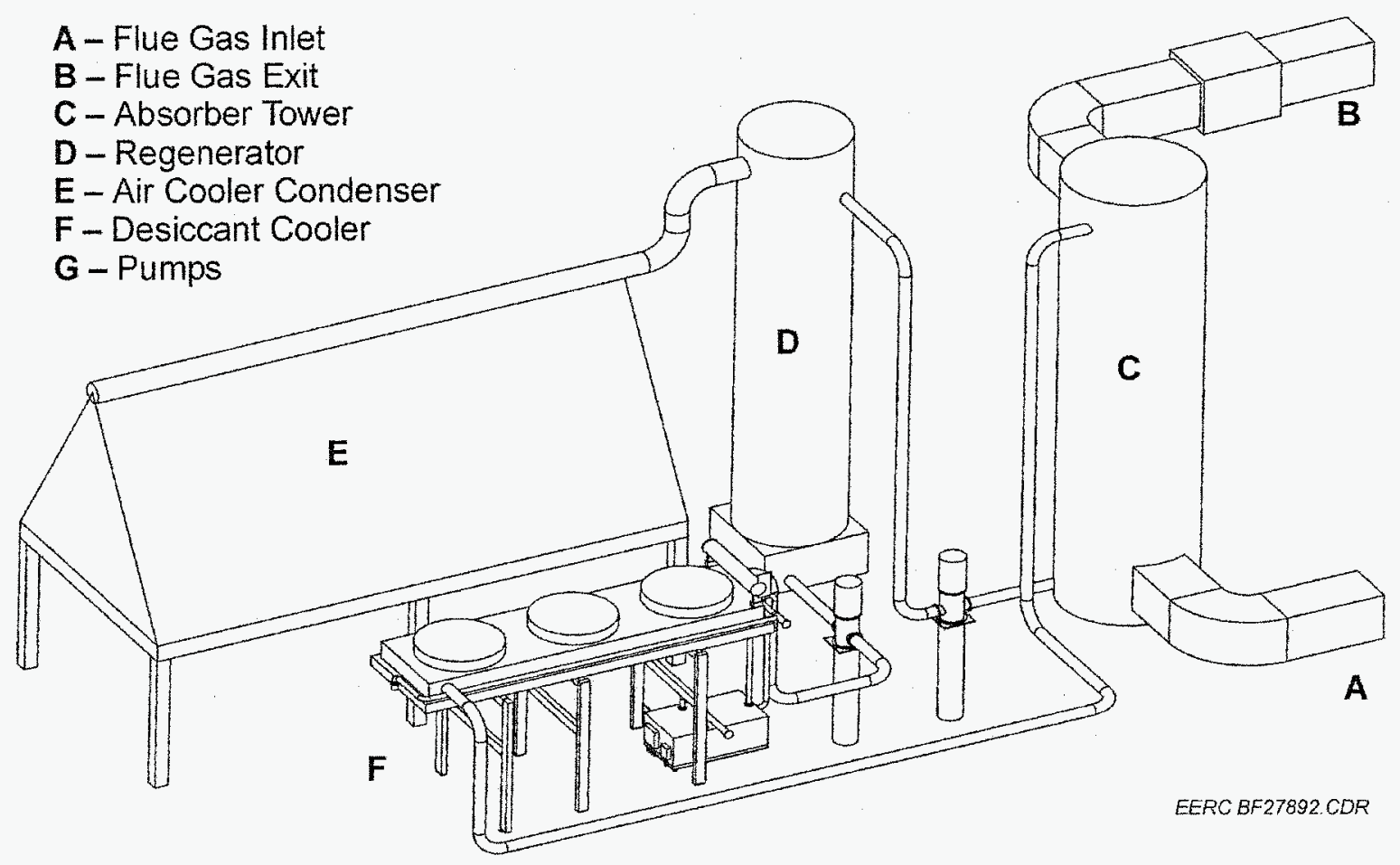

Figure 47. Layout of essential components of an LDDS.

\subsubsection{Greenfield or Retrofit Application}

When an LDSS is installed as part of a greenfield application, the FF-LDDS will be the best choice. This is due to the fact the LDDS plant design integration can be optimized well in advance of plant construction. In contrast, for most retrofit applications, it is anticipated that the SS-LDDS will be the predominant configuration as space availability will be an issue. Furthermore, installation of the SS-LDDS can be achievable without the requirement of a long-term plant outage, as the interface points to an existing plant will be minimized.

\subsubsection{Overall Water Recovery Requirement}

An FF-LDDS is best for maximum water recovery since there is more total water available. Additionally, the potential to recover water from the entire flue gas stream is achievable with less energy input when compared to recovering water from a fraction of the flue gas stream as in the SSLDDS. Once the target water recovery rate is determined, an analysis would need to be conducted to determine the applicable system to meet this need. As an example, if an NGCC with an ACC required $100 \mathrm{gpm}$ of LDDS capacity to meet the plant water demand, an SS-LDDS could be sized to accommodate this need. However, if the same NGCC plant added the option of evaporative cooling at the gas turbine inlets and gas turbine power augmentation by means of water or steam injection, the plant water need could reach a level such that an FF-LDDS would be applicable. In the case of the $2 \mathrm{X} 1 \mathrm{~F}$ Class natural gas-fired gas turbine cycle, if the plant were to be configured with an ACC for low-pressure steam turbine exhaust steam condensing, water usage for the plant would be 
approximately 250 gallons per minute (gpm), inclusive of all plant needs. Typical amounts of water available in the flue gas for different types of power plants are shown in Figure 48. When evaluated against the nominally available $375 \mathrm{gpm}$ per turbine or an available nominal total of $750 \mathrm{gpm}$ for a $2 \mathrm{X} 1$ plant, using an LDDS sized to remove approximately $33 \%$ of the available moisture would provide for all of a plant's water needs. This can be achieved without the need for any external heating or cooling introduced into the system. This is accomplished by utilizing the heat of absorption in the absorber tower to heat the solution prior to introduction into the flash tank and the cooling effect of evaporation in the flash tank to cool the solution prior to entering the absorber tower. The cooling heat exchanger to create the vacuum and condense the produced water vapor would utilize an air-cooled condenser possibly in conjunction with a ground-source heat sink. This has the potential to make this a very economical system from an operating cost standpoint.

\subsubsection{Space Availability}

As with any power plant development, the available space for construction will dictate the size and configuration of the equipment. In space-limited areas, an SS-LDSS can be a practical solution for a given water recovery target.

\subsubsection{Site-Specific Ambient Conditions}

Since the basis of the LDDS concept is to recover water in water-restricted environments, its design and sizing rely heavily on the available ambient conditions. In general, as the ambient temperatures at the design location become lower, the water recovery capacity of a fixed LDDS will improve. Likewise, given a fixed water recovery goal, the LDDS can be sized smaller as site-specific

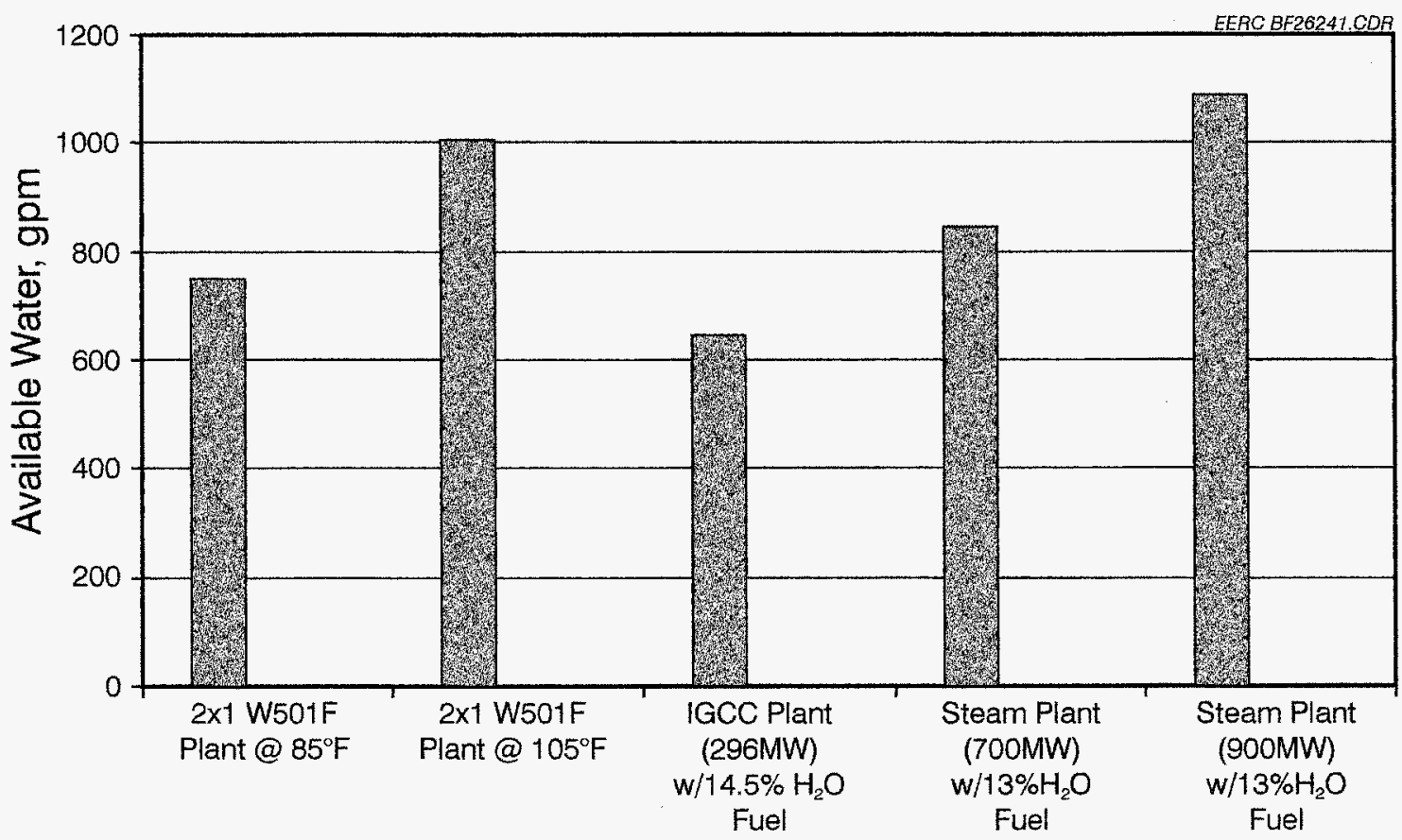

Figure 48. Typical flue gas water content. 
temperatures become lower. However, as stated previously, the external heating and cooling loads for the LDDS can be augmented by the use of low-grade heat from the plant and ground-source cooling loops as one example.

\subsection{Economic Discussion}

Based on the dynamic nature of the configuration selection and sizing process, it is not possible to fully model the economic potential of the LDDS within the scope of this project. However, to provide the necessary indicative potentials, case studies for the systems described in Table 50 are provided.

In a natural gas-fired combined-cycle system, the LDDS would interface just after the last heating surface of the HRSG. In a coal-fired plant, this system would interface downstream of a wet FGD system, where it could remove the majority of the moisture introduced by the FGD process. Case 1 is based on a pc-fired combustor producing approximately $250 \mathrm{MW}$ with an SS-LDDS operating 24 hours a day. Case 2 is based on a NG-CC 270-MW unit utilizing an FF-LDDS operating only 12 hours a day. Cost of electricity generation is a hypothetical value to provide comparative numbers between the two scenarios. Equipment and installation costs were derived from cost estimates provided by venders of applicable components of construction. System auxiliary load is based on required power inputs to the pumps and heat exchangers in the system. Maintenance costs are based on recommended maintenance schedules and replacements provided by vendors quoting equipment.

As an example of the source for the numbers given in Table 50 for Case 2, Table 51 lists the design basis for the numbers. These values were generated in ChemCad for two design scenarios. This analysis was then utilized to get vendor quotes for pricing of equipment and the actual performance of the quoted equipment. Vendor-quoted operational data were utilized to derive the values in Table 50 where they differed significantly from the ChemCad-modeled data for generating the cost of water produced. This analysis assumes no external heating or cooling are applied to the

desiccant and that the energy required comes from the heat of adsorption and evaporation in the process as described earlier.

The capital costs for Case 2 are significantly higher because of the larger size of the components for an FF-LDDS when compared to an SS-LDDS. The larger scale of the FF-LDDS also impacts the operational and maintenance costs as well. Another factor affecting the operational costs is the different combustions systems employed. In case one, the wet FGD will saturate the flue gas stream with moisture, and the removal will be less energy-intensive compared to the NG-CC in Case 2. Both of the LDDSs are sized for $75 \mathrm{gpm}$, with the LDDS in Case 1 operating twice as many hours a year, consequently producing twice as much water a year. Larger annual operating costs for the FF-LDDS in Case 2 drive the cost of the produced water to double that of the water produced in Case 1. Even though the cost of the water produced in Case 2 is higher, it may actually have a higher value than the water produced in Case 1. All water issues are site-specific, and water in Arizona has a higher value than water in Wyoming. The ability to produce water from the combustion flue gas in Arizona may be the deciding factor in obtaining permitting for the power generation system siting and operation. 
Table 50. List of Case Studies

\begin{tabular}{|c|c|c|c|c|c|c|}
\hline Case & Configuration & Recovery Rate & Plant Type & Fuel & $\begin{array}{l}\text { Flue Gas } \\
\text { Conditioning }\end{array}$ & Location \\
\hline 1 & SS-LDDS & $75 \mathrm{gpm}$ & Steam & $\mathrm{pc}$ & Wet FGD & Wyoming \\
\hline 2 & FF-LDDS & $75 \mathrm{gpm}$ & $\begin{array}{c}\text { Combined } \\
\text { cycle }\end{array}$ & NG & SCR & Yuma, AZ \\
\hline
\end{tabular}

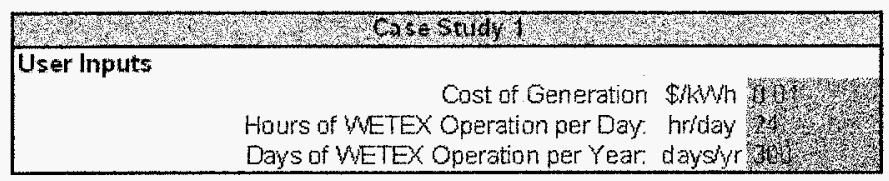

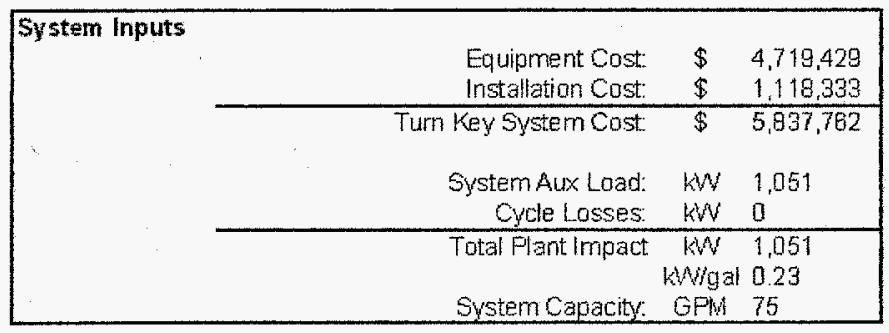

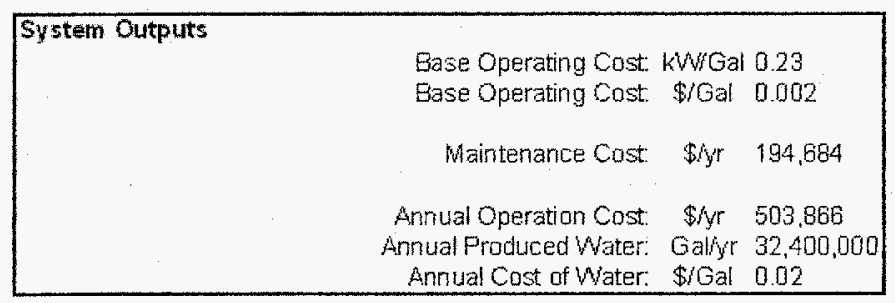

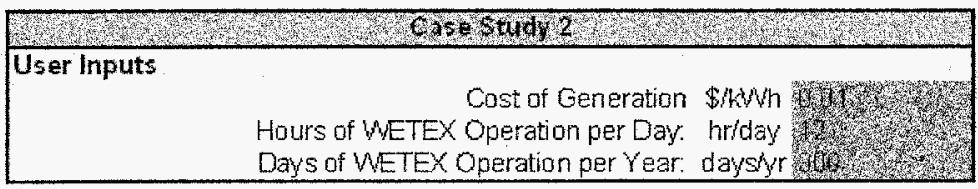

\begin{tabular}{|c|c|c|c|}
\hline \multirow[t]{4}{*}{ System Inputs } & $\begin{array}{l}\text { Equipment Cost } \\
\text { Installation Cost }\end{array}$ & $\$$ & $\begin{array}{l}7,461,000 \\
1,310,000\end{array}$ \\
\hline & Tum Key System Cost: & $\$$ & $8,771,000$ \\
\hline & $\begin{array}{l}\text { System Aux Load: } \\
\text { Cycle Losses }\end{array}$ & $\begin{array}{l}\mathrm{KW} \\
\mathrm{KW}\end{array}$ & $\begin{array}{l}1,800 \\
300\end{array}$ \\
\hline & $\begin{array}{l}\text { Total Plant Impact } \\
\text { System Capacity }\end{array}$ & $\begin{array}{c}\mathrm{kN} \\
\mathrm{kWhal} \\
\text { GPM }\end{array}$ & $\begin{array}{l}1,900 \\
0.42 \\
75\end{array}$ \\
\hline
\end{tabular}

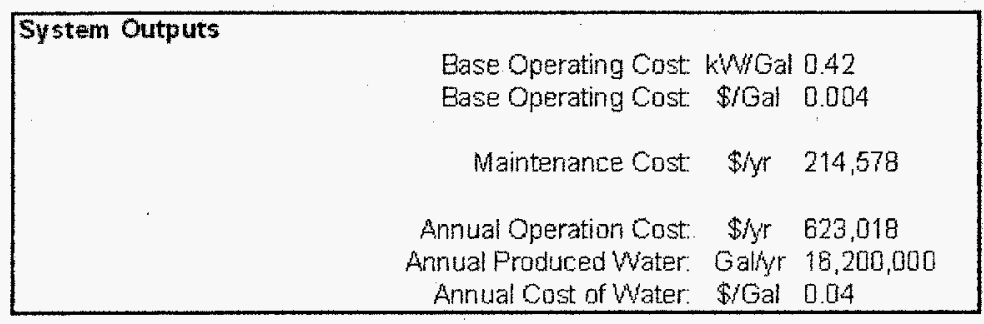


Table 51. YUMA Reference Plant WETEX Process Revised Performance

\begin{tabular}{|c|c|c|}
\hline & Design Case 5 & Alt Design Case 5 \\
\hline \multicolumn{3}{|l|}{ Stream Conditions } \\
\hline Ambient Temperature, ${ }^{\circ} \mathrm{F}$ & 67.0 & \\
\hline Recovered Water Rate, gpm & 75 & \\
\hline Inlet Flue Gas Flow Rate, lb/hr & $3,627,800$ & \\
\hline Inlet Flue Gas Water Content, vol\% & 7.87 & \\
\hline Inlet Flue Gas Dew Point, ${ }^{\circ} \mathrm{F}$ & 102 & \\
\hline Absorber Diameter, $\mathrm{ft}$ & 55 & 50 \\
\hline Absorber Packed-Bed Height, ft & 17 & 14 \\
\hline Absorber Pressure Drop, psi & 0.08 & 0.1 \\
\hline Flue Gas Temperature to Absorber, ${ }^{\circ} \mathrm{F}$ & 199.7 & 199.7 \\
\hline Flue Gas Temperature Out of Absorber, ${ }^{\circ} \mathrm{F}$ & 125.9 & 127.4 \\
\hline Stack Gas Water Content, vol\% & 6.32 & 6.31 \\
\hline Stack Gas Dew Point, ${ }^{\circ} \mathrm{F}$ & 95 & 95 \\
\hline Desiccant Stream Circulation Rate, $\mathrm{lb} / \mathrm{hr}$ & $6,856,848$ & $8,486,805$ \\
\hline Liquid-to-Gas Ratio in Absorber, wt/wt & 1.71 & 2.12 \\
\hline Desiccant Content to Absorber, wt \% & 50.2 & 50.0 \\
\hline Desiccant Temperature into Absorber, ${ }^{\circ} \mathrm{F}$ & 125.3 & 127.0 \\
\hline Desiccant Temperature Out of Absorber, ${ }^{\circ} \mathrm{F}$ & 153.0 & 149.1 \\
\hline Desiccant Temperature to Regenerator, ${ }^{\circ} \mathrm{F}$ & 153.0 & 149.1 \\
\hline Regenerator Pressure, psia & 0.85 & 0.82 \\
\hline Exhaust Gas Rate, $\mathrm{lb} / \mathrm{hr}$ & 1659 & 2141 \\
\hline Exhaust Gas Rate, acfm & 8407 & 11,555 \\
\hline \multicolumn{3}{|l|}{ Performance } \\
\hline Air Fan Water-Condenser Power, kW & 279 & 364 \\
\hline Air Fan Desiccant-Cooler Power, $\mathrm{kW}$ & 247 & 165 \\
\hline Desiccant Pump Power, $\mathrm{kW}$ & 418 & 532 \\
\hline Exhaust Gas Vacuum System Power, kW & 247 & 500 \\
\hline Recovered Water Pump Power, $\mathrm{kW}$ & 0.7 & 0.7 \\
\hline Total Power Used, $\mathrm{kW}$ & 1191 & 1561 \\
\hline CC Power Degrade Due to Pressure Drop, $\mathrm{kW}$ & 173 & 216 \\
\hline Relative Power Lost, \% of CC gross & 0.77 & 1.00 \\
\hline
\end{tabular}

Study results indicate that given the current increasing usage trends seen in power plant dry cooling technologies (Figure 49), as well as the observed increase in water rights legislation and water usage permitting difficulties, systems designed to recover the water contained in combustion flue gas streams will steadily become more commercially viable. 


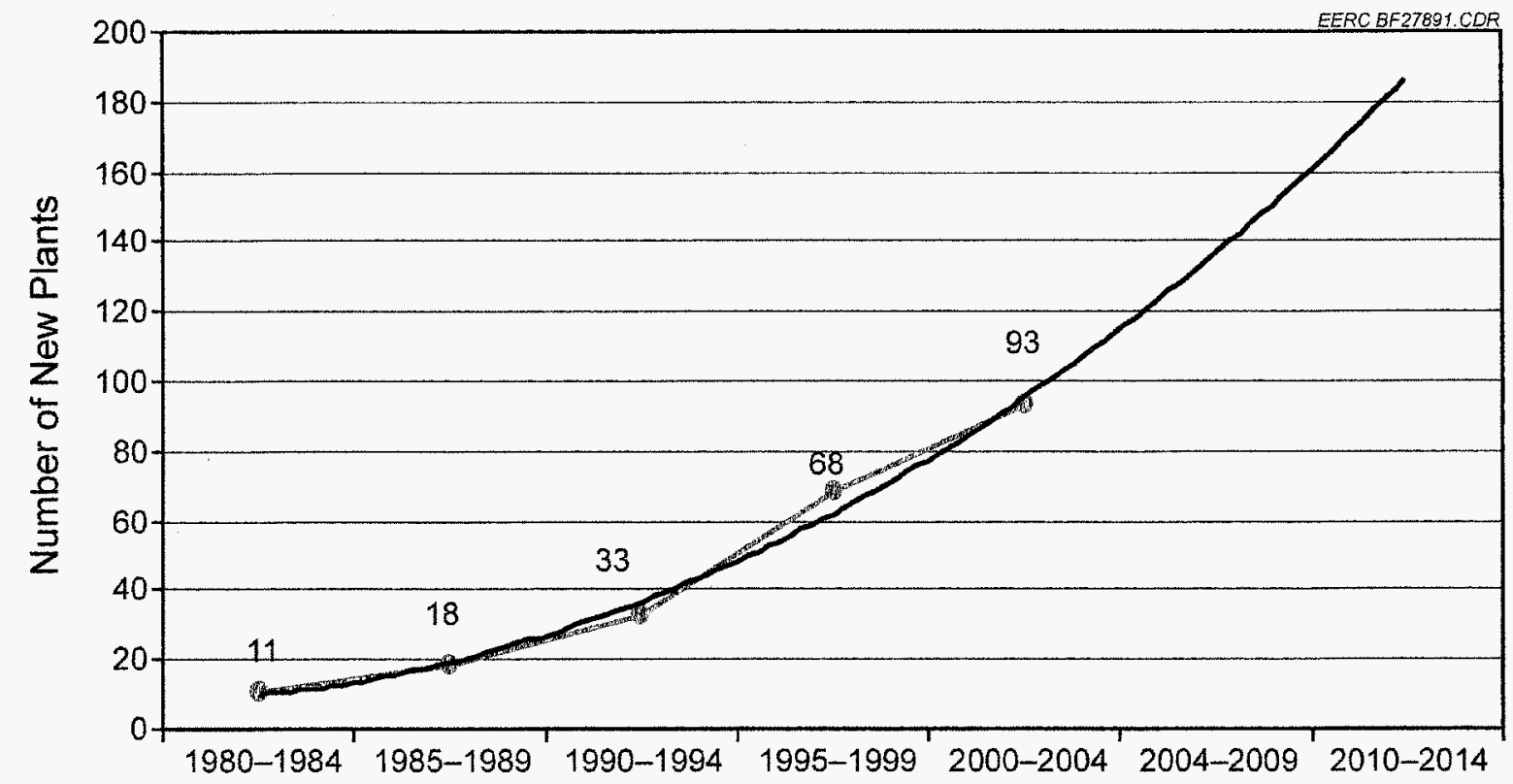

Figure 49. Dry-cooled power plant orders vs. time.

Although current economic models indicate that a net positive return on initial investment is achievable when employing this technology, it will take several years of development and continued focus on water resource management before systems such as this yield the level of return that will warrant their common use.

\subsection{CONCLUSIONS AND RECOMMENDATIONS}

A literature review was completed in order to select an appropriate liquid desiccant for evaluation. Bench- and pilot-scale tests were completed to evaluate the potential for recovering useful amounts of water from combustion flue gas using an LDDS. During pilot-scale tests, operational parameters for the desiccant absorber column and regeneration system were evaluated. In addition, a technical and economic assessment of the technology for application to commercial power plants was completed. The following conclusions/observations were based on the results.

\subsection{Desiccant Selection}

A literature search was performed to identify commercially available desiccants and their available property data. This information was compiled and used for evaluation for acceptable desiccants for the LDDS.

Desiccants were evaluated for acceptability based on the following: ability of the desiccant to remove water from the flue gas stream (partial pressure of water), heat-transfer properties (specific heat and thermal conductivity), desiccant cost (capital and maintenance), equipment corrosion, environmental effects of desiccant carryover, removal of combustion products other than water, flow 
characteristics when in solution with water (viscosity), impact of desiccant selection on system operation and cost, solubility limits (concentration range of desiccant), and EPA/Occupational Safety and Health Administration (OSHA) perception (for permitting purposes).

A weighting scheme and evaluation of available data on commercial desiccants led to the selection of three desiccants for bench-scale testing. These desiccants were lithium bromide, calcium chloride, and triethylene glycol.

\subsection{Desiccant Bench-Scale Testing}

Bench-scale combustion testing for desiccant evaluation with flue gas gave indications of carbonate formation and some interaction with ash species. Mechanical filters or settling tanks were to be determined necessary in pilot-scale work to attempt to remove any precipitates.

During bench-scale testing, the desiccant materials all performed as expected with respect to the amount of moisture removed from the flue gas stream for both the natural gas and coal combustion tests. The lower the vapor pressure of the desiccant was, the more moisture it removed from the flue gas stream. The flow behavior of all of the desiccants was as expected for the short duration of the tests.

An energy balance was performed for the CEPS spray absorber operated on natural gas when a $32 \%$ aqueous $\mathrm{CaCl}_{2}$ solution was used. The nominal spray absorber $\mathrm{L} / \mathrm{G}$ ratio of $93 \mathrm{gpm} / 1000 \mathrm{acfm}$ was used in the analysis with average temperature conditions for the test period. Because all of the CEPS tests were operated close to the same conditions, and only the desiccants and the starting flue gas moisture levels were varied for the tests, an analysis of the data was directed at the desiccant vapor pressure as a predictor of the flue gas drying potential for all tests. Two ratios were used to correlate the data. The first was the ratio of the flue gas vapor pressure leaving the absorber to the vapor pressure of the desiccant exiting the absorber. The second ratio consisted of the flue gas vapor pressure leaving the absorber to the vapor pressure of the desiccant entering the absorber. Either of these ratios may be thought of as a measure of approach to equilibrium, where the flue gas vapor pressure exiting the absorber equals that of the exiting or entering desiccant. Practically speaking, the equilibrium level may never be attained, but the approach to that level is indicative of the absorber operating conditions.

For the natural gas test using $32 \%$ aqueous $\mathrm{CaCl}_{2}$ solution, the first ratio was found to be $\mathrm{P}, \mathrm{fg}$, out $/ \mathrm{Pdes}$, out $=1.168$, and the second equal to $\mathrm{P}, \mathrm{fg}$, out $/ \mathrm{Pdes}$, in $=1.213$. To predict the performance of the absorber using other desiccants, the exiting flue gas moisture was varied, and the energy balance was performed until the specified ratio was obtained. Note that the mass balance was nearly constant since all tests were performed at a constant $\mathrm{L} / \mathrm{G}$ ratio. The final flue gas moisture value that best solved the balances was the predicted value. When these ratios were applied to the coal-fired case, it showed that the flue gas humidity would actually increase from the inlet concentration of $7.4 \% \mathrm{H}_{2} \mathrm{O}$ to over $10 \%$ depending upon the desiccant temperature.

These ratios were also applied to the other desiccants for both coal- and gas-firing conditions. For the other desiccants, an equivalent desiccant vapor pressure was calculated by increasing the 
simulated $\mathrm{CaCl}_{2}$ concentration, i.e., $55.6 \% \mathrm{CaCl}_{2}$ solution has the same vapor pressure as a $54 \%$ $\mathrm{LiBr}$ solution, and $42.3 \% \mathrm{CaCl}_{2}$ was equivalent to $90 \% \mathrm{TEG}$. Although this approach is not totally correct because of differences in heats of solution from $\mathrm{H}_{2} \mathrm{O}$ absorption, it is thought to be close enough for interpretation of the CEPS experimental results. Applying this approach to the experimental data showed that the first ratio $(\mathrm{P}, \mathrm{fg}$, out $/ \mathrm{Pdes}$,out $=1.168)$ best predicted the results. Table 51 presents a summary of the predictions for the desiccants with coal and natural-gas firing conditions.

It is believed that these results show that the operation of the absorber is independent of the desiccant composition and, under comparable operating conditions, the flue gas moisture exiting the absorber will be predictable based on desiccant concentration and temperature.

Based on the results of the bench-scale tests and review of property data of the bench-scale tested desiccants, calcium chloride was chosen as the desiccant to use in the subsequent pilot-scale tests. Cost of the desiccant as well as ubiquitous and fairly benign nature of the desiccant were leading decision factors.

\subsection{Desiccant Pilot-Scale Testing}

\subsubsection{Test Series I}

Average flue gas temperatures at the LDDS absorber inlet ranged from $202^{\circ}$ to $205^{\circ} \mathrm{F}\left(95^{\circ}\right.$ to $\left.96^{\circ} \mathrm{C}\right)$ with standard deviations of typically $0.4^{\circ} \mathrm{F}\left(0.2^{\circ} \mathrm{C}\right)$ or less. Absorber outlet flue gas temperatures ranged from $123^{\circ}$ to $145^{\circ} \mathrm{F}\left(51^{\circ}\right.$ to $\left.63^{\circ} \mathrm{C}\right)$ with typical standard deviations of $<1^{\circ} \mathrm{F}$ $\left(<0.6^{\circ} \mathrm{C}\right)$. These data indicate that desired absorber flue gas temperatures were achieved and temperature control during Test Series I was very good.

Desiccant concentration values at the inlet of the absorber column ranged from 41.0 to $47.1 \mathrm{wt} \%$, but were typically $>46 \mathrm{wt} \%$, with typical standard deviations of $\leq 0.1 \mathrm{wt} \%$, for most test periods. Desiccant concentrations greater than $\sim 47 \mathrm{wt} \%$ proved to be problematic because of crystallization of desiccant.

Desiccant temperatures at the inlet of the LDDS absorber through the nozzles ranged from $120^{\circ}$ to $135^{\circ} \mathrm{F}\left(49^{\circ}\right.$ to $\left.58^{\circ} \mathrm{C}\right)$ with typical standard deviations of $\leq 0.7^{\circ} \mathrm{F}\left(0.4^{\circ} \mathrm{C}\right)$. Desiccant temperatures exiting the LDDS absorber into the tank ranged from $124^{\circ}$ to $140^{\circ} \mathrm{F}\left(51^{\circ}\right.$ to $\left.60^{\circ} \mathrm{C}\right)$ with typical standard deviations of $\leq 0.8^{\circ} \mathrm{F}\left(0.4^{\circ} \mathrm{C}\right)$.

Table 52. Actual and Predicted Outlet Flue Gas Moisture Levels

\begin{tabular}{lccccc}
\hline Fuel & Gas & Coal & Gas & Coal & Gas \\
\hline Desiccant & $\mathrm{CaCl}_{2}$ & $\mathrm{CaCl}_{2}$ & $\mathrm{LiBr}$ & $\mathrm{LiBr}$ & $\mathrm{TEG}$ \\
Concentration, wt $\%$ & 32 & 32 & 54 & 54 & 90 \\
Inlet $\mathrm{FG} \mathrm{H}_{2} \mathrm{O}$, vol\% & 11.8 & 7.4 & 10.7 & 7.4 & 11.9 \\
Predicted Outlet $\mathrm{FG} \mathrm{H}_{2} \mathrm{O}$, vol\% & 10.0 & 9.0 & 4.0 & 3.6 & 7.0 \\
Actual Outlet $\mathrm{FG} \mathrm{H}_{2} \mathrm{O}$, vol\% & 10.1 & $8-9$ & 4.25 & 3.8 & 7.1 \\
\hline
\end{tabular}


Flue gas flow rates ranged from 430 to $438 \mathrm{acfm}\left(12.2\right.$ to $\left.12.4 \mathrm{~m}^{3} / \mathrm{min}\right)$, resulting in absorber velocities of 9.5 to $9.6 \mathrm{ft} / \mathrm{s}(2.4-2.5$ to $3.2 \mathrm{~m} / \mathrm{s})$. Calculated $\mathrm{L} / \mathrm{G}$ ratios ranged from 16.3 to $112.3 \mathrm{gal} / 1000$ acf $\left(2.18\right.$ to $\left.15.02 \mathrm{~L} / \mathrm{m}^{3}\right)$.

The desired LDDS absorber operating parameters were achieved, and operational stability was good as indicated by the low standard deviation values reported for individual parameters.

Average desiccant temperatures at the LDDS flash drum inlet ranged from $132^{\circ}$ to $162^{\circ} \mathrm{F}\left(56^{\circ}\right.$ to $\left.73^{\circ} \mathrm{C}\right)$ with standard deviations of $0.2^{\circ}$ to $8.0^{\circ} \mathrm{F}\left(0.1^{\circ}\right.$ to $\left.4.4^{\circ} \mathrm{C}\right)$. The range of flash drum inlet temperatures was a result of selected set points. However, the range of standard deviations resulted from regulator problems controlling steam flow to the desiccant heater.

Flash drum operating pressure ranged from 0.68 to 1.07 psia (35 to $55 \mathrm{mmHg}$ ) with typical standard deviations $\leq 0.1 \mathrm{psia}(\leq 5.2 \mathrm{mmHg}$ ). Higher standard deviations were the result of moisture condensation and accumulation in the pressure transmitter line attached to the vapor discharge line exiting the flash drum. In general, flash drum vacuum pressure was less than the $1.0 \mathrm{psia}(52 \mathrm{mmHg})$ value planned.

Prior to any future pilot-scale tests, the EERC intends to relocate the pressure transmitter measuring vacuum pressure to eliminate the accumulation of moisture in the pressure transmitter line. Options will also be considered for improving vacuum pressure regulator performance and control.

Sulfate content in the flash drum desiccant samples was below detection limits for Test Series $\mathrm{I},<3 \mathrm{mg} / \mathrm{L}$, consistent with the absorber desiccant samples.

Offgas from the product water condensor was dominated by air in-leakage and some $\mathrm{NO}_{\mathrm{x}}$ concentration, indicating that a small amount of $\mathrm{NO}_{\mathrm{x}}$ was dissolved in the desiccant.

Particulate sampling at the absorber exit showed a small mass loading. Analysis of the material showed this to be calcium chloride due to carryover and, based on mass percent, was probably hydrated.

Analysis of the produced water indicated water of generally very good quality requiring little upgrading for use in a steam cycle.

\subsubsection{Test Series II}

Belle Ayr subbituminous coal was fired during Test Series II to produce the flue gas. This fuel was selected because it represented a coal type of general commercial interest and it was available in sufficient quantities in the EERC's inventory.

Of thirteen individual test conditions planned, only nine test conditions were completed because of desiccant solution holdup in the flash drum and the need to modify the desiccant discharge piping to correct the problem. Desiccant holdup in the flash drum appeared to be the result 
of product water flashing from the desiccant solution in the flash drum as well as the 2-in. (5-cm) CPVC discharge line to the 100-gal (378-L) tank. The problem was solved by replacing $12 \mathrm{ft}(3.7 \mathrm{~m})$ of 2-in. (5-cm) CPVC pipe with $12 \mathrm{ft}(3.7 \mathrm{~m})$ of 4-in. $(10-\mathrm{cm}) 304$ SS pipe, used because it was available. The increased volume of the $4-i n .(10-\mathrm{cm})$ pipe allowed the product water to evolve from the desiccant solution without liquid holdup in the flash drum.

Average flue gas temperatures at the LDDS absorber inlet ranged from $134^{\circ}$ to $137^{\circ} \mathrm{F}\left(57^{\circ}\right.$ to $\left.59^{\circ} \mathrm{C}\right)$ with typical standard deviations of $<0.5^{\circ} \mathrm{F}\left(<0.3^{\circ} \mathrm{C}\right)$. Absorber outlet flue gas temperatures ranged from $134^{\circ}$ to $149^{\circ} \mathrm{F}\left(57^{\circ}\right.$ to $\left.65^{\circ} \mathrm{C}\right)$ with standard deviations of $<2^{\circ} \mathrm{F}\left(<1.1^{\circ} \mathrm{C}\right)$. These data indicate that desired absorber flue gas temperatures were achieved and temperature control during Test Series II was very good.

Desiccant concentration values at the inlet of the absorber column ranged from 42.6 to $50.7 \mathrm{wt} \%$, but were typically $>45 \mathrm{wt} \%$ with standard deviations of $\leq 0.5 \mathrm{wt} \%$, for most test periods. At desiccant concentration levels $>\sim 47 \mathrm{wt} \%$, crystallization of the desiccant can cause operational changes.

Flue gas flow rates ranged from 444 to 452 acfm $\left(12.6\right.$ to $\left.12.8 \mathrm{~m}^{3} / \mathrm{min}\right)$, resulting in absorber velocities of 9.8 to $10.0 \mathrm{ft} / \mathrm{s}(3.0 \mathrm{~m} / \mathrm{s})$. Calculated $\mathrm{L} / \mathrm{G}$ ratios ranged from 13.7 to $54.4 \mathrm{gal} / 1000 \mathrm{acf}$. LDDS absorber differential pressure ranged from 0.5 to $2.1 \mathrm{in.} \mathrm{W.C.} \mathrm{(0.9} \mathrm{to} 3.9 \mathrm{mmHg}$ ) depending on desiccant circulation rates and absorber configuration, spray tower versus packed bed. In general, the desired LDDS absorber operating parameters were achieved, and operational stability was good as indicated by the low standard deviation values reported for individual parameters.

Average desiccant temperatures at the LDDS flash drum inlet ranged from $142^{\circ}$ to $171^{\circ} \mathrm{F}\left(61^{\circ}\right.$ to $78^{\circ} \mathrm{C}$ ) with typical standard deviations of $0.2^{\circ}$ to $5.0^{\circ} \mathrm{F}\left(0.1^{\circ}\right.$ to $\left.2.8^{\circ} \mathrm{C}\right)$. The range of flash drum inlet temperatures was a result of selected set points. However, the range of standard deviations resulted from regulator problems controlling steam flow to the desiccant heater. Therefore, one of the recommended modifications to the LDDS prior to any future work is the replacement of the desiccant heater steam control regulator.

Flash drum operating pressure ranged from 0.69 to 1.36 psia (36 to $70 \mathrm{mmHg}$ ) with typical standard deviations $\leq 0.1 \mathrm{psia}$ ( $\leq 5.2 \mathrm{mmHg}$ ). Higher standard deviations were the result of moisture condensation and accumulation in the pressure transmitter line attached to the vapor discharge line exiting the flash drum. In general, the measured flash drum vacuum pressure was greater than the 1.0 psia $(52 \mathrm{mmHg})$ value planned.

Flash drum desiccant $\mathrm{pH}$ was measured continuously during Test Series II. Values ranged from 2.0 to 6.2 with standard deviations of 0.1 or less for most test periods. The first test period had a desiccant $\mathrm{pH}$ value of 6.2 with $\mathrm{pH}$ decreasing to 3.8 for Test Period 3.2. Desiccant $\mathrm{pH}$ decreased during these initial natural gas-fired test periods as carbon dioxide dissolution in the desiccant approached equilibrium.

Based on the Test Series II desiccant pH data, application of an LDDS to a coal-fired boiler system will require the implementation of a desiccant solution $\mathrm{pH}$ control strategy including a 
filtration system or settling tank to recover precipitated solids. Desiccant solution $\mathrm{pH}$ control may offer an opportunity to further reduce $\mathrm{SO}_{2}$ emissions downstream of existing control technology or possibly include $\mathrm{SO}_{2}$ emission control as part of the design basis for an LDDS.

The range of flue gas $\mathrm{NO}_{\mathrm{x}}$ concentrations are consistent with the firing of natural gas and coal in the slagging furnace at typical excess $\mathrm{O}_{2}$ concentrations $(<7 \mathrm{vol} \%)$ and furnace temperatures $\left(>2200^{\circ} \mathrm{F}\left[>1205^{\circ} \mathrm{C}\right]\right.$ and $\left.<2600^{\circ} \mathrm{F}\left[<1427^{\circ} \mathrm{C}\right]\right)$. Absorber inlet $\mathrm{NO}_{\mathrm{x}}$ concentrations of $<300 \mathrm{ppmv}$ represent natural gas firing, and values $>300 \mathrm{ppmv}$ represent coal firing. The results indicate that there was little change in $\mathrm{NO}_{\mathrm{x}}$ concentration across the LDDS absorber.

Because of the high vacuum pressure in the flash drum, product water condenser, and interconnecting piping, this gas stream may be dominated by air in-leakage. Average $\mathrm{NO}_{\mathrm{x}}$ concentrations were $110 \pm 15$ ppmv. These values are $81 \%$ lower than what was measured in the combustion flue gas, consistent with Test Series I data, and represent a very small volume. Therefore, the data indicate a small amount of flue gas was dissolved in the desiccant solution and then released in the flash drum.

Particulate sampling at the absorber exit showed a small mass loading. Analysis of the material showed this to be calcium chloride due to carryover and some small portion of sodium. Based on mass percent, the material was probably hydrated.

Although the water wash nozzles for the absorber mist eliminator were occasionally used in this study, pressure drop across the mist eliminator was never an issue indicating no impedance due to excess combustion ash or desiccant entrainment and deposition.

An upset condition occurred during this test series that caused the flash drum to overflow through the top with desiccant. This desiccant passed through mist eliminator, the water condensing heat exchanger, and into the produced water container. It was determined that under the conditions in the flash drum, water was still evolving from the desiccant in the drop leg out of the bottom of the flash drum and that this evolution of water vapor was causing holdup of desiccant in the flash drum which eventually filled the tank and overflowed it. This was remedied by replacing the 2" drop leg out of the flash drum with a section of 4" piping allow evolution of the water vapor while still allowing sufficient flow of desiccant out of the flash drum to eliminate holdup.

Spray nozzle size in the flash drum appeared to have no effect on the evolution of water from the desiccant solution. For this test series, the degree of subatmospheric pressure in the regeneration tank was the driving force on the volume of water removed from the desiccant solution.

Calcium chloride crystals formed in the mist eliminator of the regeneration tank. This may have been due to upset conditions which flooded the regeneration tank and passed desiccant through the mist eliminator into the water condensation heat exchanger and the process water collection system.

Crystallization occurred in the desiccant cooling heat exchanger located between the desiccant solution absorber pump and the desiccant solution spray nozzles in the absorber column. The coolant 
for this heat exchange was city tap water. This test series occurred during the winter months with the average temperature of the water at approximately $40^{\circ} \mathrm{F}$ which at low flow rates of desiccant was too cold and caused crystallization of the desiccant. This caused increased pressure across the heat exchanger and at times fouled spray nozzles when chunks broke loose and migrated to the spray nozzles.

The heat exchanger used to condense the produced water was fabricated with carbon steel. Because of upset conditions that introduced desiccant solution into the heat exchanger, this heat exchanger did experience some corrosion which was evident in the product water.

Product water from Test Series II was analyzed and found to be of good quality but contained more calcium than water produced in Test Series I. This is expected to come from the upset conditions that flooded the produced water side of the system contaminating components. To clean all of the contaminated components would have required complete shutdown and taken many days; this was not possible within the scope of the project. Therefore, the decision was made to clean the components as best as possible online and continue to run.

\subsubsection{Absorber Performance Analysis}

The performance of the absorber was analyzed using theory developed for mass-transfer occurring in gas absorption applications. No distinction between coal- versus gas-fired data with respect to absorber performance was found.

Tower height was not constant for the tests and was really a function of mass flow rate. As desiccant flow rate was increased, another spray level was added to manage the capacity. The tower has a severe aspect ratio, and the initial design tests were intended to reduce the wall effects. Future work should address potential wall affects by quantifying and comparing these results with tall-tower results.

At a flash drum pressure of $1 \mathrm{psi}$, a scenario exists where no energy needs to be introduced into the desiccant for the process. If this pressure is raised to 1.5 psi, an energy penalty is taken and this option is no longer viable. Flash drum pressure is a controlling factor in efficiency and energy cost of

the system. A pressure of 1 psi is achievable with an ACC for use as the heat exchanger for the produced water condenser.

A packed bed is a very energy efficient method to absorb water, and because it operates at a low desiccant flow rate, the energy cost of regenerating the desiccant is less. However, the low flow rates associated with a packed bed may be potentially problematic for use in a coal-fired system, where particulate could become difficult to wash from the system. Long-term testing will be required to ensure that this is a reasonable option.

By utilizing operating conditions similar to those found in a FGD for $\mathrm{L} / \mathrm{G}$ ratios and only regenerating a portion of the dilute desiccant to recover water, there is an opportunity for less operational and capital costs versus regenerating the entire desiccant stream to obtain the same level of moisture recovery. 
Desiccant $\mathrm{pH}$ appears to be the primary factor influencing $\mathrm{SO}_{2}$ capture in the LDDS absorber. During test periods when the absorber was operated in a spray tower configuration, significant levels of $\mathrm{SO}_{2}$ capture were observed for desiccant $\mathrm{pH}$ levels $>3$. When the absorber was operated in a packed-bed configuration, a minimal level of $\mathrm{SO}_{2}$ capture was observed for desiccant $\mathrm{pH}$ levels of 2.5 to 2.8 .

If $\mathrm{SO}_{2}$ capture in the LDDS absorber is of interest as a flue gas polishing step or as an integrated design feature, specific pilot-scale tests will be required to determine the impact of primary independent and dependent variables. In addition, a desiccant solution $\mathrm{pH}$ control strategy and filtration system will be required.

Absorber outlet mass loading, based on EPA Method 5 sample trains, ranged from 0.0005 to $0.0012 \mathrm{gr} / \mathrm{scf}\left(0.0011\right.$ to $\left.0.0027 \mathrm{~g} / \mathrm{m}^{3}\right)$. For Test Periods 3.1 and 3.2 , although small, the mass measured at the absorber outlet was greater than the mass measured at the absorber inlet. The most likely mechanism responsible for the increased mass across the absorber is simply mist eliminator carryover, specifically desiccant solution aerosol droplets. Analysis of the outlet filter for Test Period 3.1 indicated the presence of $0.0068 \mathrm{gr}(0.440 \mathrm{mg})$ of calcium, $0.0074 \mathrm{gr}(0.480 \mathrm{mg})$ of chloride, and $0.0015 \mathrm{gr}(0.098 \mathrm{mg})$ of sodium. Sulfate was less than the detection limit, $<0.0008 \mathrm{gr}(<0.050 \mathrm{mg})$. The total mass recovered on the filter was $0.0267 \mathrm{gr}(1.73 \mathrm{mg})$. Therefore, calcium and chloride combined represented $53 \%$ of the total mass collected on the filter. Adding sodium to the total, likely present as sodium chloride, increases the percent mass identified to $59 \%$. Based on the data, mist eliminator carryover is the most probable source of the mass collected at the outlet of the absorber during Test Period 3.1. The $41 \%$ of the mass that remained undocumented is likely water chemically bound to the calcium chloride. As many as six moles of water can be chemically bound to calcium chloride, representing a nearly $50 \mathrm{wt} \%$ contribution. Free water would not be a contributing factor because of the $250^{\circ} \mathrm{F}\left(121^{\circ} \mathrm{C}\right)$ filter temperature employed and the method for measuring filter mass involved oven drying of filters at $212^{\circ} \mathrm{F}\left(100^{\circ} \mathrm{C}\right)$ and cooling the filter in a desiccated container prior to determining a final weight.

When coal is fired, product water $\mathrm{pH}$ generally followed desiccant solution $\mathrm{pH}$ to lower values. Implementation of a desiccant solution $\mathrm{pH}$ control system, as previously discussed, would be expected to mitigate the impact of flue gas constituents, from coal firing, on product water $\mathrm{pH}$ as well as desiccant solution $\mathrm{pH}$, resulting in a product water $\mathrm{pH}$ comparable to DI water regardless of flue gas composition and fuel type fired. The higher $\mathrm{pH}$ of the city tap water is consistent with its calcium, magnesium, and sulfate content.

Mercury measurements for Test Series II were performed to determine if the calcium chloride would have any effect on conversion of elemental mercury to an oxidized form. It is well documented that wet FGD systems will capture available oxidized species of mercury at approximately the same efficiency as sulfur capture. If a wet FGD is $85 \%$ efficient at capturing the available sulfur in the gas stream, it will also capture $85 \%$ of the oxidized mercury in the gas stream. Based on sampling data, the LDDS captured approximately $100 \%$ of the available oxidized species of mercury entering the absorber tower and concentrated the mercury in the desiccant as the test continued. The levels of mercury in the desiccant at the end of the test period were at the lower end of other FGD and ash samples analyzed in previous pilot-scale testing at the EERC. It appeared that 
no beneficial oxidation of the mercury occurred across the absorber tower, allowing capture of more mercury than would be expected in a wet FGD system.

\subsubsection{Commercial Power Plant Evaluation}

Data and results that were collected through the testing phases of this program have provided the initial values of a commercial power plant evaluation. Although final material selection for a commercial application has not been determined, several candidate materials have been identified for consideration, ranging from corrosion-resistant alloys through readily available polymers and plastics.

Further planned testing by SPG and the EERC is, at present, in progress with specific milestones established for collection of long-term operability data.

The current conceptual commercial application for this technology can be arranged in a slipstream configuration, external to the flue gas path, or in a full-flow configuration, placed directly in the flue gas path. In a natural gas-fired combined-cycle system, the LDDS would interface just after the last heating surface of the HRSG. In a coal-fired plant, this system would interface downstream of a wet FGD system, where it could remove the majority of the moisture introduced by the FGD process.

An economic evaluation for a commercial system was also conducted. The study results indicate that given the current increasing usage trends seen in power plant dry cooling technologies, as well as the observed increase in water rights legislation and water usage permitting difficulties,

systems designed to recover the water contained in combustion flue gas streams will steadily become more commercially viable.

Although current economic models indicate that a net positive return on initial investment is achievable when employing this technology, it will take several years of development and continued focus on water resource management before systems such as this yield the level of return that will warrant their common use.

\subsection{REFERENCES}

Collings, M.E.; Dockter, B.A.; Eylands, K.E.; Hajicek, D.R.; Henderson, A.K.; Hurley, J.P.; Kleven, P.L.; Lillemoen, C.M.; Weber, G.F. Lignite Testing in a Pilot-Scale High-Temperature Advanced Furnace; Final Report for U.S. Department of Energy Contract No. DE-FC2698FT40321 and North Dakota Industrial Commission Contract No. FY98-XXX84; EERC Publication 99-EERC-03-06; Energy \& Environmental Research Center: Grand Forks, ND, April 1999a.

Collings, M.E.; Dockter, B.A.; Hajicek, D.R.; Henderson, A.K.; Hurley, J.P.; Kleven, P.L.; Weber, G.F. High-Temperature Heat Exchanger Testing in a Pilot-Scale Slagging Furnace System; Final Topical Report for U.S. Department of Energy Contract No. DE-FC26-98FT40320; 
EERC Publication 99-EERC-08-12; Energy \& Environmental Research Center: Grand Forks, ND, Dec 1999b.

Couch, G. Use of Coal in Areas of Water Shortage; CCC/103, ISBN 92-9029-419-1, IEA Clean Coal Center: London, Nov 2005; $87 \mathrm{p}$.

Harriman, L.G. The Dehumidification Handbook, 2d Ed.; Cargocaire Division of Munters Corporation: Amesbury, MA, 1990.

Herald, K., Ph.D., University of Maryland, College Park. Personal communication, 2006.

Hurley, J.P.; Weber, G.F.; Henderson, A.K.; Hajicek, D.R.; Kleven, P.L.; Collings, M.E. Engineering Development of Coal-Fired High-Performance Power Systems - Phase II; Final Report for United Technologies Research Center Contract No. DE-AC22-95PC95144; Energy \& Environmental Research Center: Grand Forks, ND, Feb 2001.

Lowenstein, A. The Effect of Material Properties on the Performance of Liquid Desiccant Air Conditioners and Dehumidifiers; Final Report; AIL Research, 1993; 82 p.

Lowenstein, A.; Slayzak, S.; Ryan, J.; Pesaran, A. Advanced Commercial Liquid-Desiccant Technology Development Study; Golden, CO, National Renewable Energy Lab, 1998; 50 p.

Oberg, V.; Goswami, D.Y. A Review of Liquid Desiccant Cooling. Advances in Solar Energy 1998, $12,431-470$.

Pesaran, A.A.; Penney, T.R.; Czanderna, A.W. Desiccant Cooling: State-of-the-Art Assessment; National Renewable Energy Laboratory, 1992, NREL Report No. TP-254-4147.

Zygarlicke, C.J. A Mineralogical Study of the Harmon Lignite Bed, Bullion Creek Formation (Paleocene) Bowman County, North Dakota. Master's Thesis, University of North Dakota, 1987. 